\title{
ENHANCING PROGRESSIVE COLLAPSE RESISTANCE OF STEEL BUILDING FRAMES USING THIN INFILL STEEL PANELS
}

\author{
A Thesis \\ presented to \\ the Faculty of California Polytechnic State University, \\ San Luis Obispo
}

\author{
In Partial Fulfillment \\ of the Requirements for the Degree of \\ Master of Science in Civil and Environmental Engineering
}

by

Victor Manuel Sanchez Escalera

May 2011 
(C) 2011

VICTOR MANUEL SANCHEZ ESCALERA ALL RIGHTS RESERVED 


\section{COMMITTEE MEMBERSHIP}

TITLE:

Enhancing Progressive Collapse Resistance of Steel

Building Frames Using Thin Infill Steel Panels

AUTHOR:

Victor Manuel Sanchez Escalera

DATE SUBMITTED:

May 2011

COMMITTEE CHAIR:

Bing Qu, Assistant Professor

COMMITTEE MEMBER: $\quad$ Rakesh Goel, Professor

COMMITTEE MEMBER: Juan Cepeda-Rizo, Ph.D. 


\begin{abstract}
Enhancing Progressive Collapse Resistance of Steel Building Frames Using Thin Infill Steel Panels

Victor Manuel Sanchez Escalera

Progressive collapse occurs when damage from a localized first failure spreads in a domino effect manner resulting in a total damage disproportionate to the initial failure. Recent building failures (e.g., World Trade Center twin towers) highlight the catastrophic outcome of progressive collapse. This research proposes a reliable and realistic retrofit technology which installs thin steel panels into steel building structural frames to enhance the system progressive collapse resistance.
\end{abstract}

The steel frames with simple beam-to-column connections, under different boundary conditions (i.e., sidesway uninhibited and sidesway inhibited, respectively), and the loss of one bottom story column were retrofitted using the proposed technology (i.e. installing thin steel panels in the structural frames). Performance of these frames was investigated. Two Finite Element (FE) models which require different modeling efforts were developed to capture the system behavior. The first model explicitly models the infill plates to capture the plate buckling behavior. The second model known as strip model represents the infill panels as diagonal strips. In addition to the FE models, a plastic analysis model derived from the prior research on seismically designed Steel Plate Shear Walls (SPSWs) was considered. The system progressive collapse resistance obtained from the two FE models and the plastic analysis procedure were compared and good agreements were observed. It was observed that installing infill plates to steel structural 
frames can be an effective approach for enhancing the system progressive collapse resistance.

Beyond the strength of the overall system, the Dynamic Increase Factor (DIF) which may be used to amplify the static force on the system to better capture the dynamic nature of progressive collapse demand was evaluated for the retrofitted system. Furthermore, the demands including axial force, shear force and bending moment on individual frame components (i.e., beams and columns) in the retrofitted system were quantified via the nonlinear FE models and a simplified procedure based on free body diagrams (FBDs). Finally, the impact of premature beam-to-column connection failures on the system performance was investigated and it was observed that the retrofitted system is able to provide stable resistance even when connection failures occur in all beams. 


\section{ACKNOWLEDGEMENTS}

I will like to express my sincere appreciation and gratitude to Dr. Bing Qu. His great knowledge, enthusiasm and encouragement are invaluable. Without his guidance this thesis would have been impossible.

Thanks to Professor Rakesh Goel and Dr. Juan Cepeda-Rizo for taking the time out of their very busy schedules to serve on my thesis defense committee.

I am very grateful for the financial support through the California Central Coast Research Partnership (C3RP) program sponsored by the Office of Naval Research.

Thank you to Maria Manzano, for the opportunity to work at the tutoring center and for the scholarships and endless meals that she provided. Also, for the generous assistance provided to other first generation college students.

Thanks to all the students and professors with whom I had interaction during my studies at Cal Poly. Especially to fellow graduate students: Brad Stirling, Gary Guo and Paul Gordon for the good times we spent together in the graduate lab.

I want to express gratitude to my family for all of their moral support. Although they have minimum understanding of what exactly is taking me so long in school, they keep providing their support and motivation. I want to especially thank my cousins Juan Sanchez and Francisco Sanchez for all of their support and input on this thesis.

(Me gustaría agradecer a mi familia por todo su apoyo moral. Aunque, ellos no tienen la mínima idea de que es lo que me está tomando tanto tiempo en la escuela, ellos me 
siguen apoyando y motivando. Especial agradecimiento para mis primos Juan y Francisco Sánchez por todo su apoyo y comentarios en mi tesis.)

To my daughter Emma Denise Sanchez Flores for understanding that Papi had to leave every week to keep working on the thesis. Thank you for understanding mi Corazon.

I want to show my appreciation to my fiancée, Carmen Hernandez, for her patience, understanding and great support. Thank you mi Amor for not getting too upset when I couldn't talk to you when I was working on my thesis. I love you.

Overall, I am tremendously grateful with GOD for the opportunity to acquire a college education and to complete this thesis. 


\section{TABLE OF CONTENTS}

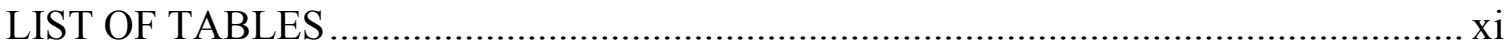

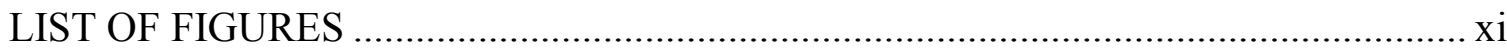

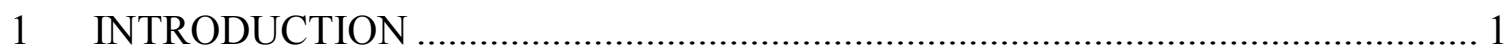

$1.1 \quad$ Scope

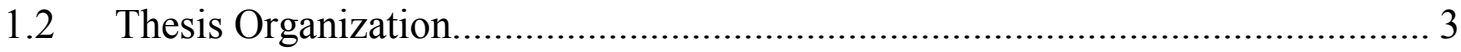

2 LITERATURE REVIEW ……………………............................................ 5

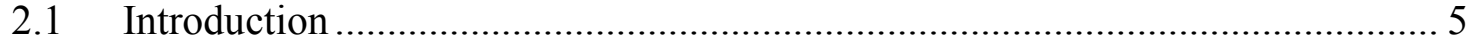

2.2 Steel Plate Shear Walls (SPSWs) ............................................................. 5

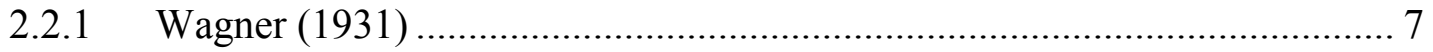

2.2.2 Thorburn et al. (1983) ...................................................................... 7

2.2.3 Timler and Kulak (1983) ................................................................. 9

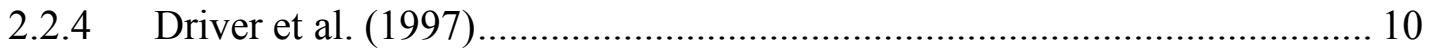

2.2.5 Behbahanifard et al. (2003)............................................................... 13

2.2.6 Berman and Bruneau (2003) .............................................................. 14

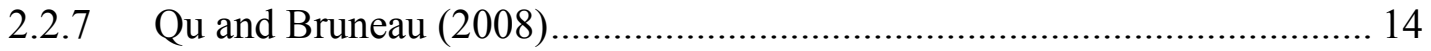

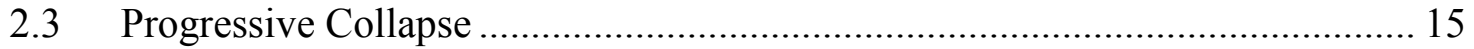

2.3.1 Previous Progressive Collapse Cases..................................................... 16

2.3.2 Code Provisions and Design Guidelines................................................. 19

2.3.3 Past Research on Enhancing Progressive Collapse Resistance ................... 21

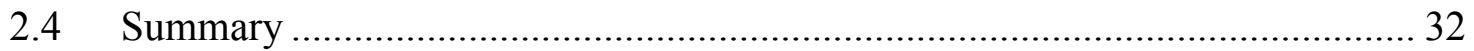

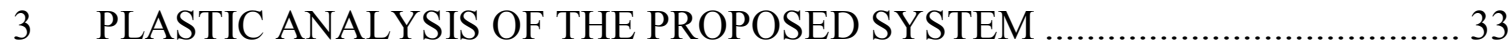

3.1 Consideration of Initial Column Failure ………………………….................... 33

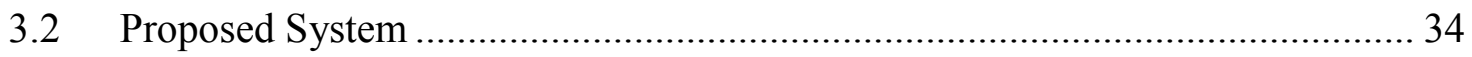

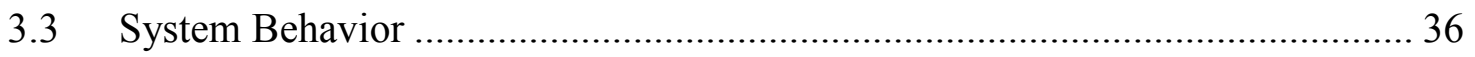

3.3.1 Infill Panel - Tension Field Action........................................................... 37

3.3.1.1 Equilibrium Method - Single Story Frame ……………………….... 37

3.3.1.2 Kinematic Method - Single Story Frame .............................................. 46

3.3.1.3 Kinematic Method - Multistory Frame ............................................... 48

3.3.2 Boundary Frame Members - Catenary Actions ......................................... 49

3.3.2.1 Beam Catenary Action- Single Story Frame ....................................... 50

3.3.2.2 Beam Catenary Action-Multistory Frame ........................................... 56

3.3.3 Combination of Tension Fields and Catenary Actions ............................... 58

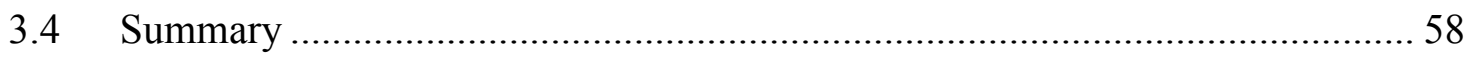

4 DEVELOPMENT OF HIGH-FIDELITY ANALYTICAL MODELS ..................... 59 


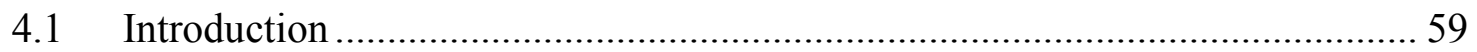

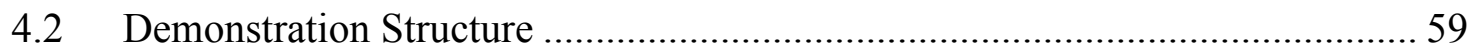

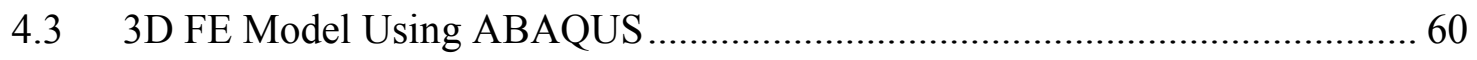

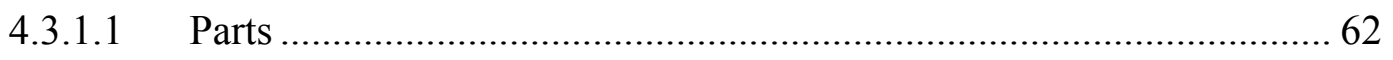

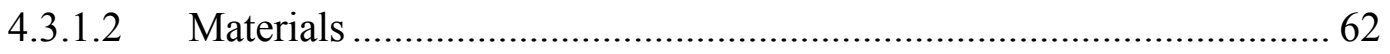

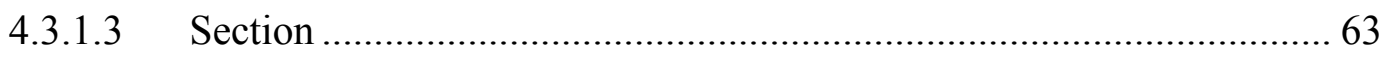

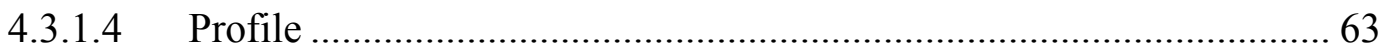

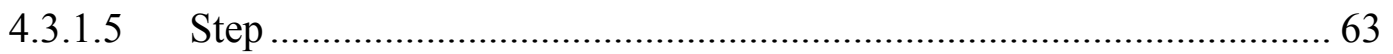

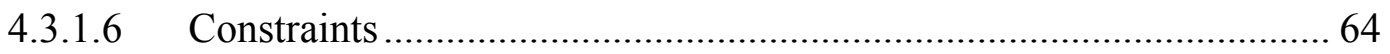

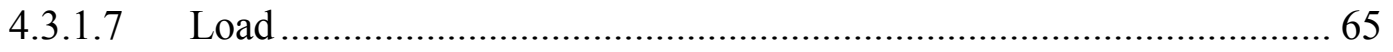

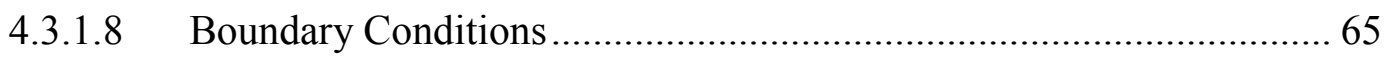

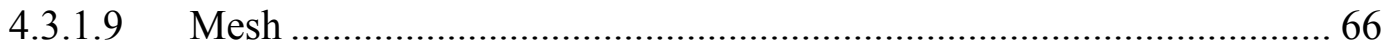

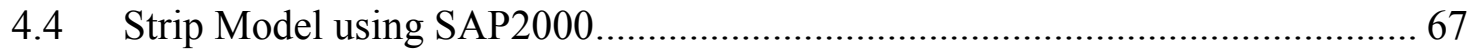

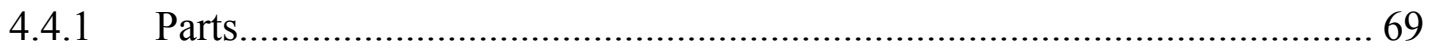

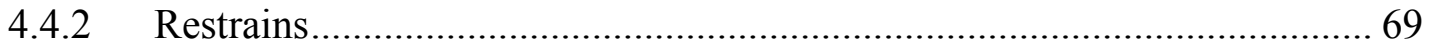

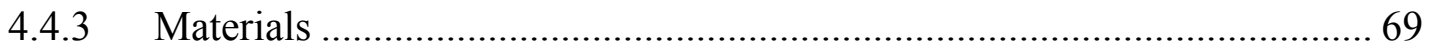

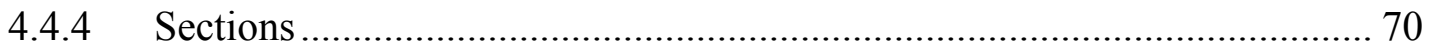

4.4.5 Plastic Hinges..................................................................................... 70

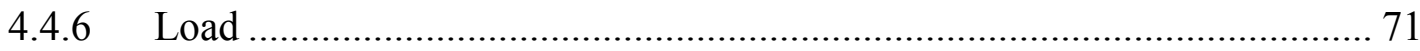

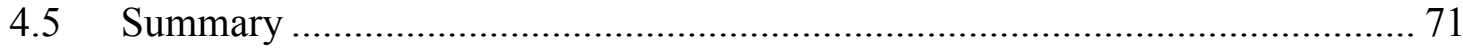

5 DISCUSSION AND COMPARISON OF RESULTS FROM DEVELOPED

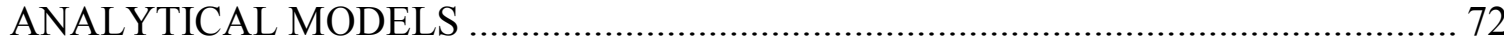

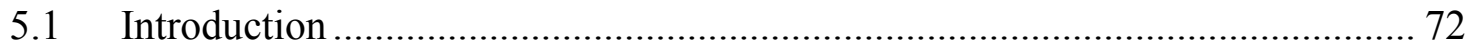

5.2 Considered Boundary Conditions .............................................................. 72

5.3 Discussion and Comparison of Results .......................................................... 74

5.3.1 Boundary Condition \#1 .................................................................... 74

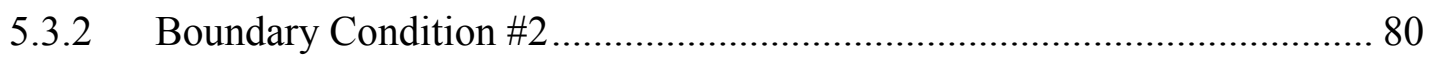

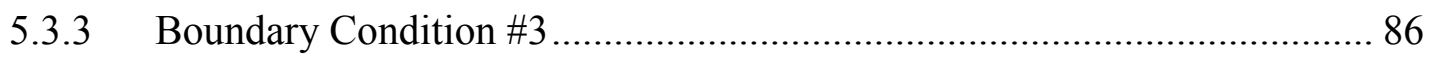

5.3.4 Boundary Condition \#4 ...................................................................... 93

5.3.5 Boundary Condition \#5 ........................................................................ 99

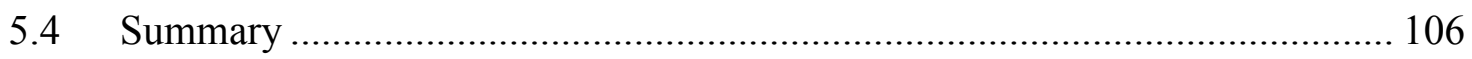

6 PSEUDO-STATIC RESPONSE OF THE PROPOSED SYSTEM ………............ 107

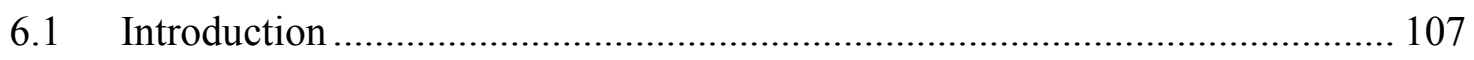

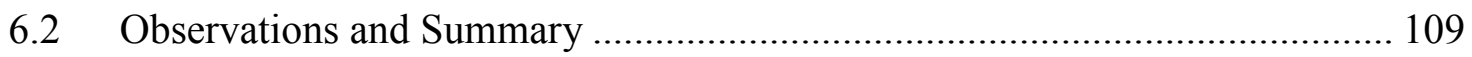

7 DEMANDS ON BOUNDARY FRAME MEMBERS ………………................... 116 


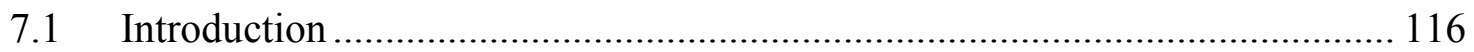

7.2 Tension Field Action along Frame Members.............................................. 117

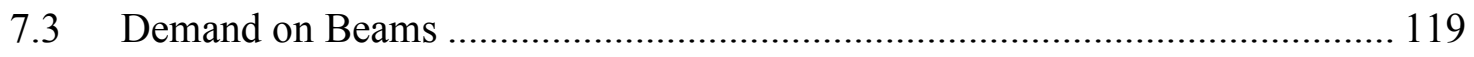

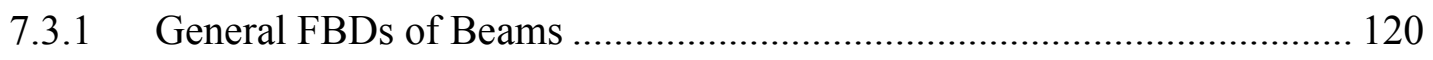

7.3.2 Results from Different Boundary Conditions ........................................... 122

7.3.2.1 Boundary Condition \#1 ............................................................... 122

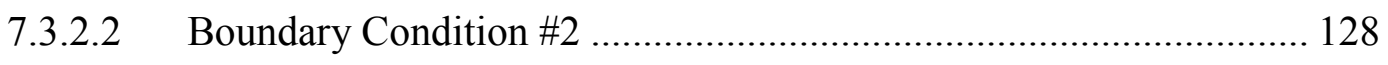

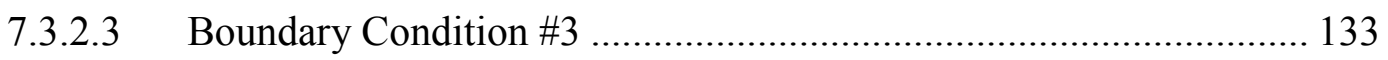

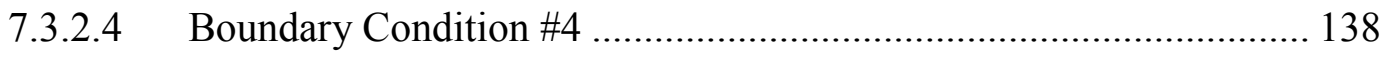

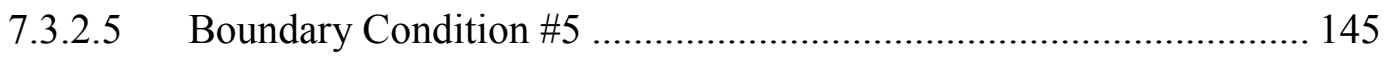

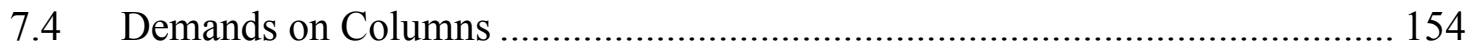

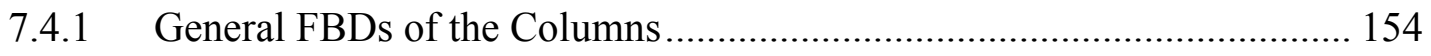

7.4.2 Results from Different Boundary Conditions .......................................... 156

7.4.2.1 Boundary Condition \#1 ............................................................... 156

7.4.2.2 Boundary Condition \#2 ………………....................................... 160

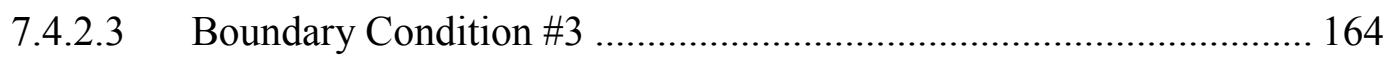

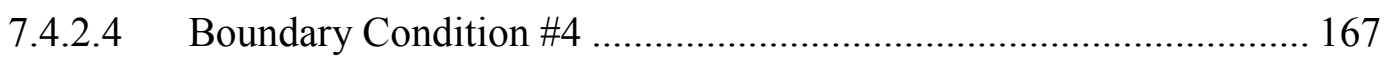

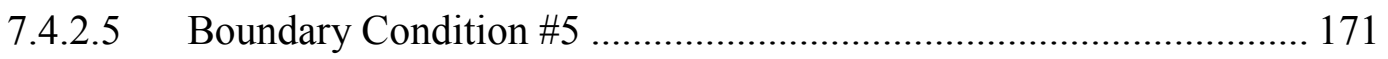

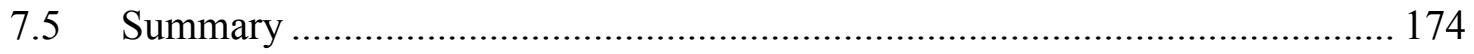

8 IMPACT OF BEAM-TO-COLUMN CONNECTION FAILURE ON SYSTEM

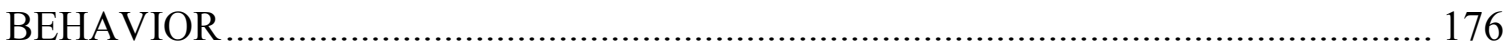

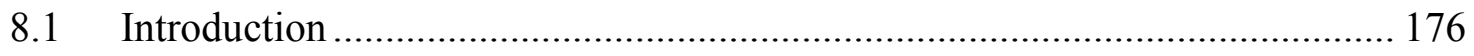

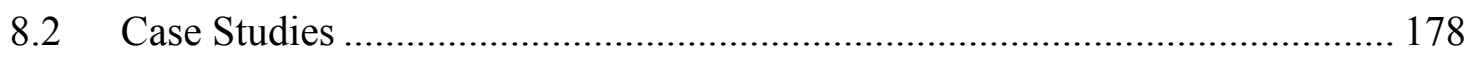

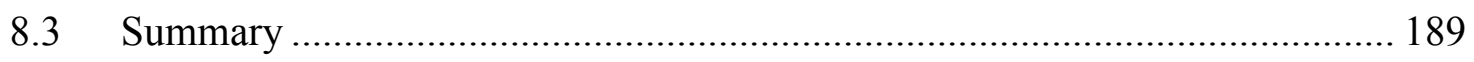

9 SUMMARY, CONCLUSIONS, AND RECOMMENDATIONS FOR FUTURE

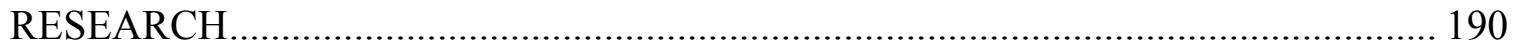

9.1 Summary and Conclusions .......................................................................... 190

9.2 Recommendations for Future Research …………………………............. 191

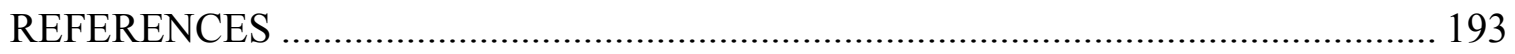

APPENDIX A - ALGORITHM USED TO DETERMINE THE PSEUDO-STATIC

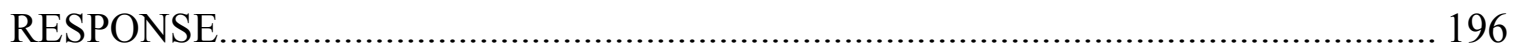




\section{LIST OF TABLES}

Table 8-1: Cases considered for system with beam-to-column failures ........................ 179

Table 8-2: Capacities of the systems with connection failures* 187

\section{LIST OF FIGURES}

Figure 2-1 General SPSW configuration (Berman and Bruneau 2008) ............................. 6

Figure 2-2: Schematic of SPSW Strip Model (Thorburn et al. 1983) ……………............ 8

Figure 2-3: FE Model Subjected to $2200 \mathrm{KN}$ (Driver et al. 1997) .................................. 11

Figure 2-4: Strip Model of Test Specimen (Driver et al. 1998)........................................ 12

Figure 2-5: Finite Element Model (Behbahanifard et al. 2003)....................................... 13

Figure 2-6: Tension Field Action of the FE Model (Qu and Bruneau 2008) ................... 15

Figure 2-7: Ronan Point March 1968 (Wearne 2000) .................................................... 17

Figure 2-8: Alfred P. Murrah Federal Building (Crowder 2004) .................................... 18

Figure 2-9: collision of flight UA175 Boeing 767 jet with south tower of WTC

(Level3.com Sep 20, 2001) ..................................................................................... 19

Figure 2-10: Plan view of the tested specimen with catenary cables

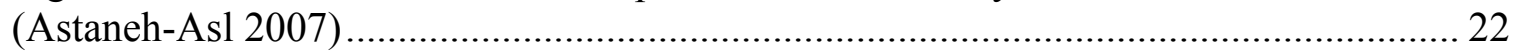

Figure 2-11: Test Results (Astaneh-Asl 2007) ……………………………………. 23

Figure 2-12: Specimen and the retrofit cable end anchorage (Astaneh-Asl, 2007)......... 24

Figure 2-13: Column removal strategy (DoD UFC 2009) ............................................. 25

Figure 2-14: Test Specimen (Astaneh-Asl et al. 2001)................................................... 26

Figure 2-15: Beam-to-column connections (left) beam-to-girder connections (right)

(Astaneh-Asl et al. 2001) ......................................................................................... 27

Figure 2-16: Specimen after testing (Astaneh-Asl at al. 2001) ……………………….... 28

Figure 2-17: Original design of fin plate joins (Li 2009) ............................................... 29

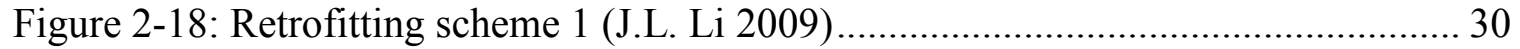

Figure 2-19: Retrofitting scheme 2 (Li 2009) ................................................................... 30

Figure 3-1: Frame before and after removal a column (Astaneh-Asl 2007)..................... 34

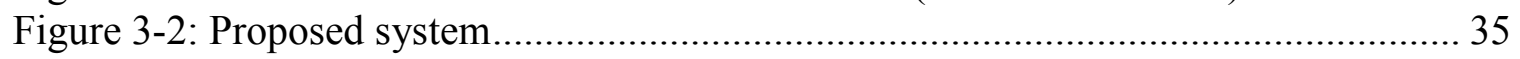

Figure 3-3: Single plate field tension action of SPSW and proposed system................... 35

Figure 3-4: Tension field actions in multistory SPSWs and the proposed system ........... 36

Figure 3-5: Strip model of a single SPSW with simple beam-to-column connection ...... 38

Figure 3-6: Zone 1 FBD - Top beam and right column ................................................. 38

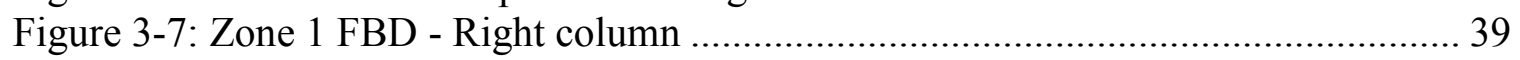

Figure 3-8: Zone 2 FBD - Top beam and right column ............................................... 41

Figure 3-9: Zone 2 FBD - Right column .............................................................. 41

Figure 3-10: Zone 3 FBD - Bottom beam................................................................... 43

Figure 3-11: Kinematic collapse mechanism single story tension field action ............... 46

Figure 3-12: Tension field distributions in a multistory frame subjected to sudden

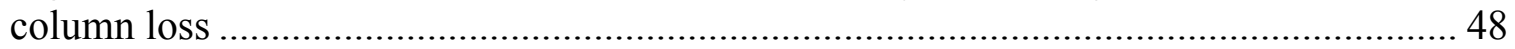

Figure 3-13: The three-hinge beam by Timoshenko (1955) ......................................... 50 
Figure 3-14: Force-displacement relationship for a three-hinge beam Astaneh-Asl (2007).....

Figure 3-15: Force-displacement relationship for a three hinge beam beyond its yield point (Astaneh-As1 2007)

Figure 3-16: Three-hinge girder with end supports axially semi-rigid

(Asteneh-Asl, 2007) 55

Figure 3-17: Vertical load resistance vs. beam cross-sectional area ............................... 56

Figure 3-18: Catenary action of a multistory frame under column loss .......................... 57

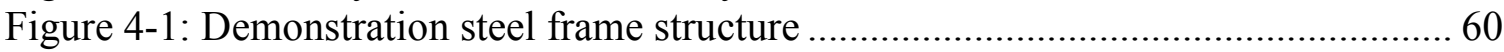

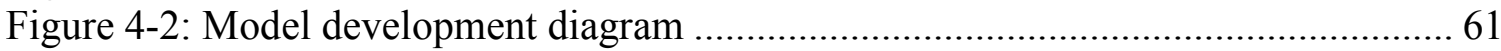

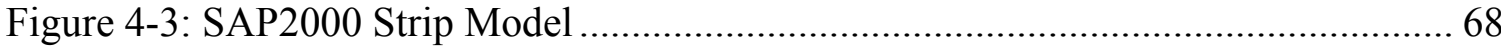

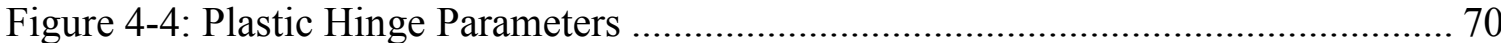

Figure 5-1: Considered boundary conditions............................................................. 73

Figure 5-2: Buckling modes for the retrofitted system under Boundary Condition \#1

(Results from ABAQUS) ............................................................................ 75

Figure 5-3: Post buckling behavior of the retrofitted system and deflection of the original frame under Boundary Condition \#1 (Results from ABAQUS) ...................... 76

Figure 5-4: Deformed shape of the retrofitted system and the original frame under Boundary Condition \#1 (Results from SAP2000) .................................................... 77

Figure 5-5: Vertical load resistance of the retrofitted system and the original frame under Boundary Condition \#1 (Results from ABAQUS) ........................................... 78

Figure 5-6: Vertical load resistance of the retrofitted system and the original frame under Boundary Condition \#1 (Results from SAP2000) .......................................... 78

Figure 5-7: Vertical load resistance of the retrofitted system and the original frame under Boundary Condition \#1 (Results from Plastic Analysis) .................................... 79

Figure 5-8: Comparison of vertical load resistance of the original frame under Boundary Condition \#1 79

Figure 5-9 Comparison of vertical load resistance of the infill panels alone under

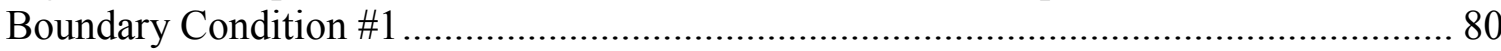

Figure 5-10: Comparison of vertical load resistance of the retrofitted system under Boundary Condition \#1 80

Figure 5-11: Buckling modes for the retrofitted system under Boundary Condition \#2 (Results from ABAQUS)

Figure 5-12: Post buckling behavior of the retrofitted system and deflection of the original frame under Boundary Condition \#2 (Results from ABAQUS) ...................... 82

Figure 5-13: Deformed shape of the retrofitted system and the original frame under Boundary Condition \#2 (Results from SAP2000)

Figure 5-14: Vertical load resistance of the retrofitted system and the original frame under Boundary Condition \#2 (Results from ABAQUS)

Figure 5-15: Vertical load resistance of the retrofitted system and the original frame under Boundary Condition \#2 (Results from SAP2000) 84

Figure 5-16: Vertical load resistance of the retrofitted system and the original frame under Boundary Condition \#2 (Results from Plastic Analysis)

Figure 5-17: Comparison of vertical load resistance of the original frame under Boundary Condition \#2. 
Figure 5-18 Comparison of vertical load resistance of the infill panels alone under

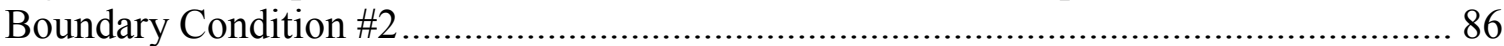

Figure 5-19: Comparison of vertical load resistance of the retrofitted system under

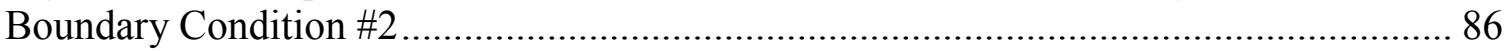

Figure 5-20: Buckling modes for the retrofitted system under Boundary Condition \#3

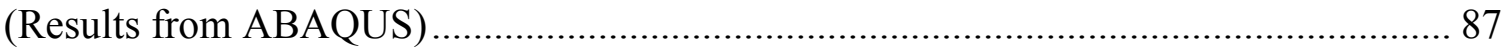

Figure 5-21: Post buckling behavior of the retrofitted system and deflection of the original frame under Boundary Condition \#3 (Results from ABAQUS) ........................ 88 Figure 5-22: Deformed shape of the retrofitted system and the original frame under

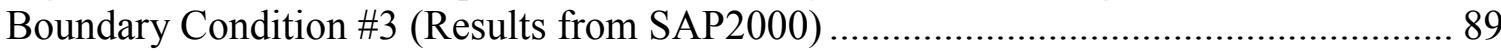
Figure 5-23: Vertical load resistance of the retrofitted system and the original frame under Boundary Condition \#3 (Results from ABAQUS) ........................................... 90 Figure 5-24: Vertical load resistance of the retrofitted system and the original frame under Boundary Condition \#3 (Results from SAP2000) ............................................ 90 Figure 5-25: Vertical load resistance of the retrofitted system and the original frame under Boundary Condition \#3 (Results from Plastic Analysis) ................................... 91 Figure 5-26: Comparison of vertical load resistance of the original frame under Boundary Condition \#3.

Figure 5-27: Comparison of vertical load resistance of the infill panels alone under

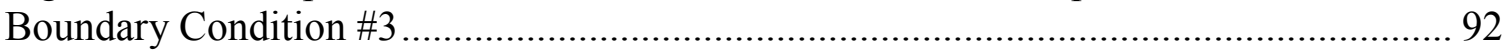
Figure 5-28: Comparison of vertical load resistance of the retrofitted system under Boundary Condition \#3.

Figure 5-29: Buckling modes for the retrofitted system under Boundary Condition \#4 (Results from ABAQUS)

Figure 5-30: Post buckling behavior of the retrofitted system and deflection of the original frame under Boundary Condition \#4 (Results from ABAQUS)

Figure 5-31 shows the deflections of the retrofitted system and the original system modeled in SAP 2000.

Figure 5-32: Deformed shape of the retrofitted system and the original frame under Boundary Condition \#4 (Results from SAP2000)

Figure 5-33: Vertical load resistance of the retrofitted system and the original frame under Boundary Condition \#4 (Results from ABAQUS).

Figure 5-34: Vertical load resistance of the retrofitted system and the original frame under Boundary Condition \#4 (Results from SAP2000) ............................................ 96 Figure 5-35: Vertical load resistance of the retrofitted system and the original frame under Boundary Condition \#4 (Results from Plastic Analysis)) .................................. 97 Figure 5-36: Comparison of vertical load resistance of the original frame under Boundary Condition \#4.

Figure 5-37: Comparison of vertical load resistance of the infill panels alone under

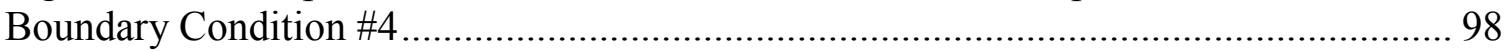

Figure 5-38: Comparison of vertical load resistance of the retrofitted system under

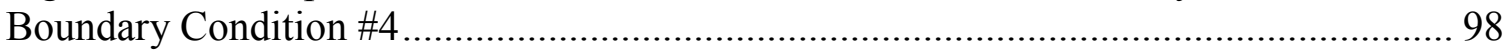

Figure 5-39: Column base reaction of the retrofitted system under Boundary

Condition \#4. 99

Figure 5-40: Buckling modes for the retrofitted system under Boundary Condition \#5 (Results from ABAQUS)... 100 
Figure 5-41: Post buckling behavior of the retrofitted system and deflection of the original frame under Boundary Condition \#5 (Results from ABAQUS) ..................... 101

Figure 5-42: Deformed shape of the retrofitted system and the original frame under Boundary Condition \#5 (Results from SAP2000) 102

Figure 5-43: Vertical load resistance of the retrofitted system and the original frame under Boundary Condition \#5 (Results from ABAQUS)..... 103

Figure 5-44: Vertical load resistance of the retrofitted system and the original frame under Boundary Condition \#5 (Results from SAP2000)

Figure 5-45: Vertical load resistance of the retrofitted system and the original frame under Boundary Condition \#5 (Results from Plastic Analysis)...... 104

Figure 5-46: Comparison of vertical load resistance of the original frame under Boundary Condition \#5. 104

Figure 5-47: Comparison of vertical load resistance of the infill panels alone under Boundary Condition \#5.

Figure 5-48: Comparison of vertical load resistance of the retrofitted system under

Boundary Condition \#5.... 105

Figure 5-49: Column base reactions of the retrofitted system under Boundary Condition \#5.....

Figure 6-1: Modified performance for the system under Boundary Condition \#1 ......... 111

Figure 6-2: Dynamic load amplification factor for the system under Boundary

Condition \#1

Figure 6-3: Modified performance for the system under Boundary Condition \#2 ........ 112 Figure 6-4: Dynamic load amplification factor for the system under Boundary Condition \#2.

Figure 6-5: Modified performance for the system under Boundary Condition \#3 ........ 113

Figure 6-6: Dynamic load amplification factor for the system under Boundary Condition \#3.... 113

Figure 6-7: Modified performance for the system under Boundary Condition \#4 ........ 114

Figure 6-8: Dynamic load amplification factor for the system under Boundary Condition \#4. 114

Figure 6-9: Modified performance for the system under Boundary Condition \#5 ........ 115 Figure 6-10: Dynamic load amplification factor for the system under Boundary Condition \#5...

Figure 7-1: Tension field actions in a structural Frame

Figure 7-2: Tension Field actions along columns and beams .................................. 118

Figure 7-3: General FBDs of beams (a) Sidesway uninhibited (b) Sidesway inhibited. 120 Figure 7-4: Axial, shear, and moment diagrams for the top anchor beam under Boundary Condition \#1

Figure 7-5: Axial, shear, and moment diagrams for the bottom anchor beam under

Boundary Condition \#1....

Figure 7-6: Axial, shear, and moment diagrams for the intermediate beam under Boundary Condition \#1

Figure 7-7: Axial, shear, and moment diagrams for the top anchor beam under

Boundary Condition \#2.

Figure 7-8: Axial, shear, and moment diagrams for the bottom anchor beam under Boundary Condition \#2. 
Figure 7-9: Axial, shear, and moment diagrams for the intermediate anchor beams under Boundary Condition \#2

Figure 7-10: Axial, shear, and moment diagrams for the top anchor beam under Boundary Condition \#3.

Figure 7-11: Axial, shear, and moment diagrams for the bottom anchor beam under

Boundary Condition \#3.

Figure 7-12: Axial, shear, and moment diagrams for the intermediate beams under Boundary Condition \#3.

Figure 7-13: Axial, shear, and moment diagrams for the top right anchor beam under

Boundary Condition \#4.

Figure 7-14: Axial, shear, and moment diagrams for the bottom right anchor beam under Boundary Condition \#4

Figure 7-15: Axial, shear, and moment diagrams for the top left anchor beam under

Boundary Condition \#4.

Figure 7-16: Axial, shear, and moment diagrams for the bottom left anchor beam under Boundary Condition \#4

Figure 7-17: Axial, shear, and moment diagrams for the intermediate beams under Boundary Condition \#4.

Figure 7-18: Axial, shear, and moment diagrams for the top right anchor beam under Boundary Condition \#5

Figure 7-19: Axial, shear, and moment diagrams for the bottom right anchor beam under Boundary Condition \#5

Figure 7-20: Axial, shear, and moment diagrams for the top left anchor beam under Boundary Condition \#5.

Figure 7-21: Axial, shear, and moment diagrams for the bottom left anchor beam under Boundary Condition \#5...

Figure 7-22: Axial, shear, and moment diagrams for the right intermediate beams under Boundary Condition \#5.

Figure 7-23: Axial, shear, and moment diagrams for the top left intermediate beam under Boundary Condition \#5

Figure 7-24: General FBDs of columns: (a) Sidesway uninhibited (b) Sidesway inhibited

Figure 7-25: Axial, shear, and moment diagrams for the right column under

Boundary Condition \#1

Figure 7-26: Axial, shear, and moment diagrams for the middle column under

Boundary Condition \#1

Figure 7-27: Axial, shear, and moment diagrams for the right column due under Boundary Condition \#2

Figure 7-28: Axial, shear, and moment diagrams for the left column under

Boundary Condition \#2.

Figure 7-29: Axial, shear, and moment diagrams for the middle column under Boundary Condition \#2.

Figure 7-30: Axial, shear, and moment diagrams for the right column under

Boundary Condition \#3.

Figure 7-31: Axial, shear, and moment diagrams for the middle column under Boundary Condition \#3. 
Figure 7-32: Axial, shear, and moment diagrams for the left column under

Boundary Condition \#4 168

Figure 7-33: Axial, shear, and moment diagrams for the middle beam under Boundary Condition \#4.

Figure 7-34: Axial, shear, and moment diagrams for the right column under

Boundary Condition \#4

Figure 7-35: Axial, shear, and moment diagrams for the left column under Boundary Condition \#5.

Figure 7-36: Axial, shear, and moment diagrams for the middle column under

Boundary Condition \#5

Figure 7-37: Axial, shear, and moment diagrams for the right column under

Boundary Condition \#5.

Figure 8-1: Tension field action distribution in the frame under Boundary

Condition \#3 and Case A connection failures....

Figure 8-2: Vertical resistance of the system under Boundary Condition \#3 and

Case A connection failures

Figure 8-3: Tension field action distribution in the frame under Boundary Condition \#3 and Case B connection failures

Figure 8-4: Vertical resistance of the system under Boundary Condition \#3 and

Case B connection failures.

Figure 8-5: Tension field action distribution in the frame under Boundary

Condition \#3 and Case $\mathrm{C}$ connection failures

Figure 8-6: Vertical resistance of the system under Boundary Condition \#3 and

Case $\mathrm{C}$ connection failures.

Figure 8-7: Tension field action distribution in the frame under Boundary

Condition \#3 and Case D connection failures.

Figure 8-8: Vertical resistance of the system under Boundary Condition \#3 and Case D connection failures 


\section{INTRODUCTION}

Progressive collapse occurs when the damage from a localized first failure spreads in a domino effect manner resulting in a total damage disproportionate to the initial failure. In Section C1.4 General Structural Integrity of the American Society of Civil Engineers (ASCE) -7 Standard: Minimum Design Loads for Buildings and Other Structures (ASCE 2005), progressive collapse is defined as "the spread of an initial local failure from element to element resulting, eventually, in the collapse of an entire structure or a disproportionately large part of it". In addition, ASCE -7 defines the resistance to progressive collapse as "the ability of a structure to accommodate, with only local failure, the notional removal of any single structural member".

Progressive collapse has been observed as one of the most catastrophic failure modes of building structures and it may be caused by different excitations (e.g. fire, blast, collision, and foundation failure) in the structures (in particular at the bottom story of the structure). In an event that a building structure is subjected to abnormal loading, in addition to bearing the localized failure caused by the excitation, the structure is subjected to its service loads (e.g. wind and gravity). Depending on the magnitude of the unexpected loading and the structure's ability to withstand local damage, the damaged structure would either continue to support the service loads or it would progressively collapse. If the structure has adequate continuity, ductility, and redundancy to resists the spread of damage, only localized failure would occur; otherwise progressive collapse develops. In most cases where progressive collapse develops, the majority of the fatal casualties are 
attributed to the structural damage caused during progressive collapse rather than to the initial abnormal load (Astaneh-Asl 2007).

This thesis investigates the behavior of a system developed for prevention of progressive collapse of steel building frames. In this system (referred to herein as "the proposed system"), the unstiffened thin infill steel panels are installed in the building structural frame to increase its continuity and redundancy. In a scenario of initial column failures which may likely trigger the system progress collapse, these infill panels are allowed to buckle in shear and then develop the diagonal tension field actions. Such tension field actions will bridge over the missing column, transfer the load from the damaged column to the adjacent columns, and consequently prevent the development of progressive collapse.

\subsection{Scope}

For the proposed system, this thesis focused on behavior modeling and system performance assessment. A total of three models were developed. Building on the prior research outcome on plastic analysis of seismically designed steel plate shear walls (SPSWs), the first model was developed based on the classic plastic analysis framework.

The second and third models were developed using the Finite Element (FE) technology. The second model is a 3D FE model which explicitly models the infill plates using shell element to capture the plate buckling behavior. The third model is a simplified 2D FE model which represents the infill panels as diagonal strips. With the developed analytical models, behavior of the proposed system including ultimate strength and dynamic 
amplification effects were evaluated followed by development and validation of the free body diagrams (FBDs) for estimating the shear force, bending moment and axial force in the beams and columns of the system. Moreover, the impact of premature beam-tocolumn connection fractures on performance of the proposed system was investigated.

\subsection{Thesis Organization}

This thesis includes a total of 9 chapters to address the key issues within the scope presented in the prior section.

Chapter 2 presents an overview of past research related to analytical modeling of SPSWs. In addition, prior investigations on progressive collapse of building structures are included.

Chapter 3 describes the proposed system and its behavior under the column removal scenario followed by derivation of a plastic analysis model for quantification of the progressive collapse resistance of the proposed system.

Chapter 4 presents the development of two analytical models: a 3D finite element model and a simplified 2D model known as strip model for validating the analytical models derived in Chapter 3.

Chapter 5 compares results obtained from the three models described in Chapters 3 and 4 together with a discussion of the effectiveness of the proposed system. 
Chapter 6 investigate the dynamic amplification effects and determines the factors which capture the dynamic nature of progressive loading and can be used to modify the performance of the proposed system obtained from the nonlinear static analyses.

Chapter 7 analyzes the demand on the boundary members (i.e. beams and columns). A procedure developed based on FBDs is presented and validated by the results from the nonlinear FE analysis.

Chapter 8 assesses the performance and robustness of the proposed system under the premature beam-to-column connection failures.

Chapter 9 presents summary, conclusions, and recommendations for future research on the proposed system. 


\section{LITERATURE REVIEW}

\subsection{Introduction}

The system considered in this thesis consists of thin infill steel panels installed in steel building frames. When an extreme event which causes the loss of a bottom story column occurs, the infill panels will buckle in shear and then develop diagonal tension field actions in the building structural frame which resists and transfers the gravity load on the building frame, preventing progressive collapse development. Such a system is proposed here based on the inspiration from SPSWs, a relatively new lateral force resisting system in seismic design community. Therefore, to have a better understanding of the overall behavior of the proposed system, an extensive literature review on SPSWs is presented in

Section 2.2 followed by a review on recent research on progressive collapse phenomenon and different retrofit strategies to enhance progressive collapse resistance of building structures in Section 2.3.

\subsection{Steel Plate Shear Walls (SPSWs)}

A conventional SPSW consists of beams, columns and infill panels as shown in Figure 2-1. These beams and columns are also known as horizontal boundary elements (HBEs) and vertical boundary elements (VBEs), respectively. The infill panel is typically a thin steel sheet which is anchored to the surrounding boundary frame elements. SPSWs have been used as lateral force resisting systems in seismic design practice in many countries such as Japan, Taiwan, Canada and the United States. 


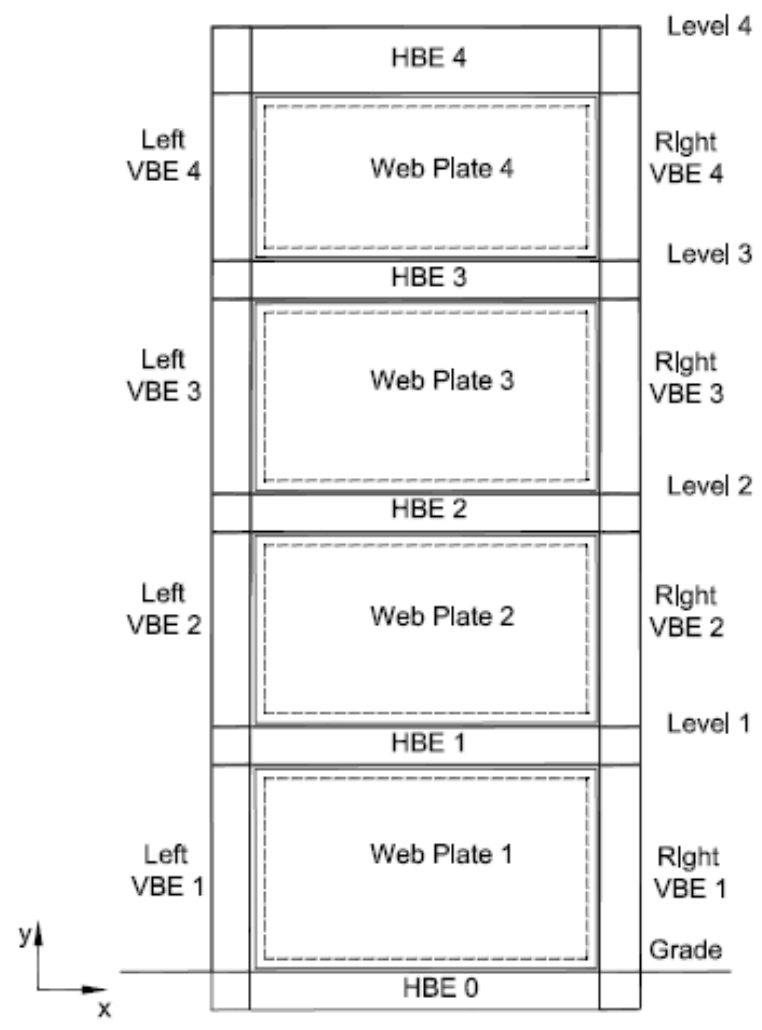

Figure 2-1 General SPSW configuration (Berman and Bruneau 2008)

Investigation on the SPSW infill panel performance was initiated from its application in aerospace engineering. To date, significant research efforts, both analytical and experimental, have been made to achieve a better understand of the panel post buckling behavior. The following literature review is presented in a chronological order to capture the evolvement of the infill panels from an aerospace application to the current seismic design application. Since this thesis focuses on analytical work, the literature review was conducted with emphasis on past analytical and simulation work. 


\subsubsection{Wagner (1931)}

While performing investigations for the National Advisory Committee for Aeronautics, Wagner showed that the thin aluminum shear panels used in aircrafts and supported by stiff boundary members develop a diagonal tension field after buckling. From his analysis, Wagner developed what he called the "pure tension field" theory which proved that the capacity of a thin plate attached to a relative stiffer boundary frame depends on the tension field action. These results ended the misconception that shear panels would provide all of their strength up to the buckling stage. In contrast, Wagner demonstrated that the buckling of these plates is not the limit state for determination of their shear capacity. Consequently, the load resistance mechanism changes from in-plane shear buckling to diagonal tension yielding.

\subsubsection{Thorburn et al. (1983)}

Thorburn et al. developed two models that would consider the behavior of thin unstiffened steel plates in SPSWs. These models focused on determination of the ultimate shear strength of SPSWs and the shear resistance of the walls prior to buckling was not addressed. Wagner's (1931) idea of pure tension field action was implemented on these models. These models are commonly known as the strip model and the equivalent brace model.

In the strip model the infill panel was modeled by a series of pin-ended inclined tension members. The strips were oriented parallel to the direction of the tension fields and were 
assigned an area equal to the strip spacing times the thickness of the plate. Figure 2-2 shows the typical orientation and arrangement of the strips.

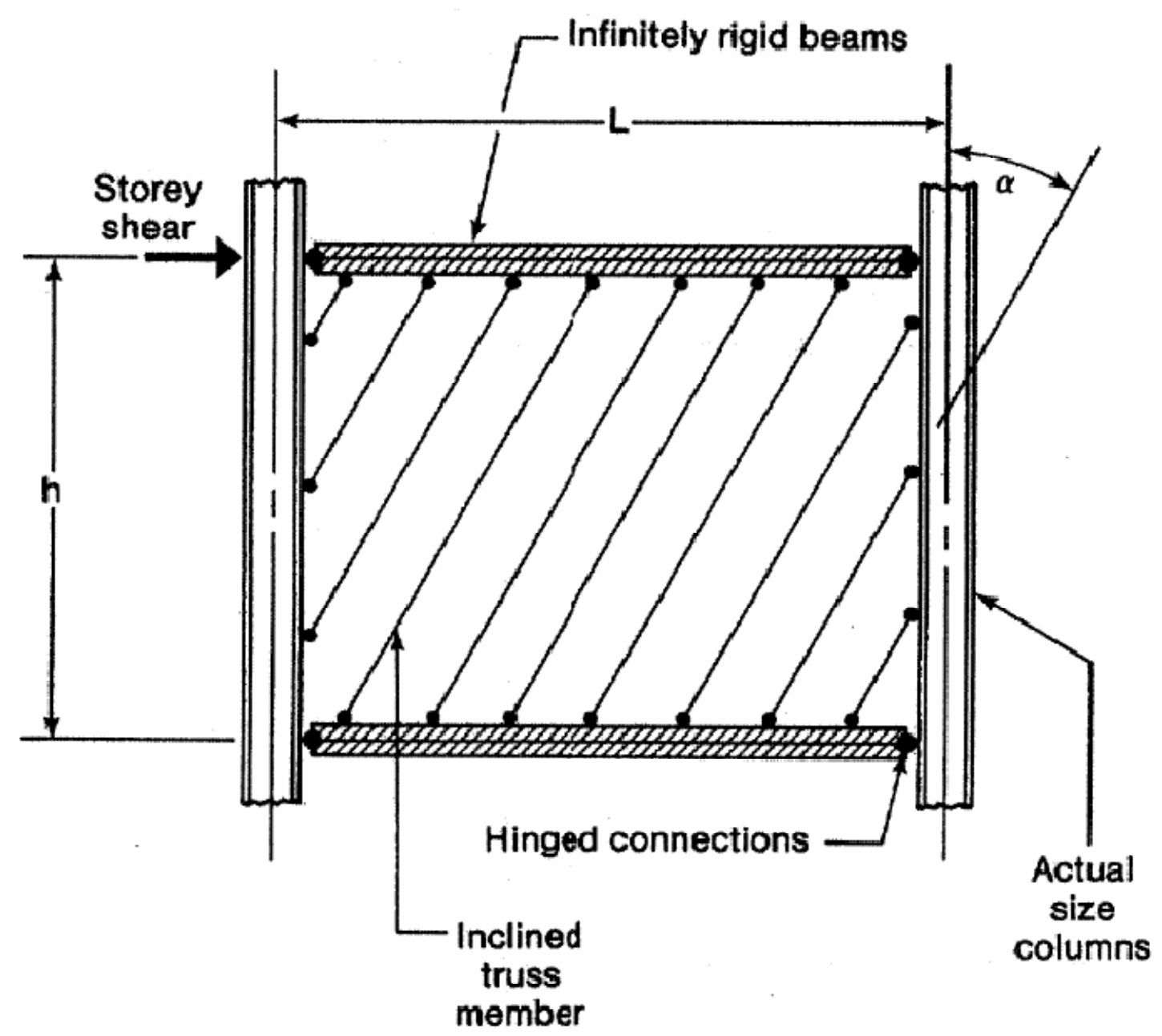

Figure 2-2: Schematic of SPSW Strip Model (Thorburn et al. 1983)

Assuming that the beams are infinitely rigid in bending, the angle of inclination $\alpha$ was found using the principle of least work and considering only the energy of the tension field and the energy in the beams and columns due to axial effects. Therefore, the equation for the inclination angle of the tension fields is: 


$$
\tan ^{4}(\alpha)=\frac{1+\frac{L \cdot t}{2 \cdot A_{c}}}{1+\frac{H \cdot t}{A_{b}}}
$$

where $\alpha=$ the angle of inclination of the tension field,

$$
\begin{aligned}
& L=\text { the bay width } \\
& t=\text { is the infill plate thickness } \\
& A_{\mathrm{b}}=\text { cross-section area of the beam } \\
& A_{\mathrm{c}}=\text { cross-section area of the column }
\end{aligned}
$$

From their analytical studies, Thorburn et al. concluded that 10 strips per panel would be sufficient to accurately model the infill plate behavior.

In the equivalent brace model the investigators modeled the infill panel with a single equivalent diagonal truss element at each floor. This element had the same story stiffness. This model is practical to determine the story stiffness.

\subsubsection{Timler and Kulak (1983)}

In 1983, Timler and Kulak performed laboratory testing of a full scale SPSW to verify the model derived by Thorburn et al (1983). The test specimen was composed of two 5 $\mathrm{mm}$ thick infill panels of $3750 \mathrm{~mm}$ bay width and $2500 \mathrm{~mm}$ story height. For the VBEs and HBEs, W18X97 and W12X87 were used, respectively. The specimen was subjected to quasi-static reverse cyclic loading to a drift of $6.25 \mathrm{~mm}$, and then it was loaded monotonically to failure. 
Timler and Kulak concluded that Thornborn's equation did not include the effects of column flexibility and they revised equation (2-1) to be:

$$
\tan ^{4}(\alpha)=\frac{1+\frac{L \cdot t}{2 \cdot A_{c}}}{1+H \cdot t \cdot\left(\frac{1}{A_{b}}+\frac{H^{3}}{360 \cdot I_{c} \cdot L}\right)}
$$

where $I_{\mathrm{c}}=$ the moment of inertia of the column and all the other terms have been previously defined.

\subsubsection{Driver et al. (1997)}

Driver et al. developed a finite element (FE) model and a strip model to simulate the behavior of a four story SPSW specimen. For the FE model, Driver et al. used the 1994 edition of the finite element software ABAQUS. The infill panels were modeled using the eight-node quadratic shell element (S8R5), while the beams and columns were modeled using the three-node quadratic beam element (B32). The infill panels were connected to the boundary frame directly, instead of modeling the fish plate which was used in the test specimen. This method to model the connection between the plate and the boundary frame was proved to be adequate. An elastic-perfectly plastic bilinear constitutive stress-strain relationship was applied to represent the material properties.

The model was restrained against out-of-plane displacement. The initial imperfection of $10 \mathrm{~mm}$ was assigned to the first buckling mode of the infill panel. Figure 2-3 shows the deformed model subject to a load of $2200 \mathrm{KN}$. 


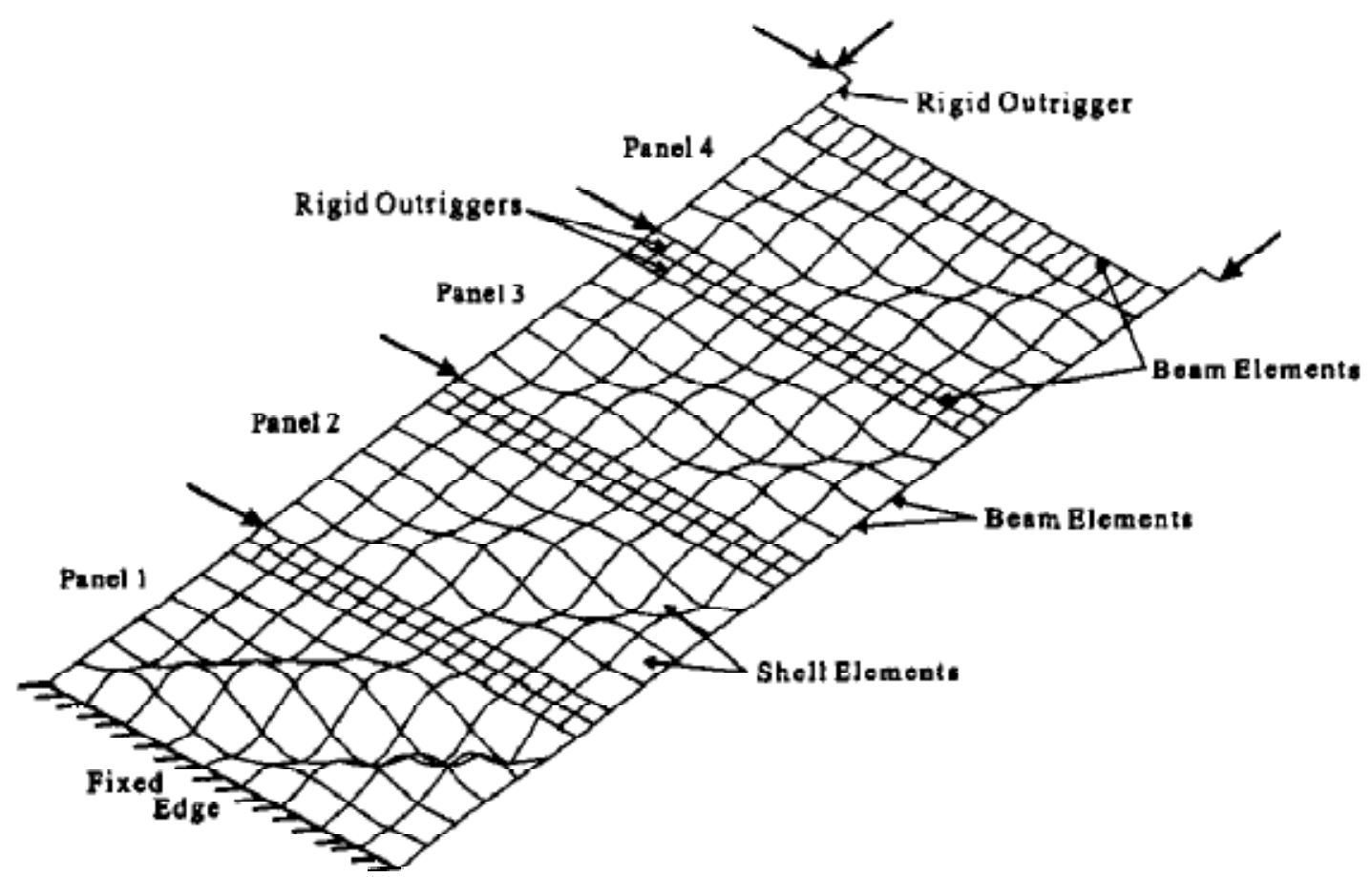

Figure 2-3: FE Model Subjected to $2200 \mathrm{KN}$ (Driver et al. 1997)

The results from the FE model accurately predicted the behavior of the specimen at lower shear forces. However, at higher loads differences were observed between the experimental and analytical results. These discrepancies were due to the fact that they did not include the geometric nonlinearity in the model.

Driver et al. also modeled their specimen using the strip model developed by Thorburn et al. (1983). A three-dimension structural analysis program called S-FRAME was used to perform this analysis. The infill panels were represented by a series of discrete, pinended diagonal tension strips, as shown in Figure 2-4. An inclination angle $(\alpha)$ of $45^{\circ}$ was considered in the model. 


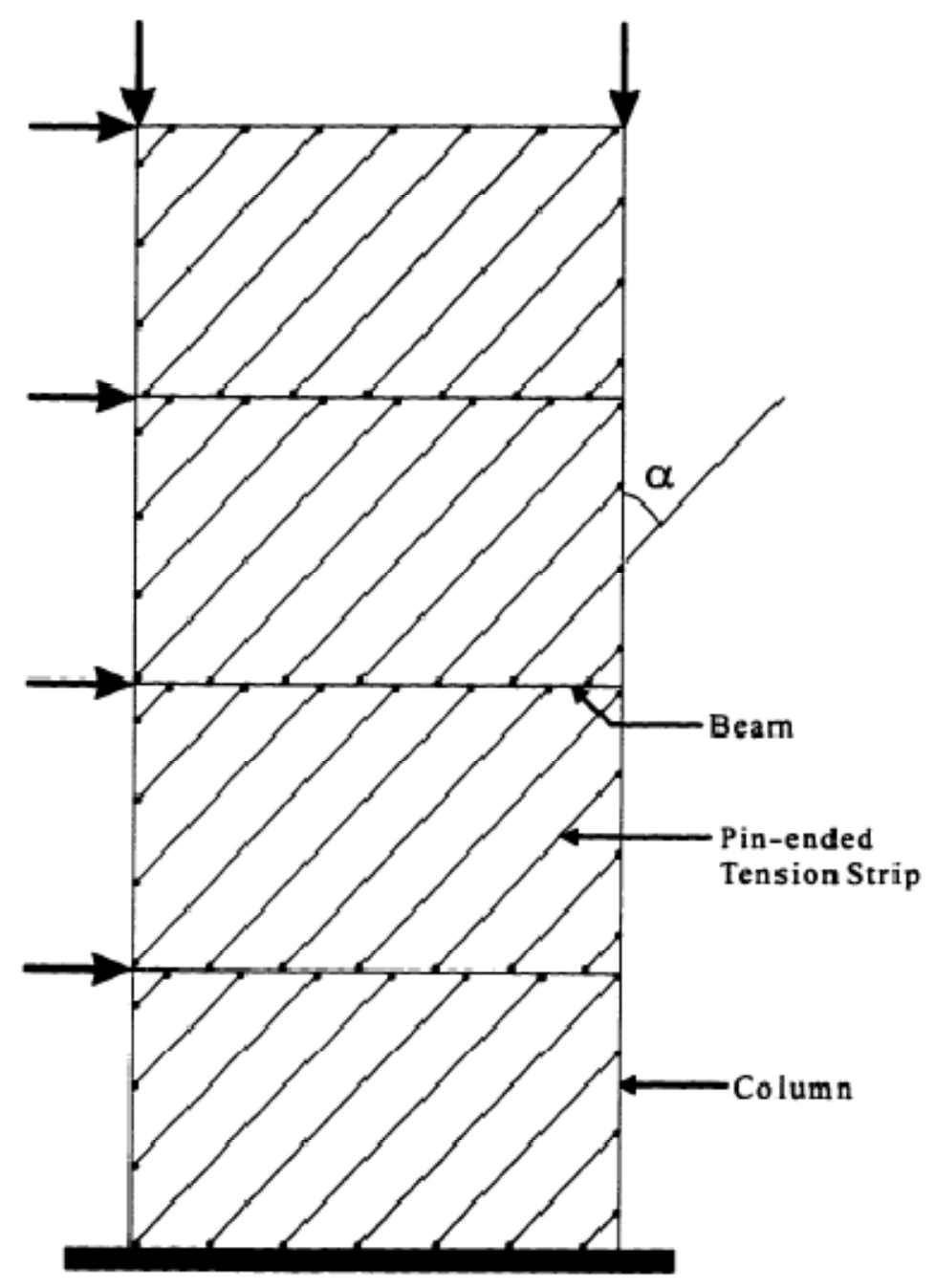

Figure 2-4: Strip Model of Test Specimen (Driver et al. 1998)

After loading began and the strips started yielding, they were subsequently removed from the model and replaced by their equivalent yielding force. Plastic hinges were placed on the surrounding frame members to simulate softening. Reasonable results were obtained from the model for the behavior of each panel and for the entire wall. Nonetheless, the model underestimated the elastic stiffness of the test specimen. 


\subsubsection{Behbahanifard et al. (2003)}

Behbahanifard et al. developed a FE model to replicate the behavior of a three-story specimen. The Software ABAQUS 2001 was used for the development of the model. The four-node shell element with reduced integration (S4R) was used to model all the components of the wall. Geometric nonlinearity was considered. Out-of-plane motion was restrained for the boundary frame. The modified kinematic hardening material was defined to model the inelastic behavior of the material. As suggested by Driver et al. (1998), the initial imperfections of $10 \mathrm{~mm}$ were introduced for the first buckling mode of the specimen. Figure 2-5 shows the post-buckling tension field behavior of the model.

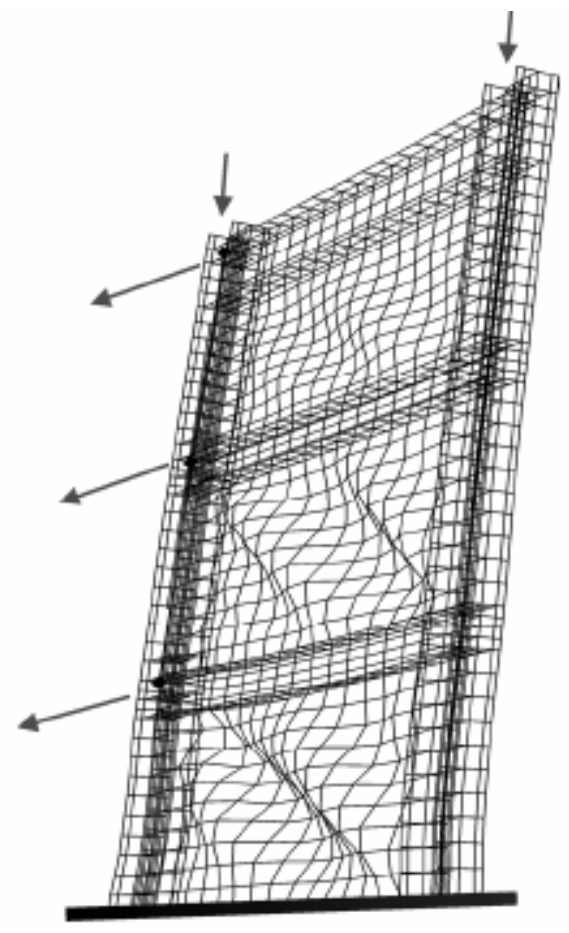

Figure 2-5: Finite Element Model (Behbahanifard et al. 2003)

It was found that the ABAQUS/Explicit provided accurate results for post buckling behavior, highly nonlinearities, and material degradation and failure. In addition, convergence was much easier and faster to achieve. To facilitate convergence, load 
increments of less than $10^{-5}$ were applied to the model. Good agreements were observed between the results of the FE model and the test specimen.

\subsubsection{Berman and Bruneau (2003)}

Based on the strip model developed by Thorburn et al. (1983), Berman and Bruneau used plastic analysis to determine the ultimate strength of SPSWs. Analytical models were derived for single story and multistory SPSWs with either simple or rigid beam-tocolumn connections.

Using both equilibrium and kinematic methods of plastic analysis, it was found that the derived equations capture the ultimate strength of SPSWs. The results were compared with other experimentally obtained results and agreement was observed. In addition, the results were identical to that provided by the CAN/CSA S16-01 which is the procedure used for calculating the shear resistance of a SPSW.

\subsubsection{Qu and Bruneau (2008)}

In an attempt to investigate the behavior of boundary frame members and the impact that they may have on the performance of SPSWs, a two-story SPSW specimen having an intermediate composite beam was tested. In addition, the investigators replicated the behavior of the SPSW via a 3D finite element model and a dual strip model.

To model the infill panels and the frame member the four-node (S4R) elements were used in ABAQUS. The model contained fixed boundary conditions for all degrees of freedom 
of the nodes at the base of the SPSW. Out-of-plane displacements on the floor levels were not allowed in the model. The model was subjected to eigenvalue buckling analysis to determine the buckling modes of the infill panels. The obtained buckling modes were used to introduce the initial imperfections of the infill panels. The model was then subjected to monotonic pushover analysis. The behavior of the model can be observed in Figure 2-6.

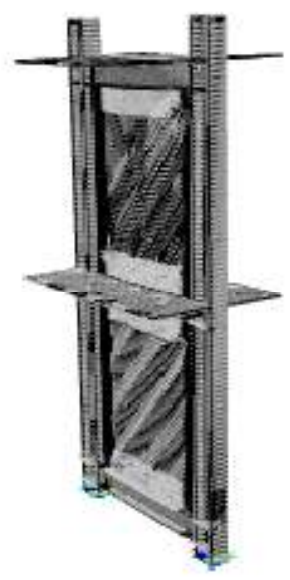

Figure 2-6: Tension Field Action of the FE Model (Qu and Bruneau 2008)

Both the strip model and the FE model yielded excellent correlation with the experimental results. It was conclude that the modeling assumptions and model development procedure utilized in the investigation are appropriate for modeling other SPSWs.

\subsection{Progressive Collapse}

As mentioned earlier, ASCE-7 (ASCE 2005) defines progressive collapse as "the spread of an initial local failure from element to element resulting, eventually, in the collapse of an entire structure or a disproportionately large part of it". The standard further states 
that buildings should be designed, "to sustained local damage with the structural system as a whole remaining stable and not being damaged to an extent disproportionate to the original local damage". In other words, progressive collapse occurs when damage from a localized first failure spreads in a domino effect manner resulting in a total damage disproportionate to the initial failure. It has been observed as one of the most catastrophic failure modes of building structures and it may be caused by different excitations (e.g. fire, blast, collision, during and foundation failure). In fact, based on the data from prior progressive collapse cases, most of the fatal casualties are attributed to the damage caused by progressive collapse rather than to the unpredicted excitations.

\subsubsection{Previous Progressive Collapse Cases}

The Ronan Point disaster in March of 1968 triggered the consideration of progressive collapse in design codes. The Ronan Point was a 22-story apartment complex designed with precast-concrete load-bearing panels in Canning Town, England. A gas explosion in the 18th floor blew out one wall which led to the collapse of the whole corner of the building as shown in Figure 2-7. Due to insufficient progressive collapse resistance, all the floors above and below the $18^{\text {th }}$ floor failed and collapsed one after the other in a progressive manner. This disastrous event initiated significant research efforts on investigating the progressive collapse behavior of building structures and it was envisioned that better continuity and ductility, thus enhanced progressive collapse resistance, might have had reduced the amount of damage (ASCE/SEI 7-2005). 


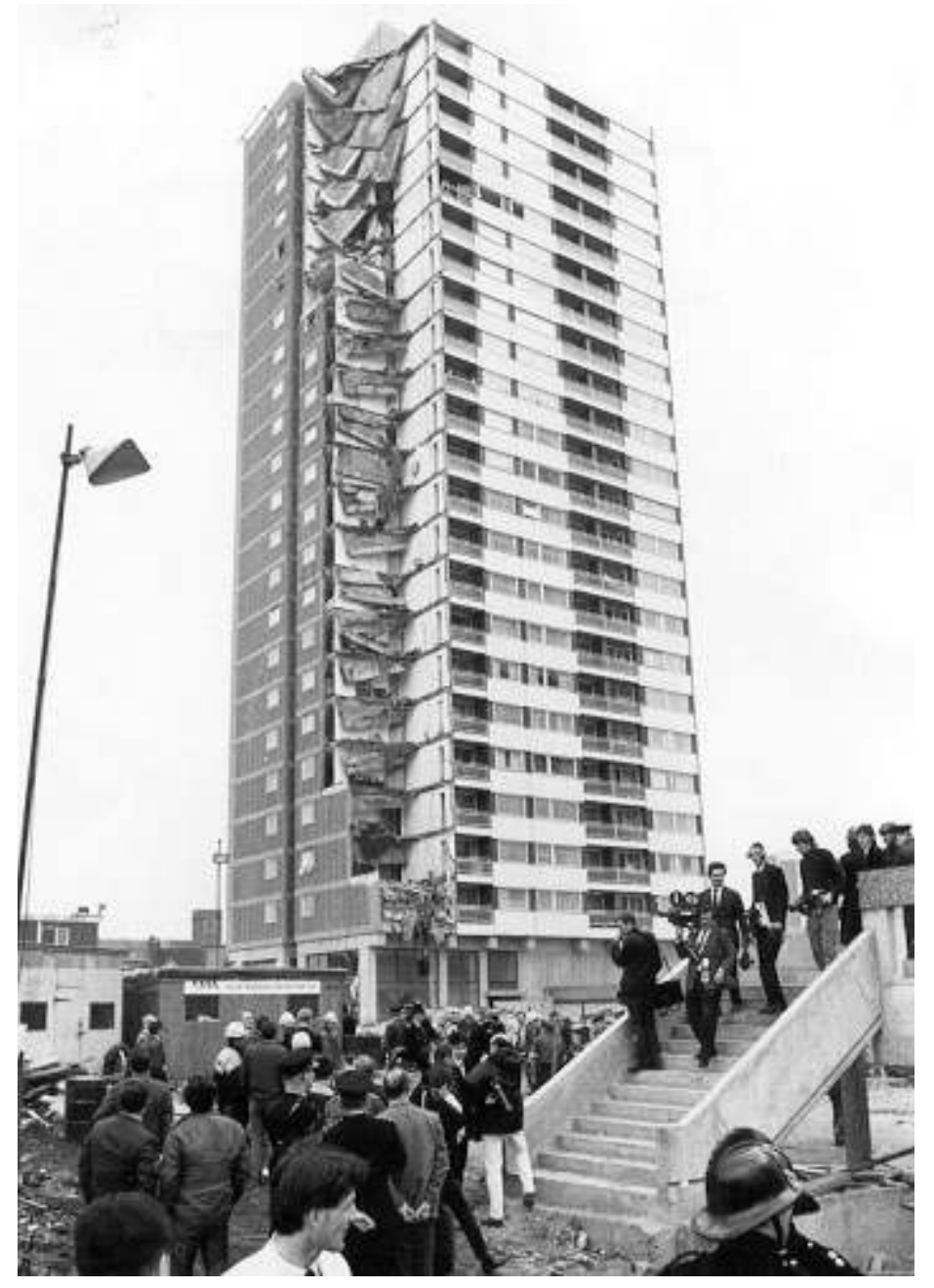

Figure 2-7: Ronan Point March 1968 (Wearne 2000)

In a more recent well planned terrorist attack on April 19, 1995 in the US, a truck containing approximately 4,000 lb of fertilizer-based explosive (ANFO) exploded outside the ninth story Alfred P. Murrah Federal Building. The blast shockwave disintegrated one of the $20 \times 36$ in. concrete perimeter columns and also caused brittle failure of two others (ASCE/SEI 7-2005). Approximately 70 percent of the building experienced dramatic collapse as shown in Figure 2-8. A total of 168 people died and many of those deaths were due to progressive collapse. If a better system that could have enhanced the 
progressive collapse resistance of this structure had been implemented, most of those lives could have been saved (ASCE/SEI 7-2005).

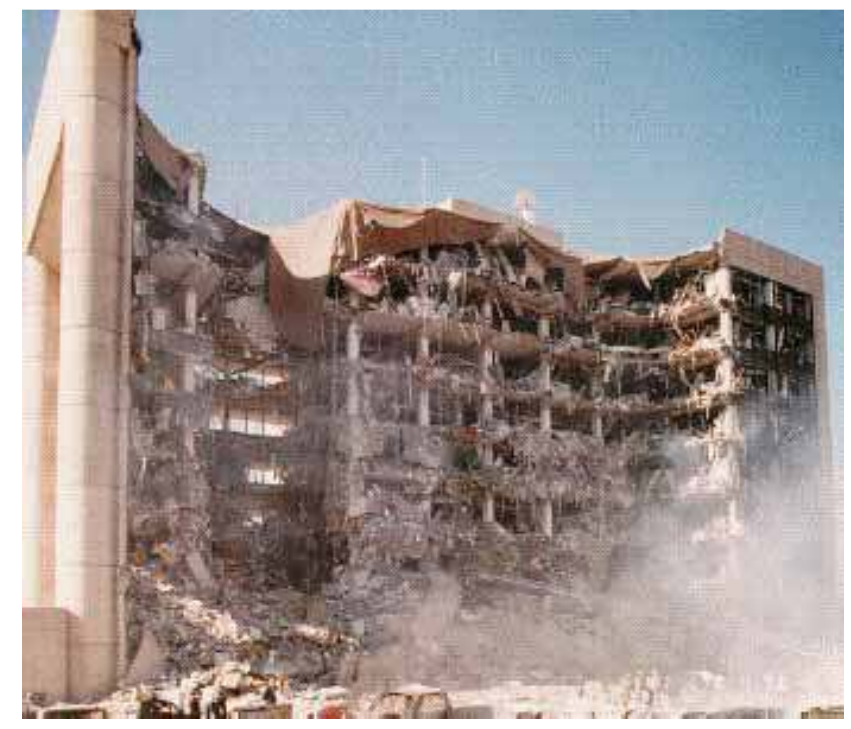

Figure 2-8: Alfred P. Murrah Federal Building (Crowder 2004)

On September 11, 2001, the twin towers of the World Trade Center (WTC) in New York City collapsed as the result of a terrorist attack. Two commercial airliners that had departed from Boston's Logan Airport were hijacked and flown into the two 110-story towers. Some technical debates rose regarding the actual cause of the localized failure; nonetheless a combination of the structural damages respectively from the impact and fires resulted in progressive collapse and consequently total structural collapse of both towers. A total of 2,270 people lost their lives at the WTC site due to the building collapse (FEMA 2002). 


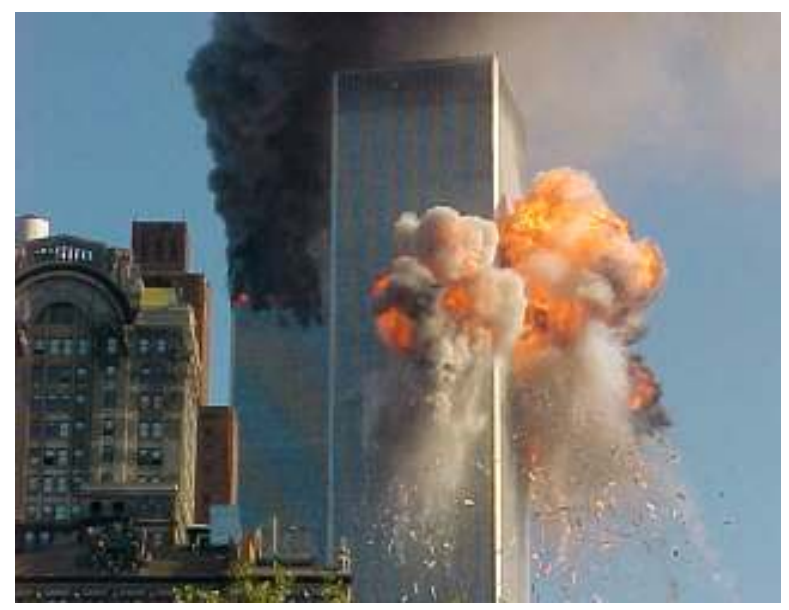

Figure 2-9: collision of flight UA175 Boeing 767 jet with south tower of WTC (Level3.com Sep 20, 2001)

\subsubsection{Code Provisions and Design Guidelines}

The ASCE standard 7, minimum Design loads for building and other structures (ASCE/SEI 7-2005) provides an intensive and comprehensive building performance statement in chapter C1. Section 1.4: General Structural Integrity. This commentary addresses the quality of general structural integrity and provides two methods to address the issue, namely direct design and indirect design. Direct design considers explicitly the resistance to progressive collapse during the design process through either (ASCE/SEI 72005):

1. Alternate Path Method- A method that allows local failure to occur, but seeks to provide alternate load paths so that the damage is absorbed and major collapse is avoided.

2. Specific Local Resistance Method- A method that seeks to provide sufficient strength to resist failure from accidents or misuse. 
The indirect design method considers the resistance to progressive collapse during the design process through the provision of minimum levels of strength, continuity, and ductility.

The Precast Concrete Institute (PCI) and the American Concrete Institute (ACI) also provide recommendations and design guidelines to preserve structural integrity. The PCI was the first American institutions to provide such guidelines in 1976 (Cleland 2007), mainly because of the lack of redundancy in precast concrete structures. These guidelines were added to the ACI in 1995. ACI extended these design recommendations to cast-inplace concrete structures to enhance structural integrity via detailing requirements. These new detailing requirement ensures that the structure would be able to redistribute load from failed members enhancing structural collapse resistance. In addition, these detailing requirements ensure tensile and moment reversal capacities and an overall increase in ductility.

In an attempt to reduce the potential of progressive collapse for new and existing facilities that experience localized structural damage through unforeseeable events, the Unified Facilities Criteria (UFC) provides design requirements (DoD 2009). These requirements were developed, independently, by the General Service Administration (GSA) and by the Department of Defense (DoD) in 2003, in an attempt to protect governmental and military facilities from potential progressive collapse caused by terrorist attacks. In 2005 the GSA integrated its requirements into the DoD Unified Facility Criteria (UFC) to publish the "Design of Buildings to Resist Progressive 
Collapse" report. This document provides design recommendation rather than detailed design requirements and equations. The appropriate design manuals and codes are suggested to be used to address specifics about the behavior and performance of the structure. According to this document, the level of design for progressive collapse depends on the level of Occupancy Category (OC) which can be assessed per section 2-1 of the document. Depending on the OC, this document specifies the following levels of progressive collapse resistance (DoD 2009):

- Tie Forces, which prescribe a tensile force capacity of the floor or roof system, to allow the transfer of load from the damaged portion of the structure to the undamaged portion,

- Alternate Path Method (APM), in which the building must bridge across a removed element, and.

- Enhanced Local Resistance, in which the shear and flexural capacities of the perimeter columns and walls are increased to provide additional protection by reducing the probability and extent of initial damage.

\subsubsection{Past Research on Enhancing Progressive Collapse Resistance}

In an attempt to increase the capacity of a steel building to prevent progressive collapse, Astaneh-Asl (2007) performed a full scale testing of a steel frame with bolted seat and web angle shear beam-to-column connections. As shown in Figure 2-10, the south side of the test specimen was a $60^{\prime}$ by $20^{\prime}$ one-story steel structure with a steel deck and concrete slab floor system and wide flange beams and columns. The height of the columns was equal to 6'. The north side of the specimen consisted of a similar steel 
frame, but it contained catenary cables running longitudinal as seen in Figure 2-10.

These catenary cables were used to develop the catenary action under the vertical load which would, ultimately, enhance the progressive collapse resistance of the frame. The center columns on each longitudinal frames of the specimen were constructed 36 inches above the laboratory floor. This action was taken to simulate the sudden lost of these columns in the event of an explosion (columns C1 and C2 from Figure 2-10 were the two columns removed). A hydraulic actuator pushing downward on the top of those two columns was implemented to simulate the gravity loads on the column.

From the results shown in Figure 2-11 it is evident that the frame with the catenary cables was able to resist higher load than the frame with no catenary cables. At the column downward displacement of 27 inches; the catenary cables were supporting over half of the column load. The investigator proposed to install the catenary cables as a method to retrofit existing structures to enhance progressive collapse resistance.

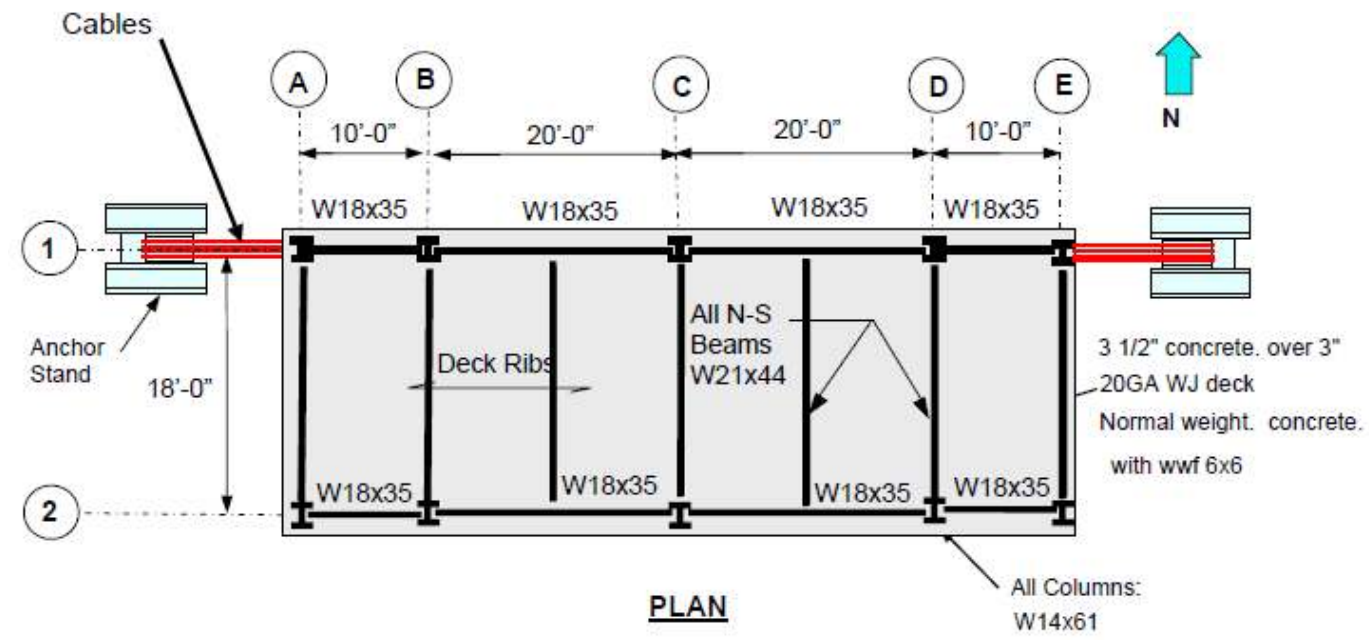

Figure 2-10: Plan view of the tested specimen with catenary cables (Astaneh-Asl 2007) 


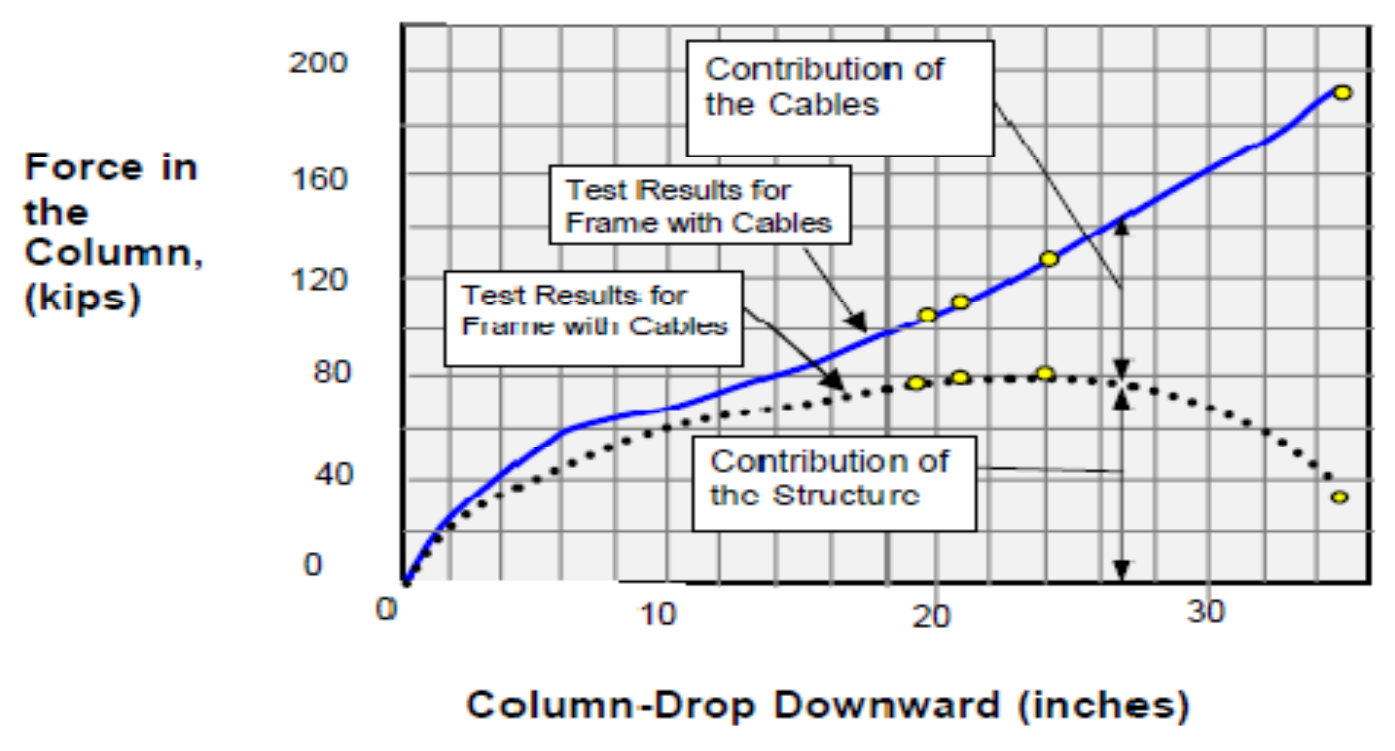

Figure 2-11: Test Results (Astaneh-Asl 2007)

Although the catenary cable provides additional vertical load resistance after a sudden column removal it would only work under specific circumstances. The catenary cables would provide additional progressive collapse resistance only when an interior column is removed due to an extreme event. In the case in which a corner column fails, the cables may lose anchorage at the end and likely provide no additional catenary action. Note that the exterior column corresponds to the end column shown in Figure 2-12. The DoD UFC requires the removal of an exterior column as part of column removal strategy to evaluate the building's capacity to prevent progressive collapse. Figure 2-13 shows the diagram outlining the column removal strategy by the DoD UFC. Therefore, the catenary cable retrofitting technique does not meet the strategic column removal plan to evaluate the systems progressive collapse resistance. 


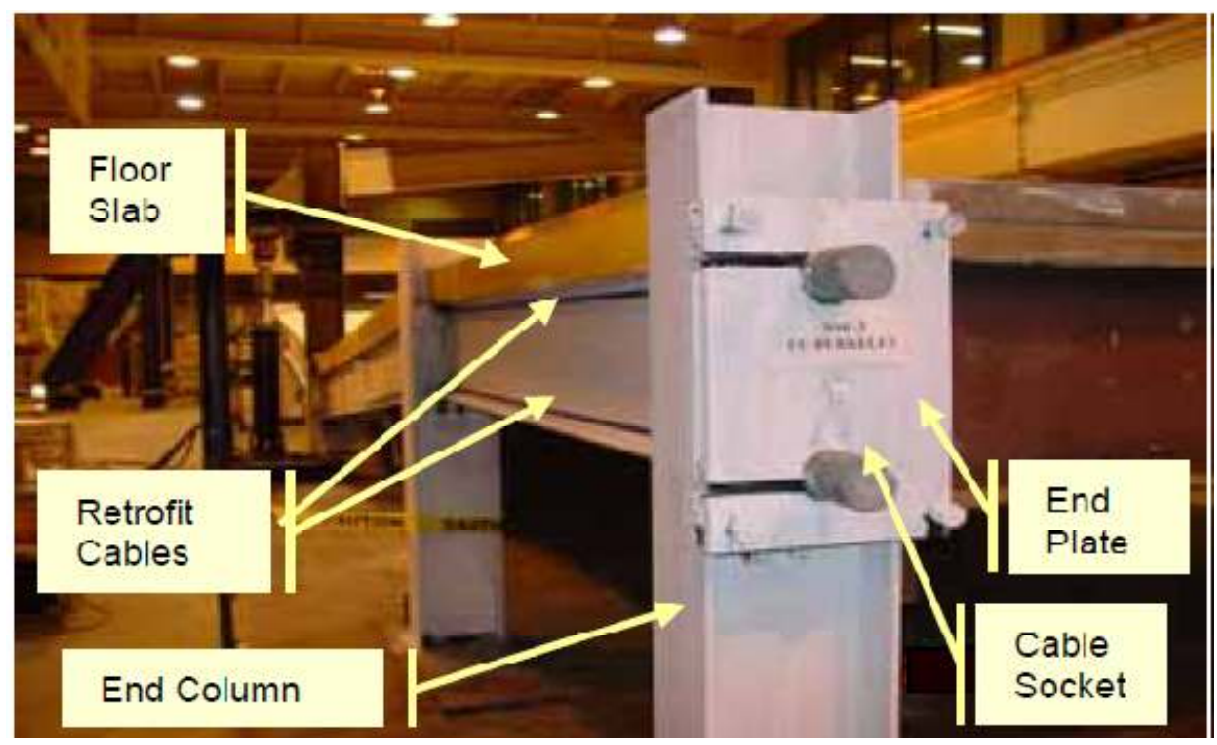

Figure 2-12: Specimen and the retrofit cable end anchorage (Astaneh-Asl, 2007) 


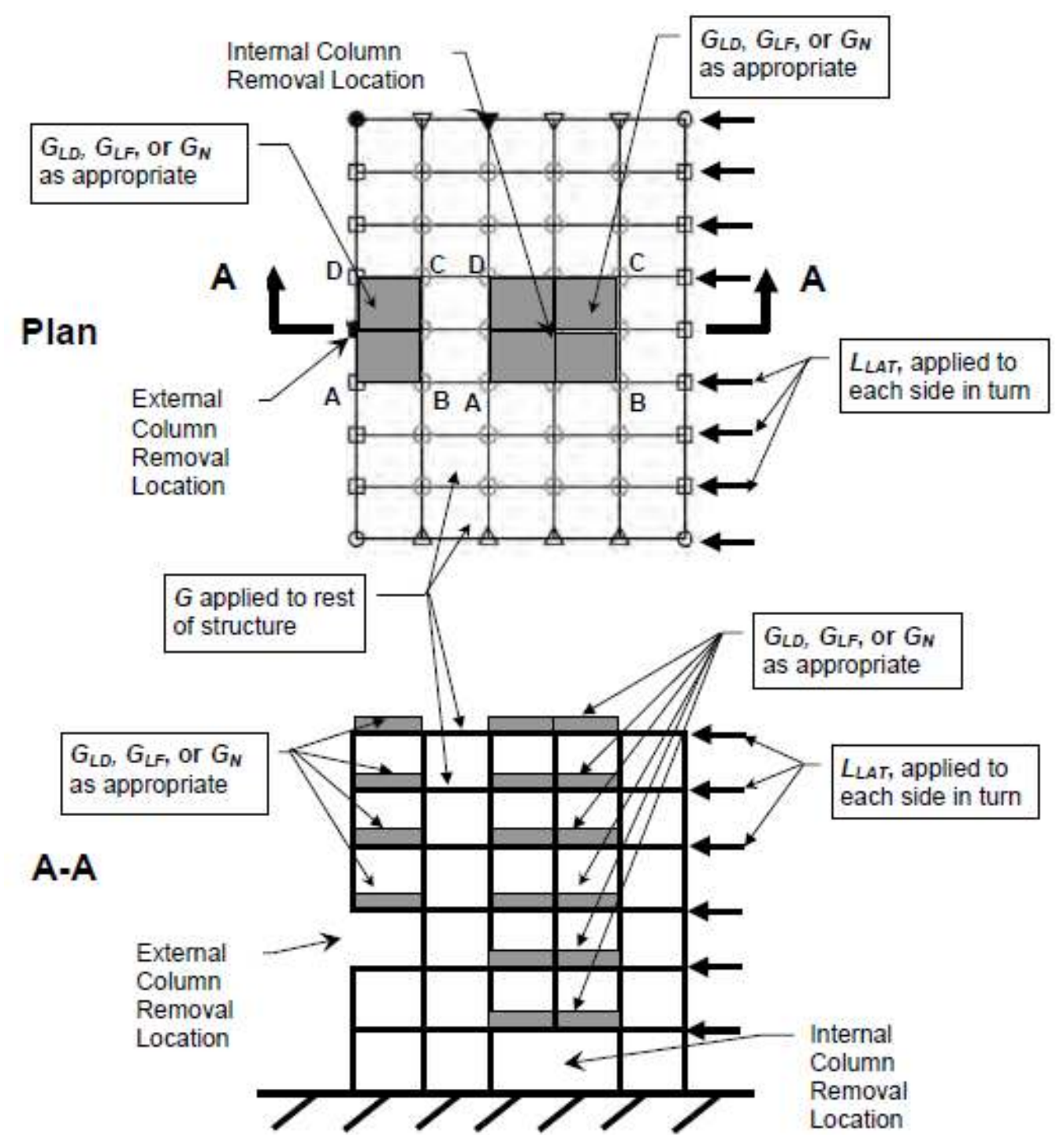

Figure 2-13: Column removal strategy (DoD UFC 2009)

Astaneh-Asl et al. (2001) also investigated the contribution of simple beam-to-column connections to the system progressive collapse resistance. The specimen consisted of a 60 foot by 20 foot one-story steel structure with a steel deck and concrete slab floor system and wide flange beams and columns. Figure 2-14 shows schematics of the plan and elevation views of the tested specimen. As seen on the elevation view the center column corresponded to the removed column. The beam-to-column shear connections 
consisted of bolted seat angles plus a single bolted angle on the web of the beam. A graphical representation of the actual connections used can be found in Figure 2-15.

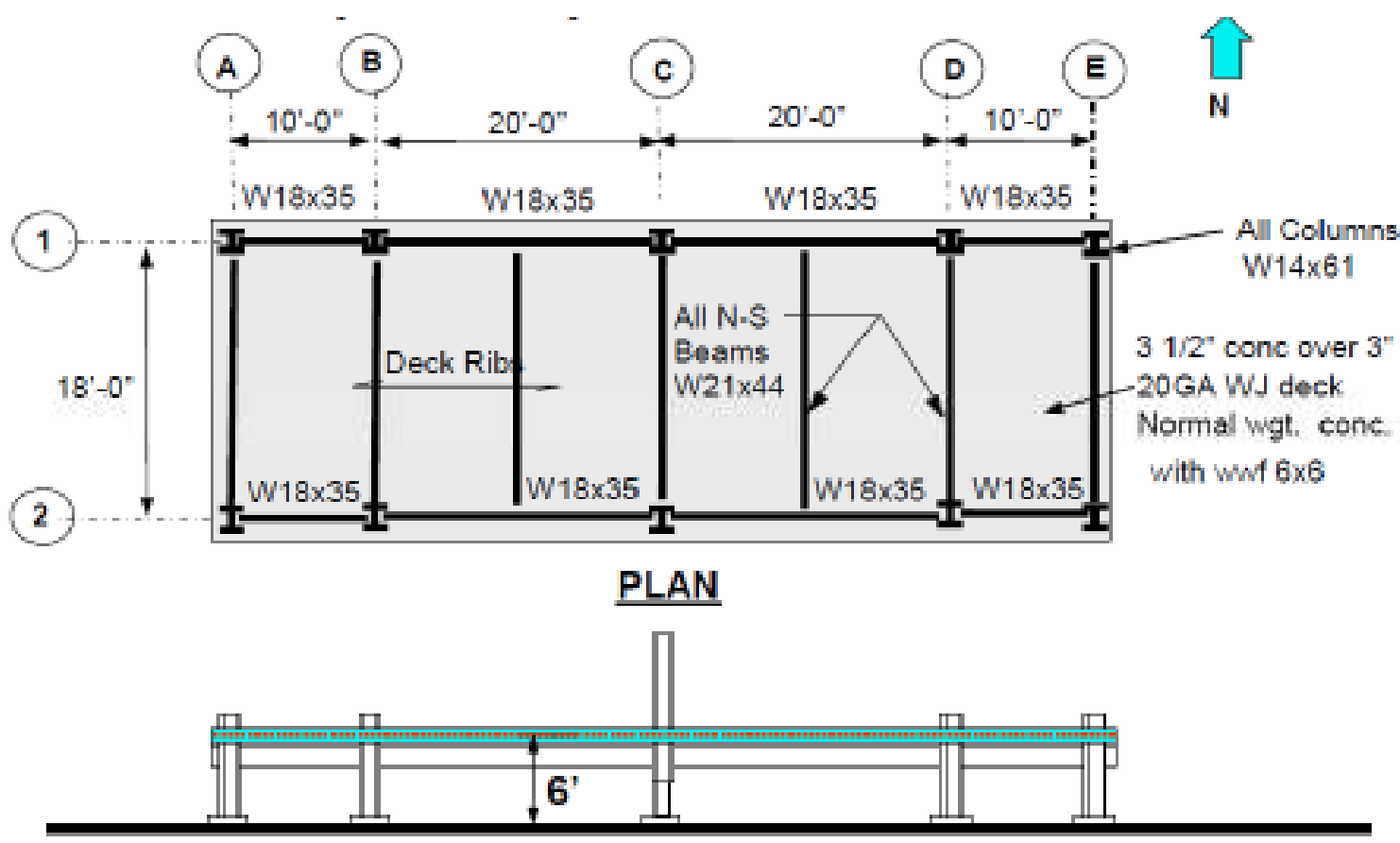

\section{ELEVATION}

Figure 2-14: Test Specimen (Astaneh-Asl et al. 2001) 


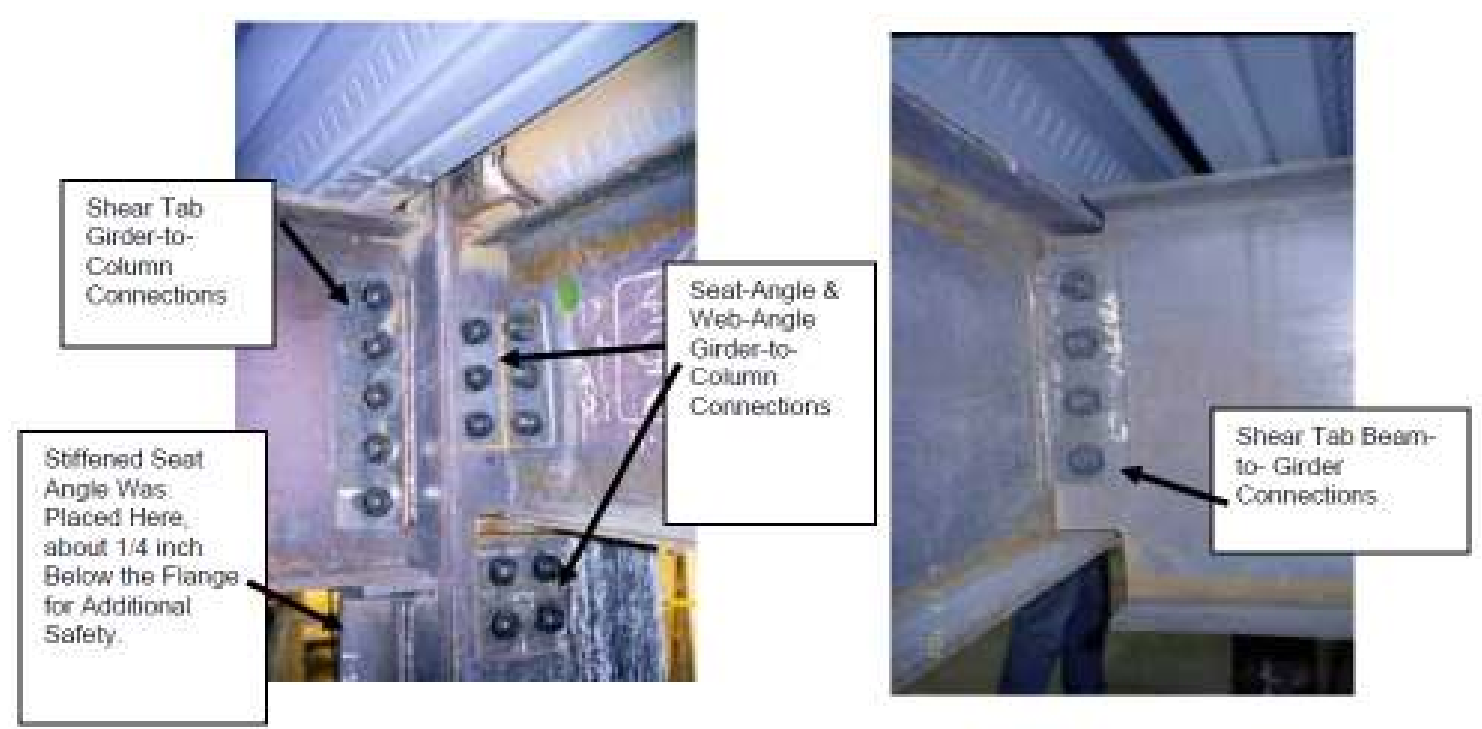

Figure 2-15: Beam-to-column connections (left) beam-to-girder connections (right) (Astaneh-Asl et al. 2001)

The specimen was loaded three times at the missing column by gradually increasing vertical downward displacements to a maximum of 19, 24 and 35 inches respectively. During the second loading it was observed that the bolts that held the longitudinal beam east of the loaded column on the seated connection at column $\mathrm{C} 2$, failed. In addition, the seated connection also yielded. Figure 2-16 shows the post-testing behavior of the specimen. During the third loading and at approximately 26 inches of downward displacement the connecting angles between the drop column $\mathrm{C} 2$ and the longitudinal beam directly east completely failed. It was noted that after the connection failed the concrete slab was transferring the applied force to the longitudinal beam east of the displacing column. 


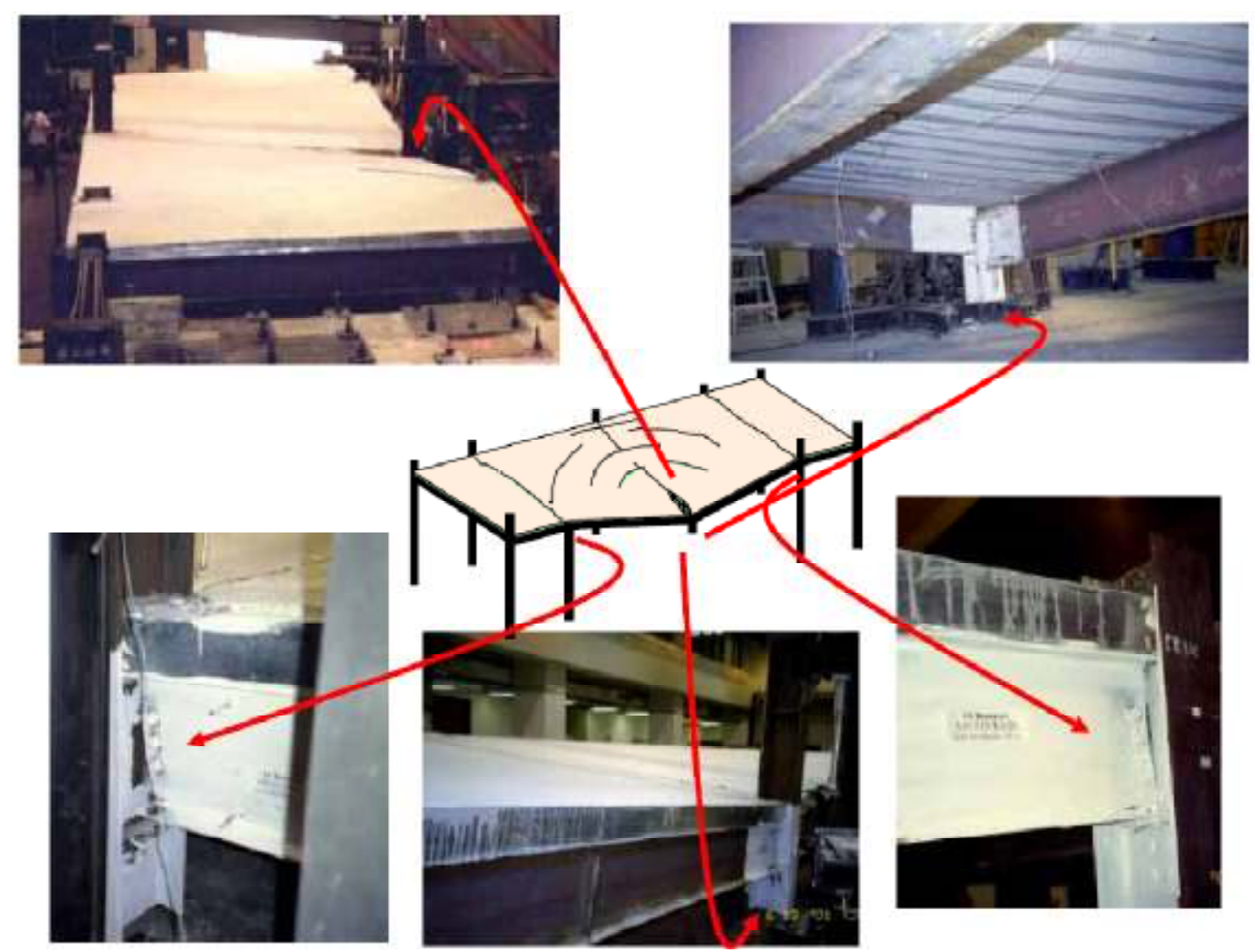

Figure 2-16: Specimen after testing (Astaneh-Asl at al. 2001)

Astaneh-Asl et al. (2001) concluded that the ultimate capacity of the structure following the loss of a column was limited by the beam-to-column connection capacity to carry axial catenary forces. If the connection bolts had not fractured in tension, it is expected that larger catenary forces could have been carried by the beam, resulting in a greater progressive collapse resistance of the structure. Therefore, if connections are not properly strengthened, the structure will fail prematurely at the joint without full development of the catenary action.

Li (2009) developed a mathematical model which was validated by FE method to show that progressive collapse resistance can be enhance by strengthening simple shear 
connections. The researcher proposed two retrofitting techniques that would change the partial-strength shear resisting joint to the full-strength moment resisting joints. Figure 2-17 shows the common design for fin plate shear joins of most steel structures.

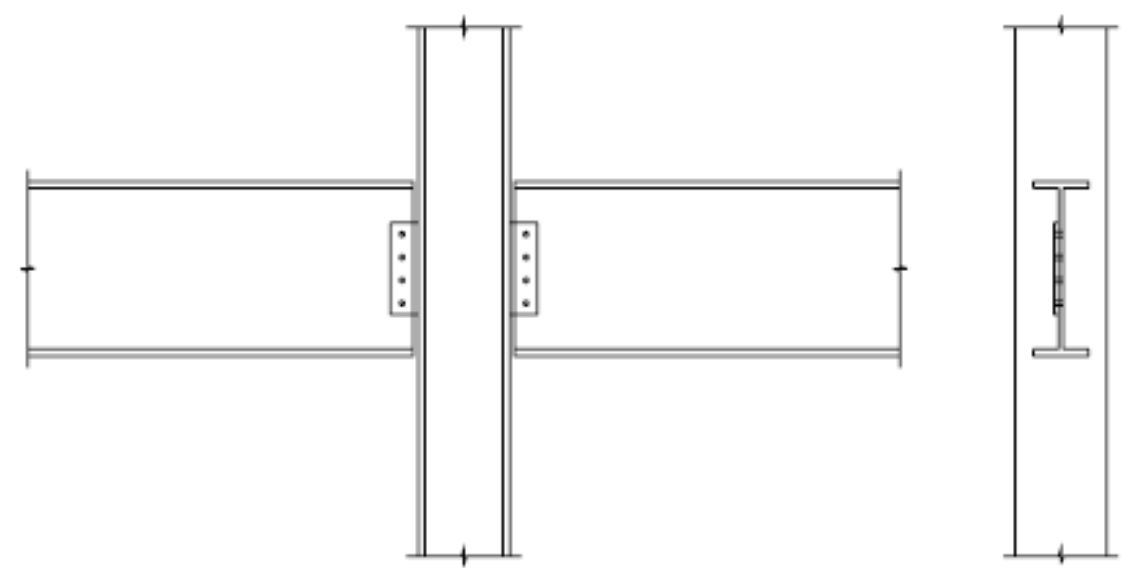

Figure 2-17: Original design of fin plate joins (Li 2009)

Two retrofitting options were investigated. Retrofitting scheme 1 is similar to the flange plate connection used in new structures (Li 2009). In addition to welding the beam flange and the stiffener to the column as shown in Figure 2-18, the lapped flange plate was connected to the flange of column and beam by butt welding and fillet welding, respectively. The objective was to transfer the weakest cross-section away from the beam-to-column joint and to improve the ductility, the continuity and the redundancy of the structure ( $\mathrm{Li} 2009)$. 


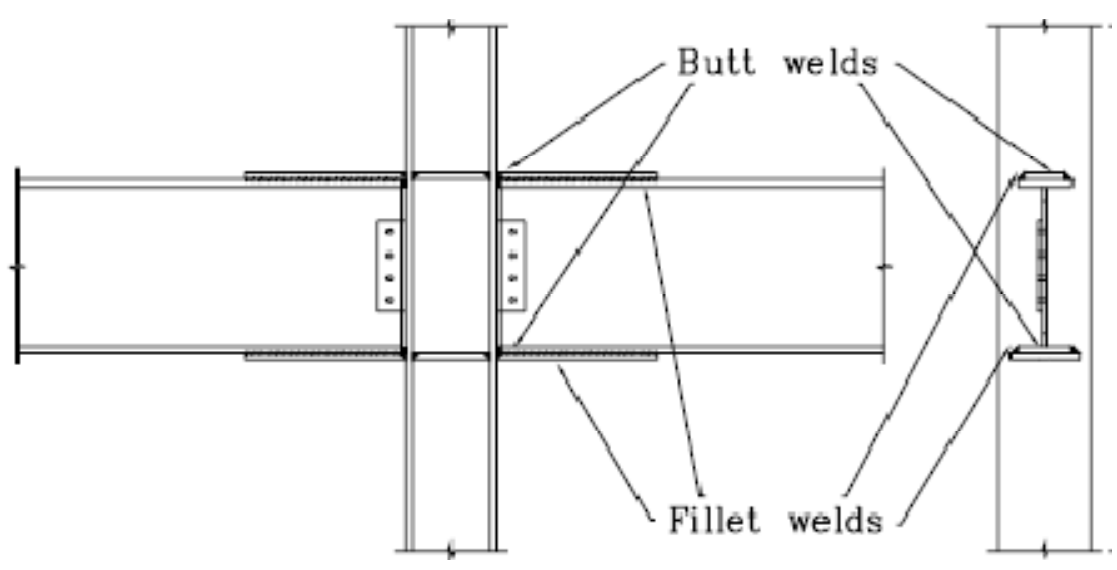

Figure 2-18: Retrofitting scheme 1 (J.L. Li 2009)

Figure 2-19 shows retrofitting scheme 2 which installs high strength bars near the beam flanges and adds thin plates to increase the beam's web thickness.

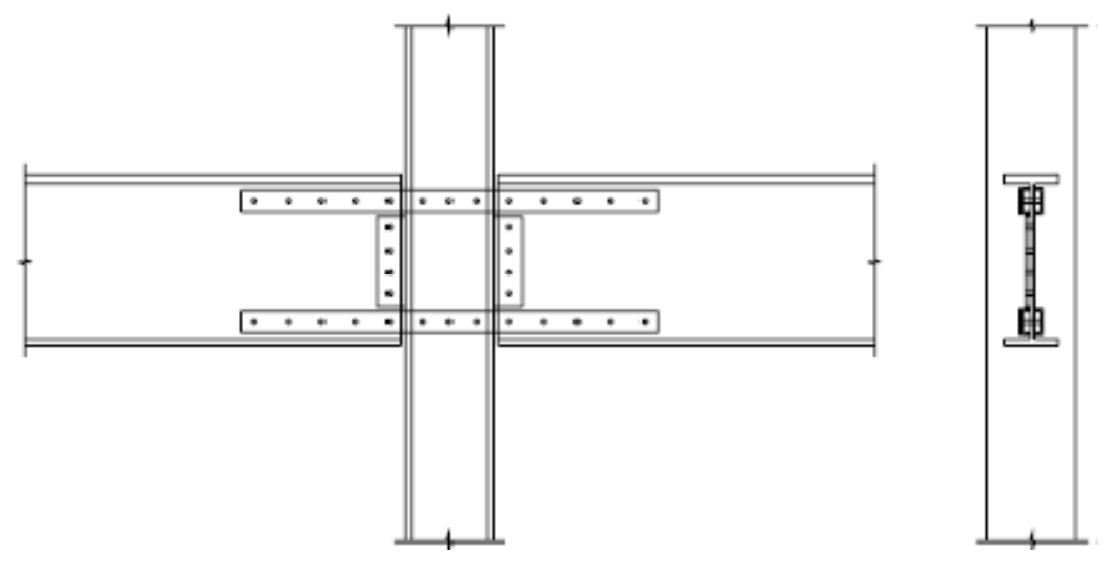

Figure 2-19: Retrofitting scheme 2 (Li 2009)

Li (2009) concluded these retrofitting techniques can improve structural ductility, increase the structural capacity to develop catenary actions in the beams, increase structural robustness, and enhance the progressive collapse resistance of the system.

Although both of these retrofitting techniques may help prevent premature beam-tocolumn fractures and therefore increase the progressive collapse resistance, the following 
disadvantages are identified. The first technique is labor intensive because it requires the removal of the floor slab near the column in order to add the welds. In addition, the quality of the weld can be compromised due to the inconvenient welding directions that can be performed due to a space restriction of the already existing structure.

Furthermore, intensive welding can cause residual stress and can potentially cause nonductile damage of the columns and beams. The second retrofitting scheme requires many holes to be drilled or punched on the existing columns and beams which can be labor intensive and very difficult to accomplish on the site. In addition, these holes reduce the net cross-section area of the beam decreasing its shear and tensile catenary capacities. By implementing the connection retrofitting techniques suggested by Li or others, the maximum progressive collapse resistance that can be obtained is equal to the tensile strength of the beams. In the event in which the vertical load exceeds the tensile strength of the beam, the beam can rupture triggering progressive collapse.

Other researchers have suggested the concept of structural compartmentalization and isolation as a means to improve the system progressive collapse resistance. The idea is to confine the structural damage to a small area. Based on this design philosophy, if progressive collapse occurs only a small compartment of the entire structure will be affected. Although this method can be feasible, compartmentalization requires small spans and spaces with independent structural systems. In comparison with the common continuity design, compartmentalization is significantly less efficient in terms of constructability and space usage (Marchand \& Alfawakhiri 2004). Furthermore, 
compartmentalization does not prevent progressive collapse; instead it limits progressive collapse damage to a small area of the entire structure.

\subsection{Summary}

An extensive literature review on analytical modeling of SPSWs and recent research outcomes on progressive collapse is presented in this chapter. Emphasis was made on the modeling of the infill panels. In addition, limitations of the current strategies for progressive collapse retrofit of steel frames were identified. 


\section{PLASTIC ANALYSIS OF THE PROPOSED SYSTEM}

\subsection{Consideration of Initial Column Failure}

Among the possible structural member damages in steel frame buildings, failures in columns are more likely to initiate progress collapse since columns are the key members to support and transfer the gravity loads acting on the frame to foundations. Past research on structural progressive collapse caused by column failures can be divided into two categories: the research focusing on the threat or loading mechanism causing the column failure; and the investigations focusing on performance evaluation and retrofit of the system vulnerable to collapse (Hoffman 2010). The second category is commonly known as the threat independent approach in which the column that may be damaged is removed from the system, i.e., assuming the damaged column surrenders all of its loadcarrying capacity. Although less accurate, this procedure is more versatile as the results are valid for any abnormal loading (Hoffman 2010). In the case where the column's entire capacity is not lost, the threat-independent approach is more conservative because it assumes that the column does not contribute any additional strength to the structure.

Figure 3-1 shows the collapse mechanism of a structure based on the threat independent approach. Such an approach will be used in this thesis for assessing the performance of the proposed system. 


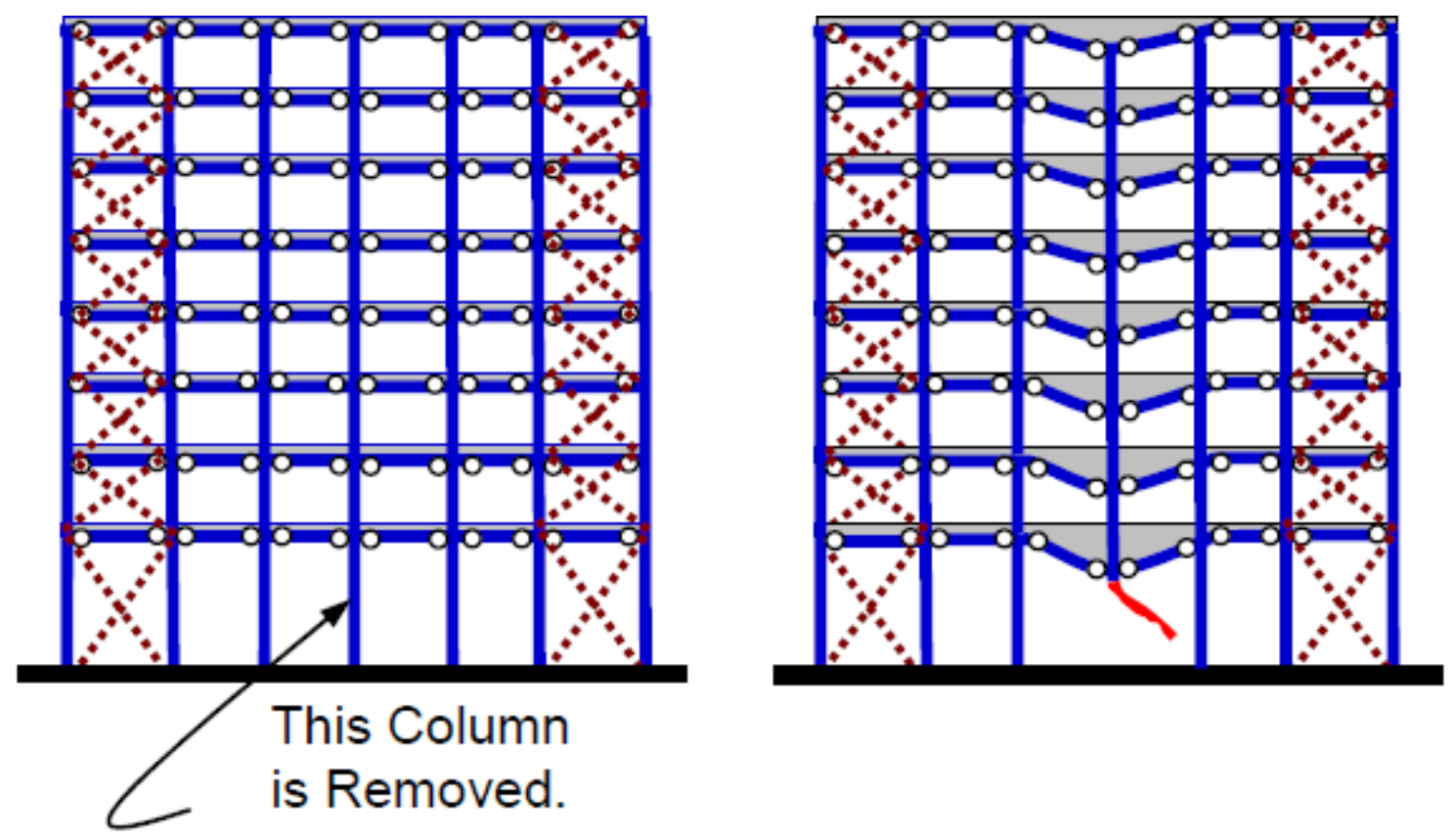

Figure 3-1: Frame before and after removal a column (Astaneh-Asl 2007)

\subsection{Proposed System}

As shown in Figure 3-2, the proposed system consists of thin infill panels installed in steel structural frames to enhance the system progressive collapse resistance. In the event of column removal, the infill panels buckle in shear followed by the formation of inclined tension field actions which provide continuity, ductility, and redundancy to limit the spread of localized damage. The tension field actions bridge over the missing column preventing the development of progressive collapse. 


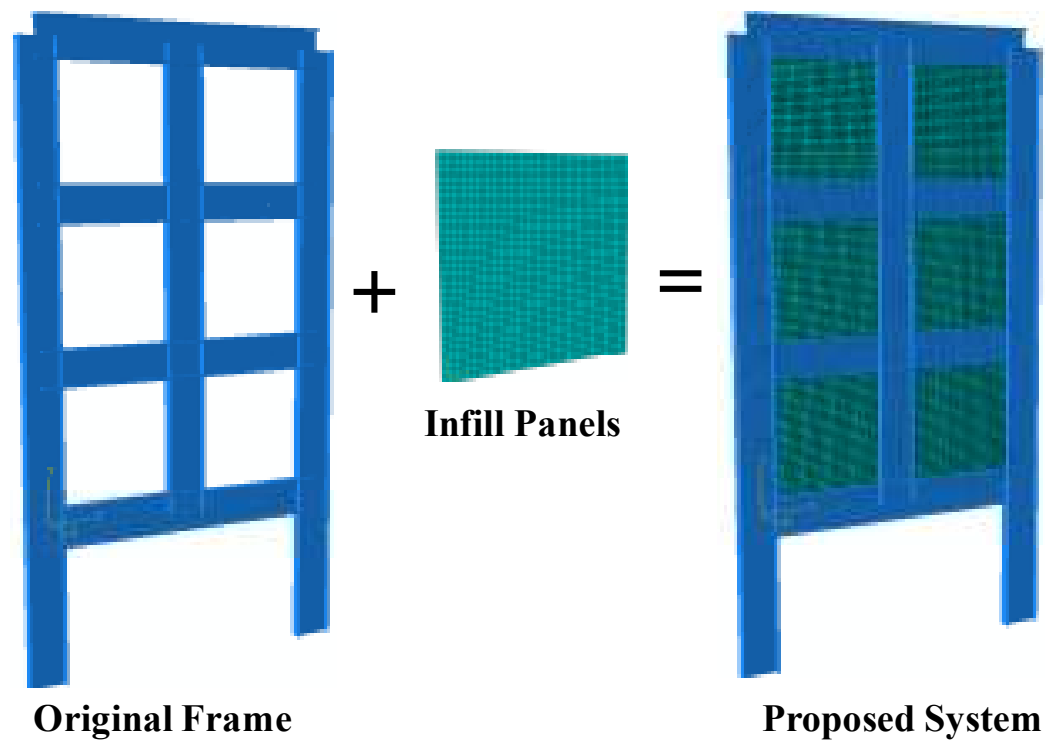

Figure 3-2: Proposed system

Although the proposed system seems very similar to SPSWs used in seismic design, their tension field actions are different. Figure 3-3 illustrates the difference between the post buckling tension field action of a conventional SPSW and that of the proposed system. As shown, the tension fields in SPSWs resist the horizontal earthquake forces, while the tension fields of the proposed system resists the vertical gravity load.
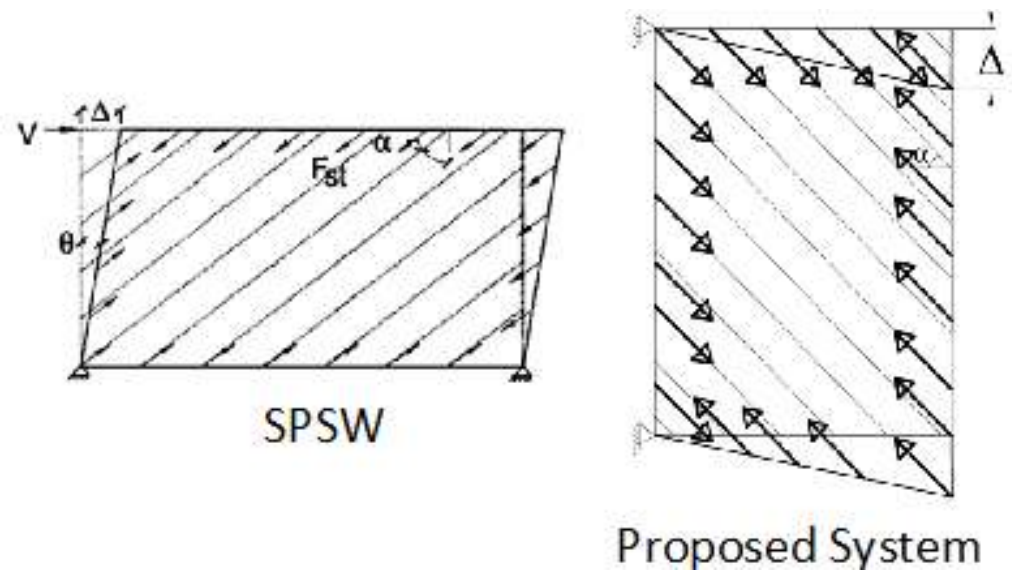

Figure 3-3: Single plate field tension action of SPSW and proposed system 
The post buckling tension filed action on a multistory building for both, a SPSW and the proposed system, can be found in Figure 3-4. The inclination of tension field action on the multistory SPSWs helps resists the lateral loading. The inclination of the tension field action of the proposed system in a multistory bridges the missing column and helps arrest progressive collapse by transferring the load to the adjacent columns.
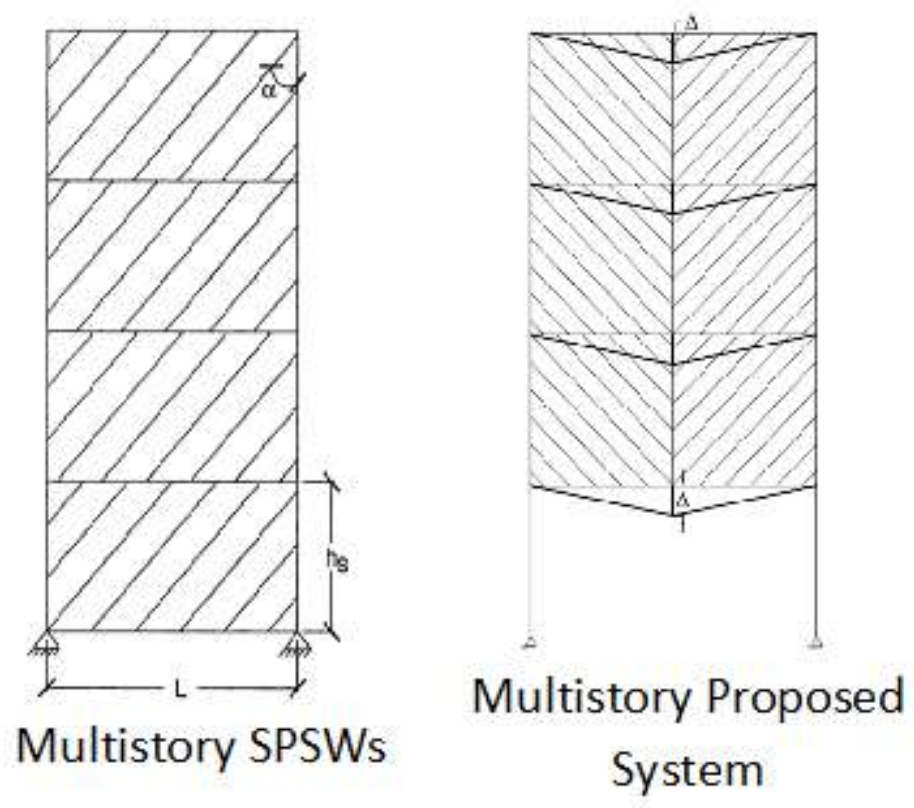

Figure 3-4: Tension field actions in multistory SPSWs and the proposed system

\subsection{System Behavior}

The behavior of the proposed system combines the infill panel tension field actions and the boundary frame catenary actions if they are allowed to develop. This section addresses the respective contributions of these two actions to the system progressive collapse resistance based on the classic plastic analysis models developed by prior researchers. The infill panels were analyzed using the strip model developed for consideration of the tension field actions by Thorburn et al. (1983). Berman and Bruneau (2003) confirmed the reliability of such a model for calculation of the SPSW plastic 
strength. Section 3.3.1 follows the work by Berman and Bruneau (2003) for analysis of the infill steel plates in the proposed system. It is recognized that the boundary conditions and the distribution of tension field actions along the height of the proposed system are different from those of conventional SPSWs (i.e. the system which has been studied by Berman and Bruneau 2003). Section 3.3.2 will analyze the behavior of boundary frame catenary action based on the results derived by Timoshenko (1955).

\subsubsection{Infill Panel - Tension Field Action}

Following the plastic analysis procedure developed by Berman and Bruneau (2003) for conventional SPSWs, the contribution of infill panels in the proposed system for the progressive collapse resistance of the overall system is investigated and equations for quantifying their contribution are developed. For comparison purpose, two methods (i.e. the equilibrium method and the kinematic method respectively) are considered. The derived equations can be used to determine the infill plate size when the applied vertical load (typically resultant gravity load acting on the frame) is known. Both the single and multistory systems are considered. It is noted that the single story analysis provides building blocks for the more complex multistory analysis.

\subsubsection{Equilibrium Method - Single Story Frame}

For analysis purpose, as shown in Figure 3-5, the infill panel is divided into the following three zones: Zone 1 which contains the strips connected to the right column and the top beam; Zone 2 which consists of strips anchored to the left and right columns; and Zone 3 which is represented by the strips attached to the left column and the bottom beam. 
Every zone is labeled and delineated by dash lines in Figure 3-5. The maximum resistance of each zone $\left(P_{i}\right)$ is found then added to determine the progressive collapse resistance capacity of the entire infill panel.

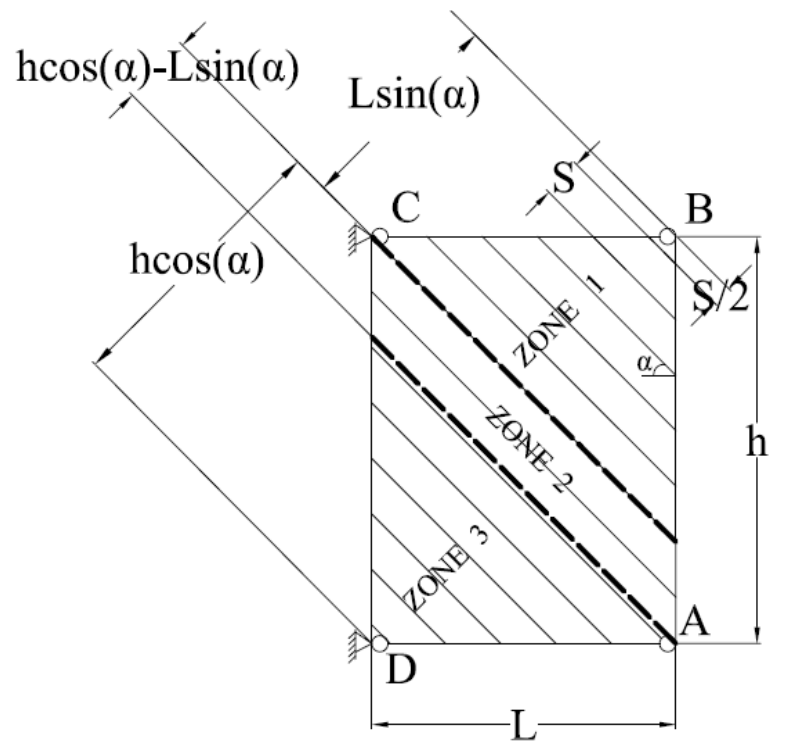

Figure 3-5: Strip model of a single SPSW with simple beam-to-column connection

\subsection{Zone 1:}

The FBDs of Zone 1 are shown in Figure 3-6 and Figure 3-7.

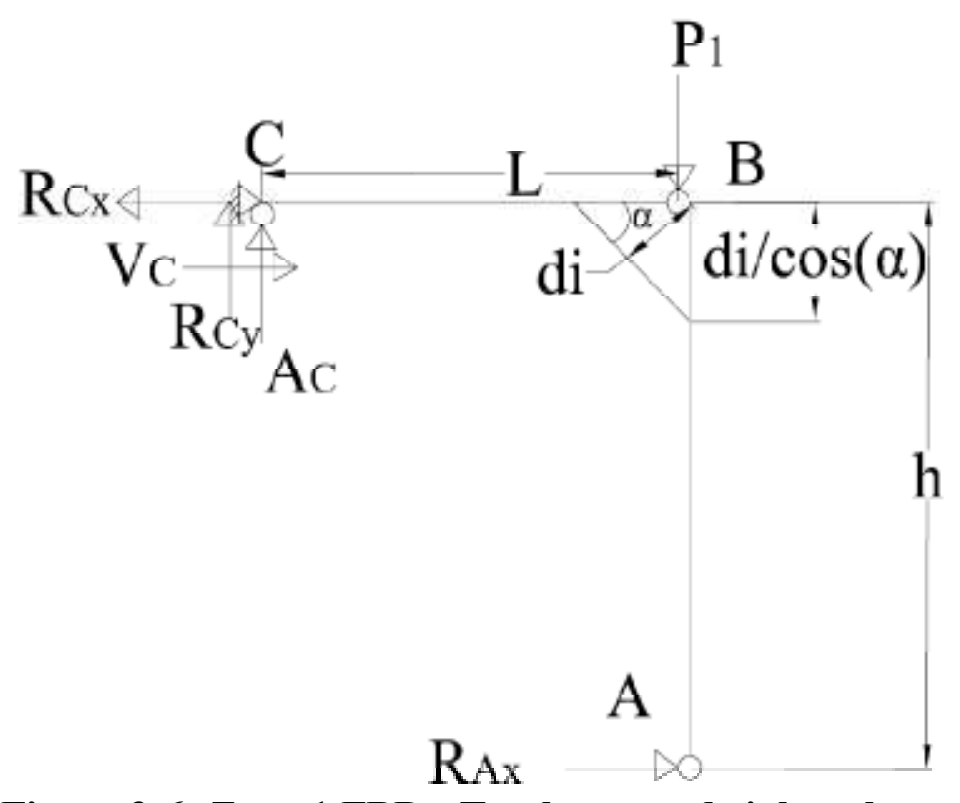

Figure 3-6: Zone 1 FBD - Top beam and right column 


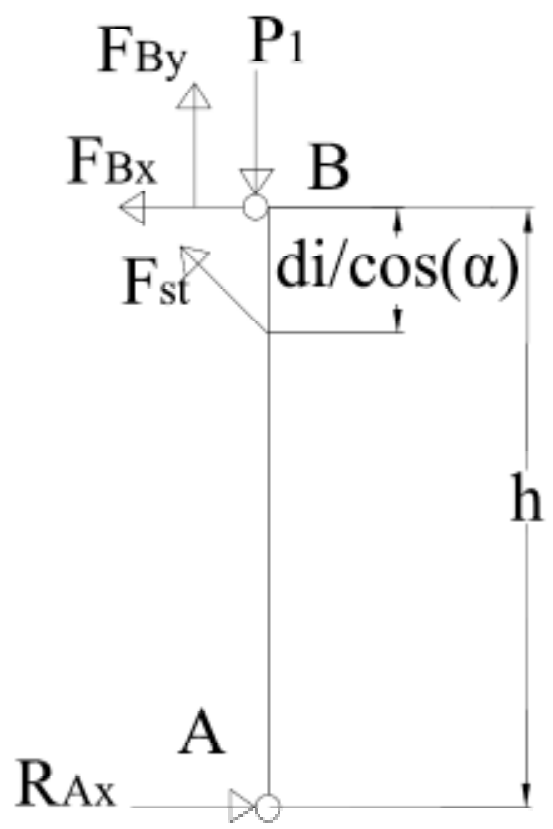

Figure 3-7: Zone 1 FBD - Right column

Summing moments about point $\mathrm{C}$ from Figure 3-6 yields:

$$
\begin{gathered}
\sum M_{C}=P_{1} \bullet L-R_{A X} \bullet h=0 \\
P_{1}=\frac{R_{A X} \bullet h}{L}
\end{gathered}
$$

where $P_{1}=$ resistance due to the strips in zone 1 ;

$$
\begin{aligned}
& h=\text { story height; } \\
& L=\text { bay width; } \\
& R_{A X}=\text { horizontal support reaction at A. }
\end{aligned}
$$

Analyzing the FBD of the column alone in Figure 3-7 and taking moment about point B, gives: 


$$
\begin{gathered}
\sum M_{B}=R_{A X} \bullet h-F_{s t} \cdot \cos \alpha \cdot\left[\frac{d_{n}}{\cos \alpha}\right]=0 \\
R_{A X}=F_{s t} \cdot\left(\frac{d_{n}}{h}\right)=0
\end{gathered}
$$

where $F_{s t}=$ force of one strip;

$d_{n}=$ perpendicular distance between the beam-column connection and the strip in zone 1; and all the other parameters have been previously defined.

Substituting (3-4) into (3-2) results in:

$$
P_{1}=\frac{d_{n} \cdot F_{s t} \bullet h}{L \cdot h}=\frac{d_{n} \cdot F_{s t}}{L}
$$

The resistance provided by one strip in zone one is:

$$
P_{1}=\frac{d_{n} \cdot F_{s t}}{L}
$$

Therefore, the total resistance provided by all the strips in zone one can be represent by:

$$
P_{1}=\sum_{n=1}^{i} \frac{d_{n} \cdot F_{s t}}{L}
$$

where $i=$ number of strips in zone 1; and all other parameters have been previously defined.

\subsection{Zone 2:}

The FBDs of Zone 2 are shown in Figure 3-8 and Figure 3-9. 


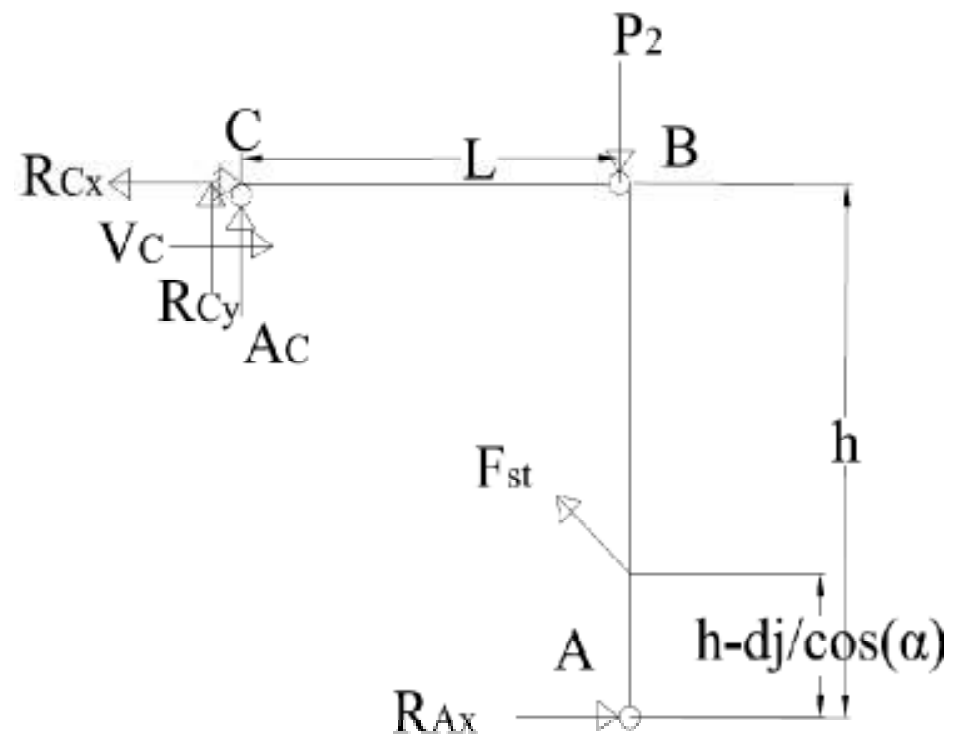

Figure 3-8: Zone 2 FBD - Top beam and right column

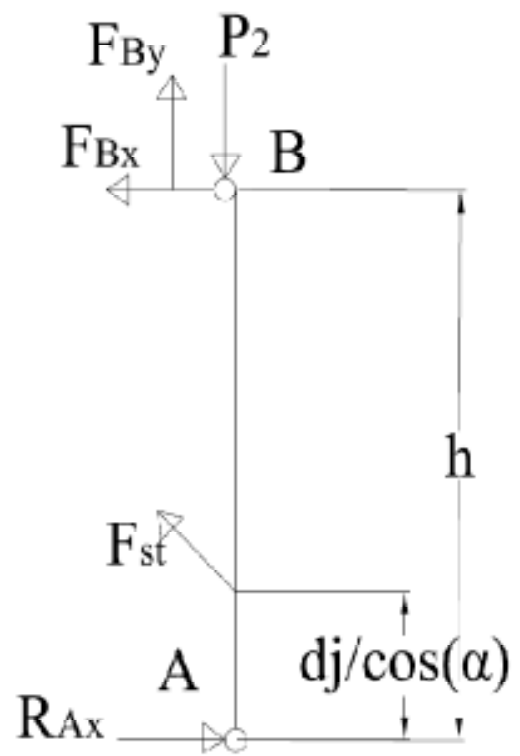

Figure 3-9: Zone 2 FBD - Right column

Summing the moments about point $\mathrm{C}$ and using the FBD in Figure 3-8 result in:

$$
\begin{gathered}
\sum M_{C}=R_{A X} \bullet h-P_{2} \cdot L-F_{s t} \cdot \cos \alpha \cdot\left[h-\left(h-\frac{d_{j}}{\cos \alpha}\right]+F_{s t} \cdot \sin \alpha \cdot L=0\right. \\
P_{2} \cdot L=R_{A X} \cdot h-F_{s t} \cdot d_{j}+F_{s t} \cdot \sin \alpha \cdot L
\end{gathered}
$$

Analyzing the FBD of the right column from Figure 3-9 yields: 


$$
\begin{gathered}
\sum M_{B}=R_{A X} \bullet h-F_{s t} \bullet d_{j}=0 \\
R_{A X}=\frac{F_{s t} \bullet d_{j}}{h}
\end{gathered}
$$

where $d_{j}=$ perpendicular distance between the top right beam-column interface and the distance to the strip in zone 2; and all the other variables have been previously defined

Substituting (3-11) into (3-9) gives:

$$
P_{2} \cdot L=\frac{F_{s t} \bullet d_{j}}{h} \cdot h-F_{s t} \cdot d_{j}+F_{s t} \cdot \sin \alpha \cdot L
$$

The resistance provided by one strip in zone $2\left(P_{2}\right)$ is:

$$
P_{2}=F_{s t} \cdot \sin \alpha
$$

where $\alpha=$ the angle of inclination of the principal tensile stresses in the strips measured from the horizontal.

The total resistance provided by the strips in Zone 2 becomes:

$$
P_{2}=\sum_{j=1}^{m} F_{s t} \cdot \sin \alpha
$$

where $m=$ number strips in zone two.

\subsection{Zone 3}

The FBDs of Zone 3 are shown in Figure 3-10. 


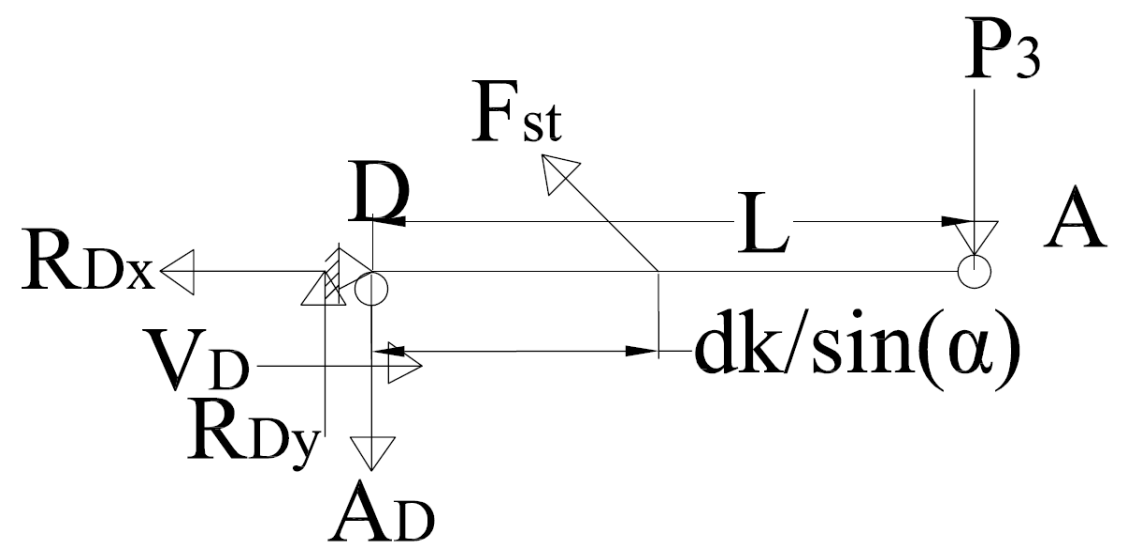

Figure 3-10: Zone 3 FBD - Bottom beam

Using FBD of the bottom beam in Figure 3-10 and summing moments about point D give:

$$
\sum M_{D}=-P_{3} \cdot L+F_{s t} \cdot \sin \alpha \cdot\left(\frac{d_{k}}{\sin \alpha}\right)=0
$$

The resistance provided by one strip $P_{3}$ in Zone 3 is:

$$
P_{3}=\frac{F_{s t} \bullet d_{k}}{L}
$$

where $d_{k}=$ the distance between the bottom left beam-column interface and the strip in Zone 3.

$$
P_{3}=\sum_{k=1}^{l} \frac{F_{s t} \bullet d_{k}}{L}
$$

where $l=$ is the number of strips in zone 3 ; and all the other parameters have been previously defined.

3.3.1.1.4 Combined resistance from all zones

The total resistance of the infill panel is equal to the summation of the capacities of all zones which becomes: 


$$
P=P_{1}+P_{2}+P_{3}
$$

Substituting the expression for the resistance of each zone gives:

$$
P=\sum_{n=1}^{i} \frac{d_{n} \bullet F_{s t}}{L}+\sum_{j=1}^{m} F_{s t} \bullet \sin \alpha+\sum_{k=1}^{l} \frac{F_{s t} \bullet d_{k}}{L}
$$

Knowing that Zones 1 and 3 have the same number of strips due to equal strip spacing and from geometry of Figure 3-5 it is known that:

$$
\begin{gathered}
i=l=\frac{L \sin \alpha}{s} \\
m=\frac{h \cos \alpha-L \sin \alpha}{s}
\end{gathered}
$$

From Figure 3-5 the distance from the upper right and the lower left strips are s/2 from their respective beam-column interface, therefore the summation of $d_{\mathrm{n}}$ and $d_{\mathrm{k}}$ can be express as follows:

$$
\sum_{n=1}^{i} d_{n}=\sum_{k=1}^{l} d_{k}=\frac{l^{2} s}{2}
$$

Substituting equation (3-22) into(3-19), gives:

$$
\begin{gathered}
P=F_{s t}\left(\sum_{n=1}^{i} \frac{d_{n}}{L}+\sum_{j=1}^{m} \sin \alpha+\sum_{k=1}^{l} \frac{d_{k}}{L}\right) \\
P=F_{s t}\left(\frac{l^{2} \bullet s}{2 L}+\sum_{j=1}^{m} \sin \alpha+\frac{l^{2} \bullet s}{2 L}\right)
\end{gathered}
$$

Substituting equations(3-20), (3-21) into (3-24), gives:

$$
P=F_{s t}\left(\frac{\left(\frac{L \sin \alpha}{s}\right)^{2} \cdot s}{2 L}+\sin \alpha \cdot\left(\frac{h \cos \alpha-L \sin \alpha}{s}\right)+\frac{\left(\frac{L \sin \alpha}{s}\right)^{2} \cdot s}{2 L}\right)
$$




$$
\begin{gathered}
P=F_{s t}\left(\frac{L \sin ^{2} \alpha}{s}+\frac{h \cos \alpha \sin \alpha}{s}-\frac{L \sin ^{2} \alpha}{s}\right) \\
P=F_{s t}\left(\frac{h \cos \alpha \sin \alpha}{s}\right)
\end{gathered}
$$

Equation (3-28) represent the force in one strip:

$$
F_{s t}=f_{y_{\text {plate }}} \cdot A_{\text {strip }}
$$

where $f_{y_{\text {plate }}}=$ plate tensile yield stress;

$$
A_{\text {strip }}=\text { Area of one strip which is define by equation (3-29). }
$$

The area of a single strip is represented by (3-29).

$$
A_{\text {strip }}=t_{\text {plate }} \cdot S
$$

where $t_{\text {plate }}=$ thickness of the plate;

$$
s=\text { spacing between strips }
$$

Equation (3-30) shows a trigonometric identity which will be used for simplification purposes:

$$
\sin \alpha \cos \alpha=\frac{\sin 2 \alpha}{2}
$$

Substituting equations(3-28),(3-29) and (3-30) into equation(3-27) yields:

$$
P=\frac{1}{2} f_{y} \bullet t_{\text {plate }} \bullet h \cdot \sin 2 \alpha
$$

It is noted that the total capacity provided by the infill panel is directly proportional to the height of the infill panel. 


\subsubsection{Kinematic Method - Single Story Frame}

The strength of a sing-story frame with infill steel panels derived in Section 3.3.1.1 can be equivalently obtained using another approach, i.e., kinematic method. Such a derivation is presented in this section to confirm the adequacy of equation (3-31).

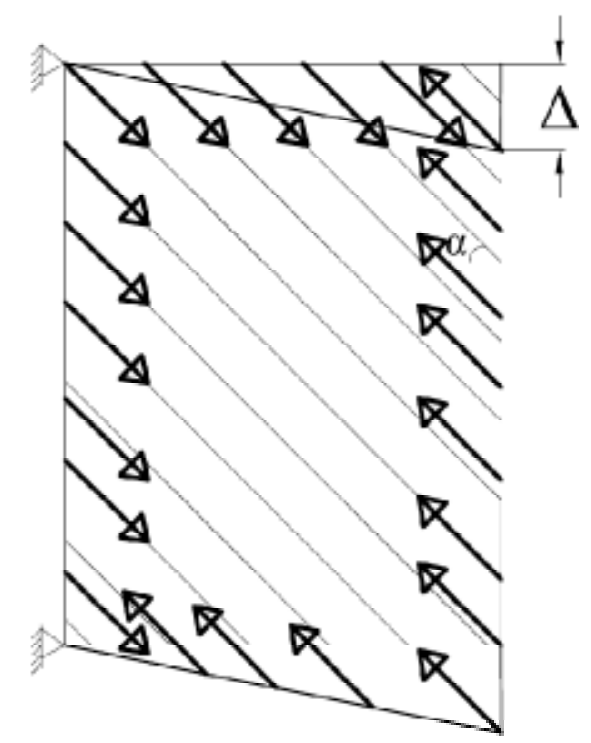

Figure 3-11 : Kinematic collapse mechanism single story tension field action

Assuming downward direction to be positive, from Figure 3-11 the external work done is equal to:

$$
W_{\text {external }}=P \cdot \Delta
$$

where $\Delta=$ vertical displacement of the right column which excites the tension field action

$$
P=\text { plastic strength of the single story frame with infill plates. }
$$

The beams and columns are assumed to remain elastic in the proposed system. As a result, their contribution to the internal work is negligible compared with the internal work done by the yielded strips. The internal energy in each strip is equal to the yielding 
force multiplied by the corresponding displacement which can be decomposed into horizontal and vertical components. Note that in the vertical direction the internal work done by the strips attached to the top beams is positive while the internal work done by the strips anchored to the bottom beam is negative due to the direction of the force in the strips; therefore their net internal work is zero. In addition, along the horizontal direction, the work done by any yielding force is zero because there is no displacement in that direction under the small deformation assumption. Consequently, the vertical component of the tension fields anchored to the right column has the only contribution to the internal work of the system. Therefore, the internal work of the system becomes:

$$
W_{\text {internal }}=\left(n_{c} A_{\text {strip }} f_{y_{\text {plate }}} \sin \alpha\right) \Delta
$$

where $n_{c}=$ number of strips anchored to the right column; and all the other parameters have been previously defined.

From Figure 3-5:

$$
n_{c}=\frac{h \cos \alpha}{s}
$$

Equating the external work to the internal work gives:

$$
\left(n_{c} A_{\text {strip }} f_{y_{\text {plate }}} \sin \alpha\right) \Delta=P \cdot \Delta
$$

Substituting equations(3-28),(3-29), (3-30) and (3-34) into equation(3-35) yields:

$$
P=\frac{1}{2} f_{y} \cdot t_{\text {plate }} \cdot h \cdot \sin 2 \alpha
$$


Comparing equations (3-31) and (3-36), it is evident that the two methods considered here (i.e. the equilibrium method and the kinematic method) provide the same prediction of the progressive collapse resistance of infill plate in a single story frame.

\subsubsection{Kinematic Method - Multistory Frame}

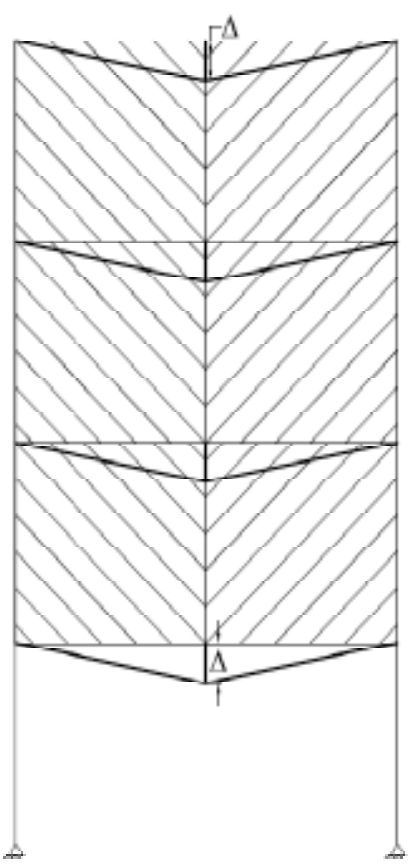

Figure 3-12: Tension field distributions in a multistory frame subjected to sudden column loss

On the basis of the results of infill plates in a single story frame presented in Section 3.3.1.2, the strength of infill plates in a multistory frame is investigated in this section.

The tension field distribution as represented by the diagonal strips in a multistory frame is illustrated in Figure 3-12. Accordingly, the external work is:

$$
W_{\text {external }}=P \bullet \Delta
$$

All the infill panels in the multistory frame are subjected to the same vertical displacement, therefore the internal work is:

$$
W_{\text {internal }}=\left(n_{c} F_{s t_{1}} \sin \alpha\right) \Delta+\ldots+\left(n_{c} F_{s t_{6}} \sin \alpha\right) \Delta
$$




$$
W_{\text {internal }}=\Delta \cdot n_{c} \cdot \sin \alpha\left(F_{s t_{1}}+F_{s t_{2}}+F_{s t_{3}}+F_{s t_{4}}+F_{s t_{5}}+F_{s t_{6}}\right)
$$

Substituting equations(3-28),(3-29), (3-30) and (3-34) into equation(3-39) yields:

$$
\begin{gathered}
W_{\text {internal }}=\frac{1}{2} \bullet \Delta \cdot f_{y} \bullet h \cdot \sin 2 \alpha\left(t_{p t_{1}}+t_{p t_{2}}+t_{p t_{3}}+t_{p t_{4}}+t_{p t_{5}}+t_{p t_{6}}\right) \\
W_{\text {internal }}=\frac{1}{2} \bullet \Delta \cdot f_{y} \bullet h \cdot \sin 2 \alpha\left(\sum_{i=1}^{n} t_{p t_{i}}\right)
\end{gathered}
$$

Equating the external work calculated by equations $(3-37)$ to the internal work by equation (3-41) gives:

$$
P=\frac{1}{2} \cdot f_{y} \cdot h \cdot \sin 2 \alpha\left(\sum_{i=1}^{n} t_{p t_{i}}\right)
$$

where, $n=$ number of plates contributing to the internal work of the multistory structure

$$
t_{p t_{i}}=\text { the thickness of the } i^{\text {th }} \text { plate. }
$$

\subsubsection{Boundary Frame Members - Catenary Actions}

The catenary action in boundary frame members has been investigated by Timoshenko (1955) and Astaneh-Asl (2007). Their analysis assumes that a multi-span frame subjected to sudden removal of an interior column is equipped with a sufficient lateral load resisting system which would prevent frame sway in the horizontal direction. Such assumption allows the catenary force $T$ to develop in the beam segments which would provide the vertical resistance of the system against collapse. The analysis presented here was originally derived by Timoshenko (1955) to develop the load-displacement relationship for elastic beam members. 


\subsubsection{Beam Catenary Action- Single Story Frame}

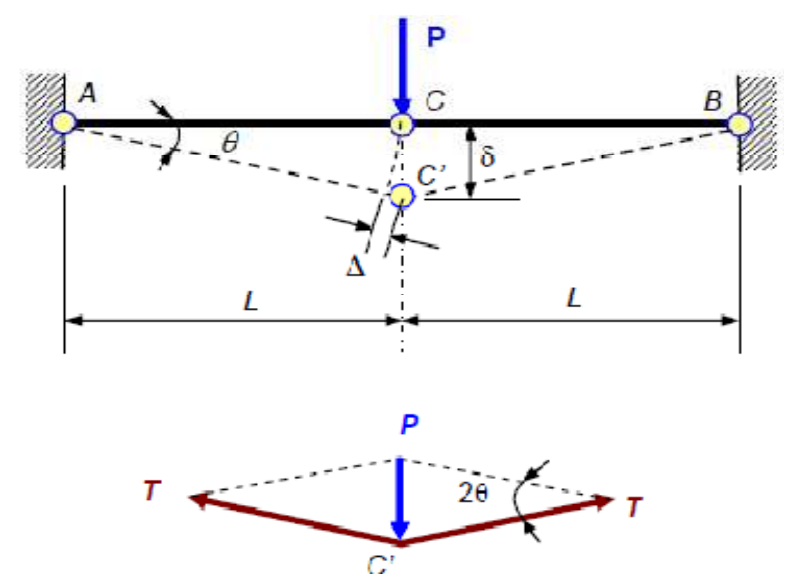

Figure 3-13: The three-hinge beam by Timoshenko (1955)

From Figure 3-13 AC'B is the deflected shape of a three-hinge beam ACB. The beam is assumed to have the same material properties and to be symmetrical about point $\mathrm{C}$. The relationship between the applied load and the vertical displacement at point $C^{\prime}$ can be found from equilibrium equation and deformation compatibility. Therefore, the strain of either one of the beams under the vertical load can be found by:

$$
\varepsilon=\frac{\Delta}{L}=\frac{\left(\frac{L}{\cos \theta}-L\right)}{L}=\frac{1}{\cos \theta}-1
$$

where, $\varepsilon=$ axial tensile strain in the beam

$$
\begin{aligned}
& \Delta=\text { axial elongation of each deflected beam segment } \\
& \theta=\text { rigid body rotation of the beam segment } \\
& L=\text { length of each beam segment of the three-hinge beam }
\end{aligned}
$$


The angle $\theta$ can be treated a small angle because during the initial elastic phase the displacements are small. Therefore, the second order small angle approximation $1+\frac{\theta^{2}}{2}$ can be substituted for $1 / \cos \theta$ into equation (3-43) resulting in:

$$
\varepsilon=\frac{\theta^{2}}{2}
$$

The tensile force in the beam due to the displacement is:

$$
T=A E \varepsilon=A \cdot E \cdot \frac{\theta^{2}}{2}
$$

where $T=$ axial tensile force in the beam which is known as the catenary action

$$
\begin{aligned}
& A=\text { cross sectional area of the beam } \\
& E=\text { modulus of elasticity }
\end{aligned}
$$

From Figure 3-13, the equilibrium equation of point C' along the vertical direction can be obtained as:

$$
P=2 \cdot \theta \cdot T
$$

Solving for $T$ in equation (3-46) and equating it to equation (3-45) gives the applied vertical load $P$ to be:

$$
P=A E \theta^{3}
$$

where $P=$ vertical load applied at the interior hinge of the system; and all the other parameters have been previously defined. 
Substituting $\frac{\delta}{L}$ for $\theta$ in equation (3-47) yields the vertical displacement $\delta$ as a function of the vertical applied load $P$ to be:

$$
\delta=L \cdot \sqrt[3]{\frac{P}{A \cdot E}}
$$

This equation suggests that the relationship between the vertical load and the vertical displacement is nonlinear. Solving for $\theta$ in equation (3-46) gives:

$$
\theta=\frac{P}{2 \cdot T}
$$

Substituting equation (3-49) into equation (3-47) and solving for the catenary force $T$ gives the following:

$$
T=\sqrt[3]{\frac{P^{2} \cdot A \cdot E}{8}}
$$

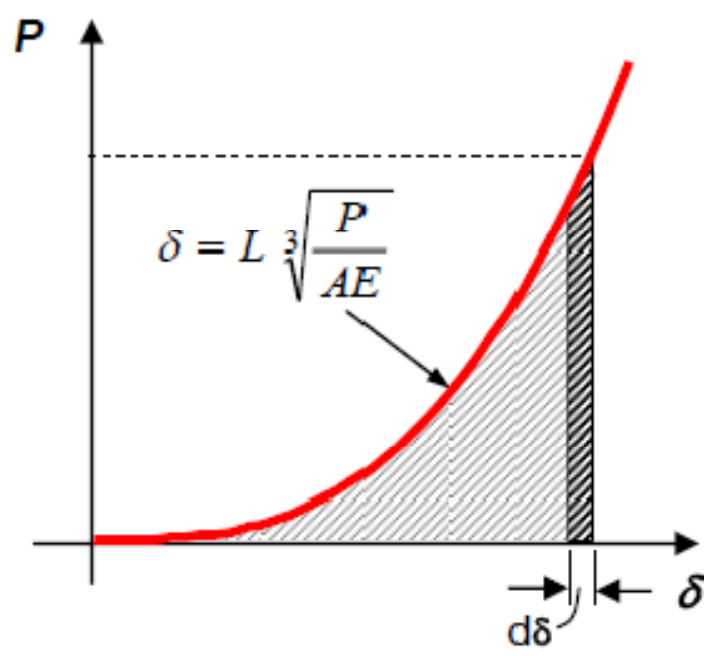

Figure 3-14: Force-displacement relationship for a three-hinge beam Astaneh-Asl (2007) 
A graphical representation of Timoshenko's force-displacement relationship for a three hinge beam is shown in Figure 3-14. Astaneh-Asl (2007) used those results to find the beams elastic strain energy $U_{e}$ :

$$
U_{e}=\int_{0}^{\delta} P \cdot d \delta
$$

Solving for $P$ in terms of $\delta$ in equation (3-48) and substituting those results into equation (3-51) yields:

$$
U_{e}=\frac{A \cdot E}{L^{3}} \int_{0}^{\delta} \delta^{3} \cdot d \delta=\frac{A \cdot E \cdot \delta^{4}}{4 L^{3}}=\frac{P \cdot \delta}{4}=\frac{P \cdot L}{4} \cdot \sqrt[3]{\frac{P}{A E}}
$$

where, $U_{e}=$ the elastic strain energy of the three-hinge beam;

$$
d \delta=\text { incremental vertical displacement under the applied load } P .
$$

The above derived equation is valid when the system remains elastic. The following equations should be considered for the cross-section when the first yielding occurs in the system:

$$
\begin{gathered}
\varepsilon_{y}=\frac{F_{y}}{E} \\
\theta_{y}=\sqrt{2 \cdot \varepsilon_{y}}=\sqrt{\frac{2 \cdot F_{y}}{E}} \\
T_{y}=A E \varepsilon_{y}=A F_{y} \\
P_{y}=2 \cdot \theta_{y} \cdot T_{y}=A \cdot F_{y} \cdot \sqrt{\frac{8 \cdot F_{y}}{E}} \\
\delta_{y}=L \cdot \sqrt[3]{\frac{P_{y}}{A \cdot E}}=L \cdot \sqrt{\frac{2 \cdot F_{y}}{E}}
\end{gathered}
$$


where, $\varepsilon_{y}=$ yield strain;

$$
\begin{aligned}
& F_{y}=\text { yield stress; } \\
& T_{y}=\text { axial tensile yield capacity; } \\
& P_{y}=\text { applied vertical load at time of yielding; } \\
& \theta_{y}=\text { rigid body rotation of the beam at yielding; } \\
& \delta_{y}=\text { vertical displacement under applied load at the time of yielding of the beam. }
\end{aligned}
$$

Assuming no strain hardening, the axial force in the beam remains constant at $T_{\mathrm{y}}$ while the applied load $P$ continue to increase due to an increase in the vertical deflection (Astaneh-Asl 2007). Figure 3-15 presents the force-displacement relationship beyond the beam's yielding point. Note that the horizontal axis shows the vertical displacement normalized by the beam length. The post yield region becomes linear due to no additional resistance contribution due to the beam's catenary forces.

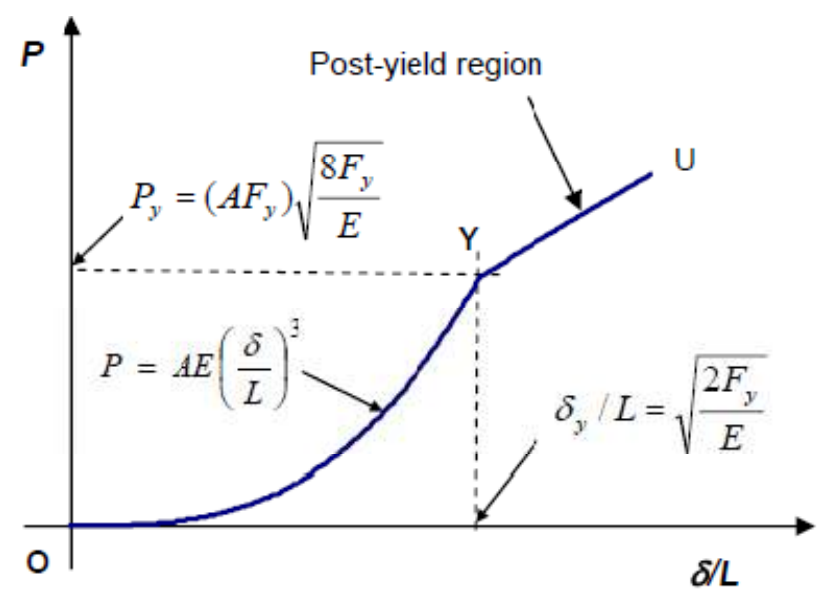

Figure 3-15: Force-displacement relationship for a three hinge beam beyond its yield point (Astaneh-Asl 2007) 
All the above mentioned equations assume the presence of perfect horizontal restraints at the ends of the beam as suggested in Figure 3-13. In reality the connection and the supporting structure may not be ideally rigid and therefore the end supports shown in Figure 3-16 are more realistic.

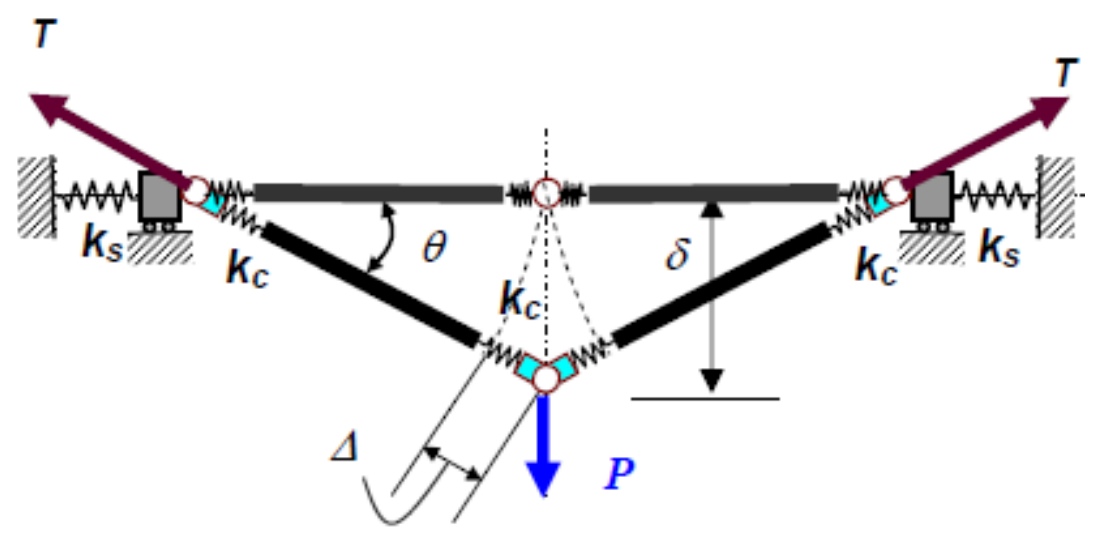

Figure 3-16: Three-hinge girder with end supports axially semi-rigid (Asteneh-Asl, 2007)

In this case, the connections are represented by a spring whose stiffness is $K_{\mathrm{c}}$ and the interaction between the connections and the supporting structure is also represented by a spring whose stiffness is $K_{\mathrm{s}}$. This suggests that the catenary action which provides the vertical load resistance does not solely depend on the tensile strength of the beam segments, but also on the rotation and tensile capacity of the connections and on the stiffness of the supporting structure. In most cases the tensile strength of the beam-tocolumn connections controls the development of catenary force. In general $K_{\mathrm{c}}$ can be relatively smaller compared to $K_{\mathrm{s}}$ for steel structures and especially for steel structures with bolted shear connections that experience slippage and bolt-hole elongation (Astaneh-Asl 2007). 


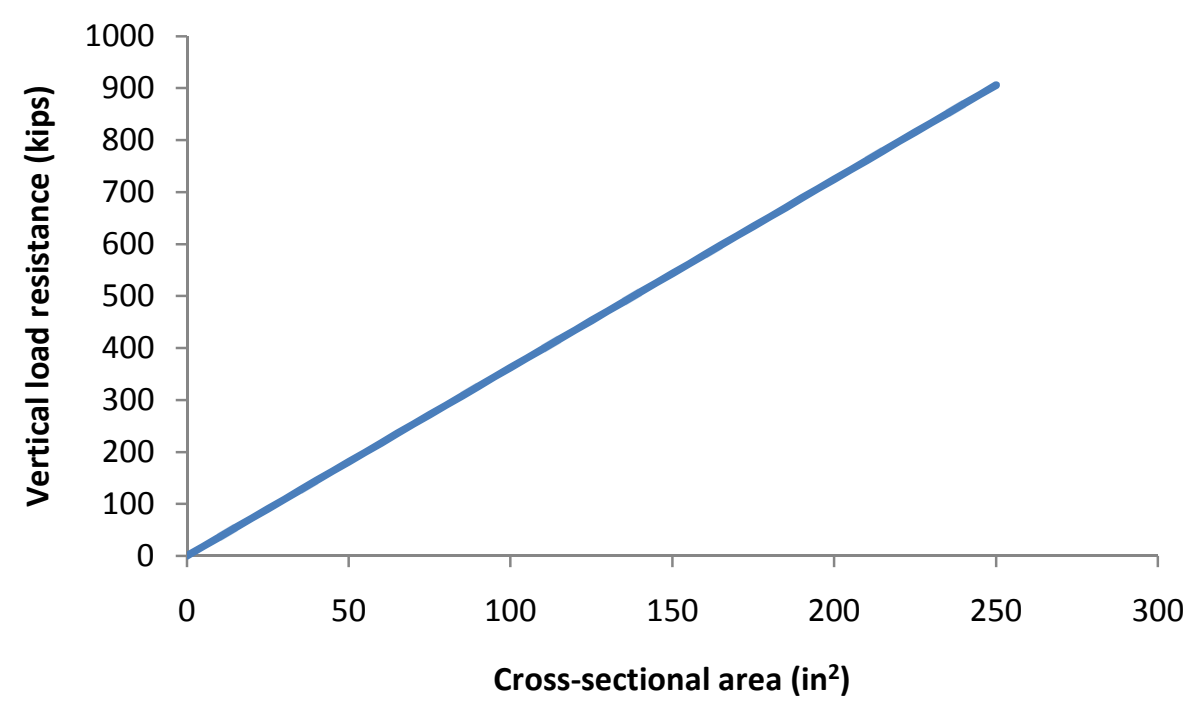

Figure 3-17: Vertical load resistance vs. beam cross-sectional area

Figure 3-17 is a graphical representation of the vertical load resistance at the time of the first yield of the two beams adjacent to the missing column with respect to their crosssectional areas. A linear relationship was observed. It is noted that this graph assumes constant vertical displacement normalized by the beam's length to be .05 and constant elastic modulus of 29000 (ksi). In addition, the catenary action in the beams was fully developed due to the ideally rigid connection and supporting structure.

\subsubsection{Beam Catenary Action-Multistory Frame}

The same assumption used to derive the catenary action of the three hinge beam can apply to the multistory frame case. Similar to the single story frame, the following assumptions were made for multistory frames: 1) the frame is subjected to a sudden column removal; 2) the connections allow catenary action to develop in the beams; 3) the frame is equipped with a sufficiently rigid lateral load resistance system which would 
prevent the frame sidesway and allow the catenary force to develop in the beams; and 4) the beams on both sides of the missing column have the same length. Under these assumptions the catenary forces on a multistory frame develop according to those represented by the arrows on Figure 3-18. Every arrow corresponds to a catenary force $T$.

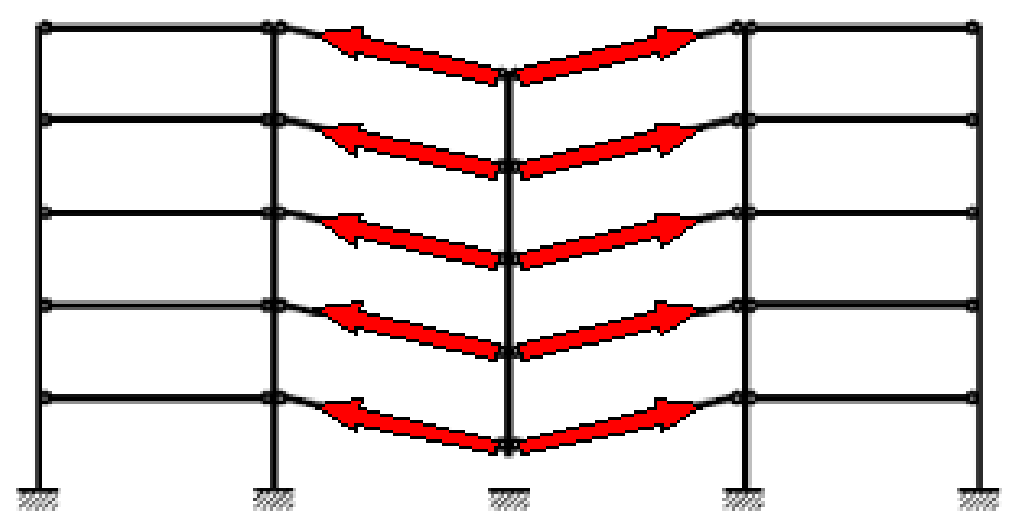

Figure 3-18: Catenary action of a multistory frame under column loss

The magnitude of $T$ is derived in the previous section and it is estimated by equation (3-45). Therefore the total progressive collapse resistance contribution of the multistory frame becomes:

$$
P=b \cdot \frac{1}{2} \cdot \theta^{3} \cdot A \cdot E
$$

where, $b=$ number of beams adjacent to the columns directly above the missing column; and all the other variables were previously defined.

Incidentally, when the beams on both sides of the missing column do not have the same length, equation (3-58) should not be used for calculating the catenary actions. However, 
if needed, the equations corresponding to such cases can be similarly derived using the presented FBDs and procedures.

\subsubsection{Combination of Tension Fields and Catenary Actions}

The system progressive collapse resistance respectively provided by the infill panel tension field actions and the boundary frame catenary actions can be found by adding equations (3-41) and (3-58) to get:

$$
P=\frac{1}{2} \cdot f_{y} \cdot h \cdot \sin 2 \alpha\left(\sum_{i=1}^{n} t_{p t_{i}}\right)+b \cdot \frac{1}{2} \cdot \theta^{3} \cdot A \cdot E
$$

\subsection{Summary}

This chapter describes the proposed system and its plastic behavior under sudden column removal. The progressive collapse resistance of this system was quantified by equation (3-59) which combines the contributions of the infill plate tension field actions and the boundary frame catenary actions. Results from this chapter will be verified by FE results presented in the subsequent chapters. 


\section{DEVELOPMENT OF HIGH-FIDELITY ANALYTICAL MODELS}

\subsection{Introduction}

In order to validate the analytical models derived in Chapter 3 for calculation of the progressive collapse resistance of the proposed system, high-fidelity FE models were developed and analyzed. Two FE models were considered and these two models require different modeling efforts and have different levels of accuracy. The first model is a 3D FE model developed using the commercially available simulation software package, ABAQUS 6.10 (Simulia 2008). This model explicitly models the infill plates and is able to capture the plate buckling behavior. The second model is a simplified 2D FE model developed using another commercially available simulation software package, SAP2000, which represents the infill panels with diagonal strips based on the concept of strip model proposed by Thorburn et al. (1983). This chapter presents in detail the procedure and modeling techniques used to develop both models.

\subsection{Demonstration Structure}

The FE models described in this chapter were developed according to a demonstration steel frame structure which consists of a four-story two-span frame retrofitted with the infill panels. As shown in Figure 4-1, the damaged column at the bottom story which may trigger progressive collapse of the system was omitted to provide an initial condition for the analysis. Incidentally, both the damages in interior and exterior columns are considered in this thesis although Figure 4-1 only shows the interior column removal. 


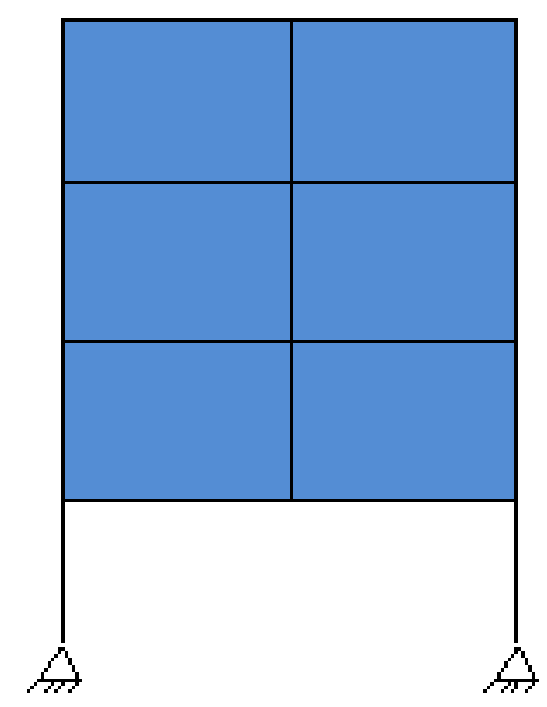

Figure 4-1: Demonstration steel frame structure

\subsection{D FE Model Using ABAQUS}

Figure 4-2 shows a graphical representation of the modeling approach implemented to develop the ABAQUS model. The modeling process started with a simple single-story frame followed by a multistory frame.

The exact post buckling behavior of the infill panels cannot be directly captured due to the discontinuous response (bifurcation) that occurs at the point of buckling (Simulia, 2008). In order to eliminate the bifurcation, the post buckling problem was turn into a continuous response problem through the introduction of initial geometric imperfections. In an infill panel such imperfections are attributed to distortion due to welding, floor beam deflections, and eccentric fish plate connections (Driver et al., 1997). Therefore, the eigenvalue analysis which captures the buckling modes of the system was conducted first and then based on these buckling modes initial imperfections were introduced into the system for the subsequent nonlinear static analysis. The graphical user interface 
ABAQUS CAE was used for most of the model development. The main modules used were Part, Materials, Sections, Profiles, Steps, Constraints, Load, Boundary Conditions, and Mesh. An explanation of the input of each of these modules is presented below.

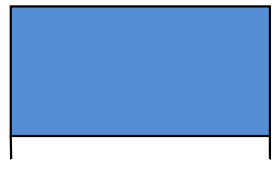

Single Frame

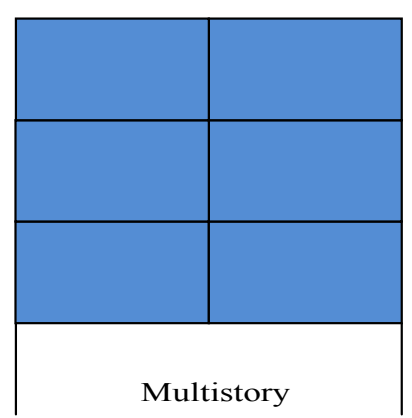

-

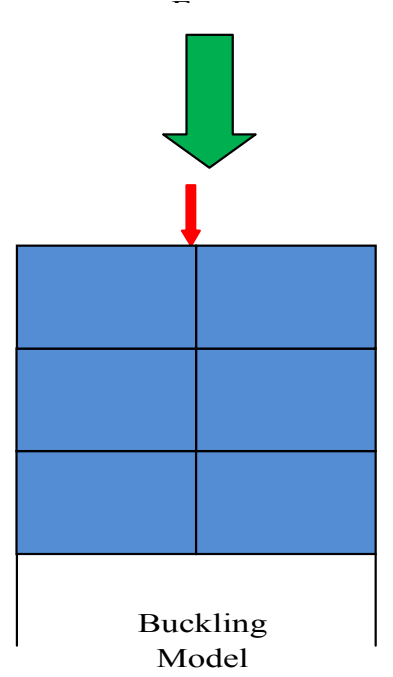

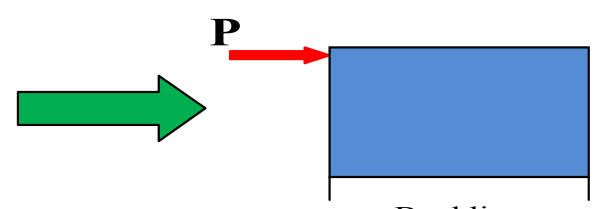

Buckling Model

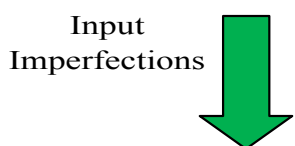

Single Story Model Validated
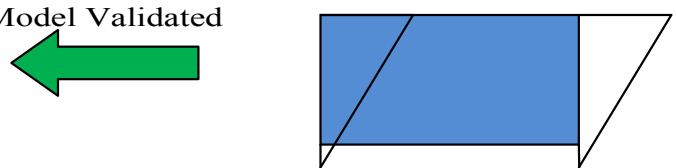

Predetermine Displacement

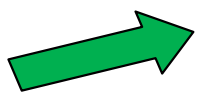

Input Imperfectio

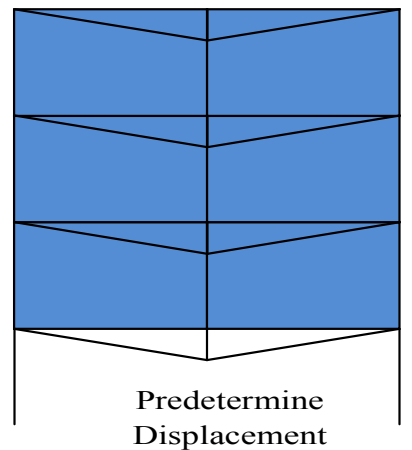

Figure 4-2: Model development diagram 


\subsubsection{Parts}

Three different parts were created for the development of the single story simulation, namely beam, column and infill panel. The beam and column consisted of a 3D deformable type with basic features, shape, and type consisting of wire and planar, respectively. The infill panel part was created using a 3D deformable type with basic features, shape and type consisting of shell and planar, respectively. Using the assembly module these three parts was included multiple times to generate the necessary number of beams, columns and infill panels. Defining the material's properties was the subsequent step in developing the FE model.

\subsubsection{Materials}

In this analysis, the steels used in boundary frame and infill panels are assumed to be both elastic-perfectly plastic but with different yield stresses. As such, two materials were defined in the materials module. The first material with higher yield strength (50 ksi) was created for the boundary frame elements (BFEs) (e.g. beams and columns) and the second with lower yield strength (36 ksi) was defined for the infill panel. The elastic properties assigned to both materials consisted of Young's Modulus of 29000000 psi and Poisson's ratio of 0.3 . For the plastic material properties, the plastic strain with the magnitude of zero was assigned to both material models to ensure the elastic-perfectly plastic property. Both materials were modeled to be isotropic together with a simple rate independent constitutive behavior. In addition, the von mises yield surface was used as the yield criterion. These material properties were assigned to the sections describe in Section 4.3.1.3. 


\subsubsection{Section}

Beam and shell sections were created for the BFEs and the infill panels, respectively. The infill plate thickness was assumed to be .118 in (i.e., $3 \mathrm{~mm}$ ). It is noted that such plates may not be available in the AISC section database; however, the results obtained from this analysis can be used to validate the equations derived in the Chapter 3 . The beam sections were defined similarly using the section profiles described in Section 4.3.1.3.

\subsubsection{Profile}

The profile consisted of the cross section corresponding to a W36-256 provided by the AISC Steel Construction Manual (AISC 2005). The focus of the model was on the inelastic behavior of the infill panels; therefore an elastic boundary element which is ensured by the large cross-sections was selected. A ratio of the cross-sectional areas of the boundary frames to the infill panel was approximately 3.55 . Such a big ratio allowed for stiff boundary and facilitated the appreciation of the post buckling behavior of the infill panel.

\subsubsection{Step}

Abaqus/Standard uses the Riks method to solve the buckling problems. In order to accurately capture the post buckling behavior of the infill panels, the model was subjected to two different step procedures. The buckling modes were determined through a linear perturbation analysis. The buckling modes acquired were then used to introduce 
the infill plate imperfections into the post buckling analysis model which was modeled using a static, general step corresponding to a general procedure type. For this step the nonlinear geometry was turn on and the automatic stabilization consisted of an energy fraction of 0.0002 for convergence purpose.

\subsubsection{Constraints}

The ABAQUS/CAE interface provides a wide variety of constraints, but all of the member to member interactions for this model were defined through the Tie displacement constraint. ABAQUS allows for two Tie formulations, namely, surface-to-surface formulation, and a node-to-surface formulation. Surface-to-surface formulation was implemented to define all the interactions between all parts of the model. This formulation requires no common joints between the two constrained parts. This constraint requires one surface to be defined as master surface and the other as the slave surface. The boundary displacement of the part containing the surface defined as master is imposed to the part containing the surface defined as slave to ensure the deformation compatibility between the two parts.

The columns were defined as master when connected to the beams. For the interaction between the BFEs the tie rotational degree of freedoms was turn off to allow for free rotation in beam-to-column connections (i.e., simple shear connections were considered here). For the interaction between the BFEs and the infill panel, the BFEs were selected as master surface and the infill panel as the slave surface. In this case the tie rotational degree of freedom was turn on to simulate the welded connections between the infill 
panel and the BFEs. It is noted that if the rotational degree of freedom is turn off the buckling analysis of the infill panel would yield inaccurate results or plate buckling would not occur.

\subsubsection{Load}

For the buckling mode analysis, a load of 1 kip was applied vertically downward on every beam-column connection above the removed column. This loading direction yielded the buckling shape of the infill panels under sudden column removal.

For the subsequent nonlinear static analysis (i.e. push-down analysis), a predetermined displacement was assigned to all the columns above the missing column. A ratio of the downward vertical displacement $(\Delta)$ to the bay width $(L)$ of $5 \%$ was used as the target downward displacement. As such, the bay width of 180 in the example model yielded a displacement of 9 in.

\subsubsection{Boundary Conditions}

Pin boundary conditions were applied to the nodes at the base of the columns. In addition, the out-of-plane displacement of the floor levels was restricted. This was model by setting the displacement in the out-of-plane direction equal to 0 for all the nodes of beams. The horizontal motion restriction if necessary was modeled by restricting the horizontal motion at the end of the short beam outriggers assigned at every exterior beam-to-column connections. It is noted that both the sidesway inhibited and sideway 
uninhibited boundary conditions were considered in this thesis and more detailed descriptions about these boundary conditions are presented in Chapter 5 .

\subsubsection{Mesh}

Each of the parts developed in section 4.3.1.1 were meshed individually. For the boundary frame members a 2-node linear beam element (B31) was assigned. This element type allows for transverse shear deformation, three translational degrees of freedom $u_{x}, u_{y}$, and $u_{z}$ and three rotational degrees of freedom $\theta_{x}, \theta_{y}$, and $\theta_{z}$ at each end of the element. Furthermore, B31 elements can be subjected to large axial strains which allows for the accurately modeling of the development of catenary action of the beam.

The infill panels were modeled using the S4R element which consists of 4-node doubly curved thin or thick shell, reduced integration, hourglass control, and finite membrane strains. The S4R element formulation allows for thickness changes as a function of inplate deformation. Also, they do not have any unconstrained hourglass modes and do not experience transverse shear locking. The S4R strain formulation provides accurate solutions for in-plane bending behavior (Simulia, 2008). In addition, this element yields accurate response when undergoing large-scale buckling behavior, which involves smallstrains but large rotations and severe bending.

The seeding was assigned to the boundary elements and infill panels using the built-in function-global seeding in the ABUQUS/CAE interface. An approximate global seeding size of 5 was selected for both, the boundary frame elements and the infill panels. The 
edge length of any of the parts divided by the global seeding number would yield the number of elements along that edge. A total of 36 elements were assigned to each boundary frame member whereas each infill panel was modeled using 1296 elements.

\subsection{Strip Model using SAP2000}

The actual behavior of the system can be appreciated using the 3D FE model in ABAQUS, but such a modeling procedure is too onerous and can be computationally expensive for multi-story frames. In addition, the preprocessor and postprocessor of ABAQUS are not as friendly as those used by conventional practicing engineers. Therefore, a need exists to develop a more practical and simple model to simulate the behavior of the proposed system.

Based on the strip model developed by Thorburn et al. (1983), a simplified 2D FE model was developed in the commercially available software package SAP2000 for the proposed system. In the strip model, the boundary frames were considered by beamcolumn elements and the diagonal strips were considered by truss elements. This section provides a detail explanation of the model development.

The angle of inclination of each strip was found using equation(4-1) per the NEHRP Recommended Provisions and Commentary for Seismic Regulations for New Buildings and Other Structures (Federal Emergency Management Agency, 2004). Note that for multistory structures $A_{\mathrm{b}}, A_{\mathrm{c}}$ and $I_{\mathrm{c}}$ were taken as the average of the two adjacent floors. 


$$
\alpha=\tan ^{-1} \sqrt[4]{\frac{1+\frac{t_{w} L}{2 A_{c}}}{1+t_{w} h\left(\frac{1}{A_{b}}+\frac{h^{3}}{360 I_{c} L}\right)}}
$$

where, $t_{\mathrm{w}}=$ thickness of the infill panel

$$
\begin{aligned}
& h=\text { distance between beam centerlines } \\
& A_{\mathrm{b}}=\text { cross-section area of a beam } \\
& A_{\mathrm{c}}=\text { cross-section area of a column } \\
& I_{\mathrm{c}}=\text { moment of inertia of a column } \\
& L=\text { distance between column centerlines }
\end{aligned}
$$

The exact location of the strips along the column and the beam were found using trigonometry analysis of the plate, the angle of inclination and the number of strips. As seen in Figure 4-3, a total of 20 strips were used to represent each infill panel.

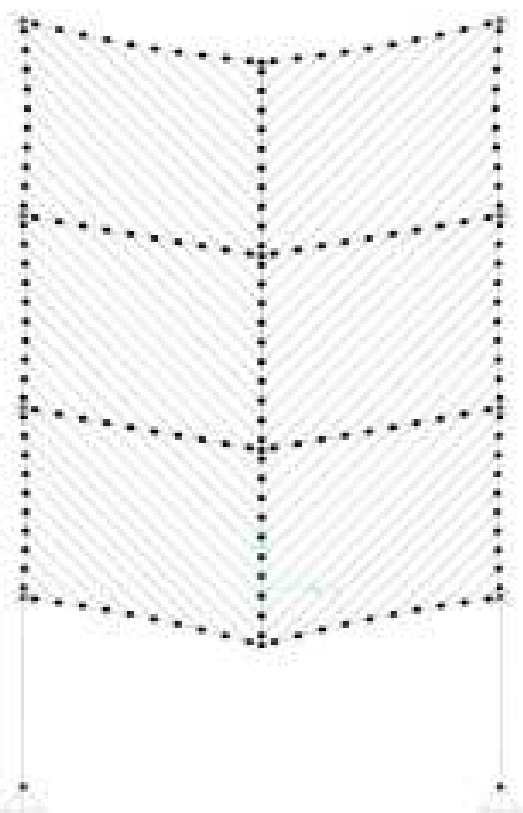

Figure 4-3: SAP2000 Strip Model 


\subsubsection{Parts}

All the parts that constitute the formation of the entire frame were developed using the node and line icons on the SAP2000 user interface. First, the nodes for the boundary elements were drew and placed on their corresponding coordinates. Then the lines connecting all the boundary nodes, which represent the boundary elements, were added. Nodes along the columns and beams were added to serve as the connections between the strips and the boundary frame. Finally, the strips were added by connecting the node on the beams to its corresponding node on the columns.

\subsubsection{Restrains}

Consistent with the 3D FE model in ABAQUS, the translational deformations in the $\mathrm{x}, \mathrm{y}$, and $\mathrm{z}$ directions was restrained at the two column base nodes to simulate pin connections at the foundation. Additional restrains were added on the column nodes at each floor level, depending on the case being investigated. All investigated cases will be explained in the subsequent chapter. The strip-to-boundary-frame and beam-to-column connections were modeled as hinges (i.e. setting the frame member partial fixity spring equal to zero for major and minor moments, and torsions).

\subsubsection{Materials}

Two material properties were created. The material assigned to the boundary frames was the A992Fy50 which is defined by default in the materials module of SAP 2000. This material has minimum yield strength of $50 \mathrm{ksi}$ and the effective yield strength was also set to $50 \mathrm{ksi}$ because the program uses the effective yield stress to compute the member 
strength. The A36 steel was assigned to the strips. The effective and minimum yield strength was also set to $36 \mathrm{ksi}$ for this material type.

\subsubsection{Sections}

Consistent with the ABAQUS model, the boundary frame element sections were W36256. The strips were defined by using a general section with area equal to the thickness of the infill panel multiplied by the perpendicular distance between the strips and all the other properties were set to unit.

\subsubsection{Plastic Hinges}

Axial load plastic hinges were assigned to all the strips and the beams. The hinge consisted of a deformation controlled (ductile) hinge which was affected by the axial load on the member. The deformation control parameters consisted of symmetrical elastic perfectly plastic material properties with a stress-strain hinge type. The actual assigned strains and stresses that constitute the elastic-perfectly plastic curve can be found in Figure 4-4. The relative length of the hinge was $1 \%$.

\begin{tabular}{|c|c|c|c|c|}
\hline Point & Stress/SF & Strain/SF & & \\
\hline$E-$ & -1 & -10000 & & 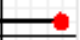 \\
\hline D- & -1 & -200 & & \\
\hline C- & -1 & -6 & & \\
\hline B- & -1 & 0 & & \\
\hline $\mathrm{A}$ & 0 & 0 & & \\
\hline $\mathrm{B}$ & 1. & 0. & \multirow{4}{*}{$\sqrt{\checkmark}$ Symmetric } & \\
\hline C & 1. & 6. & & \\
\hline $\bar{D}$ & 1. & 200. & & \\
\hline$E$ & 1. & 10000. & & \\
\hline
\end{tabular}

Figure 4-4: Plastic Hinge Parameters 
Note that the plastic hinge was assigned on the center of every strip and at $10 \%$ of the length of the beam from each end.

\subsubsection{Load}

One load pattern was created with a dead load type and a self weight multiplier of one. Also, a linear static load case was used to assign a concentrated downward force of two kips on each floor level node above the missing column. A nonlinear static load was created to model the drop of the structure due to the removal of the column. Geometry nonlinearly parameters were assigned to consider p-delta and large deformation effects. The target downward displacement was selected to be 9 inches and it was assigned to the node connecting the removed column.

\subsection{Summary}

The modeling procedures and details of two FE models are presented in this chapter. The main objective of modeling the system using ABUQUS was to observe the actual behavior of the system with consideration of plate buckling. Modeling of the system using SAP2000 was more practical and such a model is able to provide results similar to the ABAQUS model as will be discussed in Chapter 5. The strip model in SAP2000 which is more convenient will be used for most of the parametric investigations. Results from the SAP2000, ABAQUS and plastic analysis models will be compared in Chapter 5. 


\section{DISCUSSION AND COMPARISON OF RESULTS FROM DEVELOPED ANALYTICAL MODELS}

\subsection{Introduction}

This chapter compares the system progressive collapse resistance using the models developed in Chapters 3 and 4. Results for the original frame are also presented to confirm the effectiveness of the proposed system. Note that the original frame refers to the frame without any infill panels, while the retrofitted system refers to the proposed system (i.e. the frame with infill panels).

\subsection{Considered Boundary Conditions}

Figure 5-1 presents the different boundary conditions for which the global behavior was quantified for both the original frame and the retrofitted system. A total of five Boundary Conditions (i.e. Boundary Conditions \#1 through 5) were considered. Boundary Conditions \#1 through 3 corresponded to the scenarios of losing the interior column of the frame while Boundary Conditions \#4 and 5 took into account the loss of an exterior column. For Boundary Condition \#1 sidesway was uninhibited on both sides of the frame. Boundary condition $\# 2$ inhibits sidesway deflection on one side of the frame, assuming the presence of an infinitely rigid lateral load resisting system, while the other side of the frame allows sidesway deflection. Boundary condition \#3 inhibits sidesway on both sides of the frame imitating infinitely rigid lateral load resisting systems on both sides of the frame. Condition \#4 allows sidesway while condition \#5 inhibits sidesway deflection. For quantification of the system vertical load resistance, all the five boundary conditions were investigated in the nonlinear push down analysis in which a downward 
deformation equal to $5 \%$ of the beam length was assumed along the line of the damaged column.

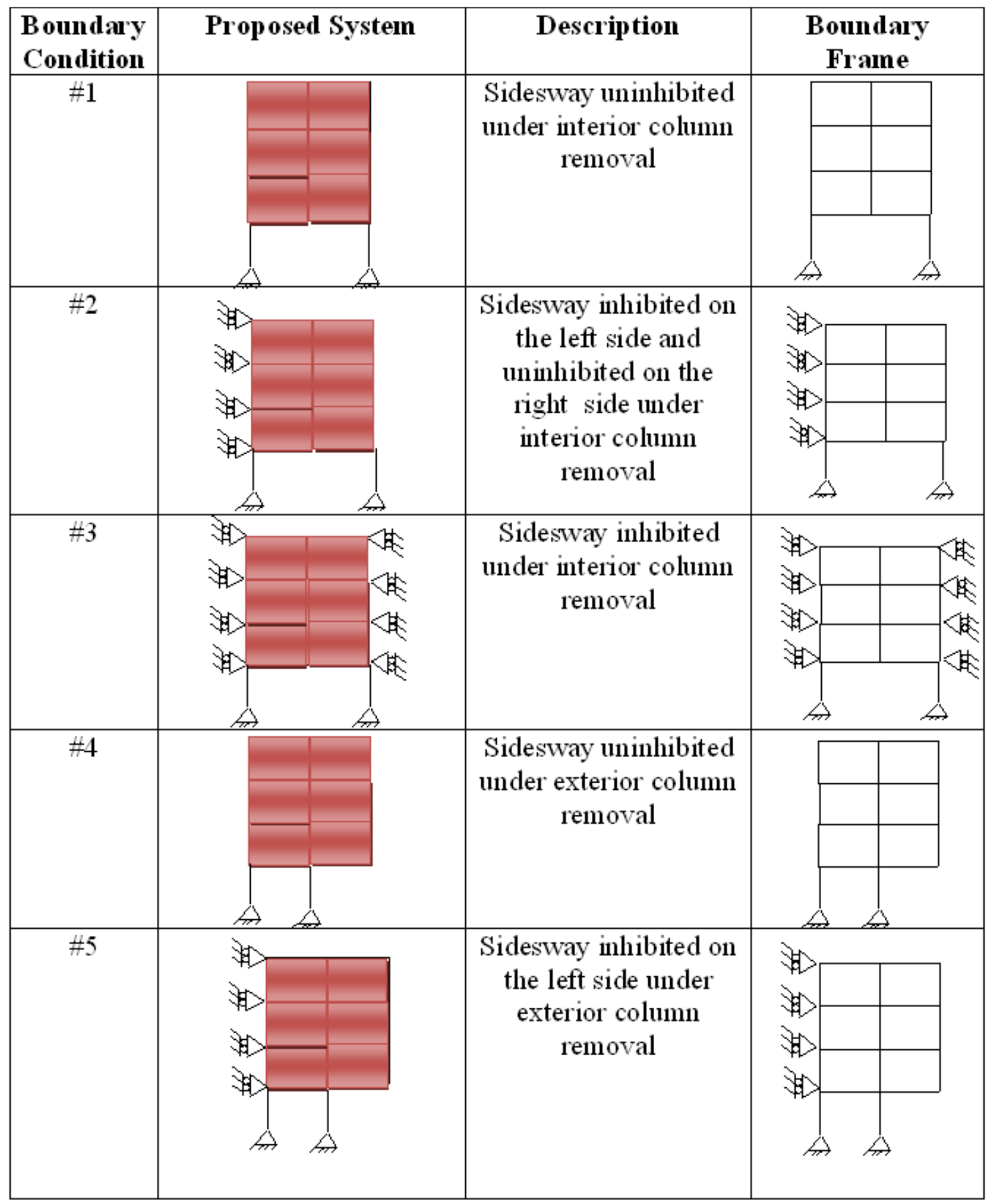

Figure 5-1: Considered boundary conditions 


\subsection{Discussion and Comparison of Results}

\subsubsection{Boundary Condition \#1}

Boundary Condition \#1 corresponds to the system under interior column removal and sidesway uninhibited on both sides of the frame. As discussed in Section 4.3, the FE modeling of the system using ABAQUS consisted of two models, i.e. one model for buckling mode analysis and the other model for inelastic pushdown analysis. Through the first model the buckle modes for each infill panel was found. Then, the modes were used to introduce the initial imperfections of the infill panels in the pushdown analysis model. The initial imperfections enable the infill panels in the push down model to develop the post buckling tension field actions. The initial imperfection corresponding to the first buckling mode had a magnitude of $20 \%$ of the infill panel thickness and the imperfections of each higher mode were reduced by $80 \%$ of the previous one. Such a modeling strategy considered the reduced impact of higher modes on initial imperfection of the infill plates. The first ten modes shown in Figure 5-2 were considered in this study. Note that for other boundary conditions using all ten buckling modes was not necessary and only the first buckling mode for each infill panel was judged to be sufficient. 

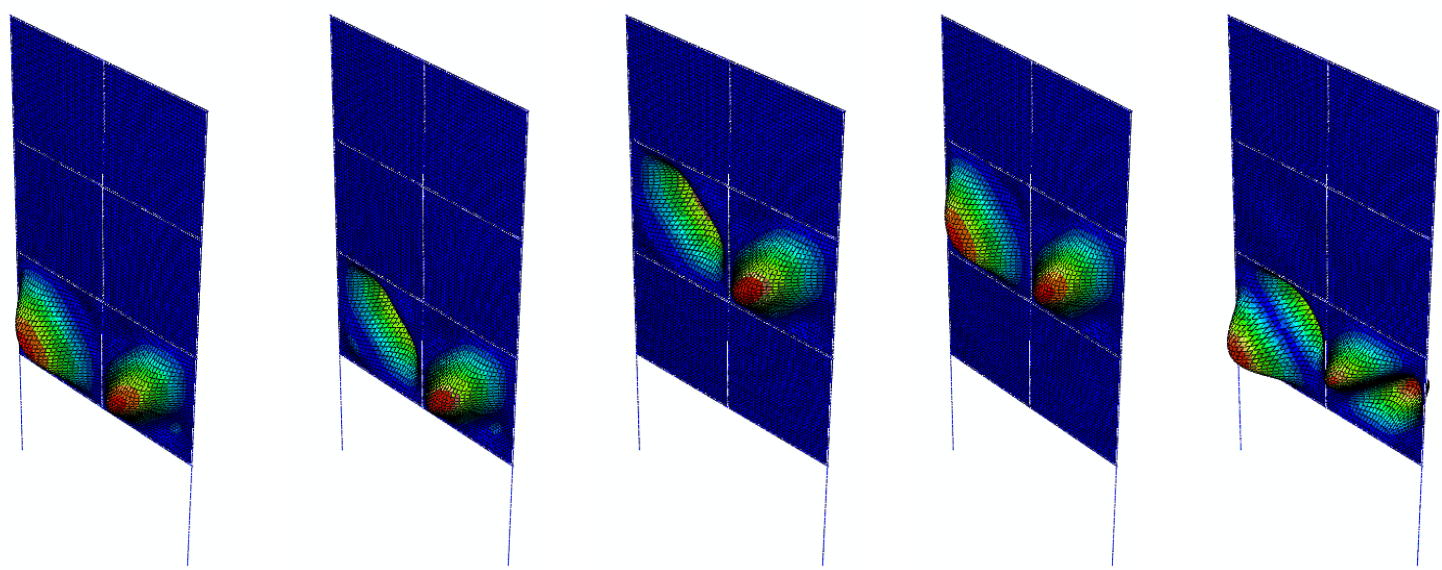

(a) $1^{\text {st }}$ mode

(b) $2^{\text {nd }}$ mode

(c) $3^{\text {rd }}$ mode

(d) $4^{\text {th }}$ mode

(e) $5^{\text {th }}$ mode
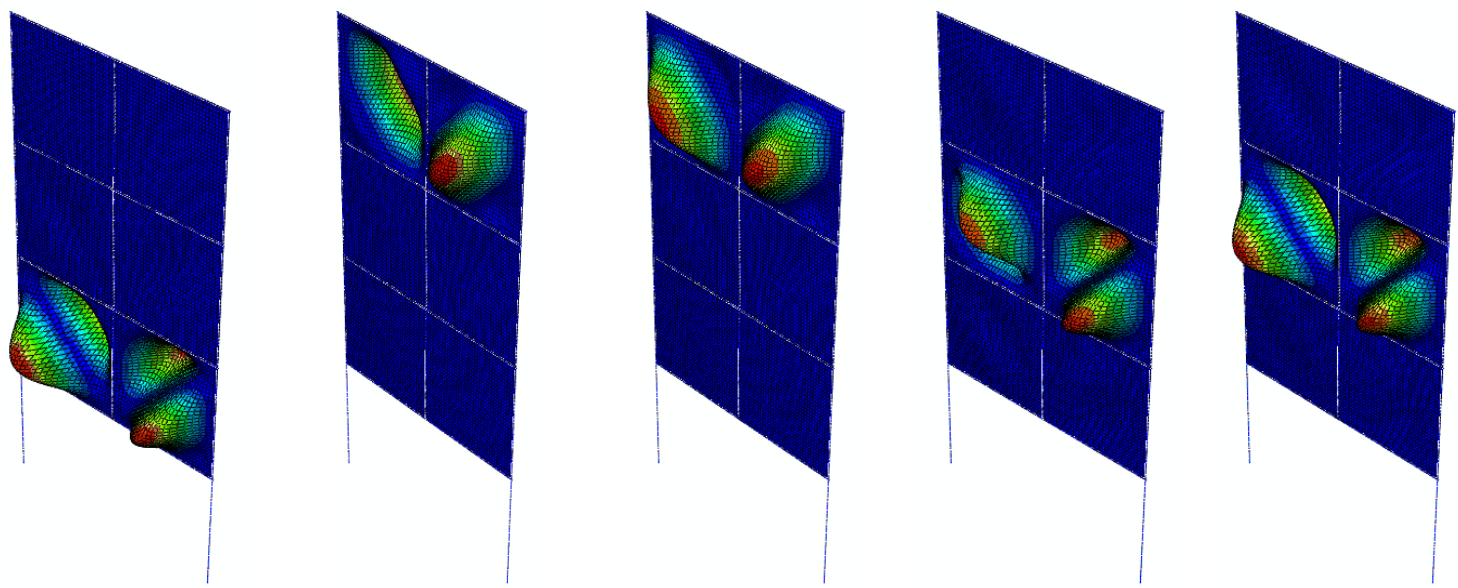

(f) $6^{\text {th }}$ mode

(g) $7^{\text {th }}$ mode

(h) $8^{\text {th }}$ mode

(i) $9^{\text {th }}$ mode

(j) $10^{\text {th }}$ mode

Figure 5-2: Buckling modes for the retrofitted system under Boundary Condition \#1 (Results from ABAQUS)

Figure 5-3 show the post buckling tension field action of the infill panels and the deflected shape of the boundary frame under Boundary Condition \#1. The tension field action of the infill panels bridge over the missing column providing structural redundancy and greater progressive collapse resistance than the frame alone. 

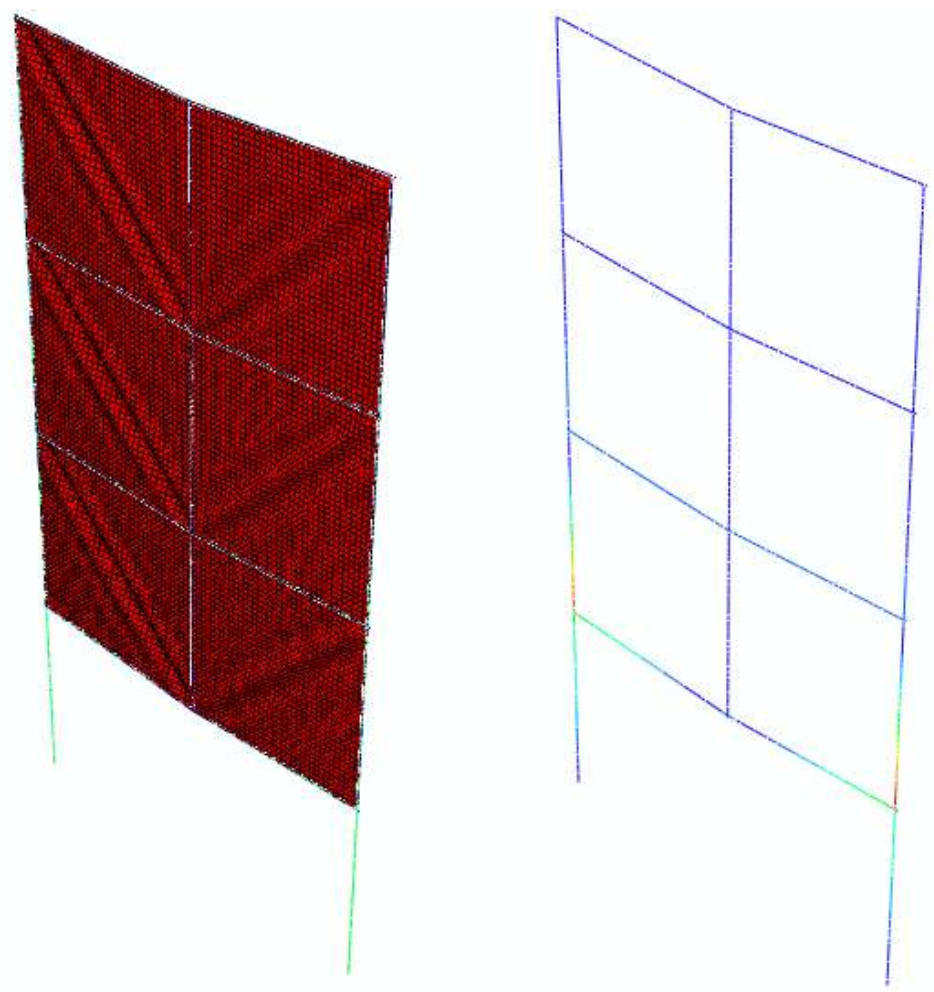

Figure 5-3: Post buckling behavior of the retrofitted system and deflection of the original frame under Boundary Condition \#1 (Results from ABAQUS)

As discussed in Chapter 4, the strip model in SAP 2000 was also considered in this study for comparison purpose. A total of 20 diagonal strips were used to model the infill panel. Figure 5-4 shows the behavior of the strip model at a maximum column drop of 9 inches. 


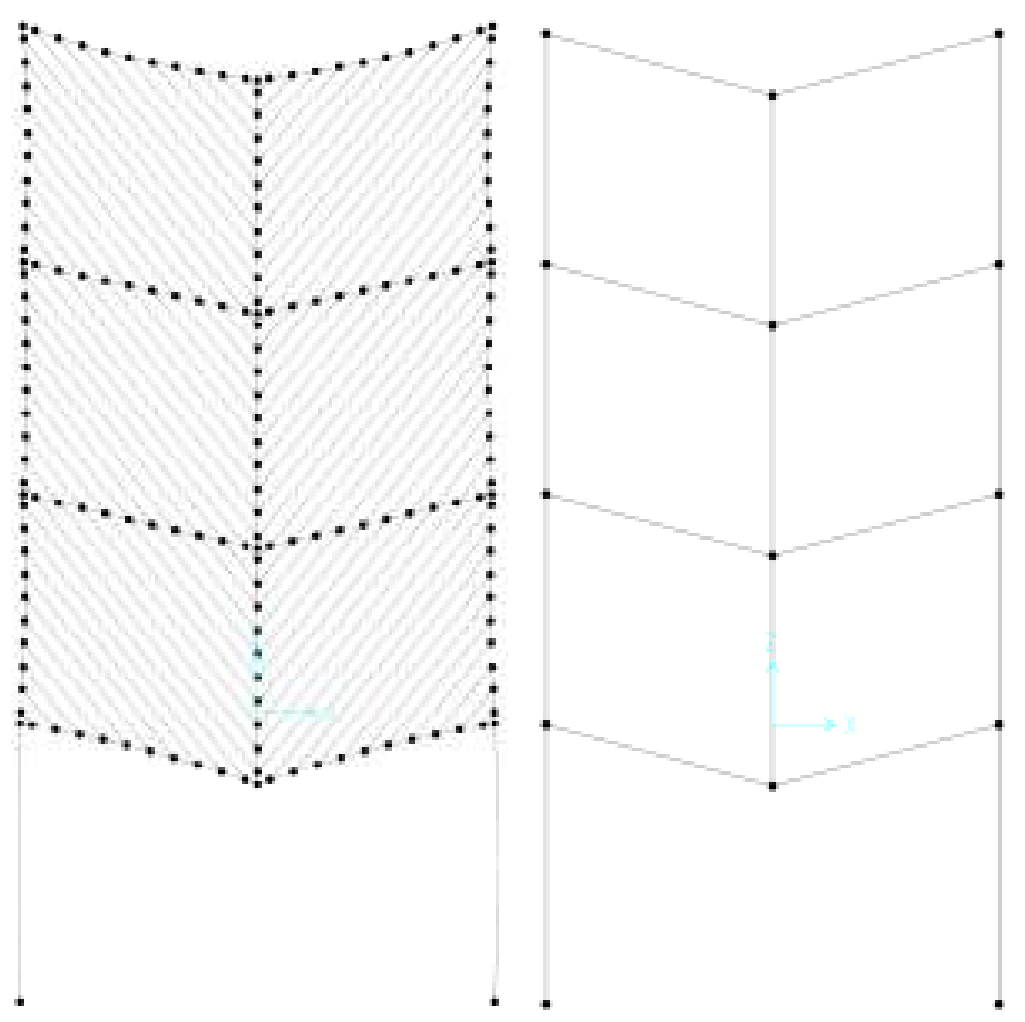

Figure 5-4: Deformed shape of the retrofitted system and the original frame under Boundary Condition \#1 (Results from SAP2000)

Since the lateral displacement was allowed on both sides, it was expected that the catenary action would not develop in the beam members due to the absence of the anchorage at the beam ends. Therefore, the vertical load resistance would be provided by the infill panels only. Such a behavior was consistently observed from the results shown in Figure 5-5 to Figure 5-7. Through the models from ABAQUS, SAP2000 and plastic analysis, the vertical load resistance of the original frame was almost zero while the resistance of the retrofitted system was about 2300 kips. The vertical load resistance of the retrofitted system from all models (i.e. from ABAQUS, SAP2000, and plastic analysis, respectively) can be found in Figure 5-5 to Figure 5-7. Comparison of the resistance provided by the boundary frame only, infill panels only, and panels plus boundary frame can be found in Figure 5-8, Figure 5-9, and Figure 5-10, respectively. 
These results indicate that the progressive collapse resistance of a gravity load resisting frame can be significantly enhanced by the thin infill panels, which can possibly prevents progressive collapse by redistributing the load from the missing column to adjacent columns.

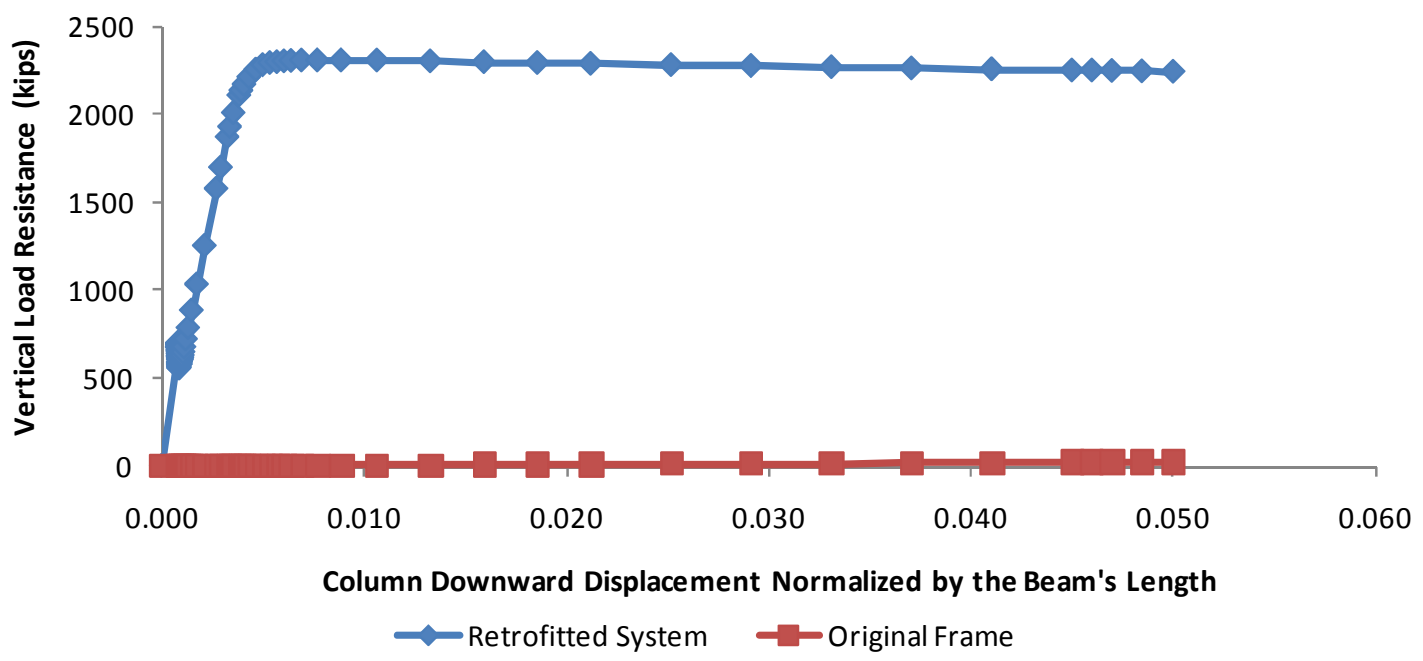

Figure 5-5: Vertical load resistance of the retrofitted system and the original frame under Boundary Condition \#1 (Results from ABAQUS)

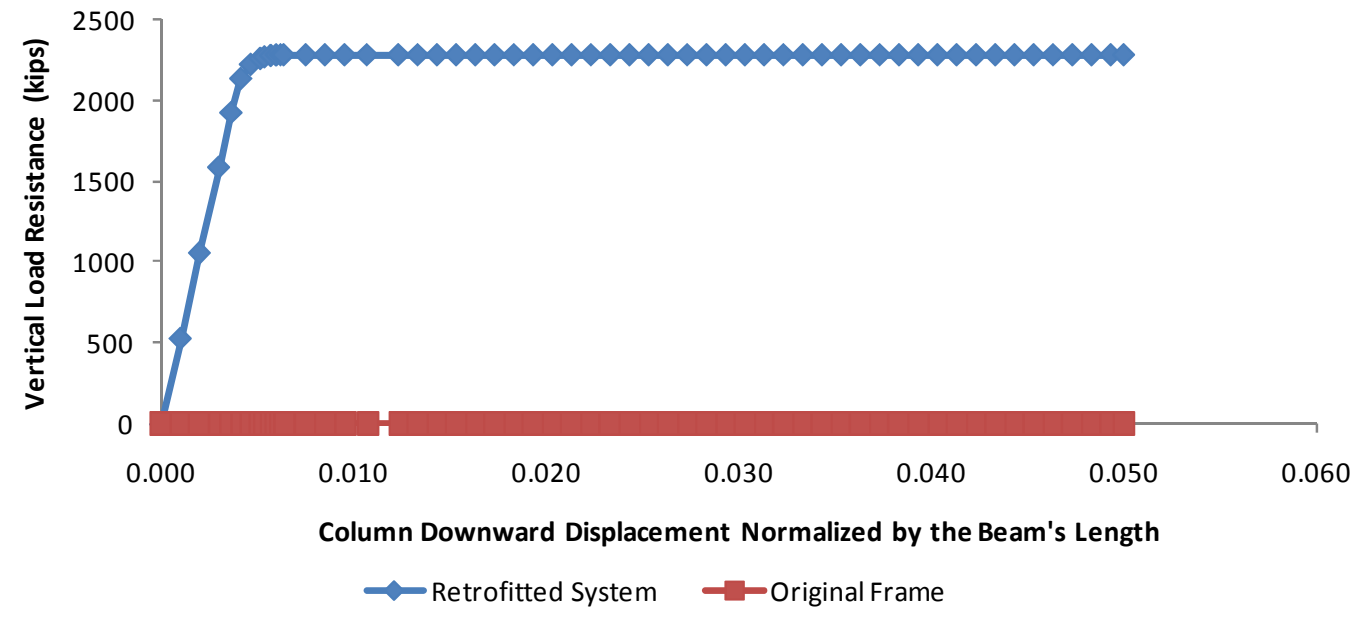

Figure 5-6: Vertical load resistance of the retrofitted system and the original frame under Boundary Condition \#1 (Results from SAP2000) 


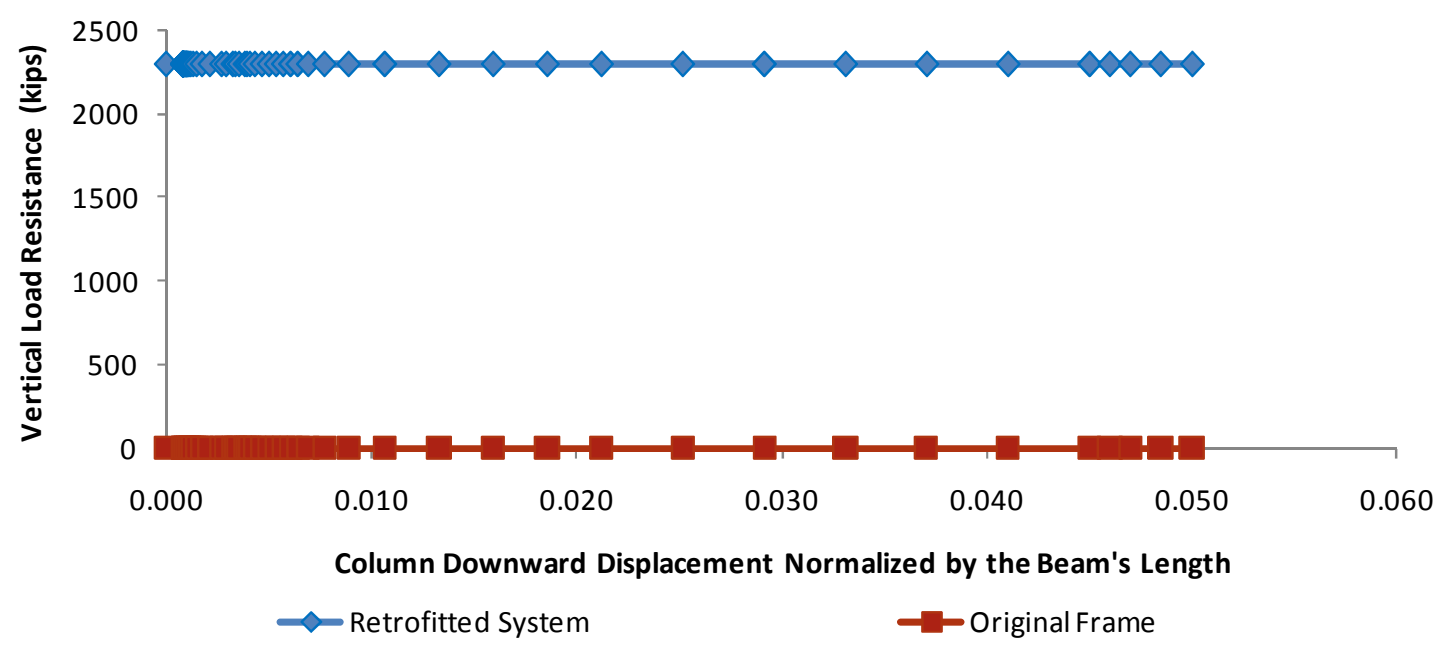

Figure 5-7: Vertical load resistance of the retrofitted system and the original frame under Boundary Condition \#1 (Results from Plastic Analysis)

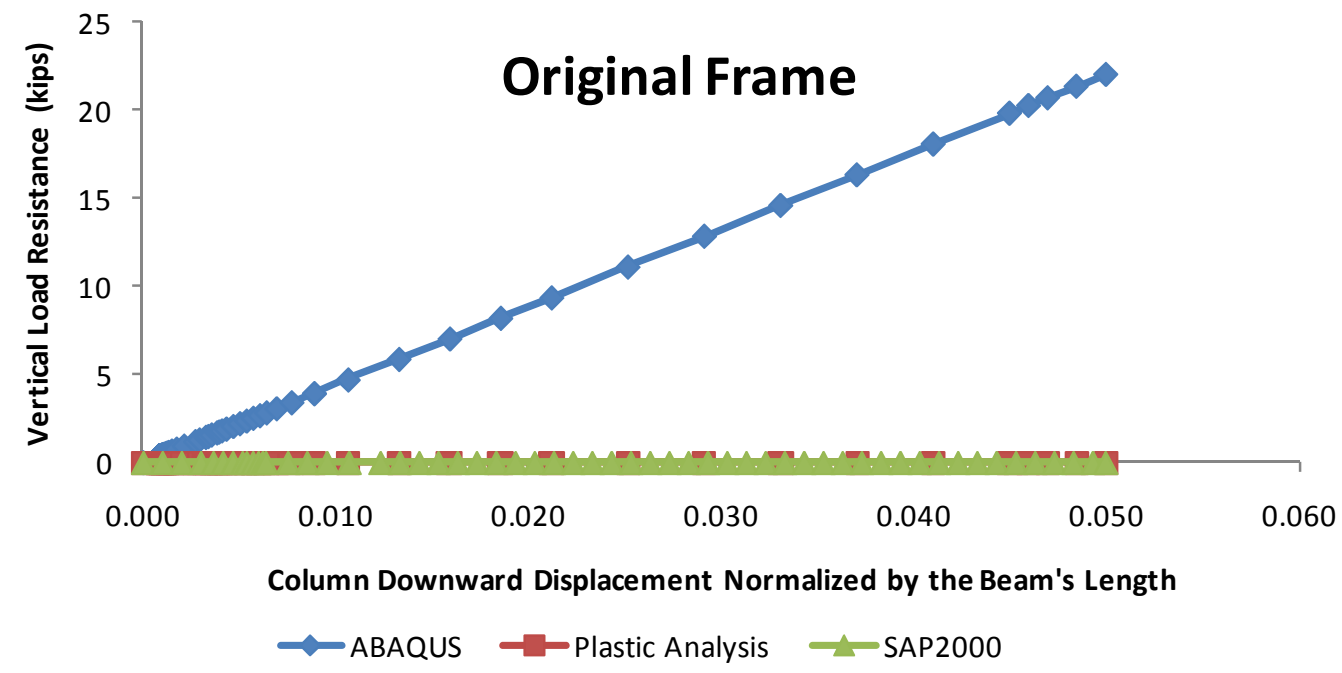

Figure 5-8: Comparison of vertical load resistance of the original frame under Boundary Condition \#1 


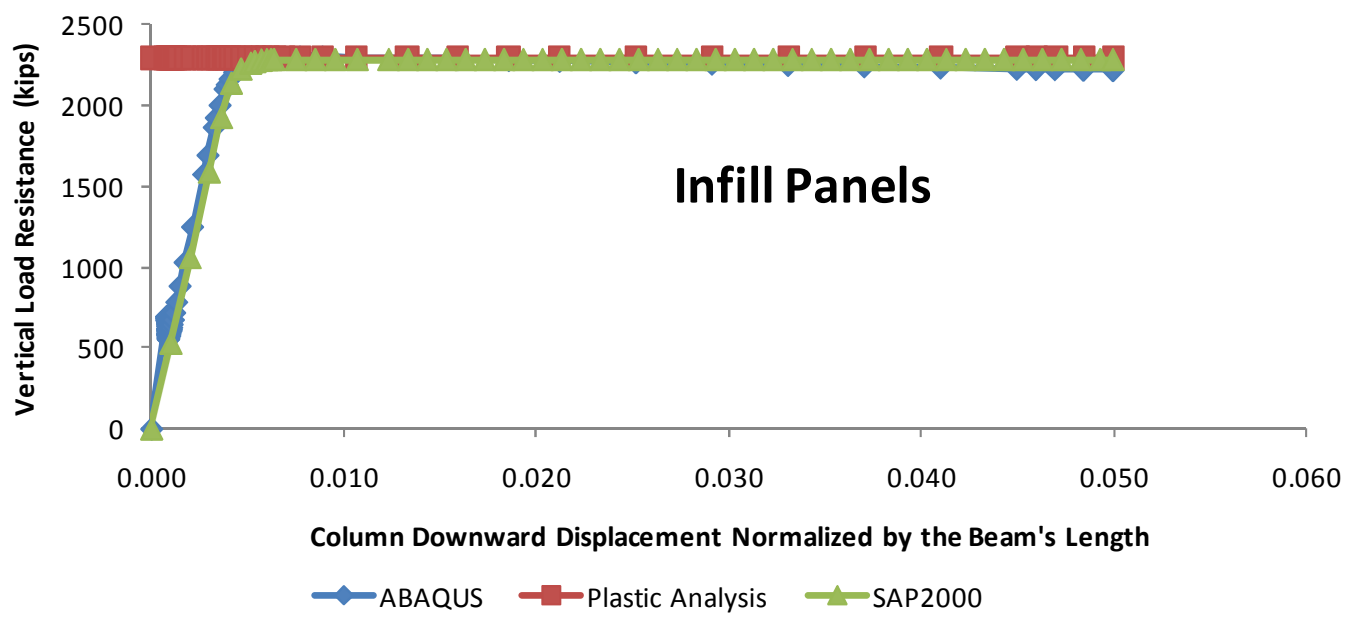

Figure 5-9 Comparison of vertical load resistance of the infill panels alone under Boundary Condition \#1

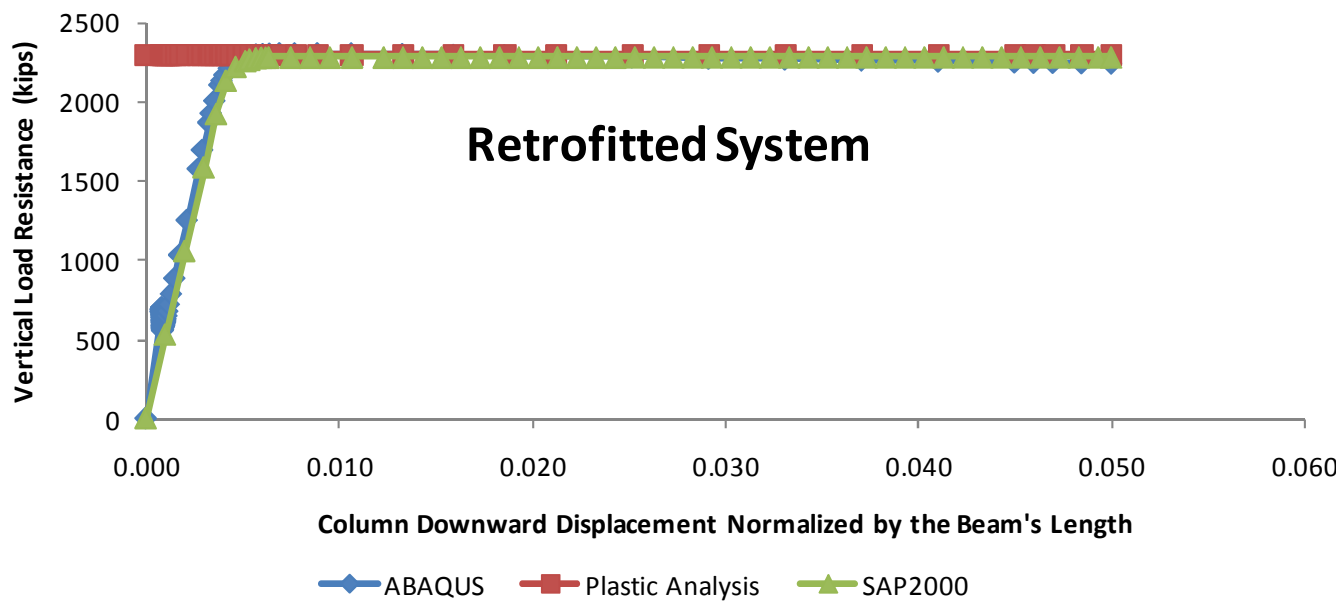

Figure 5-10: Comparison of vertical load resistance of the retrofitted system under Boundary Condition \#1

\subsubsection{Boundary Condition \#2}

Figure 5-11 show the buckling modes of the system for boundary condition \#2 which corresponds to the system with lateral motion constrained on one side and permitted on the other side of the frame subjected to interior column removal. The first buckling mode of each infill panel was captured within the first eight modes of the system. The first six 
buckling modes shown in Figure 5-11 were used to introduce the initial imperfections of the infill panels into the push down model.
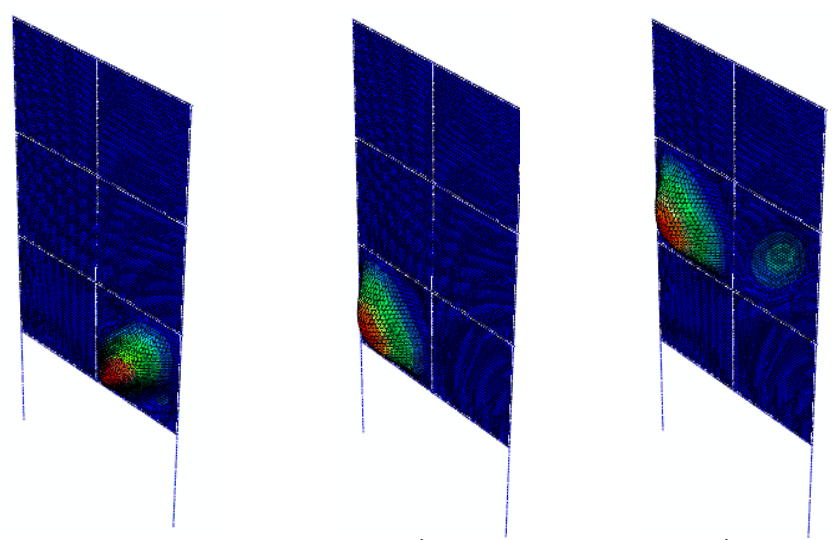

(a) $1^{\text {st }}$ mode

(b) $2^{\text {nd }}$ mode

(c) $3^{\text {rd }}$ mode
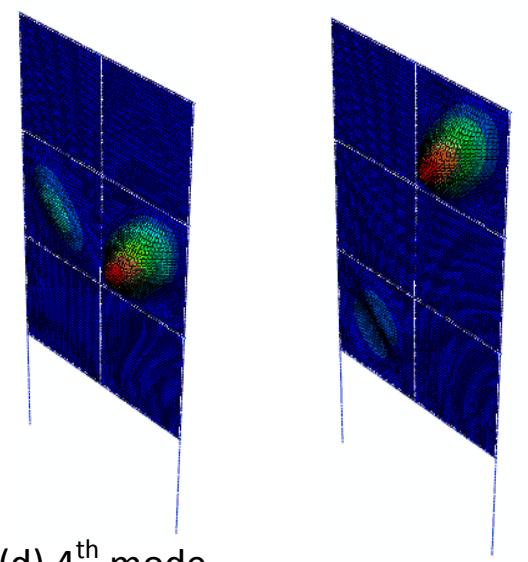

(d) $4^{\text {th }}$ mode

(e) $7^{\text {th }}$ mode

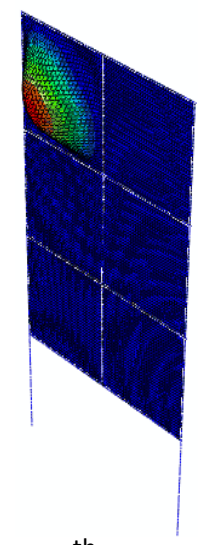

(f) $8^{\text {th }}$ mode

Figure 5-11: Buckling modes for the retrofitted system under Boundary Condition \#2 (Results from ABAQUS)

Although sidesway was inhibited on one side, the beam catenary actions are not able to develop due to the sidesway deflection uninhibited on the other side of the frame which results in the absence of anchorage effect required by the catenary action. Consequently, the tension fields of the infill panels transfer the load from the missing column to the adjacent columns as seen in Figure 5-12. 

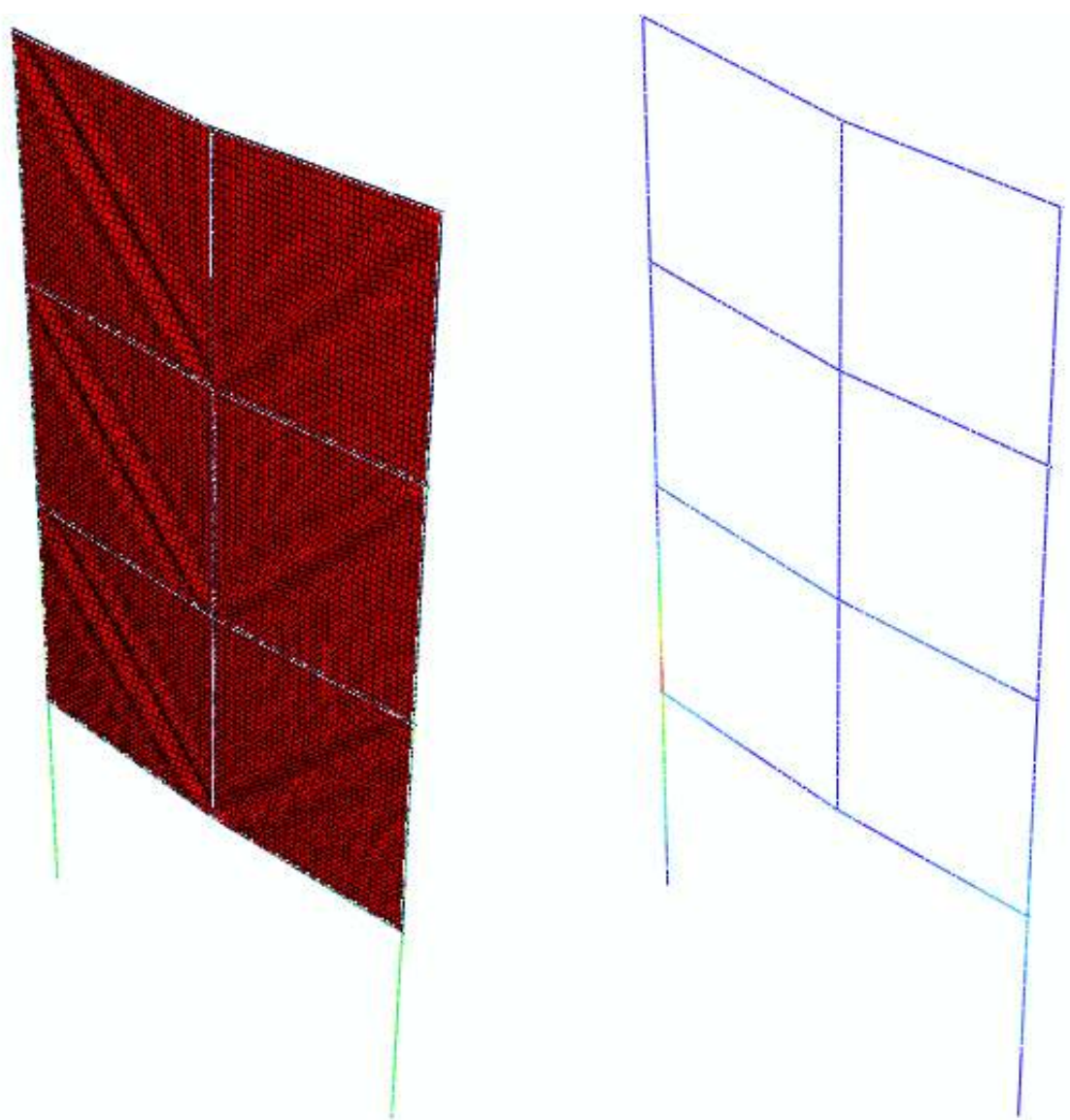

Figure 5-12: Post buckling behavior of the retrofitted system and deflection of the original frame under Boundary Condition \#2 (Results from ABAQUS)

Figure 5-13 shows the deflected shape of the retrofitted system modeled using the strip model. Note that the general behavior of the system was identical to the system with sidesway on both sides. 


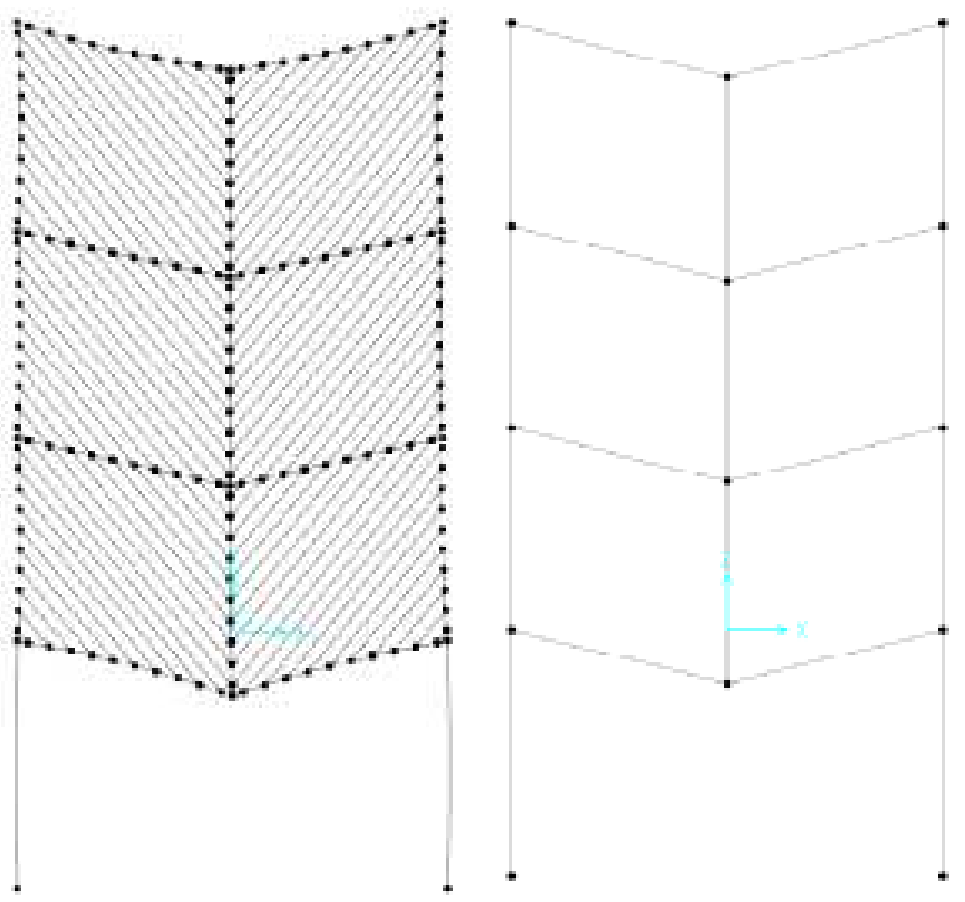

Figure 5-13: Deformed shape of the retrofitted system and the original frame under Boundary Condition \#2 (Results from SAP2000)

The contribution of the boundary frame alone to the vertical load resistance of the retrofitted system was close to zero due to the absence of catenary action. The retrofitted system exhibited a vertical load resistance of 2300 kips at the end of the analysis. It is concluded that under this boundary condition the original system could have a greater ability to transfer the load from the missing column and avoid progressive collapse if retrofitted with infill panels. The vertical load resistance for the original frame and the retrofitted system are compared in Figure 5-14 to Figure 5-19. 


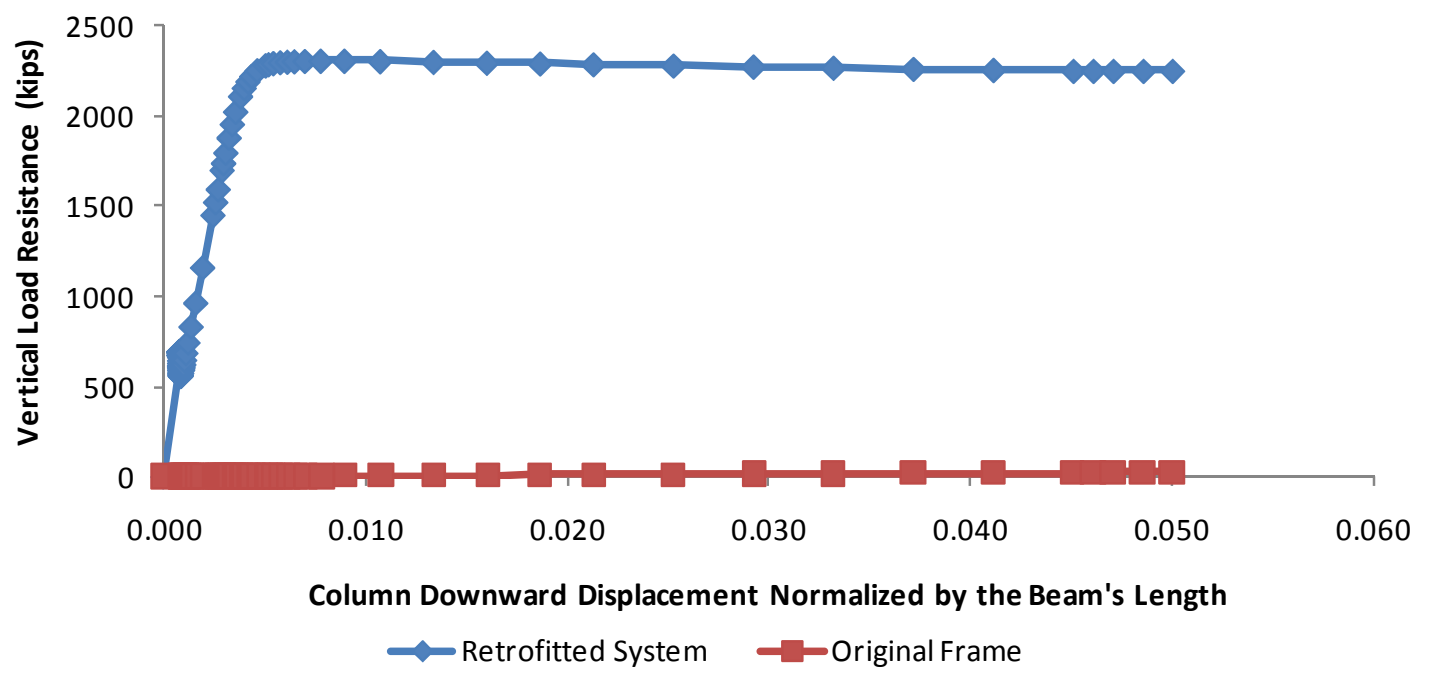

Figure 5-14: Vertical load resistance of the retrofitted system and the original frame under Boundary Condition \#2 (Results from ABAQUS)

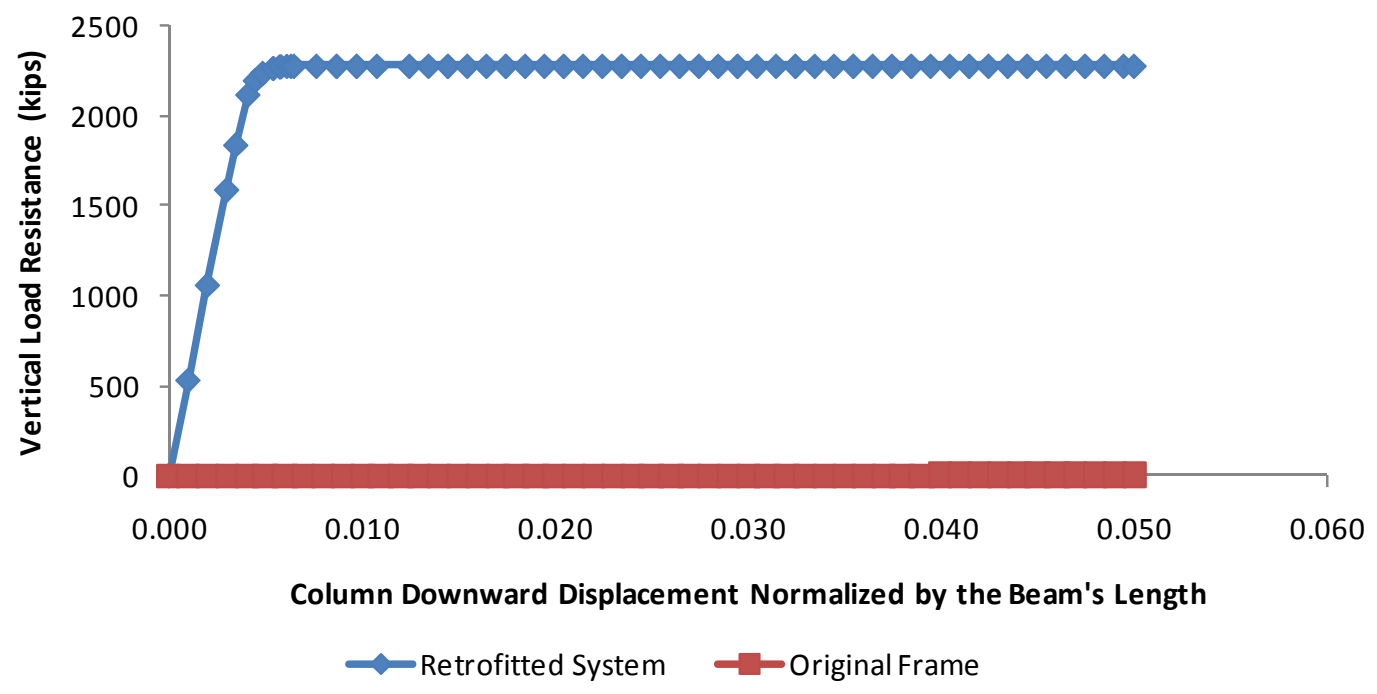

Figure 5-15: Vertical load resistance of the retrofitted system and the original frame under Boundary Condition \#2 (Results from SAP2000) 


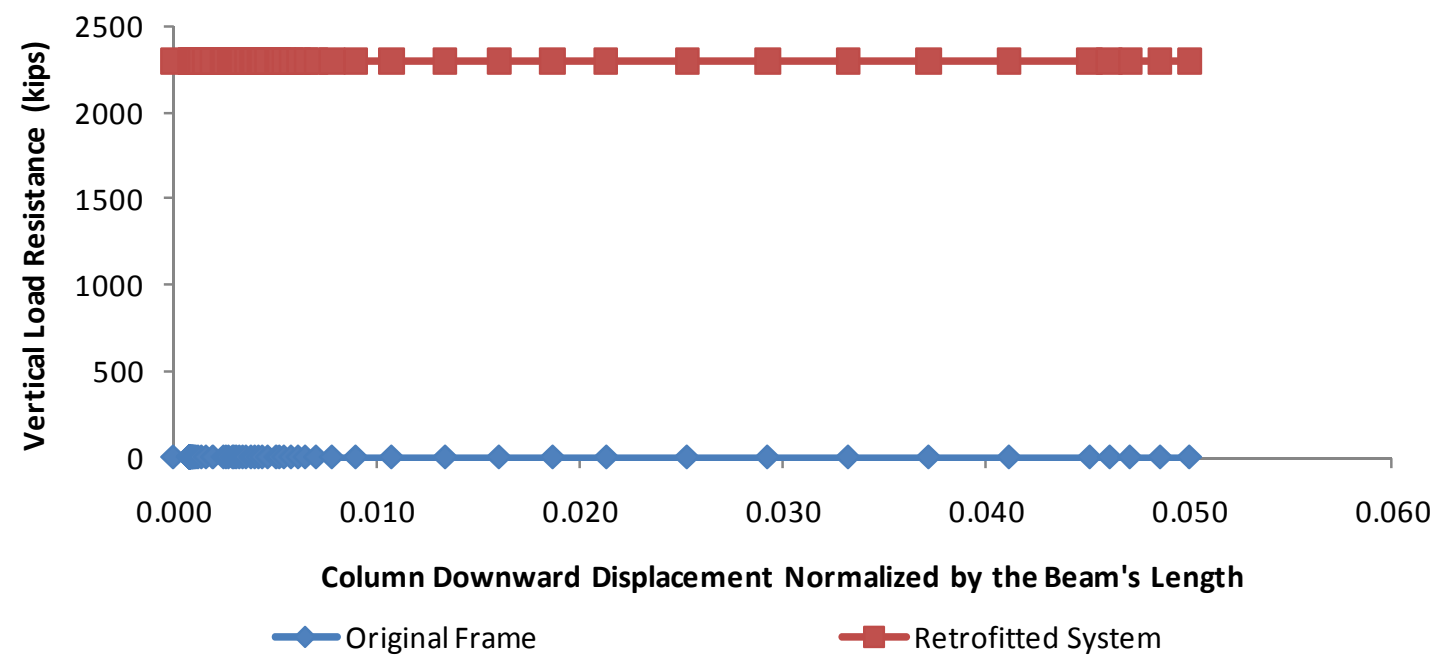

Figure 5-16: Vertical load resistance of the retrofitted system and the original frame under Boundary Condition \#2 (Results from Plastic Analysis)

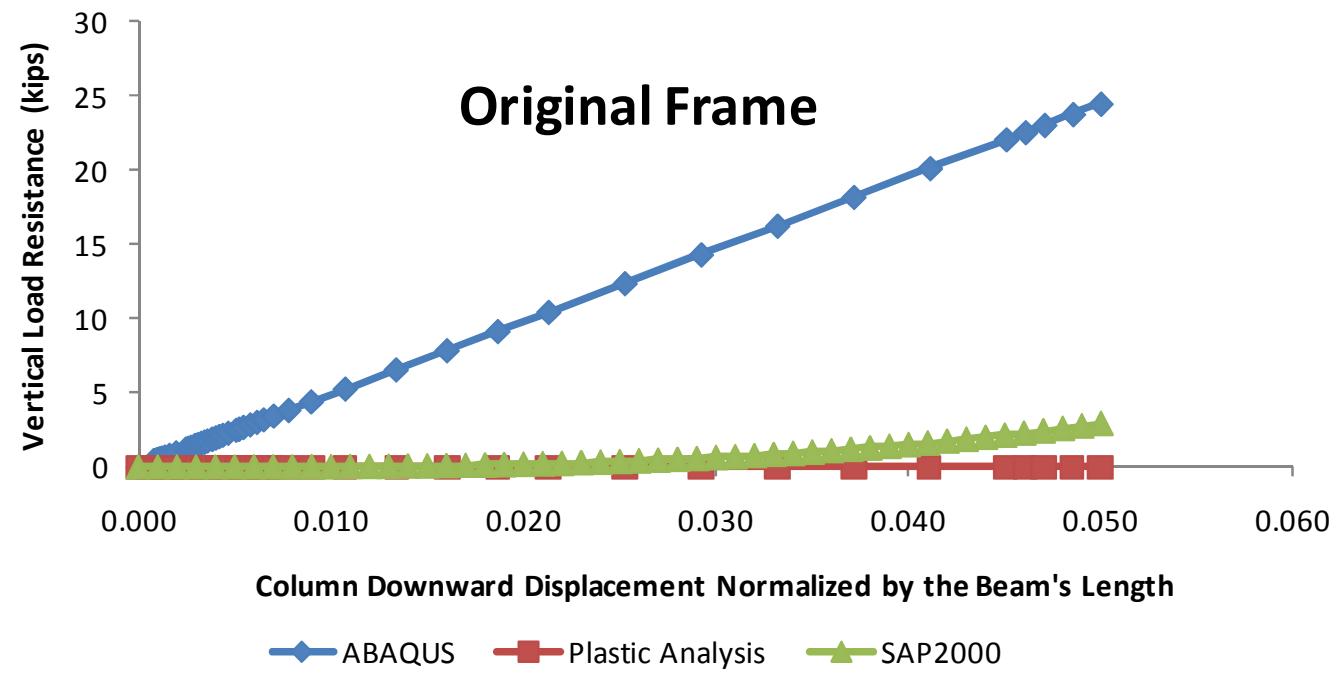

Figure 5-17: Comparison of vertical load resistance of the original frame under Boundary Condition \#2 


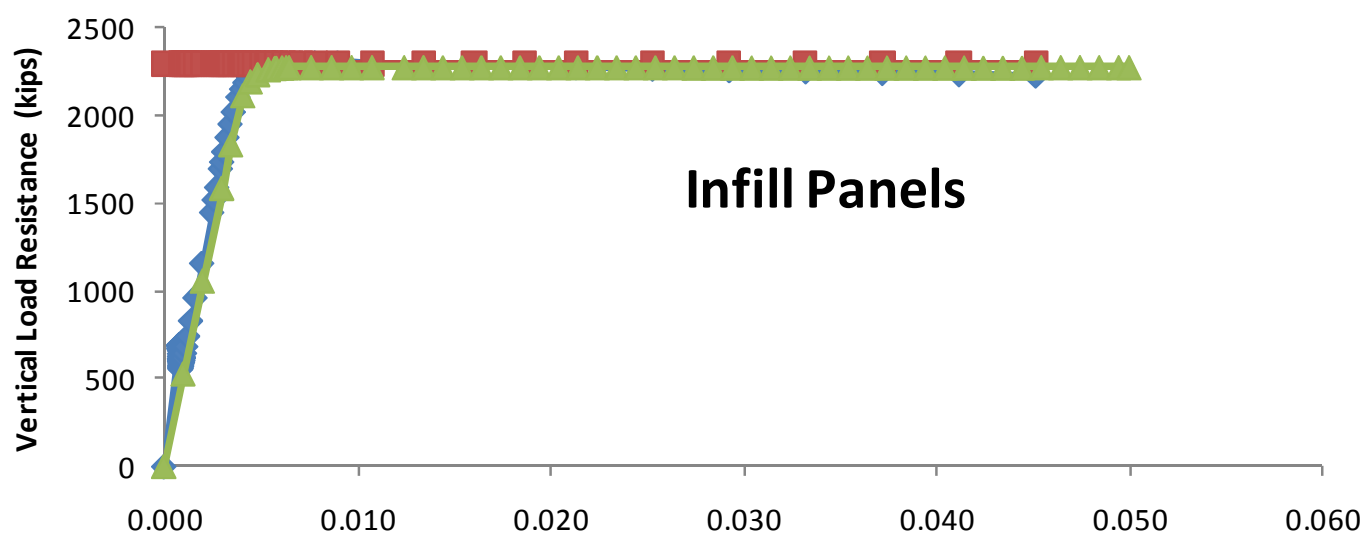

Column Downward Displacement Normalized by the Beam's Length

$\longrightarrow$ ABAQUS $\quad \longrightarrow$ SAP2000

Figure 5-18 Comparison of vertical load resistance of the infill panels alone under Boundary Condition \#2

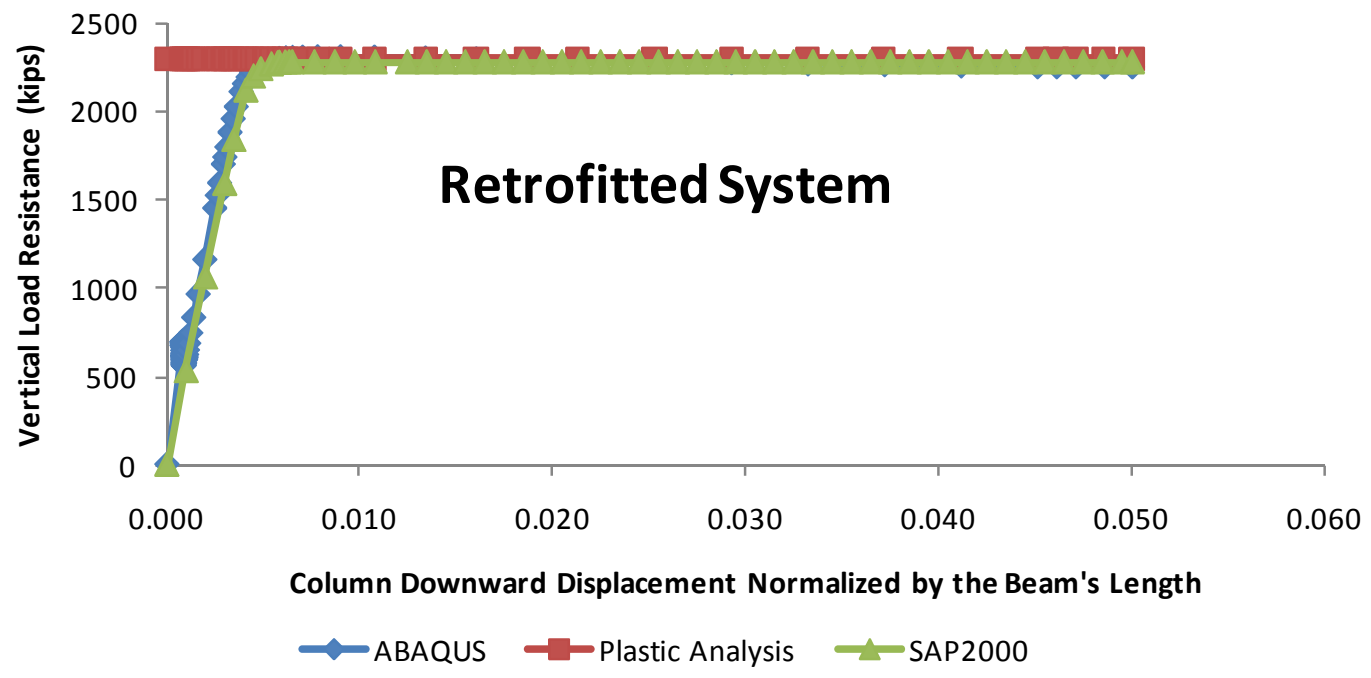

Figure 5-19: Comparison of vertical load resistance of the retrofitted system under Boundary Condition \#2

\subsubsection{Boundary Condition \#3}

Boundary condition \#3 corresponds to the system under interior column removal and sidesway inhibited conditions on both sides of the frame. The first ten buckling modes of the system were used to introduce the imperfections of infill panels. Figure 5-20 is a graphical representation of these buckling modes. 


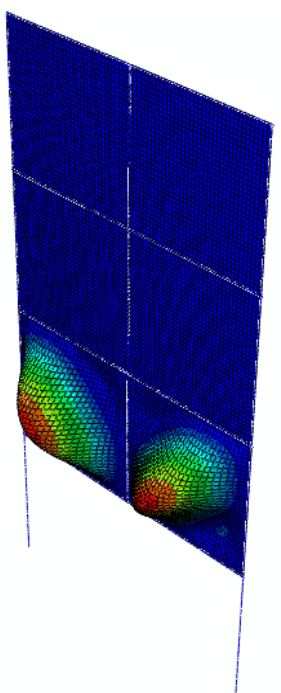

(a) $1^{\text {st }}$ mode

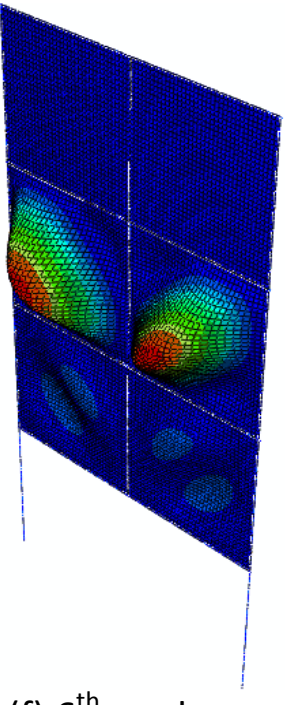

(f) $6^{\text {th }}$ mode

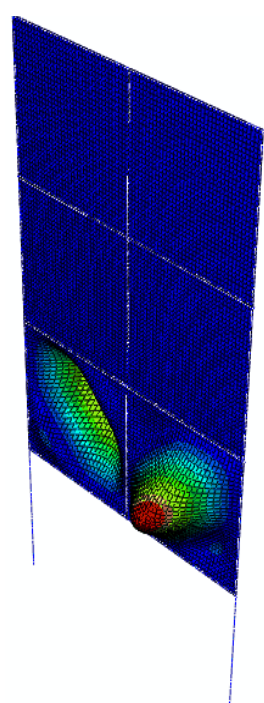

(b) $2^{\text {nd }}$ mode

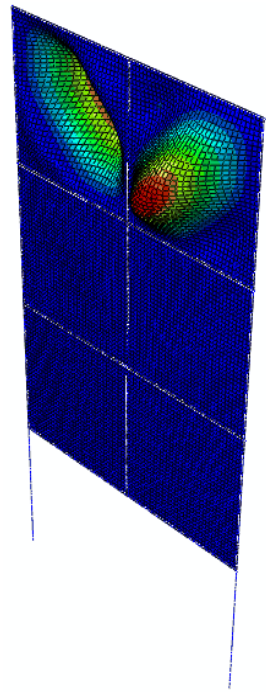

(g) $7^{\text {th }}$ mode

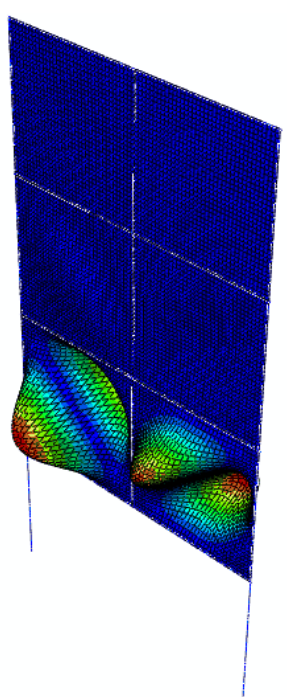

(c) $3^{\text {rd }}$ mode

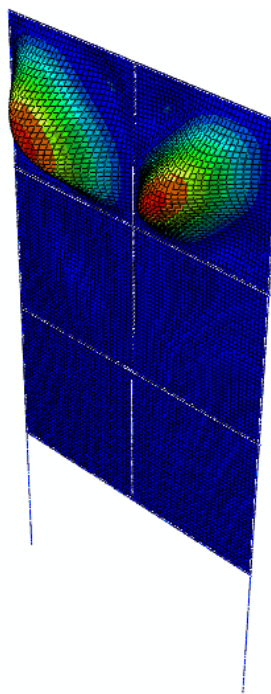

(h) $8^{\text {th }}$ mode

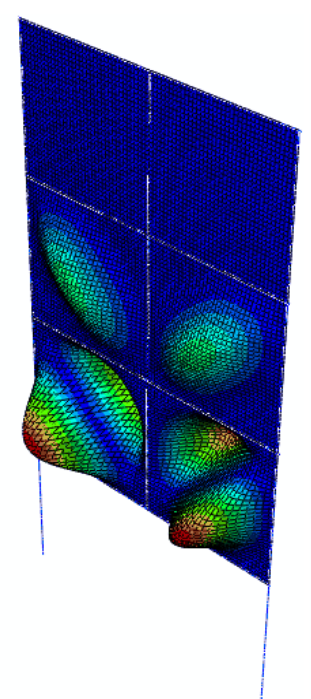

(d) $4^{\text {th }}$ mode

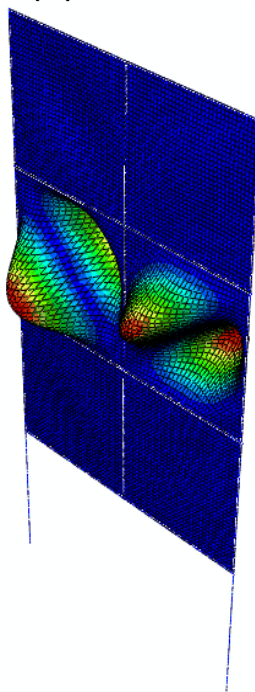

(i) $9^{\text {th }}$ mode (e) $5^{\text {th }}$ mode
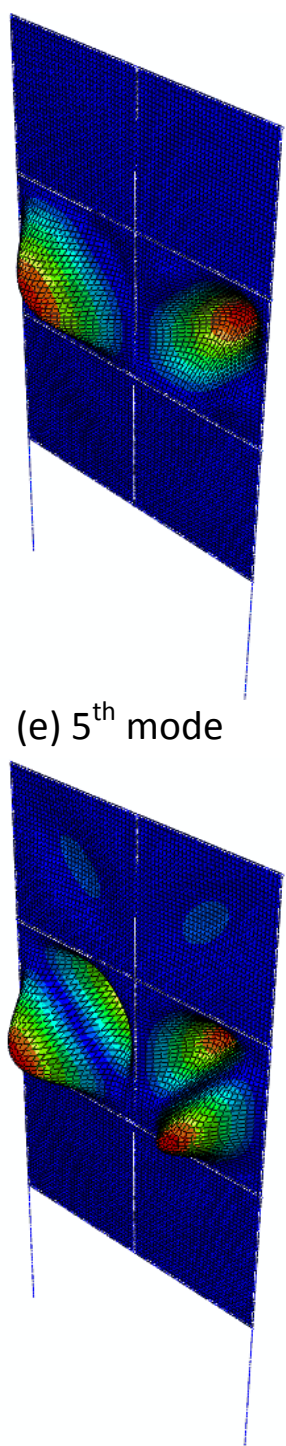

(j) $10^{\text {th }}$ mode

Figure 5-20: Buckling modes for the retrofitted system under Boundary Condition \#3 (Results from ABAQUS)

By inhibiting sideway on both sides of the frame, the catenary actions are able to develop in the beams. In a real structure the development of the catenary action along the beam depends on the tensile strength of the beam-to-column connections. The impact of beamto-column connection failures on the system performance will be investigated in Chapter 8. 
The post buckling behavior of the infill panels is similar to those from the previous boundary conditions. The tension field actions of the infill panels are shown in Figure $5-21$.
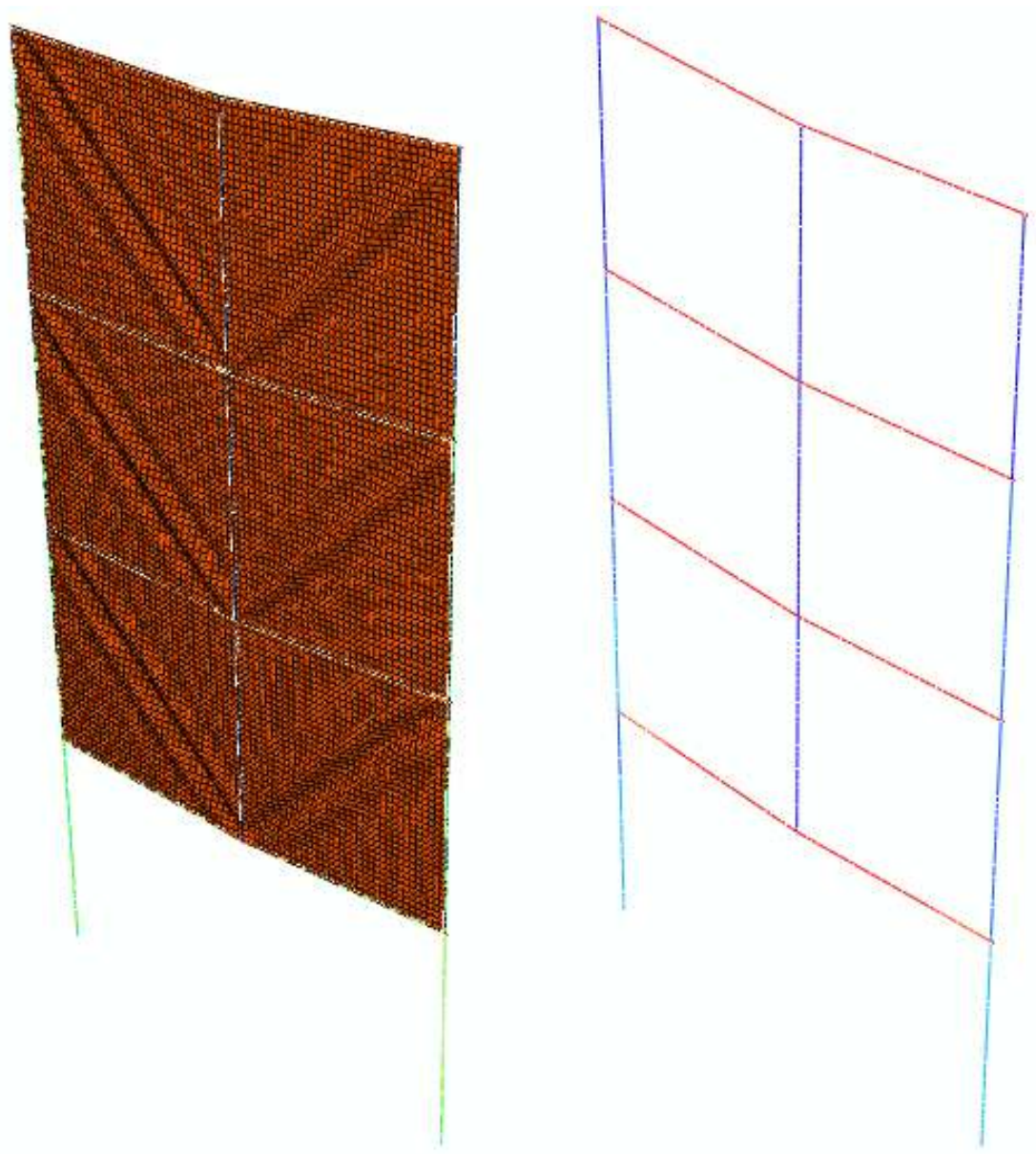

Figure 5-21: Post buckling behavior of the retrofitted system and deflection of the original frame under Boundary Condition \#3 (Results from ABAQUS)

Figure 5-22 shows the deflections of the retrofitted system and the original system modeled in SAP 2000. 


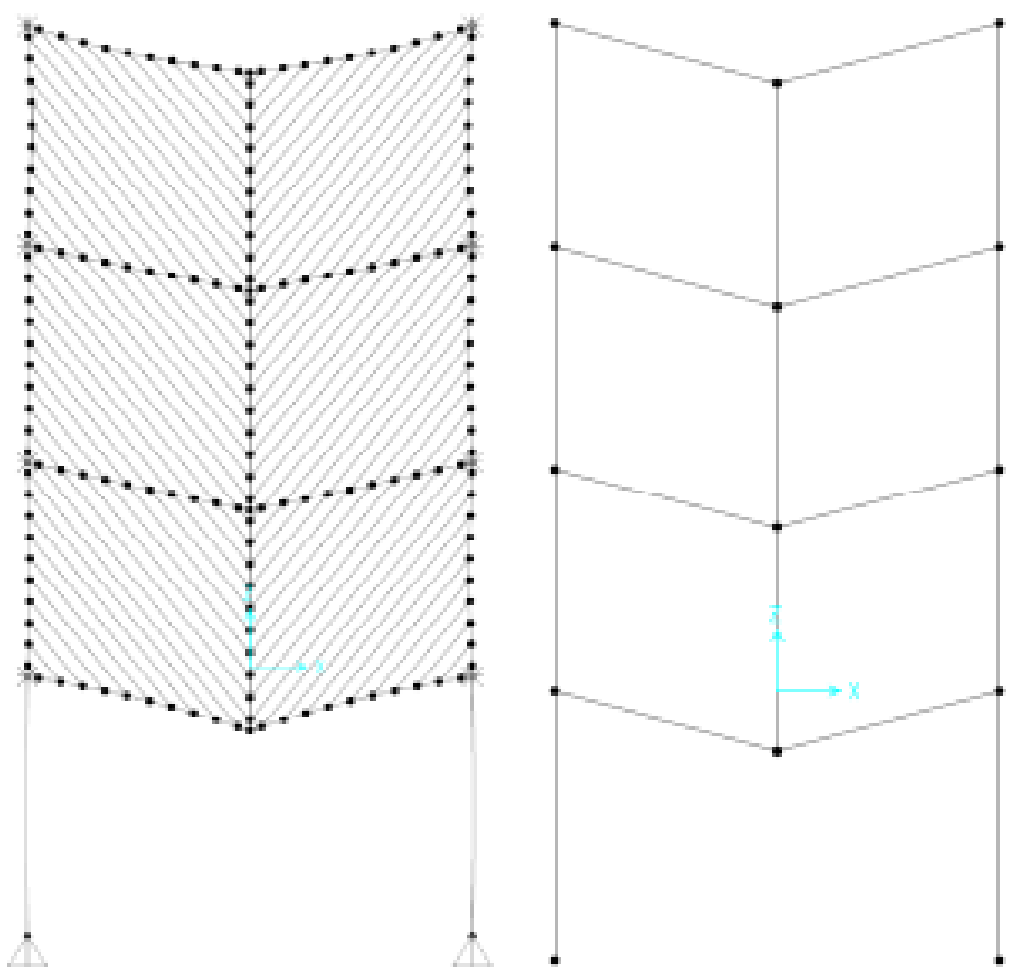

Figure 5-22: Deformed shape of the retrofitted system and the original frame under Boundary Condition \#3 (Results from SAP2000)

The vertical load resistance of the infill panels remains constant as the Boundary Conditions \#1 and 2. However, different from Boundary Conditions \#1 and 2, the beams under this case provide vertical load resistance due to the development of the catenary action. The vertical load resistance due to the beam catenary actions is directly proportional to the cross section area of the beams as seen in equation (3-58). The cross sectional area of one beam used for this model is 74.79 square inches and there are 8 beams providing catenary action which adds up to a cross sectional area of 600 square inches. The vertical load resistance provided by the original frame and the retrofitted system is presented in Figure 5-23 to Figure 5-28 for all three models. 


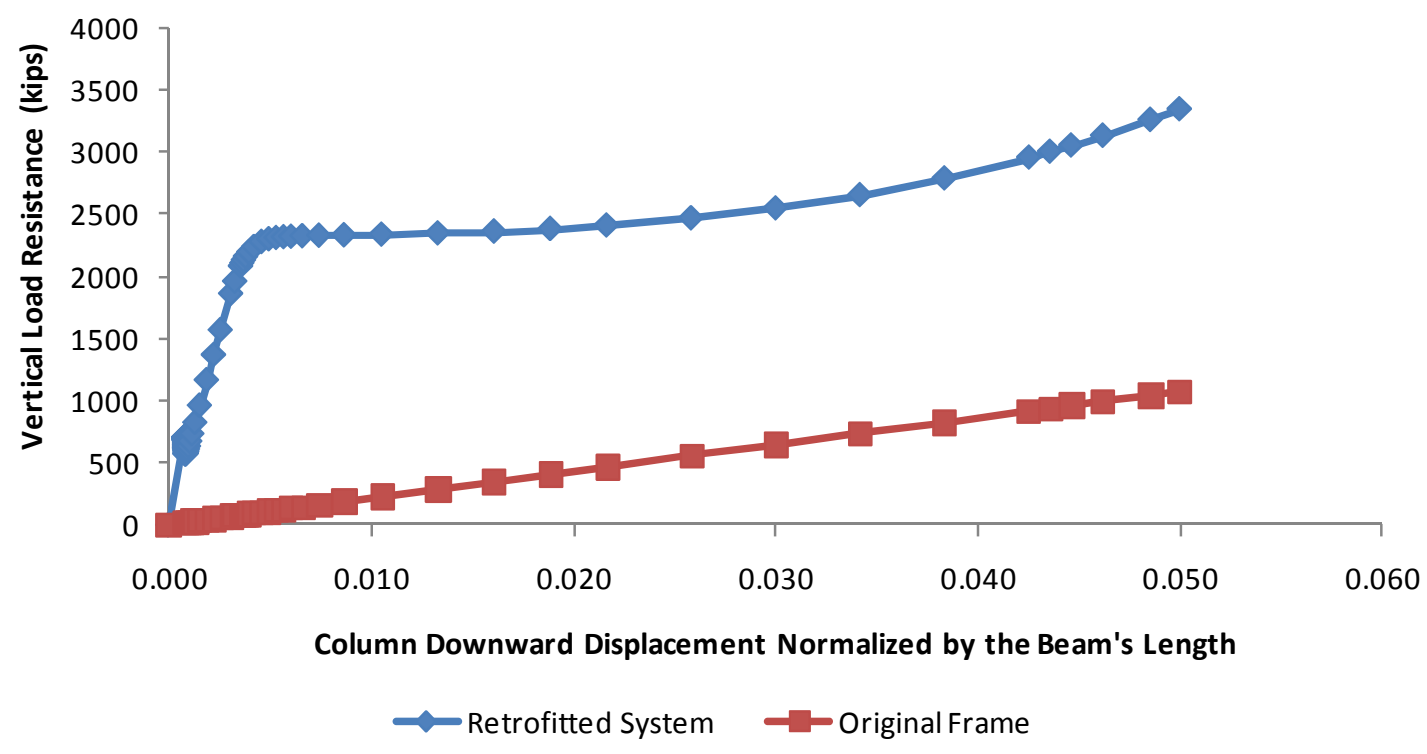

Figure 5-23: Vertical load resistance of the retrofitted system and the original frame under Boundary Condition \#3 (Results from ABAQUS)

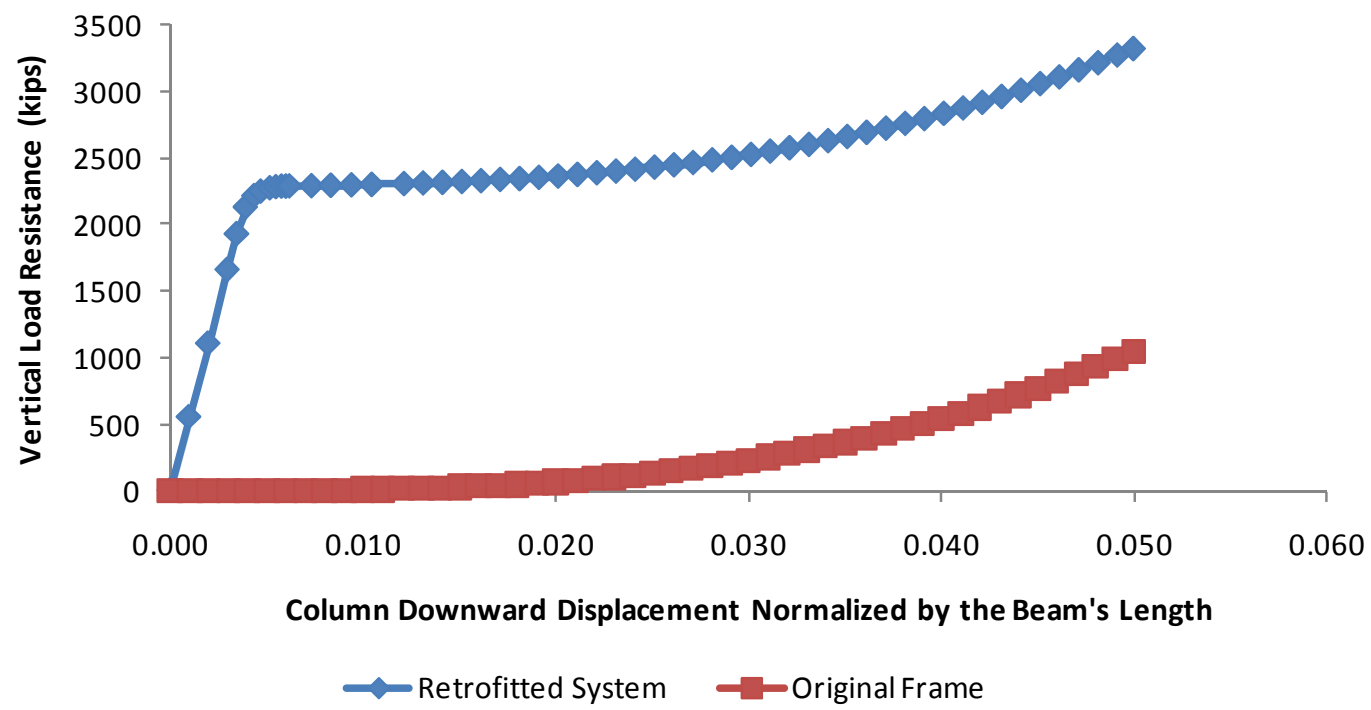

Figure 5-24: Vertical load resistance of the retrofitted system and the original frame under Boundary Condition \#3 (Results from SAP2000) 


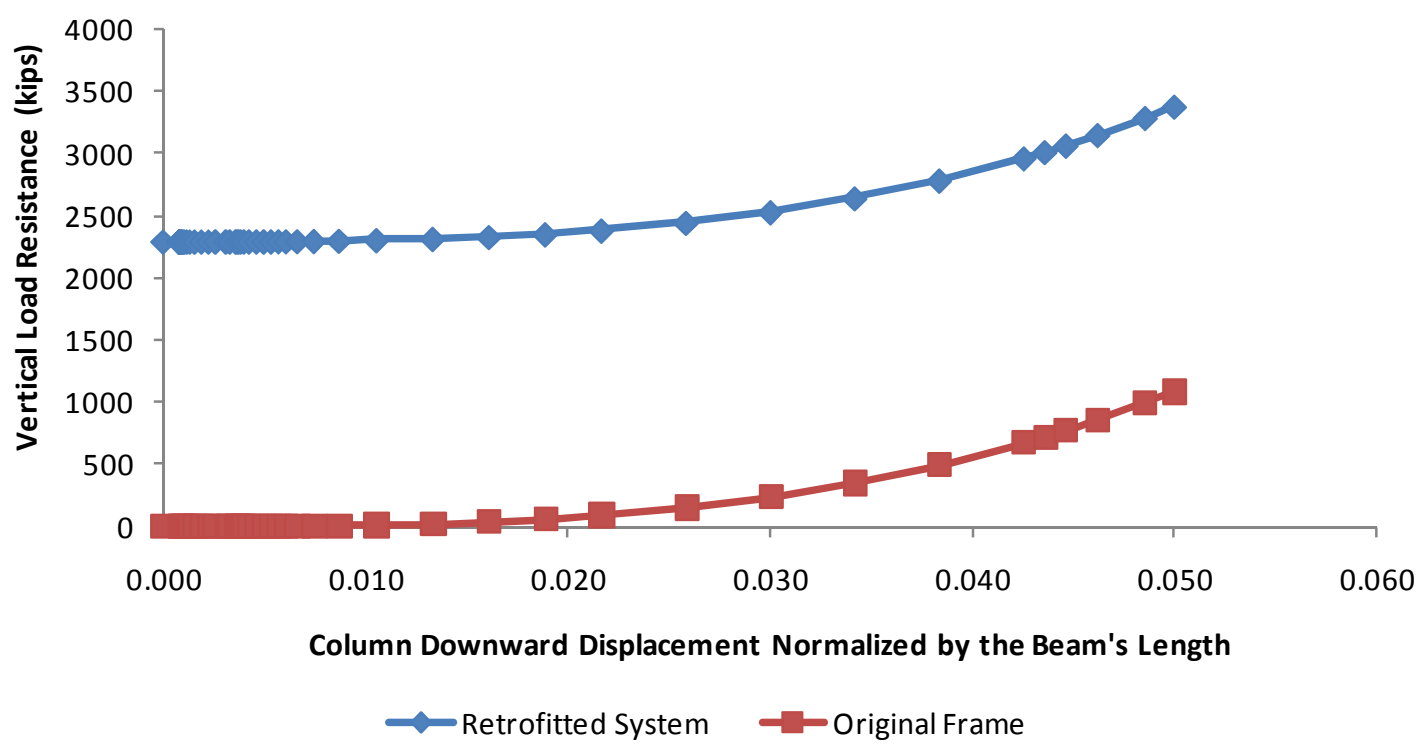

Figure 5-25: Vertical load resistance of the retrofitted system and the original frame under Boundary Condition \#3 (Results from Plastic Analysis)

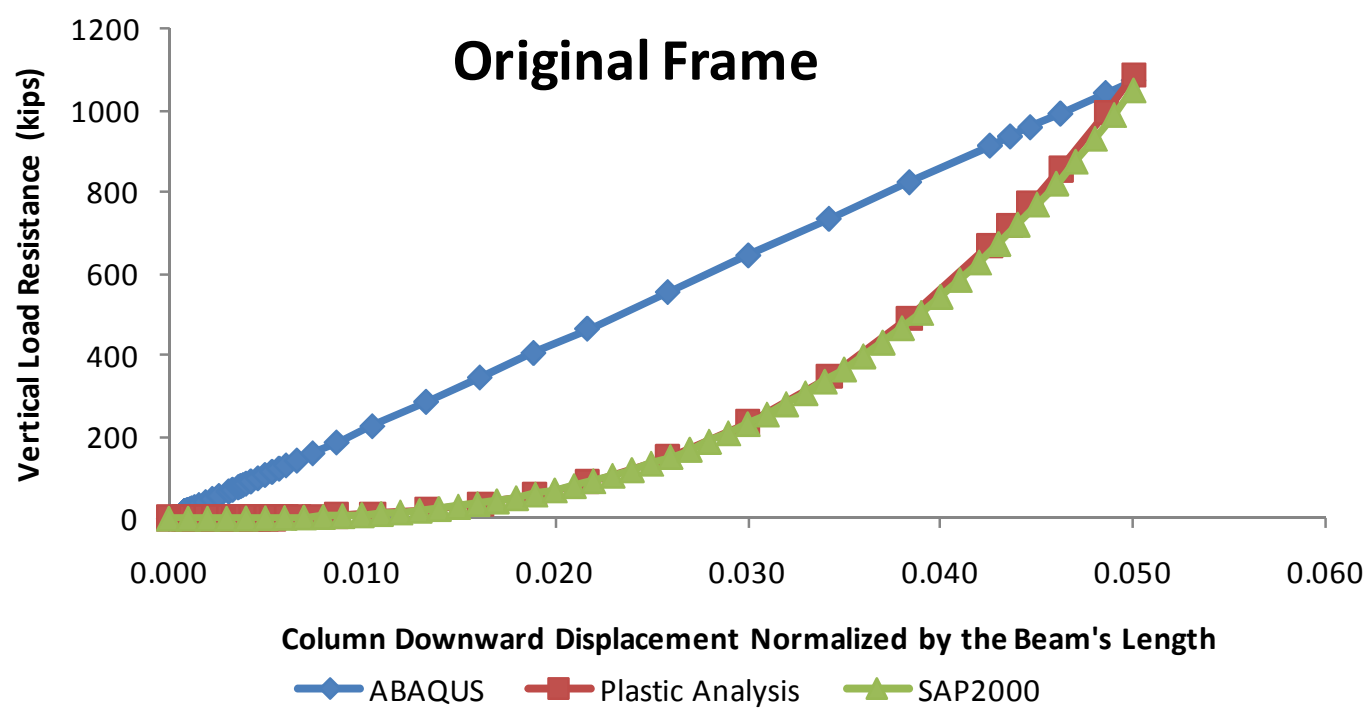

Figure 5-26: Comparison of vertical load resistance of the original frame under Boundary Condition \#3 


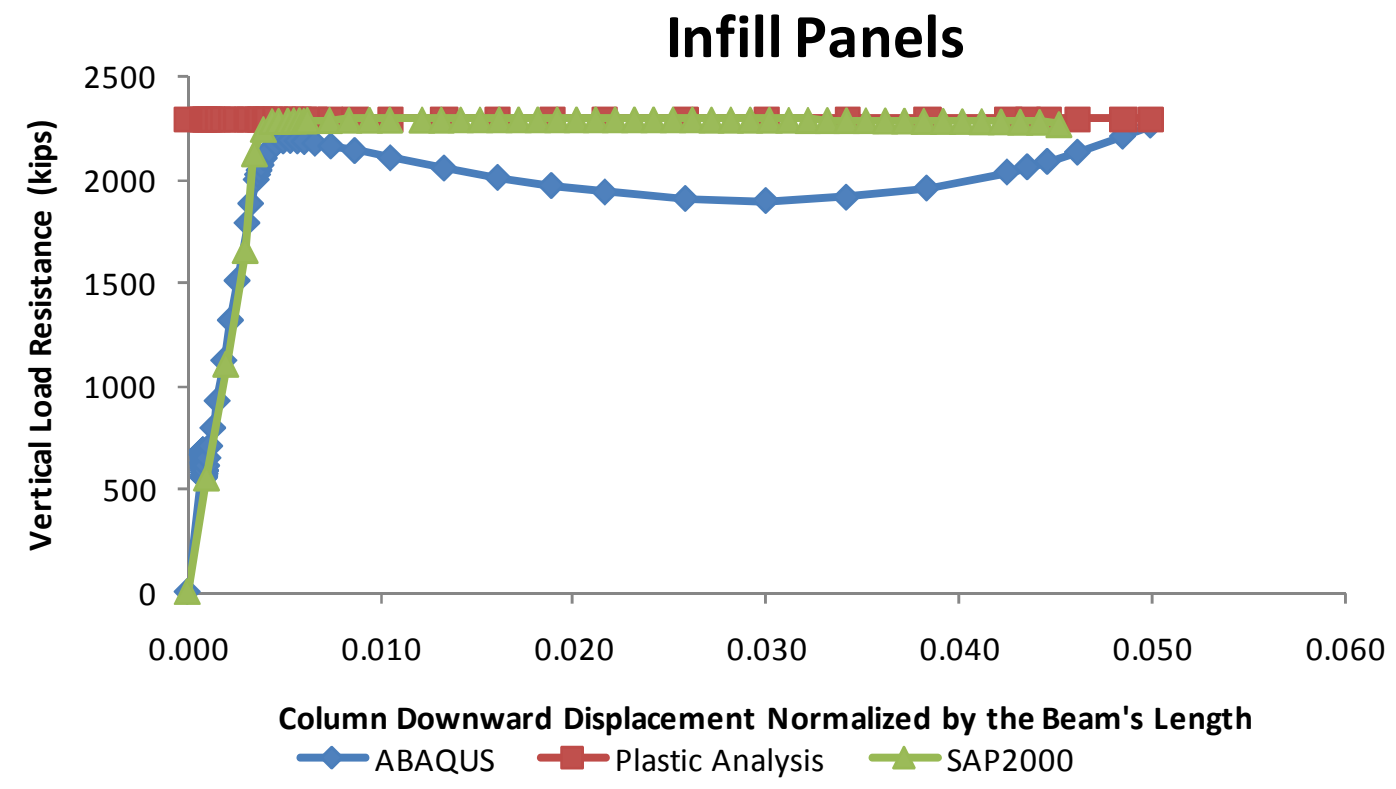

Figure 5-27: Comparison of vertical load resistance of the infill panels alone under Boundary Condition \#3

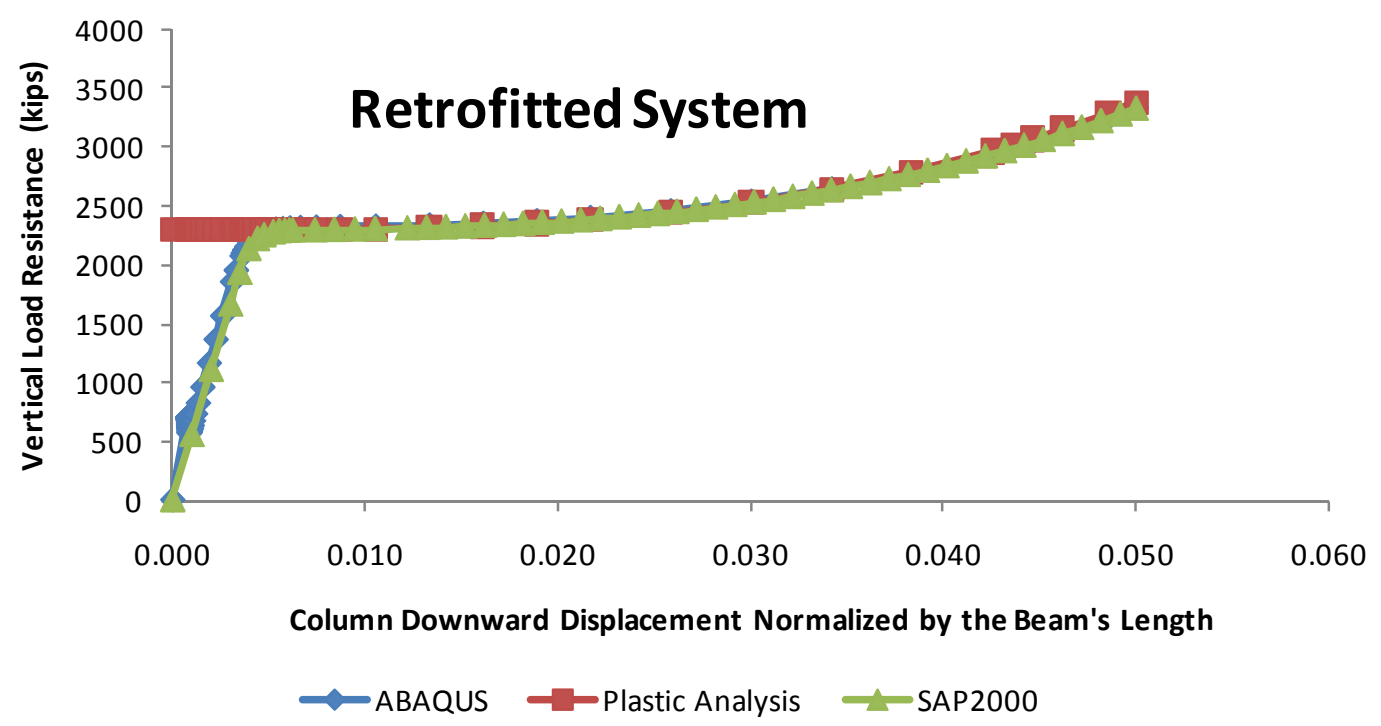

Figure 5-28: Comparison of vertical load resistance of the retrofitted system under Boundary Condition \#3 


\subsubsection{Boundary Condition \#4}

Boundary Condition \#4 refers to the system under exterior column removal and this condition allows sidesway deflection of the frame. It is necessary to include the first 17 buckling modes in the analysis in order to capture at least the one buckle mode for every infill panel. The buckle modes presented in Figure 5-29 were used to introduce the initial imperfections into the push down analysis model. The tension field actions of the infill panels are shown in Figure 5-30.

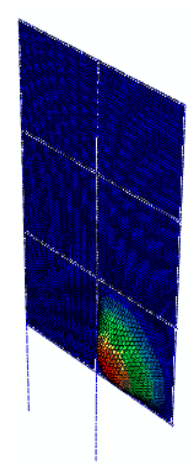

(a) $1^{\text {st }}$ mode

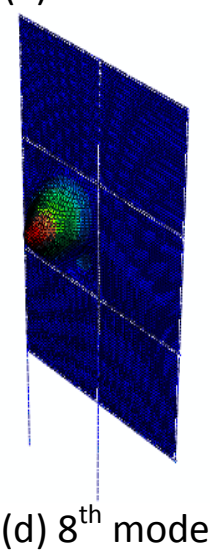

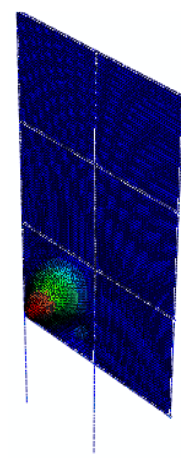

(b) $2^{\text {nd }}$ mode

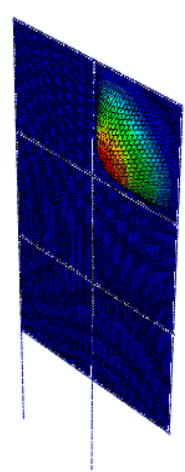

(e) $13^{\text {th }}$ mode

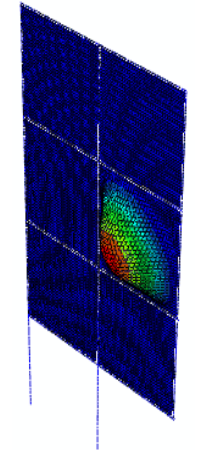

(c) $5^{\text {th }}$ mode

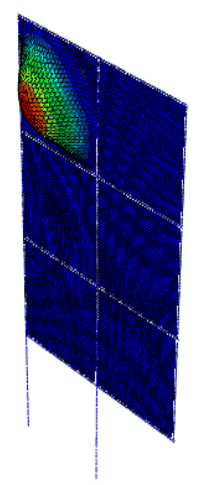

(f) $17^{\text {th }}$ mode

Figure 5-29: Buckling modes for the retrofitted system under Boundary Condition \#4 (Results from ABAQUS) 


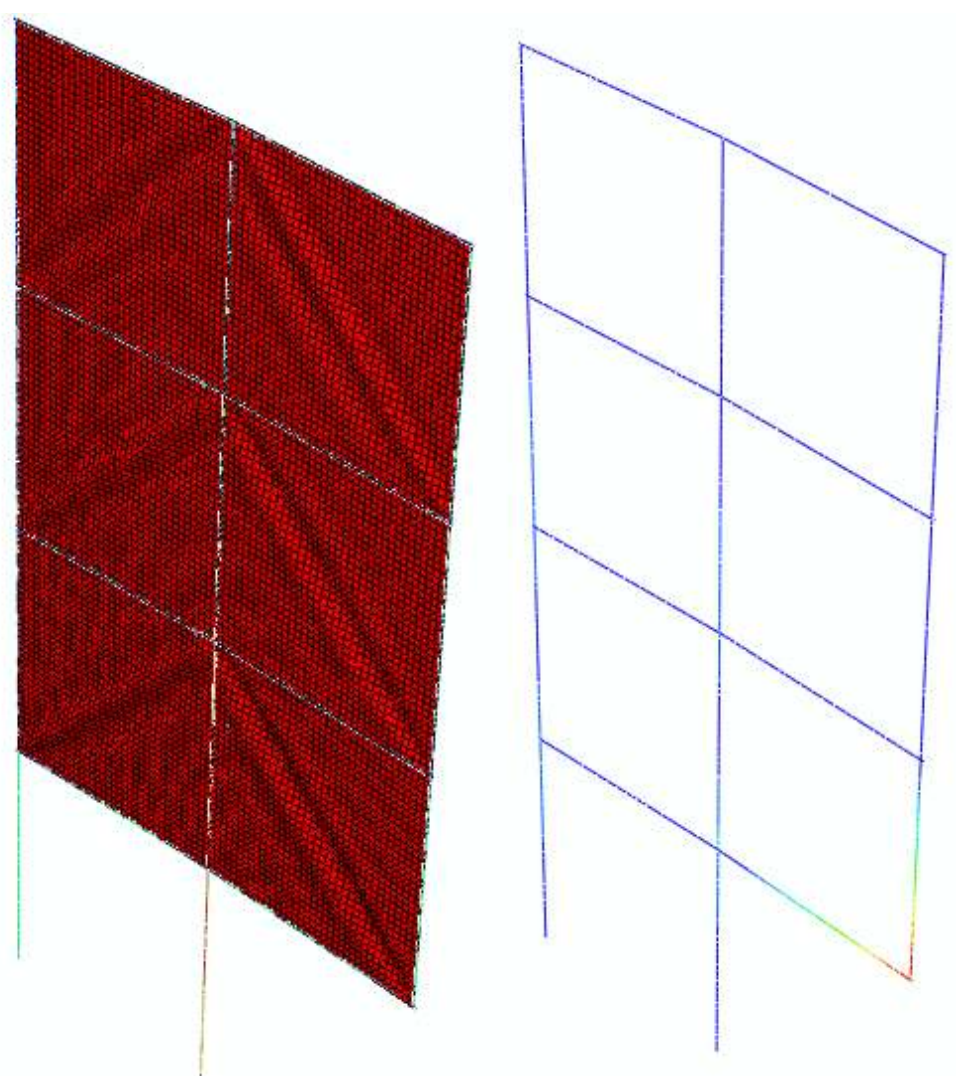

Figure 5-30: Post buckling behavior of the retrofitted system and deflection of the original frame under Boundary Condition \#4 (Results from ABAQUS)

When subjected to removal of an interior column such as those considered in Boundary Conditions \#1 through 3, the retrofitted system forms "V" shape tension field actions at each story as shown previously. However, under Boundary Condition \#4, the tension field actions in the retrofitted system are completely different. As shown in Figure 5-30, the tension field actions exhibit an "inverted V" shape distribution in the frame. This tension field action configuration helps transfer the vertical load from the exterior column to the adjacent column. This special distribution of tension field actions results in tension in the left column and compression in the middle column. Distributions of the axial loads in the left and middle columns are compared in Figure 5-39. 
Figure 5-31 shows the deflections of the retrofitted system and the original system modeled in SAP 2000.

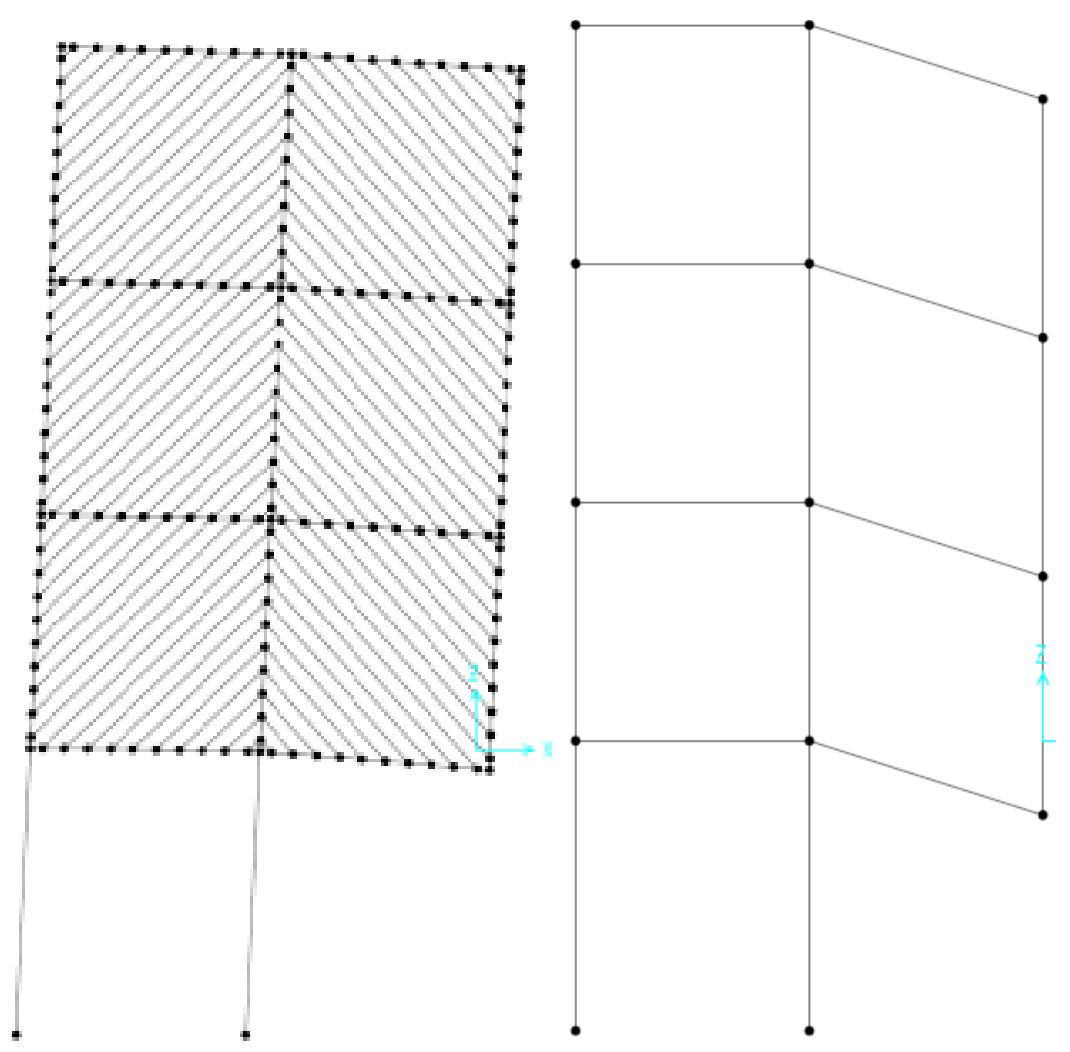

Figure 5-32: Deformed shape of the retrofitted system and the original frame under Boundary Condition \#4 (Results from SAP2000)

The vertical load resistance of the system under Boundary Condition \#4 is provided by the three infill panels on the right hand side and is about 1200 kips. It is noted that the beams cannot develop catenary actions because sidesway was uninhibited. The resistance for the original frame and the retrofitted system can be found in Figure 5-33 to Figure 5-35 and a resistance comparison based on results from different models are presented in Figure 5-36 to Figure 5-38. 


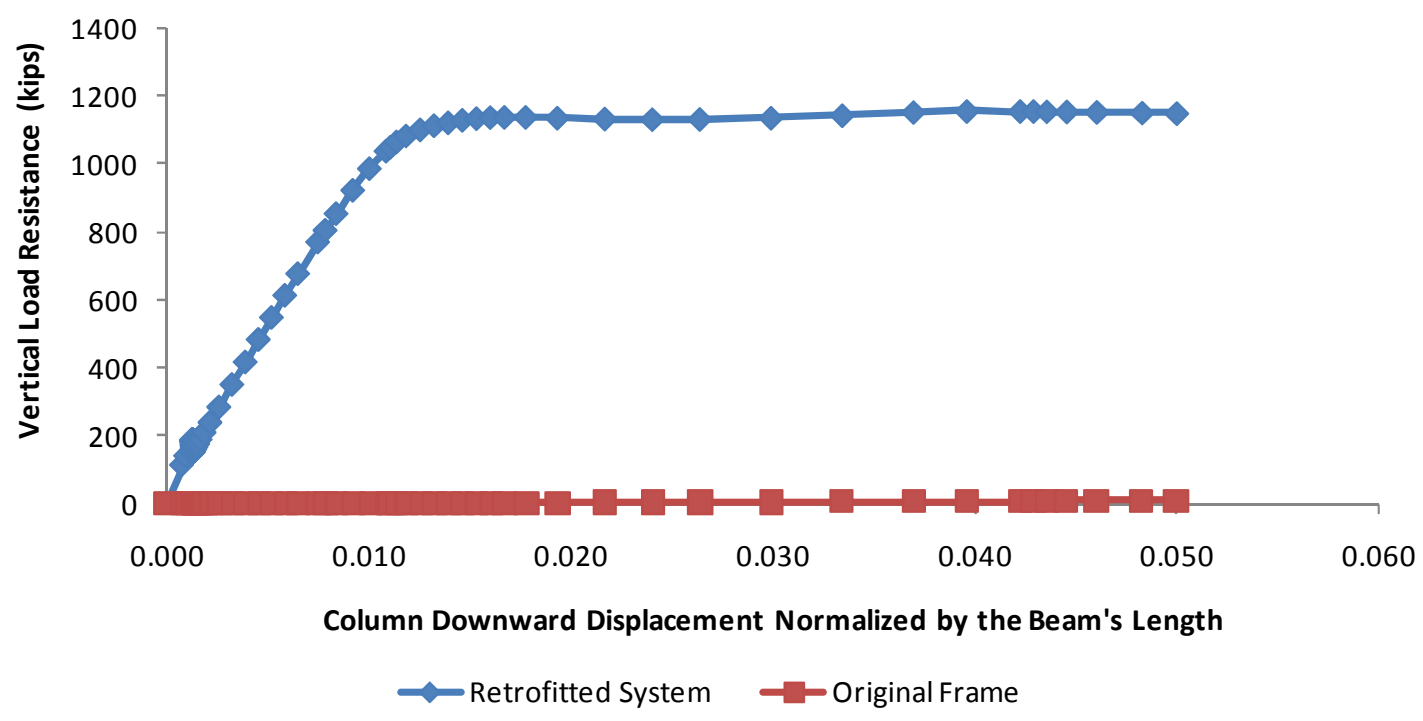

Figure 5-33: Vertical load resistance of the retrofitted system and the original frame under Boundary Condition \#4 (Results from ABAQUS)

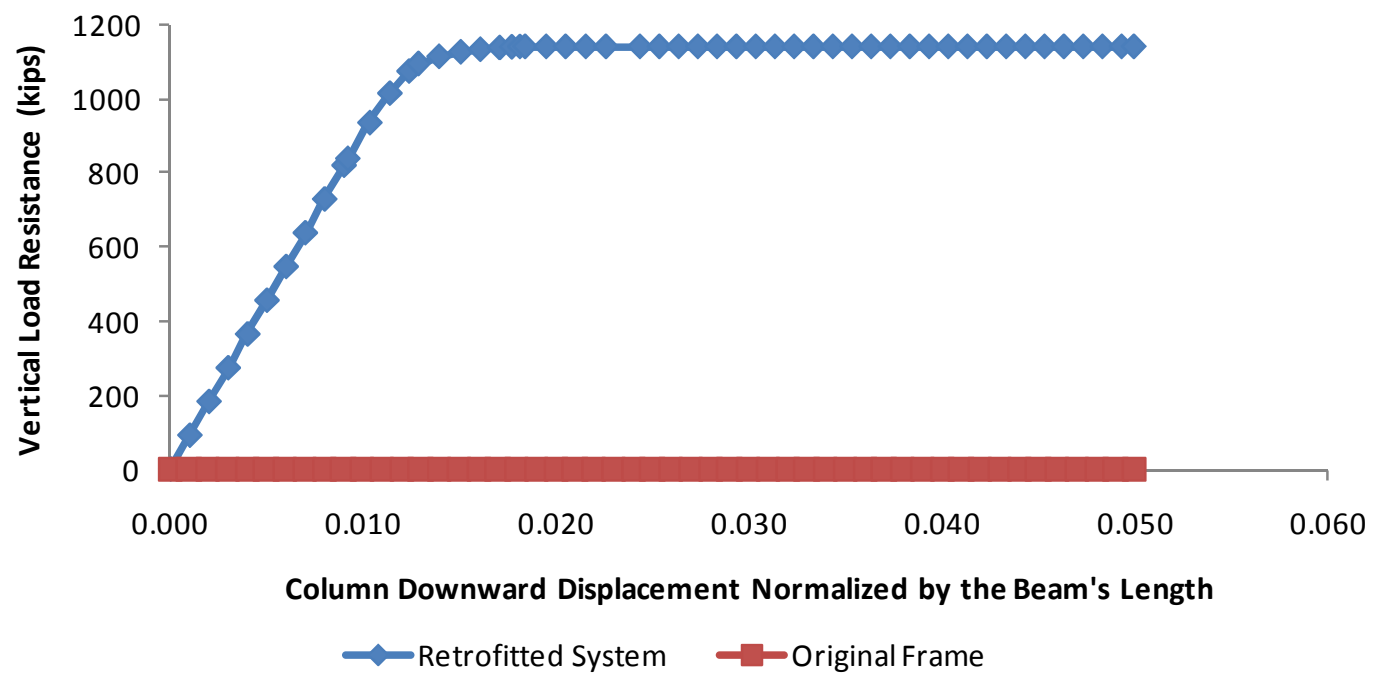

Figure 5-34: Vertical load resistance of the retrofitted system and the original frame under Boundary Condition \#4 (Results from SAP2000) 


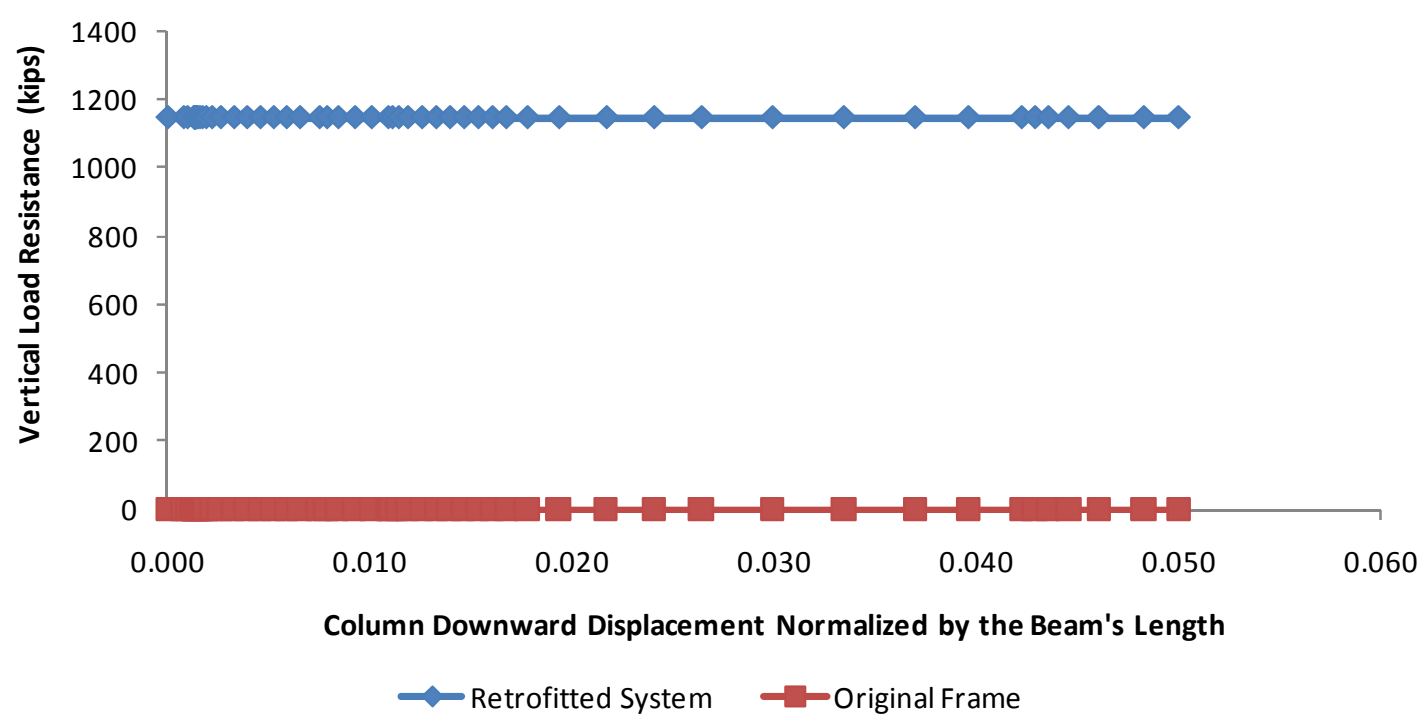

Figure 5-35: Vertical load resistance of the retrofitted system and the original frame under Boundary Condition \#4 (Results from Plastic Analysis))

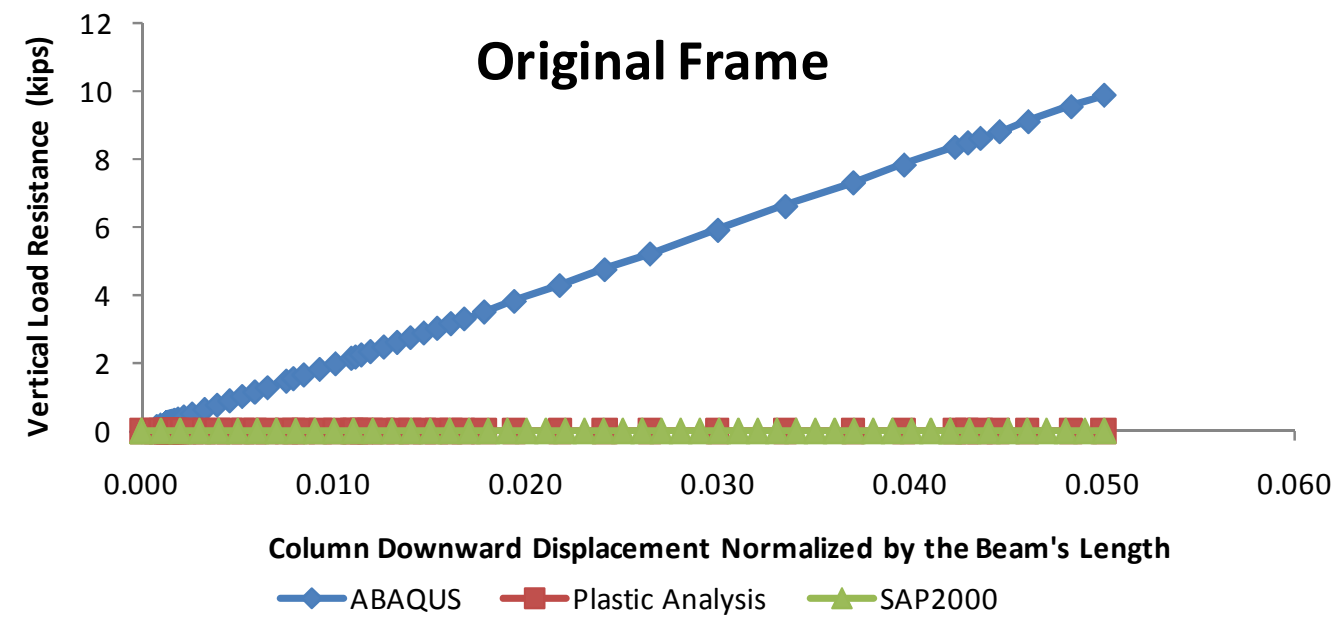

Figure 5-36: Comparison of vertical load resistance of the original frame under Boundary Condition \#4 


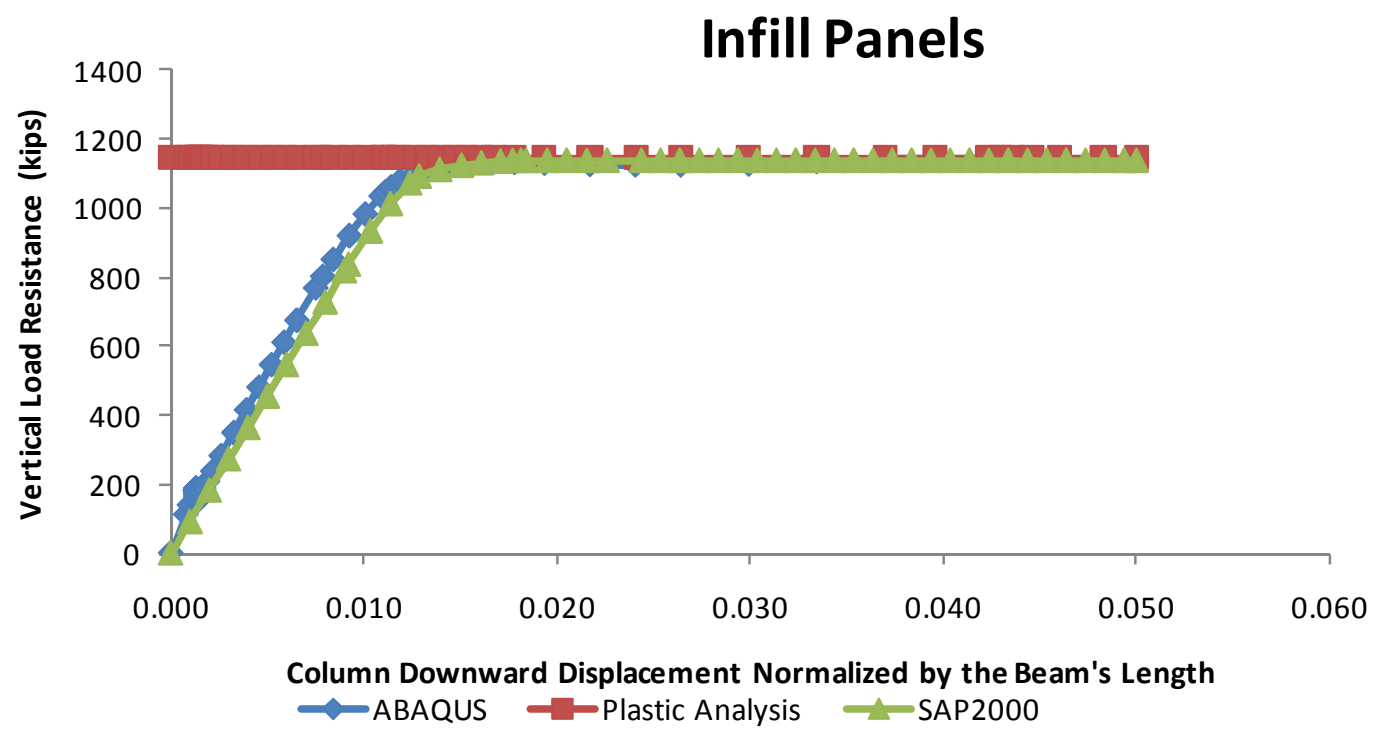

Figure 5-37: Comparison of vertical load resistance of the infill panels alone under Boundary Condition \#4

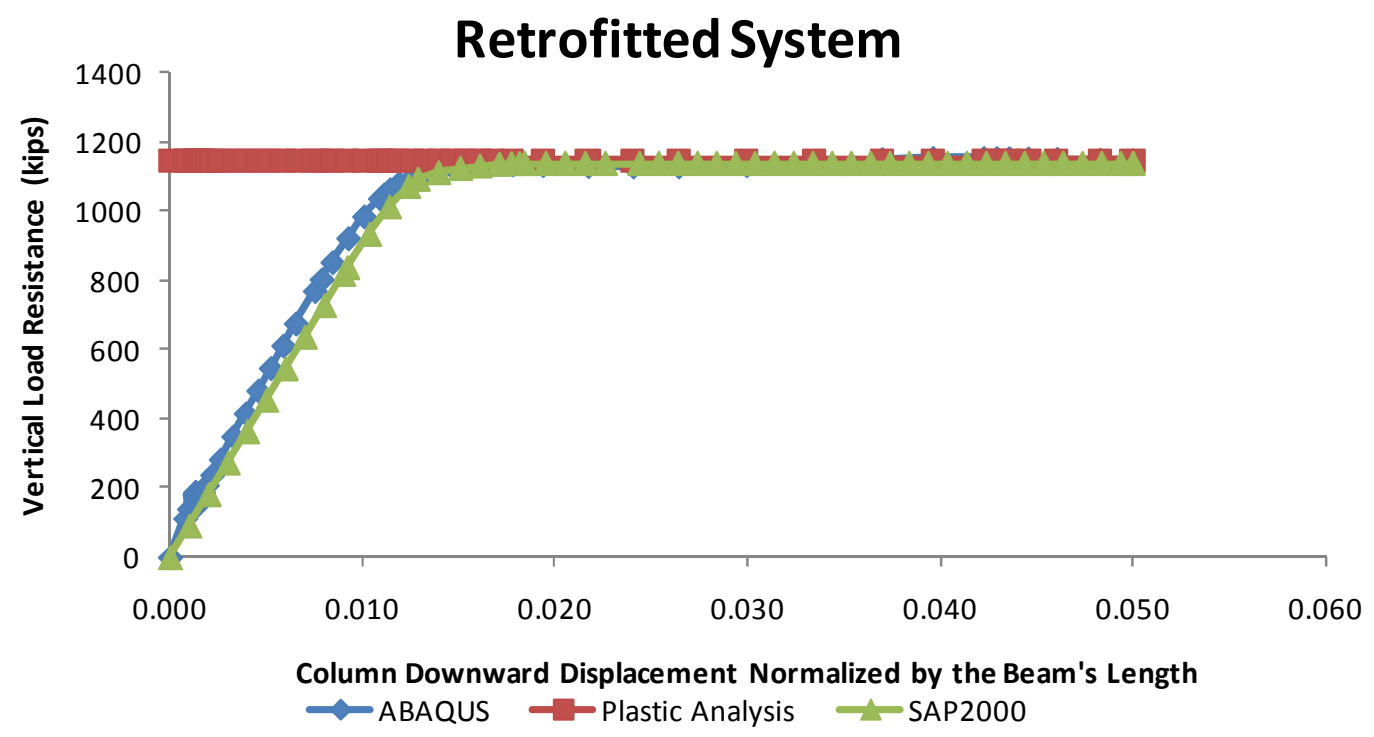

Figure 5-38: Comparison of vertical load resistance of the retrofitted system under Boundary Condition \#4 


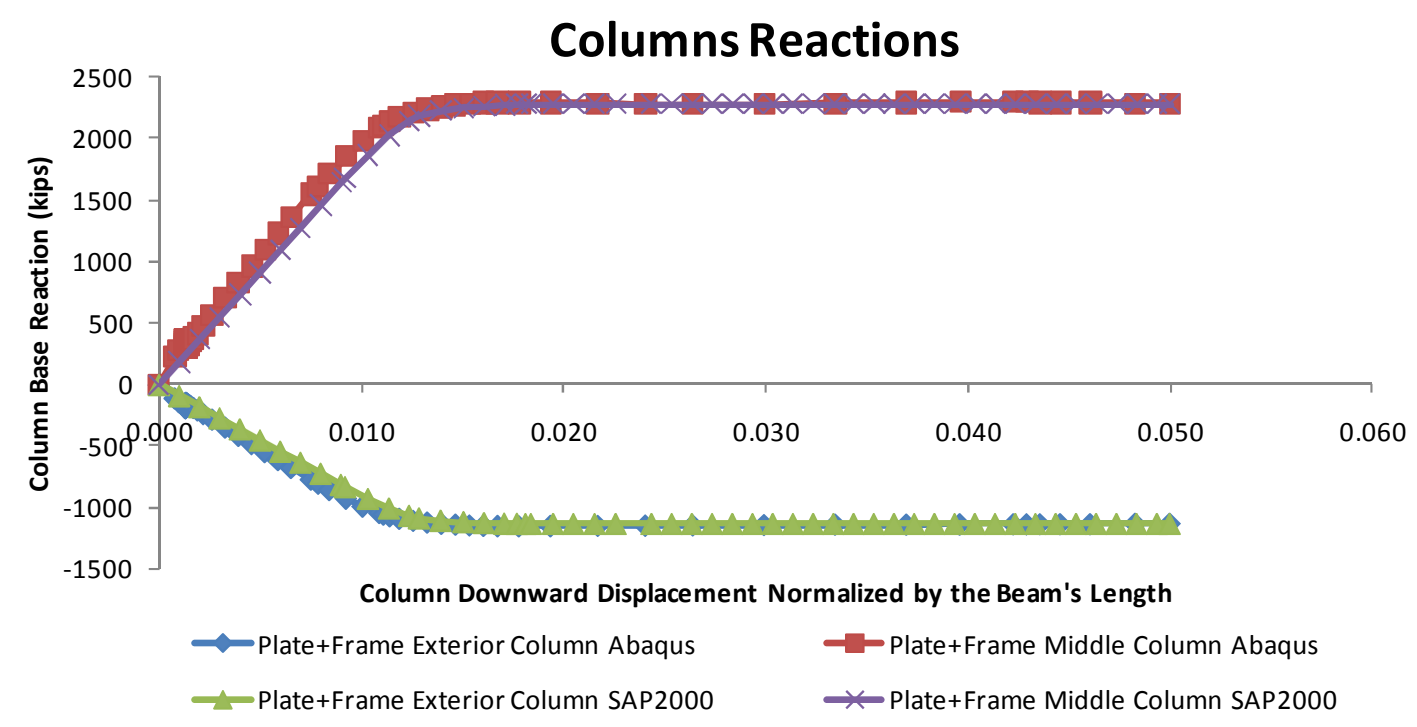

Figure 5-39: Column base reaction of the retrofitted system under Boundary Condition \#4

\subsubsection{Boundary Condition \#5}

The buckling modes of the system under Boundary Condition \#5 are presented in Figure 5-40. Note that sidesway is only inhibited on the left side of the frame under this boundary condition. It is also noted that the buckle amplitude of some plates (such as the one at the fourth story of the left bay) are too small to be visualized. The initial imperfections corresponding to the presented buckle modes were introduced into the push down analysis model. 


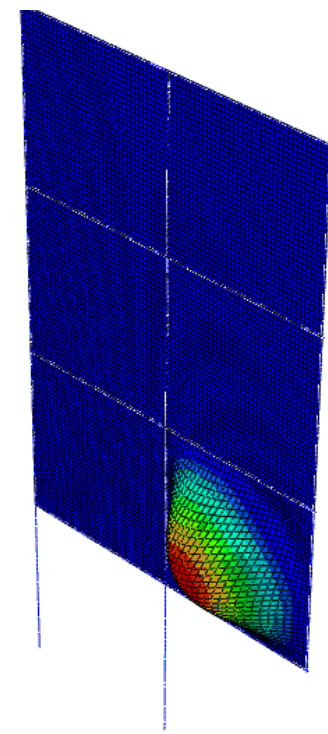

(a) $1^{\text {st }}$ mode

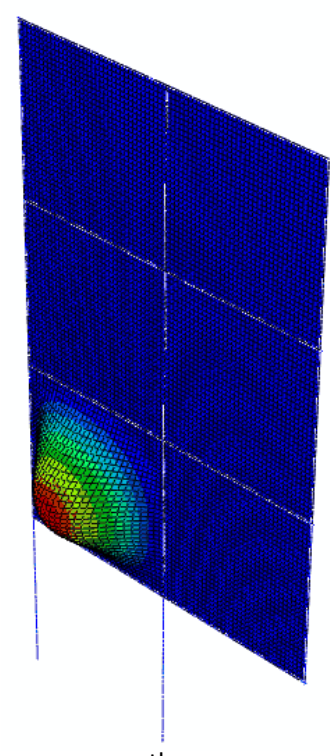

(d) $13^{\text {th }}$ mode

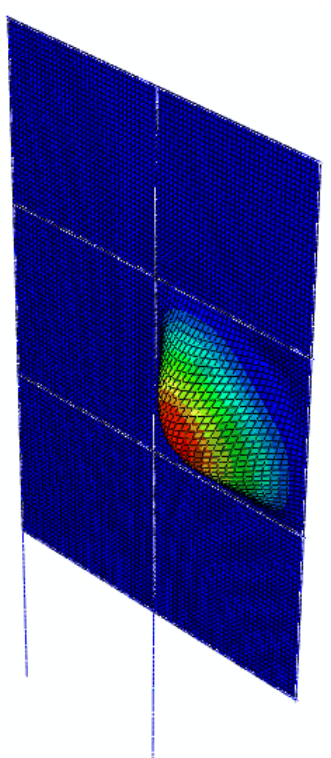

(b) $2^{\text {nd }}$ mode

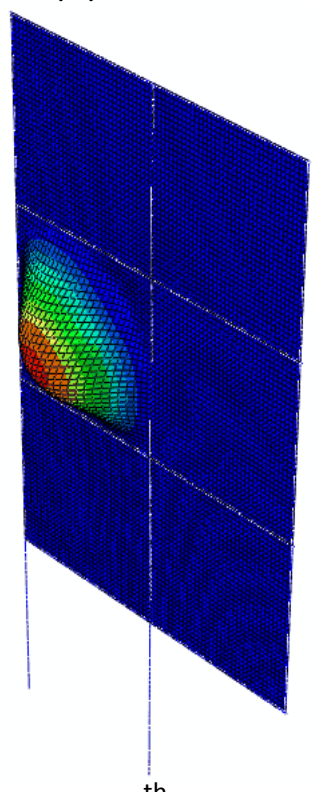

(e) $17^{\text {th }}$ mode

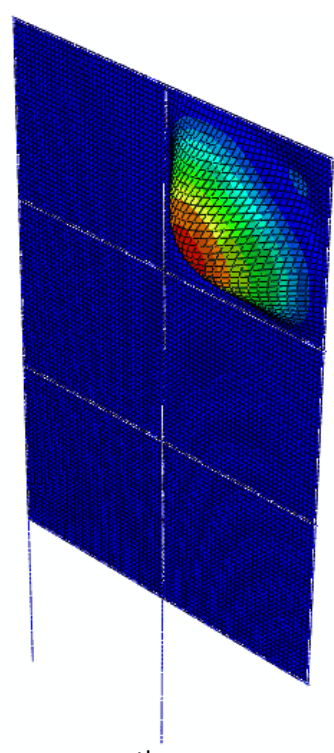

(c) $6^{\text {th }}$ mode

Figure 5-40: Buckling modes for the retrofitted system under Boundary Condition \#5 (Results from ABAQUS)

The post buckling tension field actions were only achieved by the three infill panels on the right hand side of the frame as seen in Figure 5-41. Since horizontal displacement is not allowed on the left side of the frame, the tension field actions are not able to form in the left bay of the frame. Different from Boundary Condition \#4, both the middle column 
and the left column are under compression (see Figure 5-49 for the axial force comparison in these two columns).
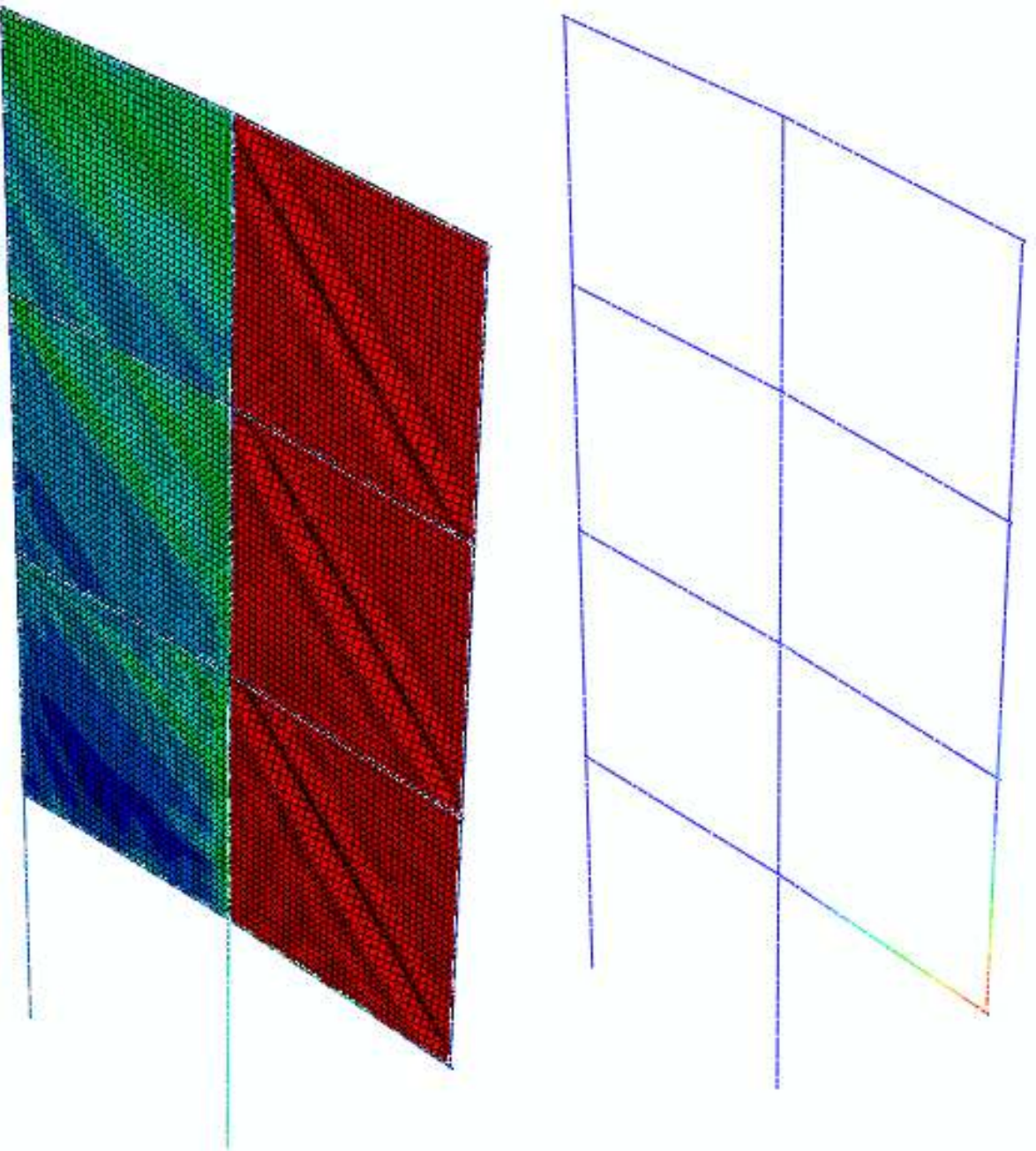

Figure 5-41: Post buckling behavior of the retrofitted system and deflection of the original frame under Boundary Condition \#5 (Results from ABAQUS)

Figure 5-42 shows the deformations of the retrofitted system and the original system obtained from the SAP2000 models. 

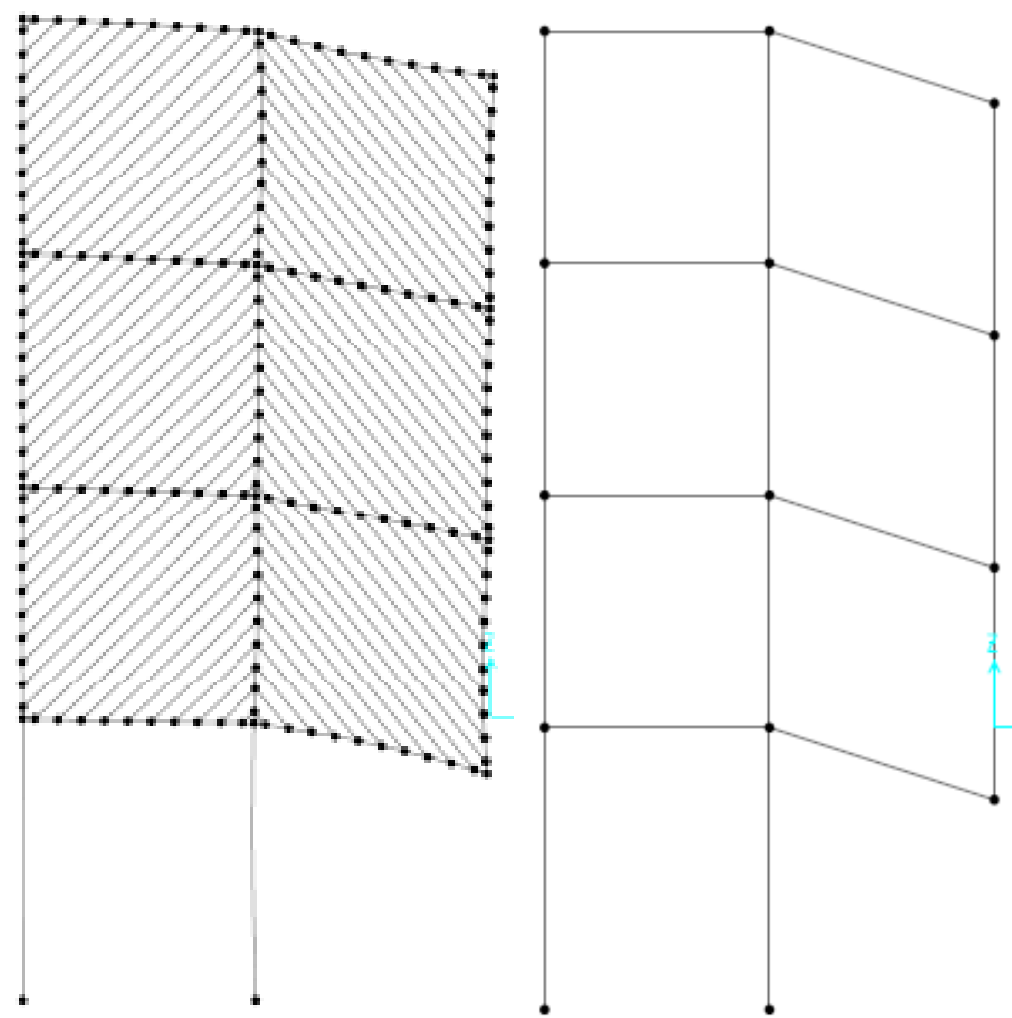

Figure 5-42: Deformed shape of the retrofitted system and the original frame under Boundary Condition \#5 (Results from SAP2000)

Comparing the results from Boundary Conditions \#4 and 5, it is observed that the vertical load resistances are identical to 1200 kips in both cases due to the same tension field action distributions in the right bay of the frame. Moreover, the beams cannot develop catenary actions either. The resistance for the original frame and the retrofitted system can be found in Figure 5-33 to Figure 5-35 and a resistance comparison based on results from different models are presented in Figure 5-36 to Figure 5-38. 


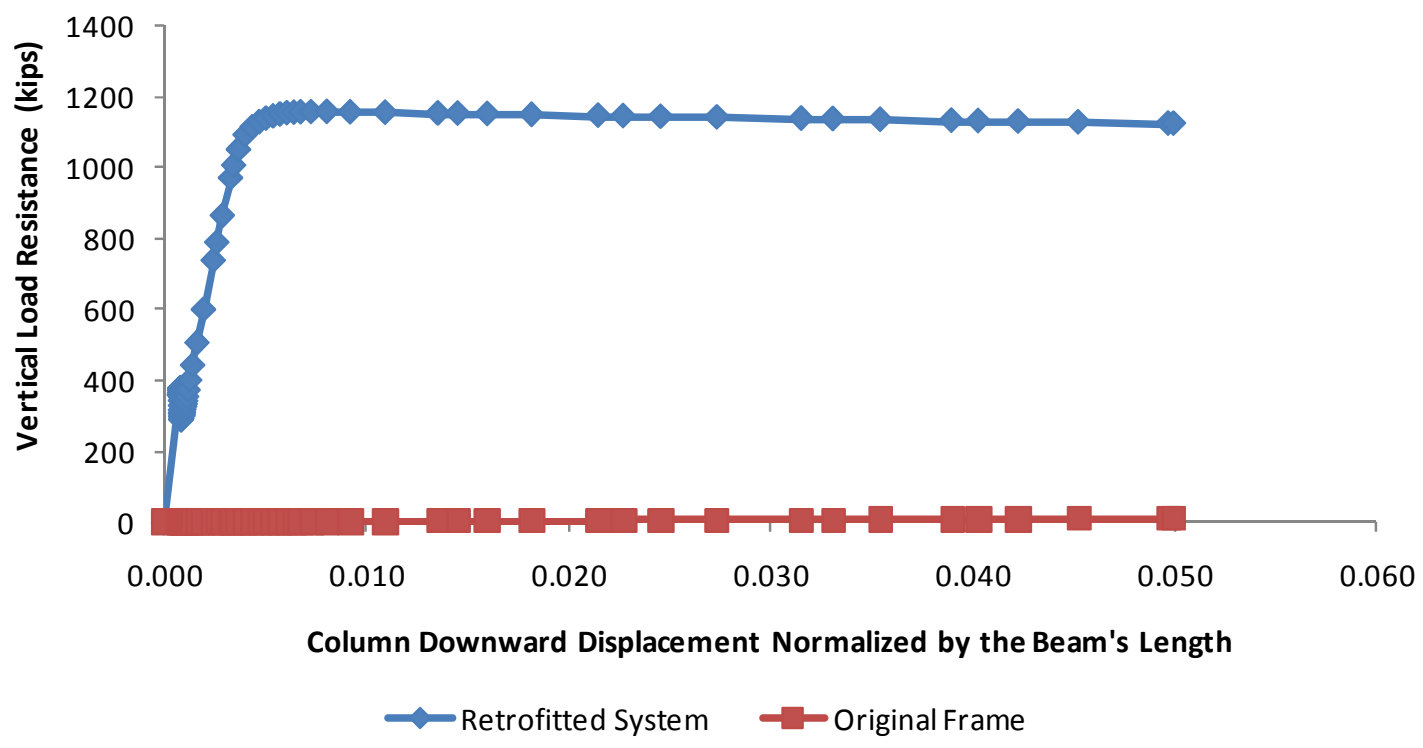

Figure 5-43: Vertical load resistance of the retrofitted system and the original frame under Boundary Condition \#5 (Results from ABAQUS)

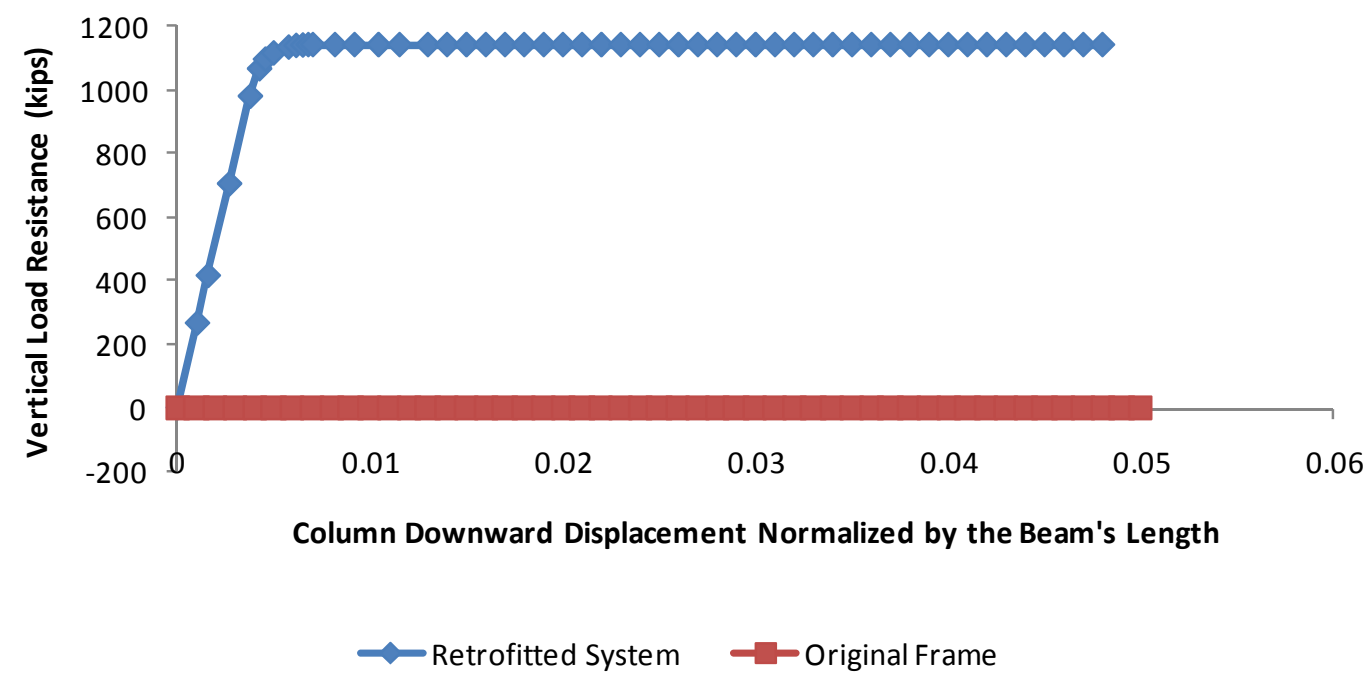

Figure 5-44: Vertical load resistance of the retrofitted system and the original frame under Boundary Condition \#5 (Results from SAP2000) 


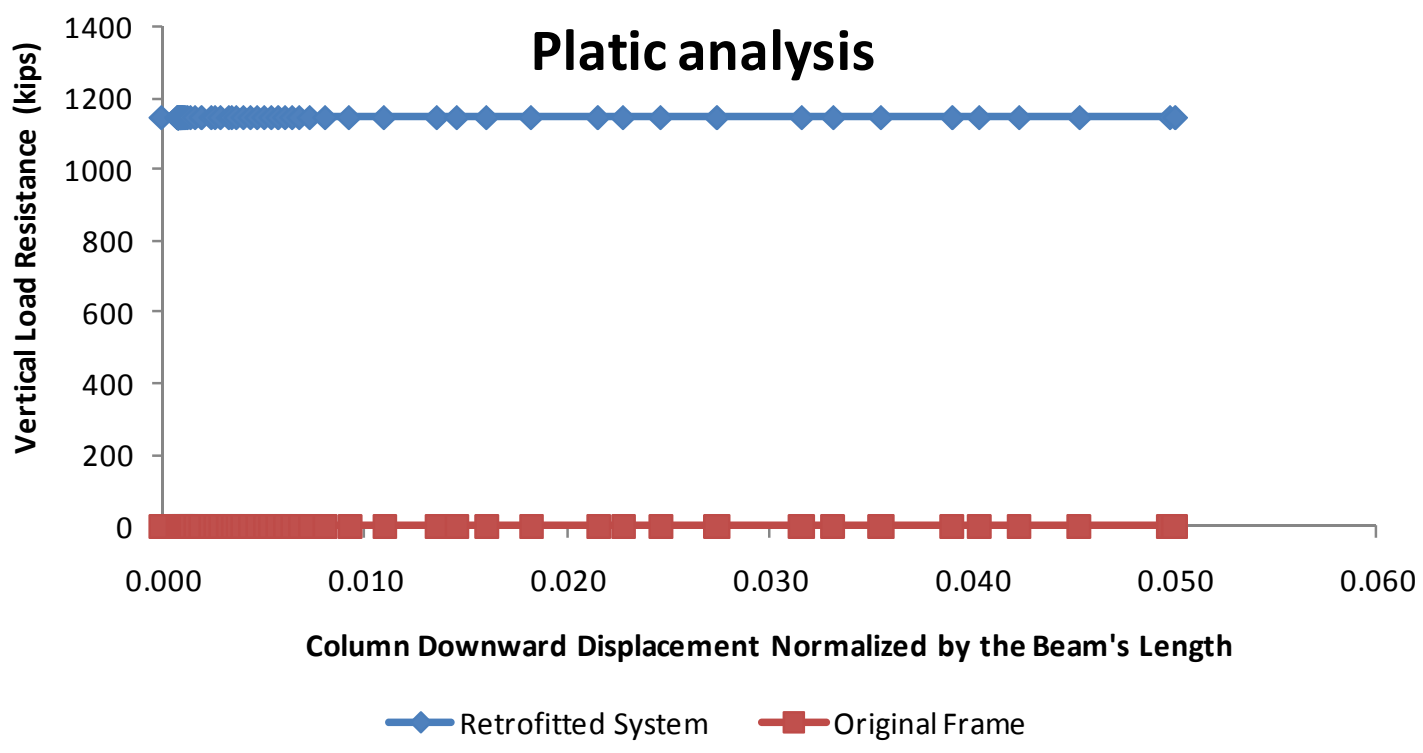

Figure 5-45: Vertical load resistance of the retrofitted system and the original frame under Boundary Condition \#5 (Results from Plastic Analysis)

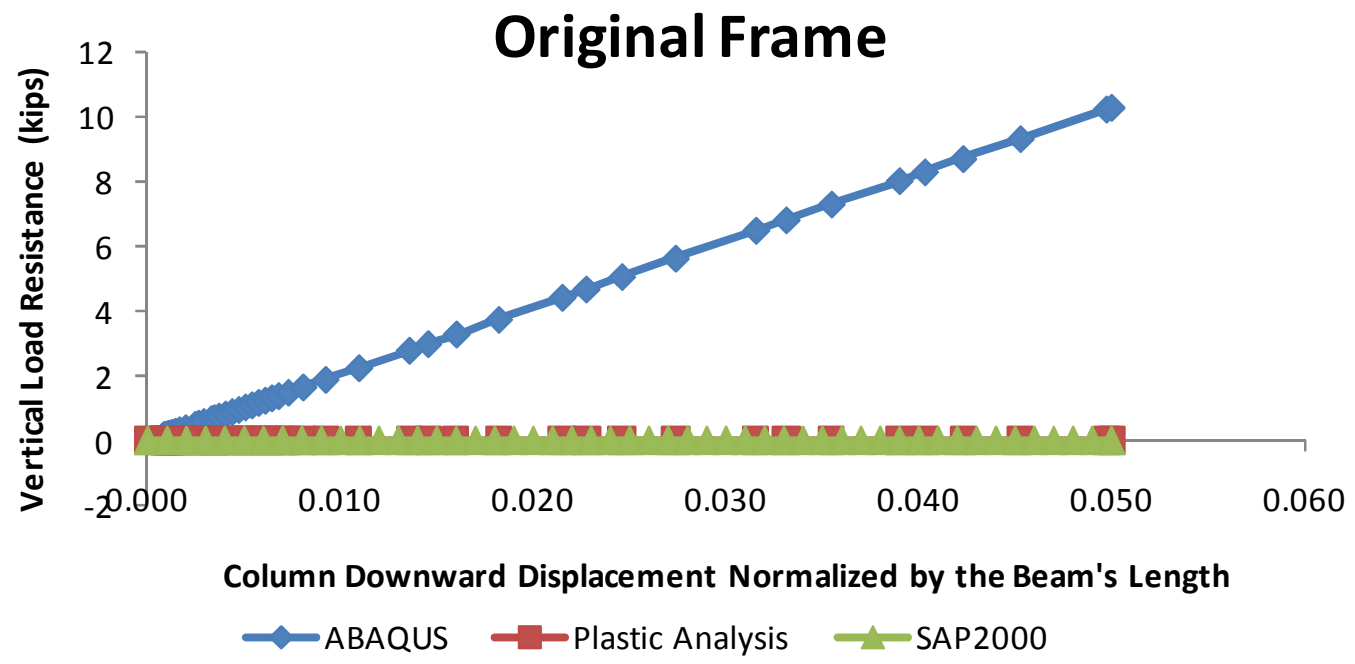

Figure 5-46: Comparison of vertical load resistance of the original frame under Boundary Condition \#5 


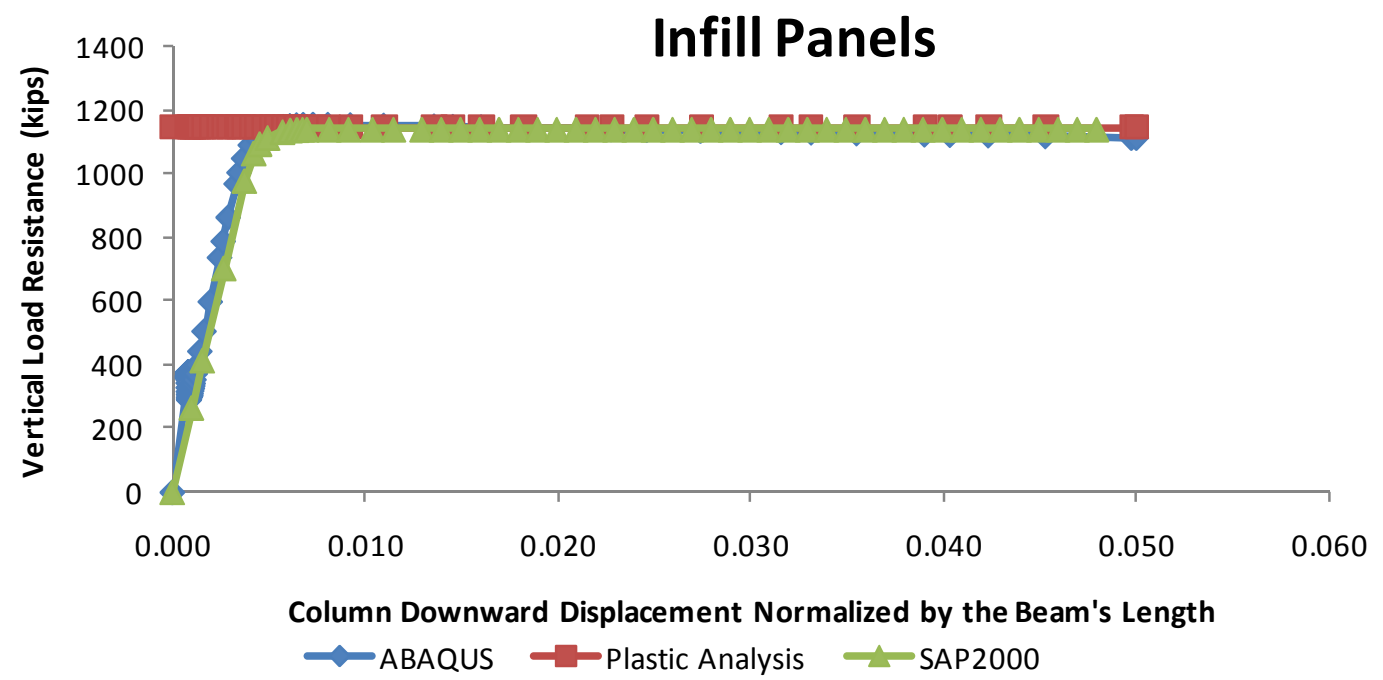

Figure 5-47: Comparison of vertical load resistance of the infill panels alone under Boundary Condition \#5

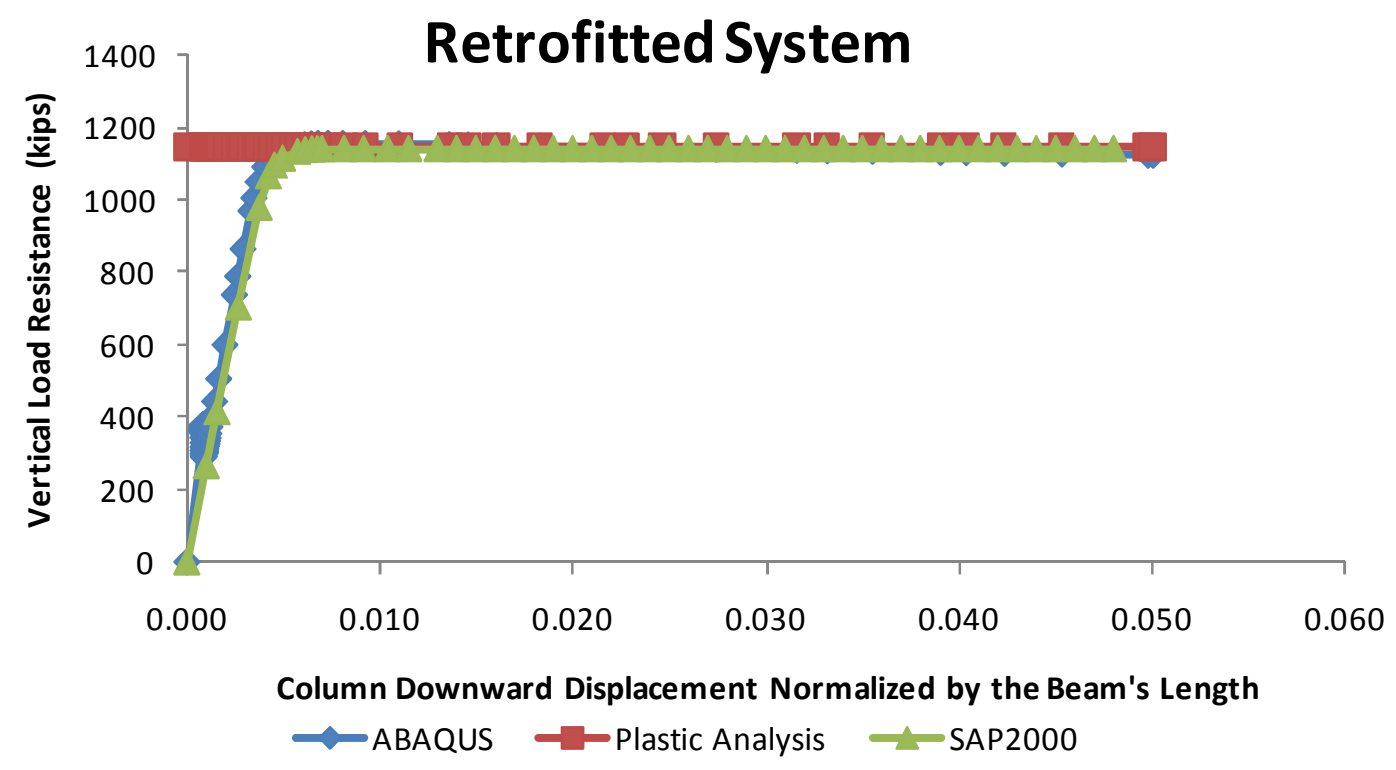

Figure 5-48: Comparison of vertical load resistance of the retrofitted system under Boundary Condition \#5 


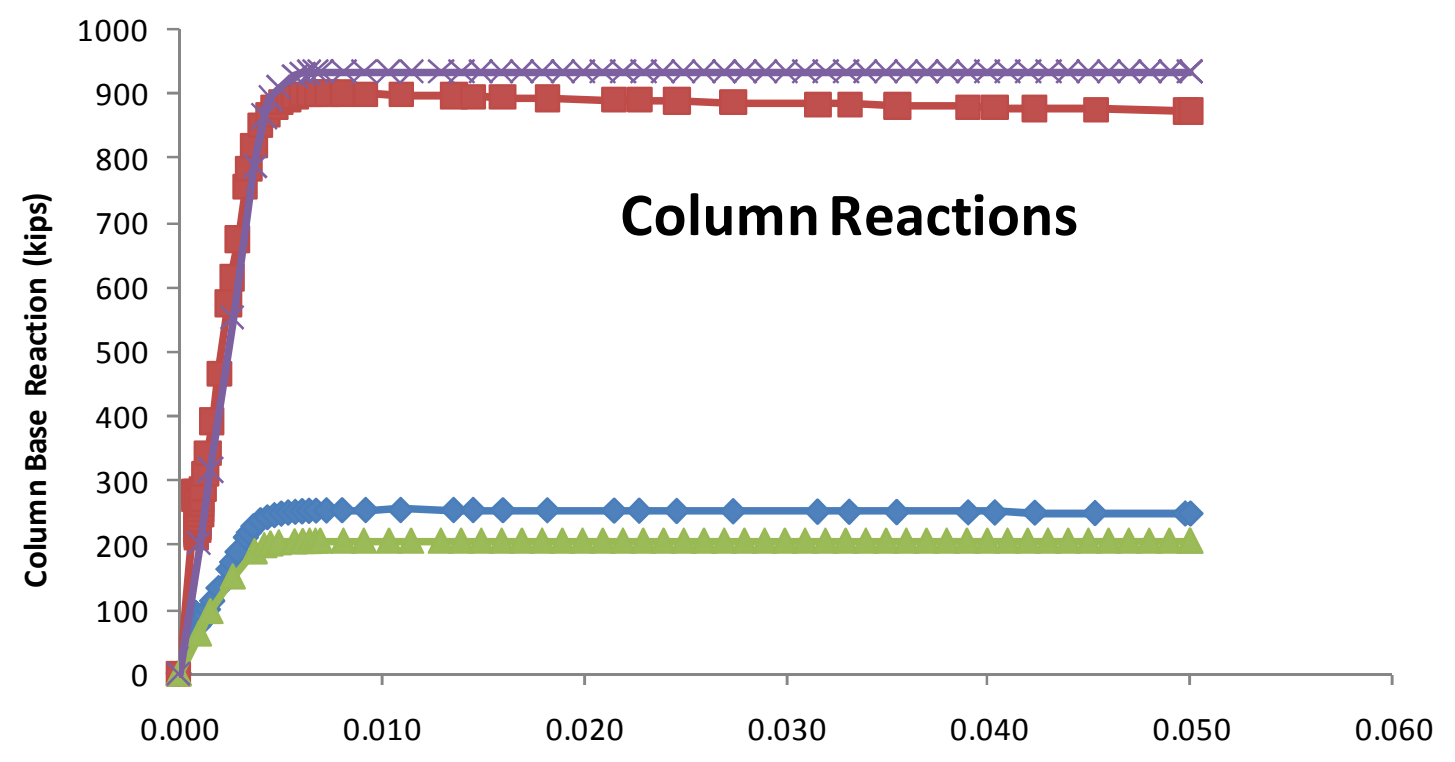

Column Downward Displacement Normalized by the Beam's Length

$\sim$ Plate+Frame Exterior Column Abaqus Plate+Frame Middle Column Abaqus

$\leftarrow$ Plate+Frame Exterior Column SAP2000 $\longleftarrow$ Plate+Frame Middle Column SAP2000

Figure 5-49: Column base reactions of the retrofitted system under Boundary Condition \#5

\subsection{Summary}

The chapter compares the progressive collapse resistance of the retrofitted system and the original system based on the three analytical models developed in Chapters 3 and 4 . A total of five boundary conditions were investigated. Through all the consider cases, it was consistently observed that the system strength can be significantly enhanced with the use of infill steel panels in the steel building structural frame. Moreover, it was found that all the three analytical models including the plastic analysis model and two FE models provide similar results, indicating the adequacy of these models. 


\section{PSEUDO-STATIC RESPONSE OF THE PROPOSED SYSTEM}

\subsection{Introduction}

As mentioned previously, the FE models presented in this thesis assume the threat of a single column failure and these models were investigated using the nonlinear static analysis procedure. As such, the nonlinear dynamic effects which may exist in the system were not considered in the analysis. When a sudden column failure occurs, building structures may exhibit highly nonlinear dynamic response due to the gravitational acceleration. While conducting the nonlinear dynamic analysis on the developed FE models is likely to provide a more accurate estimate of the system performance, it is overly complicated and may not be convenient for practical applications. Alternatively, UFC allows using a so-called dynamic increase factor (DIF) to modify the structural resistance obtained from static analyses to get the dynamic response. According to the UFC document (DoD 2009), a constant DIF of 2 should be used for modifying the results from linear elastic analysis. The DoD provide a more complex equation to determine the DIF for responses acquired using nonlinear static analysis. It was determined that most steel frames should considered a DIF value of 1.3 and 1.5 (Marchand \& Alfawakhiri, 2004). Given that the dynamic effects of the proposed system may be different from conventional systems, the DIF values recommended by the UFC may not be proper for modifying the performance of the

proposed system. As such, this chapter evaluates the DIF values for the proposed system based on an approach developed by Izzuddin et al. (2007). 
Izzuddin et al. (2007) simulates the sudden column loss as a sudden application of the gravity load on the affected frame. During the initial stage of the column loss, the gravity load exceeds the static structural resistance. Then, the structure starts displacing causing the differential work done over the incremental deformations to transform into additional kinetic energy, leading to increasing velocities (Izzuddin 2004). At greater deformations, the static resistance provided by the system exceeds the gravity loading above the missing column and the energy absorbed by the system reduces the kinetic energy in the system resulting in decreasing velocities. Assuming removal of a single column the maximum dynamic response occurs when the kinetic energy is reduce to zero which occurs essentially when the energy absorbed by the system is identical to the work done by the gravity load (Izzuddin 2004).

Equation (6-1) provides the energy under the nonlinear static response curve. This energy is equated to the differential work from equation (6-2) to find the corresponding sudden applied gravity loading. A graphical representation of the maximum nonlinear dynamic response can be obtained by plotting the gravity loading determined from equation (6-4) against the corresponding displacement. Since such a curve is assembled from a nonlinear static response, it is referred to as the pseudo-static response (Izzuddin et al. 2007).

$$
U_{n}=\int_{0}^{u_{d, n}} \alpha \cdot P \cdot d U_{s}
$$

where, $U_{n}=$ kinetic energy

$P=$ nonlinear static loading

$d U_{s}=$ deferential displacement of the nonlinear static response 
$\alpha=$ constant

$$
W_{n}=\alpha \cdot \lambda_{n} \cdot P_{0} \cdot u_{d, n}
$$

where, $W_{n}=$ differential work over a finite displacement of $u_{d, n}$

$P_{0}=$ nonlinear dynamic load

$\lambda_{n}=$ dynamic load amplification factor (DLAF) which is identical to the DIF defined by UFC.

$u_{d, n}=$ dynamic displacement

$$
\begin{gathered}
W_{n}=U_{n} \\
P_{n}=\lambda_{n} \cdot P=\frac{1}{u_{d, n}} \int_{0}^{u_{d, n}} P \cdot d U_{s}
\end{gathered}
$$

An algorithm based on the abovementioned equations is presented in Appendix A and was used to determine the pseudo-static response of the proposed system with the use of the nonlinear static results obtained from the ABAQUS models presented in Chapter 4. All the five boundary conditions presented in Figure 5-1 were considered and the results are presented in the next section.

\subsection{Observations and Summary}

As shown in Figure 6-1, Figure 6-3, Figure 6-5, Figure 6-7, and Figure 6-9, when compared with the nonlinear static responses, the pseudo-static responses reach a higher displacement level for the same vertical loads due to the dynamic effects. These same figures also include demand using the constant DFA of 1.3 and 1.5. It is noted, that the 
demand using those constant values are more conservative than the pseudo-static approach.

In practice, with the actual gravity load, the maximum dynamic displacement demand on the system can be identified from the pseudo-static response curves. Alternatively, with the deformation capacity (i.e. ductility) of the system, the maximum gravity load which the system can resist without experiencing progressive collapse failures can also be identified from the pseudo-static response curves. Incidentally, ductility of the beam-tocolumn connections is an important factor that should be considered to ensure the desirable system performance. When the maximum dynamic displacement exceeds the deformation capacity, premature failures may occur in the system. The impact of these failures on the system performance will be discussed in Chapter 8 .

The dynamic load amplification factors are presented in Figure 6-2, Figure 6-4, Figure 6-6, Figure 6-8, and Figure 6-10 for Boundary Condition \# 1 through 5 shown in Figure $5-1$, respectively. Note that the DLAF values can be calculated by simply dividing the nonlinear static response by the pseudo-static response at the same displacement level. It is also noted that the DLAF is not constant at the different levels of column downward displacement, indicating that dynamic amplification effects depend on the level of nonlinearity and applying a constant value for DLAF may not be proper for capturing the actual system performance. 


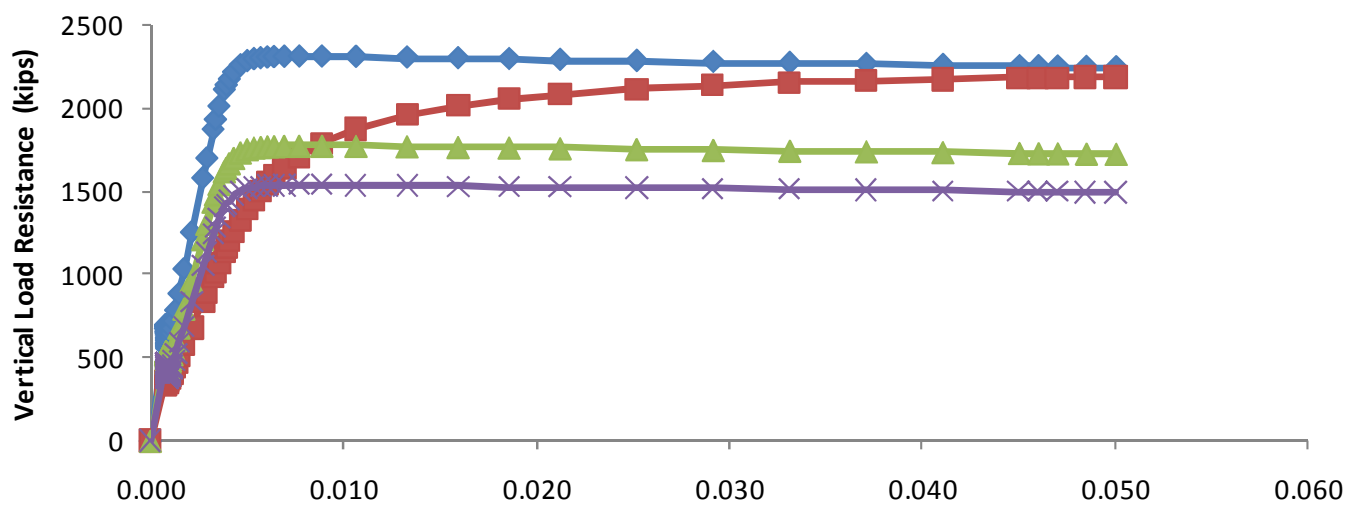

Column Downward Displacement Normalized by the Beam's Length $\sim$ Nonlinear Static Response $\quad-$ Pseudo-static Response $\quad \longrightarrow$ DIF $=1.3 \quad \longleftarrow$ DIF $=1.5$

Figure 6-1: Modified performance for the system under Boundary Condition \#1

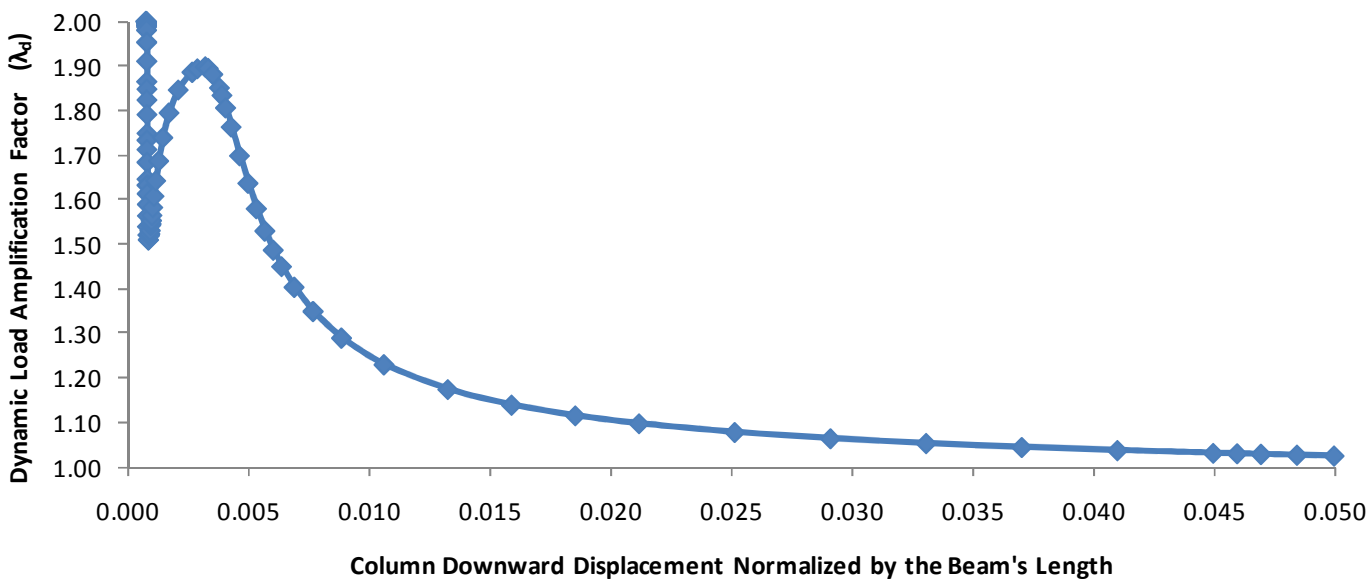

Figure 6-2: Dynamic load amplification factor for the system under Boundary Condition \#1 


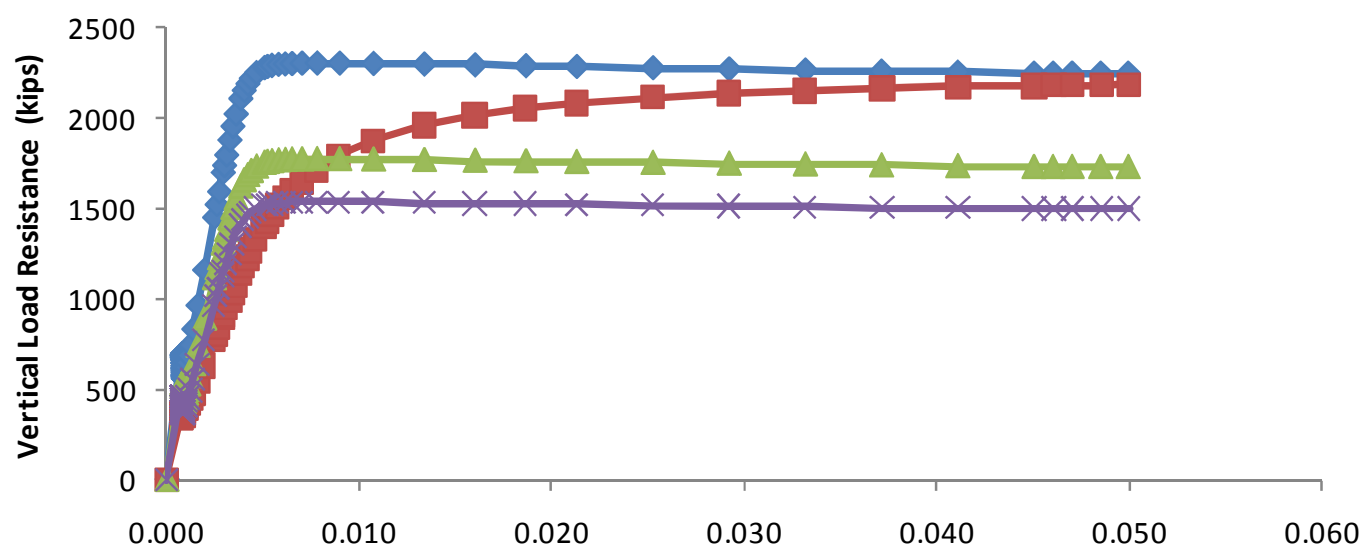

Column Downward Displacement Normalized by the Beam's Length

$\longrightarrow$ Nonlinear Static Response $\quad \longrightarrow$ Pseudo-static Response $\quad \leftarrow$ DIF $=1.3 \leftarrow$ DIF $=1.5$

Figure 6-3: Modified performance for the system under Boundary Condition \#2

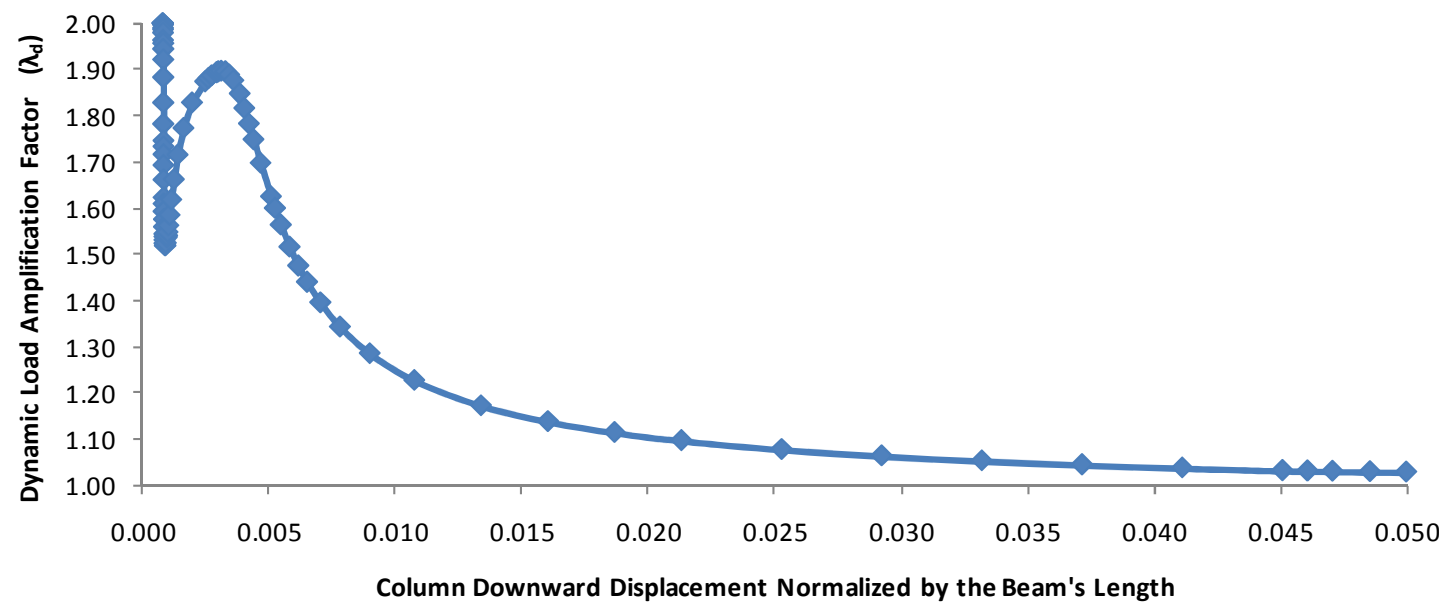

Figure 6-4: Dynamic load amplification factor for the system under Boundary Condition \#2 


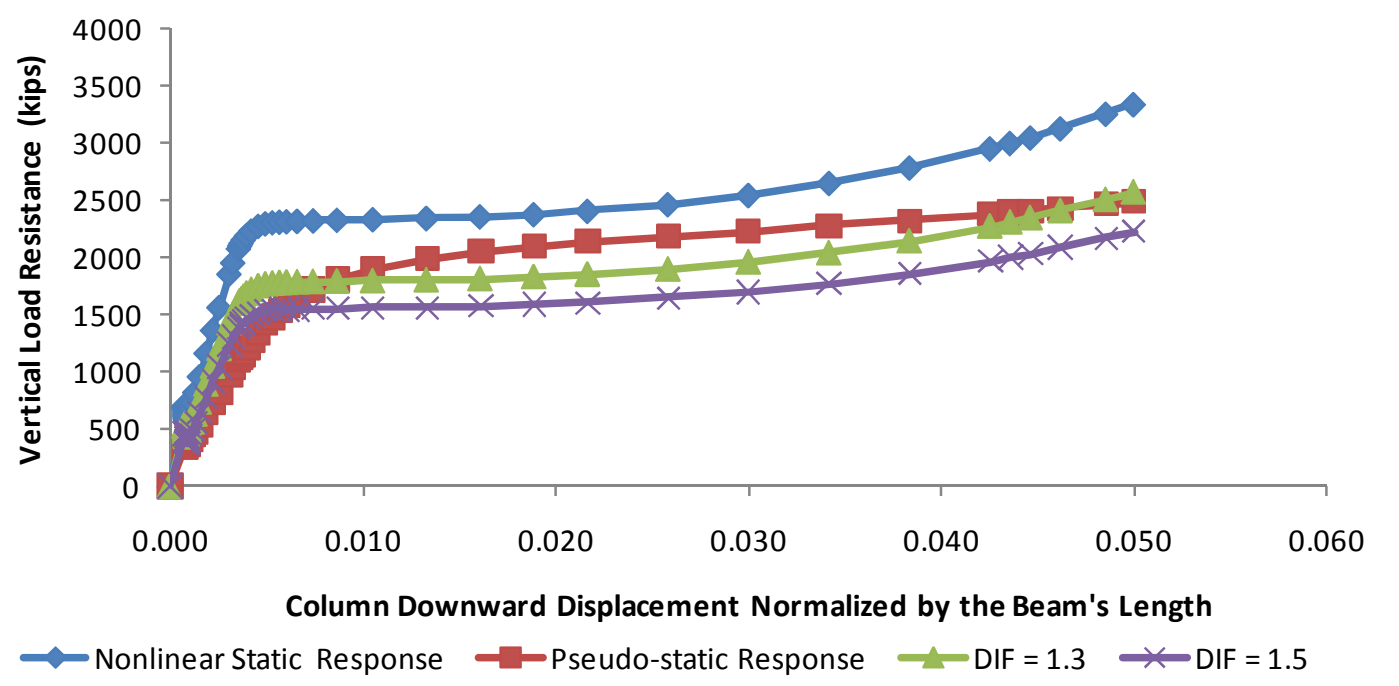

Figure 6-5: Modified performance for the system under Boundary Condition \#3

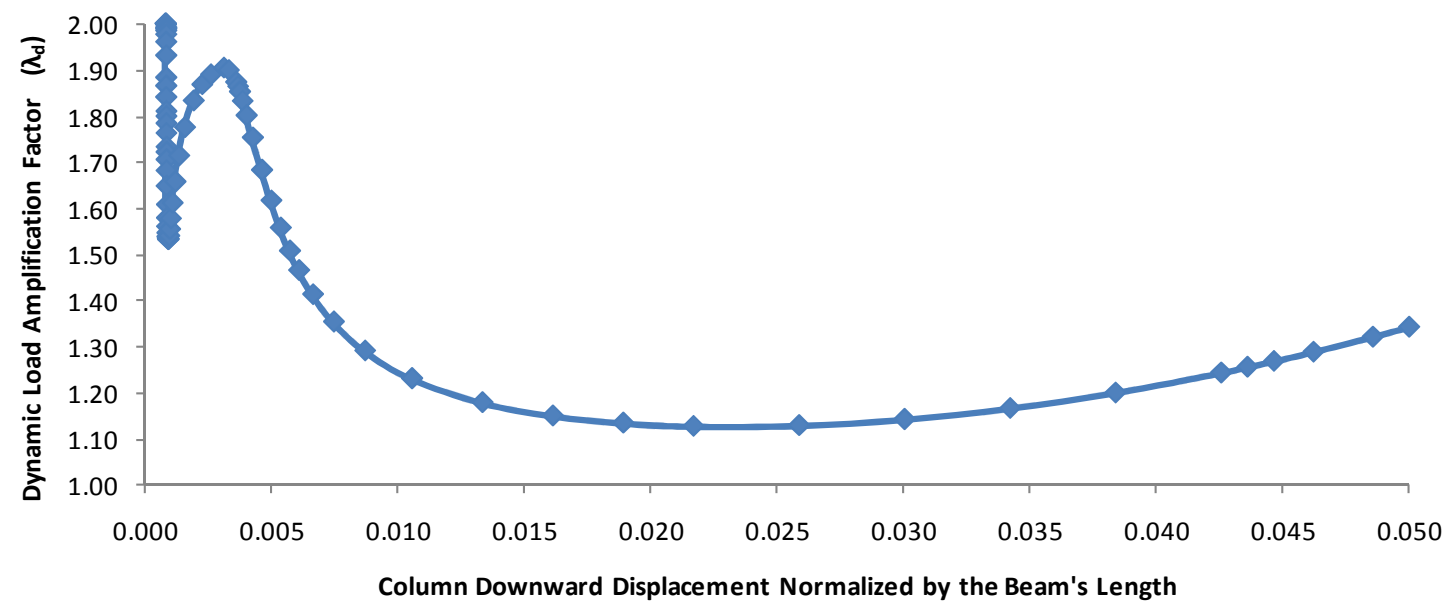

Figure 6-6: Dynamic load amplification factor for the system under Boundary Condition \#3 


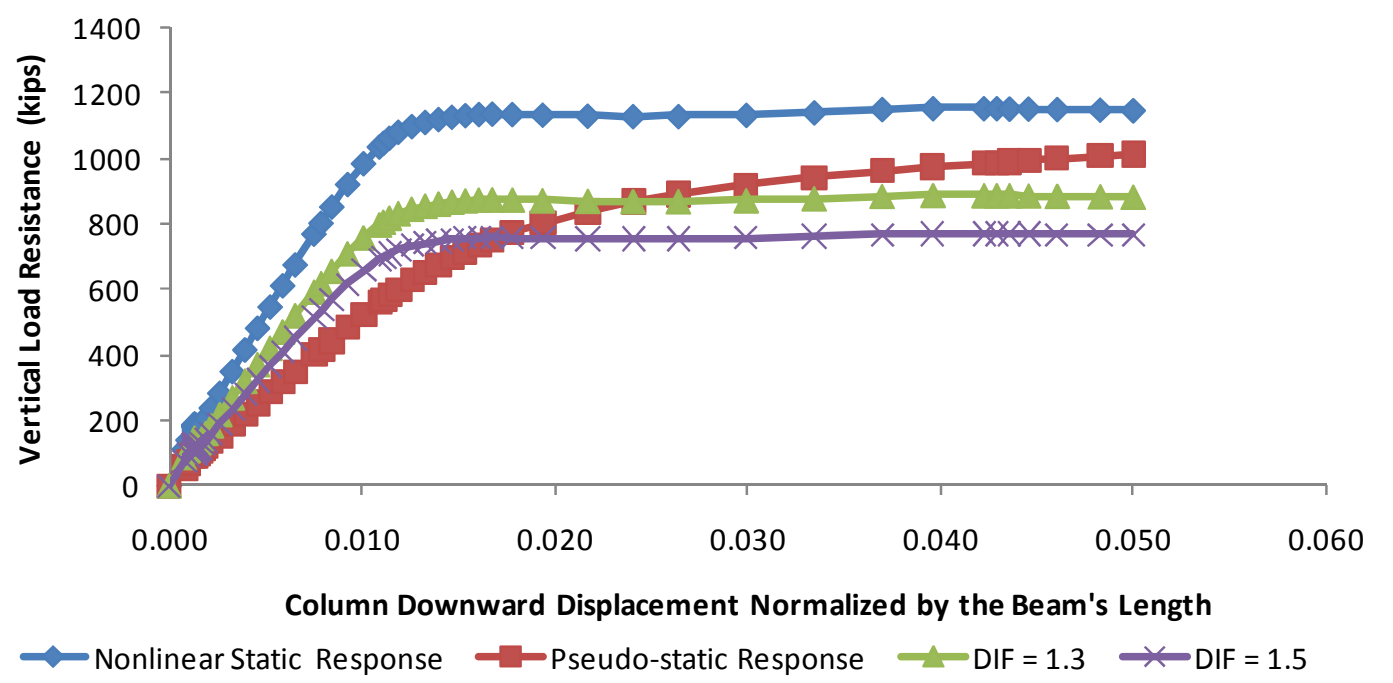

Figure 6-7: Modified performance for the system under Boundary Condition \#4

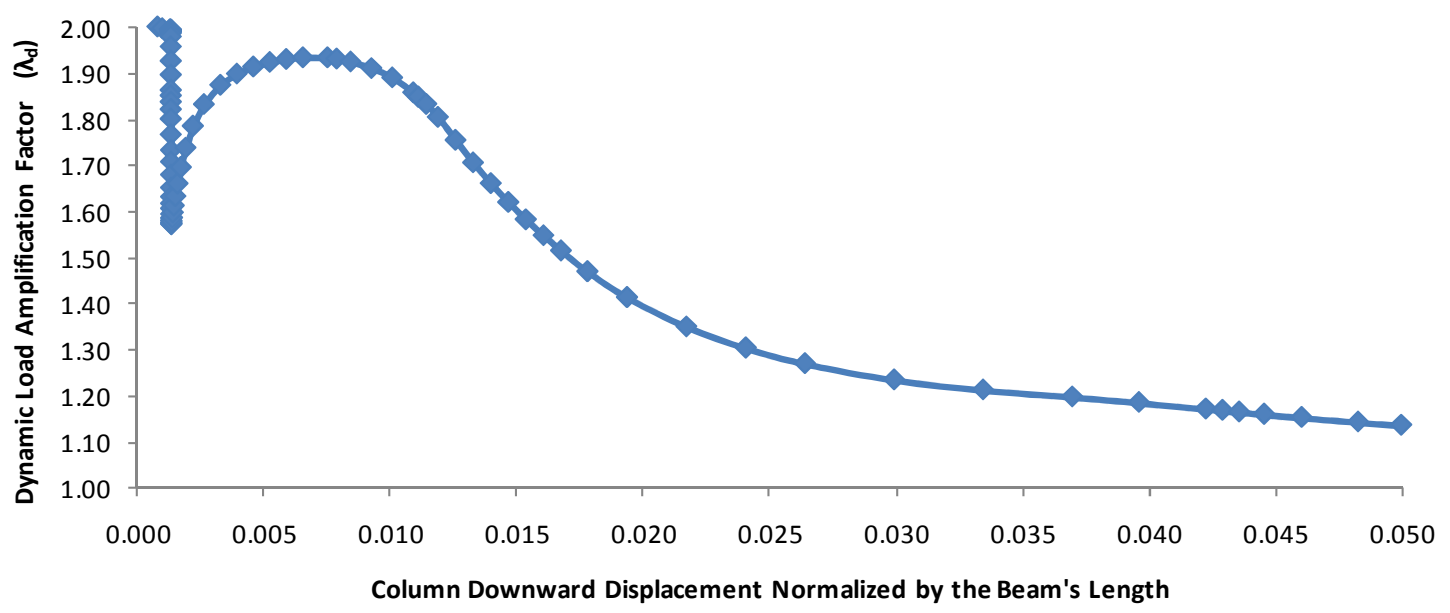

Figure 6-8: Dynamic load amplification factor for the system under Boundary Condition \#4 


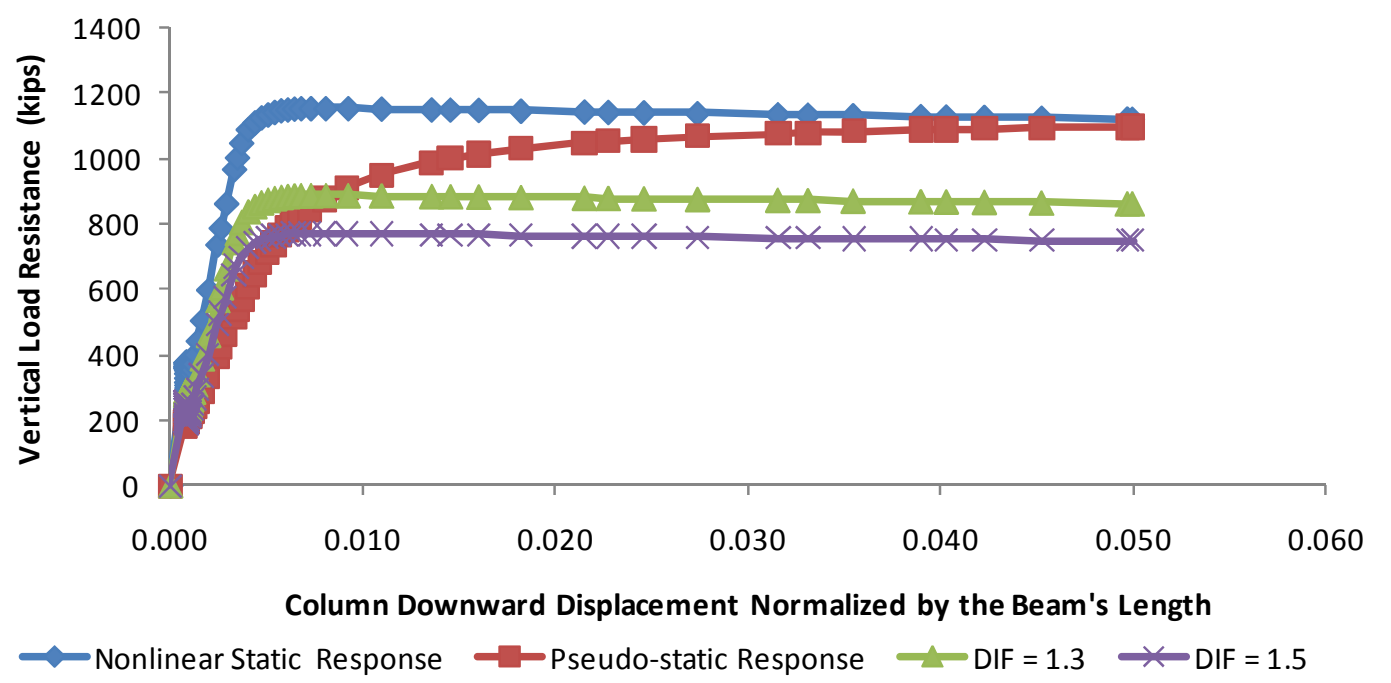

Figure 6-9: Modified performance for the system under Boundary Condition \#5

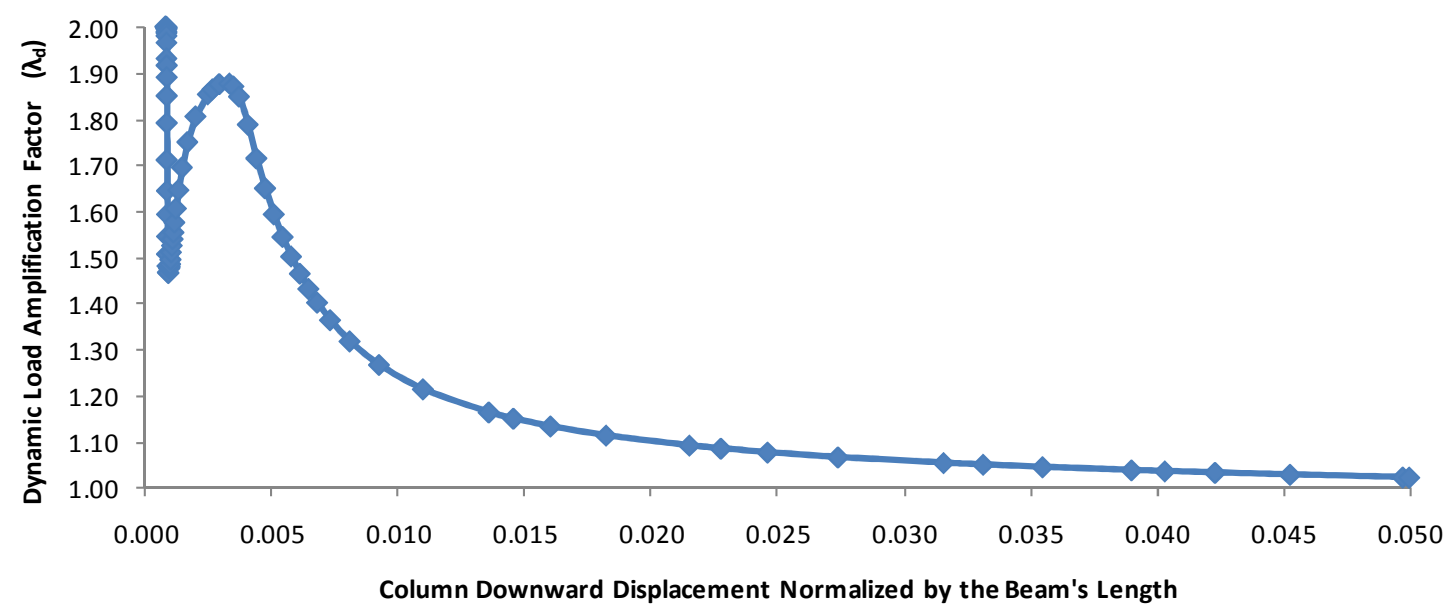

Figure 6-10: Dynamic load amplification factor for the system under Boundary Condition \#5 


\section{DEMANDS ON BOUNDARY FRAME MEMBERS}

\subsection{Introduction}

Consideration of the demands imposed on the beams and columns by the infill panel tension field actions (also known as: diagonal tension field action, plate tension field action, field action, plate yielding forces, etc.) is essential to prevent the premature boundary frame failure and hence to ensure the desirable performance of the proposed system. The demands on the beams and columns of SPSWs under seismic load have been investigated by Berman and Bruneau (2008) and Qu and Bruneau (2010). The procedure developed by Berman and Bruneau (2008) to estimate the demands on the columns consists of determination of the fundamental plastic collapse mechanism and linear beam analysis. Their method will be used to formulate a simplified procedure for estimating the demands on the boundary frame elements in the proposed system. Simple FBDs for the beams and columns with infill panel tension field actions will be presented. Based on these FBDs the demands on frame members are quantified using only linear static analysis. For the boundary conditions illustrated in Figure 5-1, the demands on frame members obtained from the developed simplified procedure will be compared to those from the nonlinear static analysis using the strip model. A downward displacement equal to $2.5 \%$ of the bay width of the frame was assumed along the damaged column in all analysis cases. Incidentally, detailed descriptions about the strip models were presented in Chapter 4. 


\subsection{Tension Field Action along Frame Members}

As shown in Figure 7-1, the strip model simplifies the infill panels as diagonal tension strips. Once the collapse mechanism due to the removal of interior column develops in the system, uniform tension fields will form in the structural frame, resulting in the distributed loads acting along the frame members. It is noted that for the case of removal of an exterior column, similar behavior is expected.

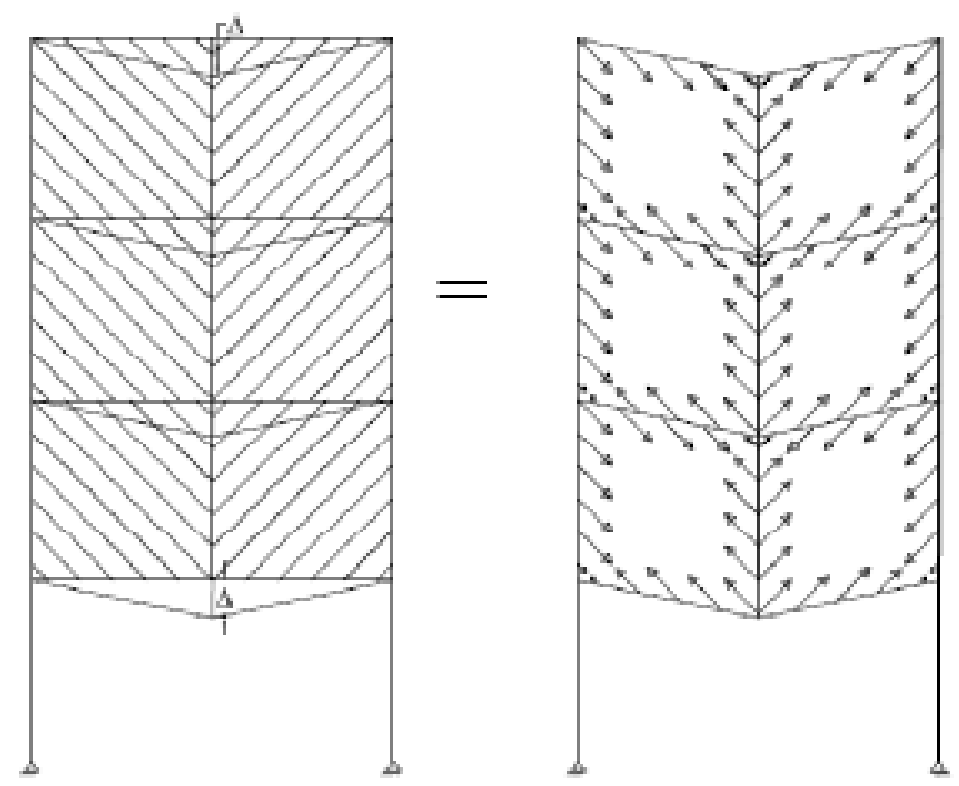

Figure 7-1: Tension field actions in a structural Frame

As shown in Figure 7-2, the diagonal tension field actions along columns can be decomposed into two components: the horizontal and vertical components, i.e. $\omega_{c x}$ and $\omega_{c y}$, respectively. Similarly, as shown in Figure7-2b, the tension field actions along beams can be categorized as $\omega_{b x}$ and $\omega_{b y}$. Following the classic procedure of static analysis, Berman and Bruneau (2008) derived the following equations for calculating the tension field actions along the structural frame. 


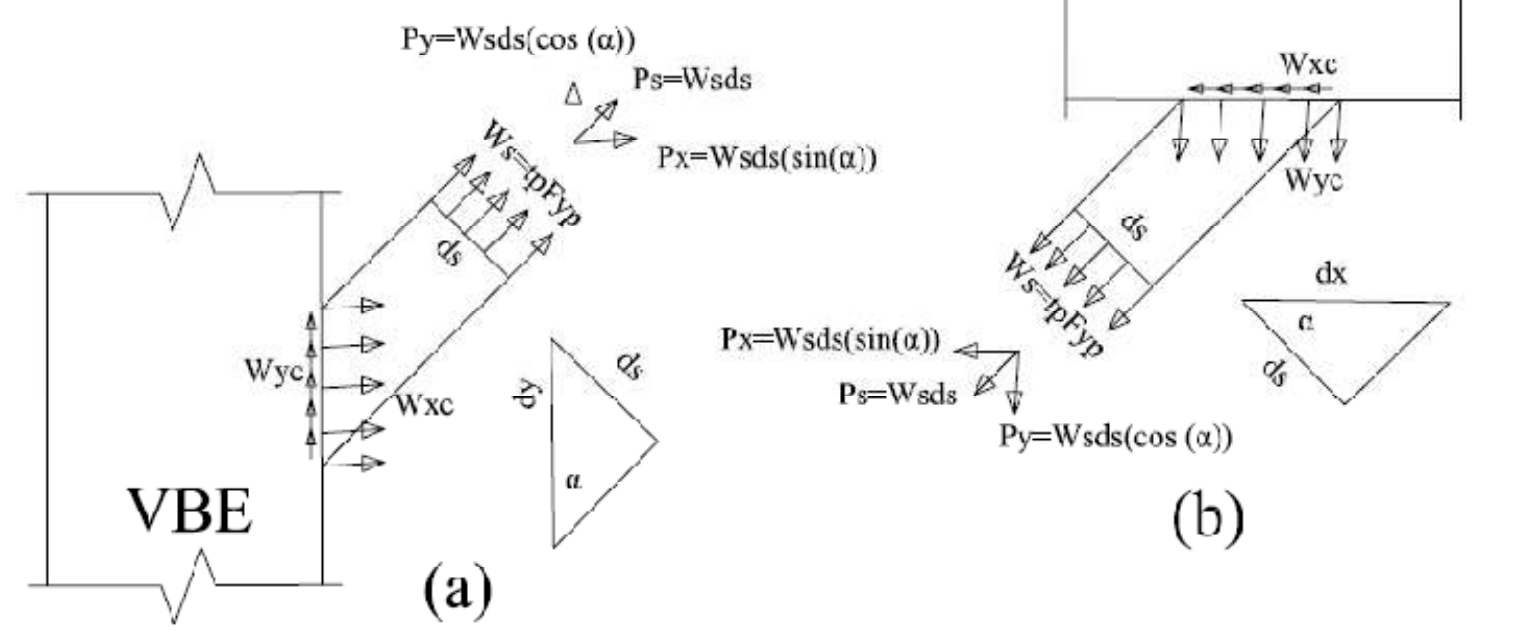

Figure 7-2: Tension Field actions along columns and beams

$$
\begin{gathered}
\omega_{c y}=\frac{1}{2} t_{p} F_{y p} \sin (2 \alpha) \\
\omega_{c x}=t_{p} F_{y p}(\sin (\alpha))^{2} \\
\omega_{b x}=\frac{1}{2} t_{p} F_{y p} \sin (2 \alpha) \\
\omega_{b y}=t_{p} F_{y p}(\cos (\alpha))^{2}
\end{gathered}
$$

where, $t_{p}=$ plate thickness

$$
\begin{aligned}
& F_{y p}=\text { plate yield strength } \\
& \omega_{c y}=\text { vertical distributed loads on column from tension field actions } \\
& \omega_{c x}=\text { horizontal distributed loads on column from tension field actions } \\
& \omega_{b x}=\text { horizontal distributed loads on beam from tension field actions } \\
& \omega_{b y}=\text { vertical distributed load on beam from tension field actions }
\end{aligned}
$$


As suggested by equations (7-1) to (7-4) the distributed loads on each boundary frame member depends on the thickness of the infill panel at each floor level. The required thickness of the infill panels at different floor levels can be determine strategically based on the vertical load resisted by the notional removed column. For simplicity, the system presented on this thesis contains a uniform plate thickness along the different floor levels.

\subsection{Demand on Beams}

The demands on beams depend on the boundary conditions of the retrofitted system. When sidesway is inhibited on both sides of the frame, the beam is subjected to: 1) catenary action force and 2) vertical and horizontal components of the infill panel tension field actions above and below the beam. When sidesway is uninhibited on one side or both sides of the frame, the beam is subjected to 1) axial compression force resulted from the horizontal component of the infill panel tension field actions acting on the columns, and 2) vertical and horizontal components of the infill panel tension field actions above and below the beam. 


\subsubsection{General FBDs of Beams}

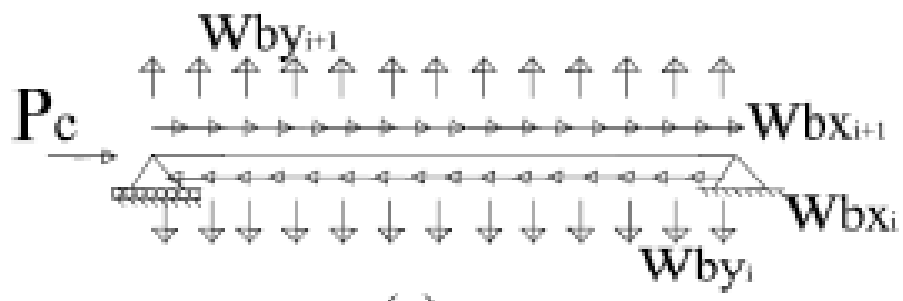

(a)

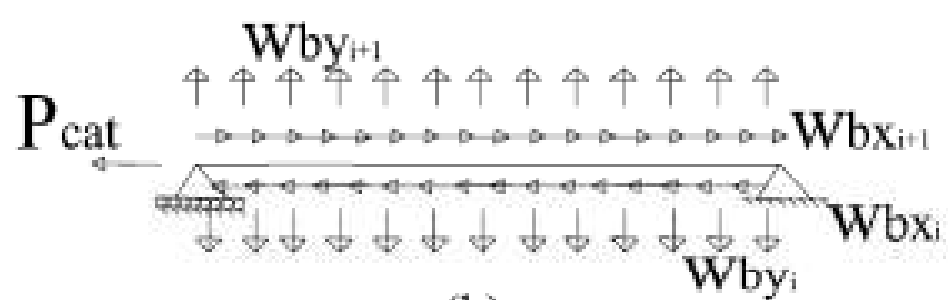

(b)

Figure 7-3: General FBDs of beams (a) Sidesway uninhibited (b) Sidesway inhibited

Figure 7-3 shows the FBDs for the beams under sidesway uninhibited and sidesway inhibited boundary conditions, respectively. The simplified procedure will use these FBDs to determine the demands on the beams. In the case when sidesway is uninhibited, compression load, $\boldsymbol{P c}$, will develop at the end of the beam due to the horizontal component of the infill panel tension field actions along the columns (Berman and Bruneau 2008). Considering the column length tributary to each beam, the axial compressive force on the beam becomes:

$$
P c=\omega_{c x i} \frac{h_{i}}{2}+\omega_{c x i+1} \frac{h_{i+1}}{2}
$$

Where, $h_{i}=$ story height below the beam

$h_{i+1}=$ story height above the beam

$\omega_{c x i}$ and $\omega_{c x i+1}=$ horizontal components of the tension field actions along columns in the $\mathrm{i}^{\text {th }}$ and $\mathrm{i}+1^{\text {th }}$ story respectively. 
Physically, the infill panel tension field actions pull the columns towards each other, and the beams act as "shoring" to keep the columns apart. It is recognized that, when sidesway is inhibited, the abovementioned compression force will not develop at the end of the beams since the horizontal components of the infill panel forces will be transferred to the horizontal restraints which prevent sidesway of the structure. In addition, due to the presence of the horizontal restraints, the beams develop catenary action which is denoted as Pcat in Figure 7-3b and can be calculated using equation (3-45). Note that the catenary action only develops when sidesway is inhibited on both sides as explained in Chapter 3. For both considered boundary conditions, i.e., the sideway uninhibited and inhibited cases, roller supports and the axial forces determined respectively from equations (7-5) and (3-45) are applied at the left ends of the beams, and pin supports were assigned at the right ends. It should be noted that such boundary conditions assumed in the FBDs are not adequate for deformation calculation however they are able to capture the actual internal force distribution in the beams as shown in the following sections.

In addition to the axial forces acting at the ends, beams are subjected to the horizontal and vertical components of the infill panel tension field actions above and below, i.e., $\omega_{b x_{i}}, \omega_{b x_{i+1}}, \omega_{b y_{i}}$, and $\omega_{b y_{i+1}}$ as shown in Figure 7-3. While Figure 7-3 shows the general FBDs for intermediate beams, these FBDs can also be used to determine the demands on anchor beams (i.e. those having infill panels only on one side) by setting the infill panel tension field actions on one side equal to zero. Moreover, when the tension field actions above and below are identical, i.e., when the infill plates above and below an 
intermediate beam have the same strength and thickness, the resultant infill panel forces are equal to zero.

\subsubsection{Results from Different Boundary Conditions}

In order to validate the beam FBDs presented in Section 7.3.1, the demands on beams including axial force, shear force and bending moment are compared to those obtained from the nonlinear static push down analysis using the 2D FE model, i.e., the strip model (see Chapter 5 for details). Described below are the detailed result comparisons for both anchor beams and intermediate beams. Note that the demands on the beams on both sides of the middle column are mirror images under the symmetric boundary conditions (i.e. Boundary Conditions \#1, and \#3 presented in Figure 5-1). Therefore, only results for the left-side beams were presented for such cases. In addition, since identical plates are assumed in every floor level, the intermediate beams are expected to have the same demands distribution. As such, only one intermediate will be studied. When plates having different thicknesses are installed in the frame, the demands in intermediate beams can be similarly obtained using the FBD shown in Figure 7-3.

\subsubsection{Boundary Condition \#1}

Boundary condition \#1 corresponds to the frame in which sidesway is uninhibited on both sides of the frame and the interior column is removed. Under this boundary condition, no catenary action will develop in the beams and therefore the FBD from Figure 7-3 (a) is used. 


\subsection{Anchor Beams}

Figure 7-4 and Figure 7-5 show the demands on the top and bottom anchor beams respectively. It is evident that the nonlinear static analysis and the simplified procedure give similar results. While results are only provided for the anchor beams in the left bay, similar results can be obtained for the anchor beams in the right bay due to the symmetric loading, geometry, and boundary conditions. As shown, the top anchor beam experiences only compressive axial force. However, the bottom anchor beam experiences both compressive and tensile axial forces. For the shear and bending moments, the top and bottom anchor beams have similar distributions. 

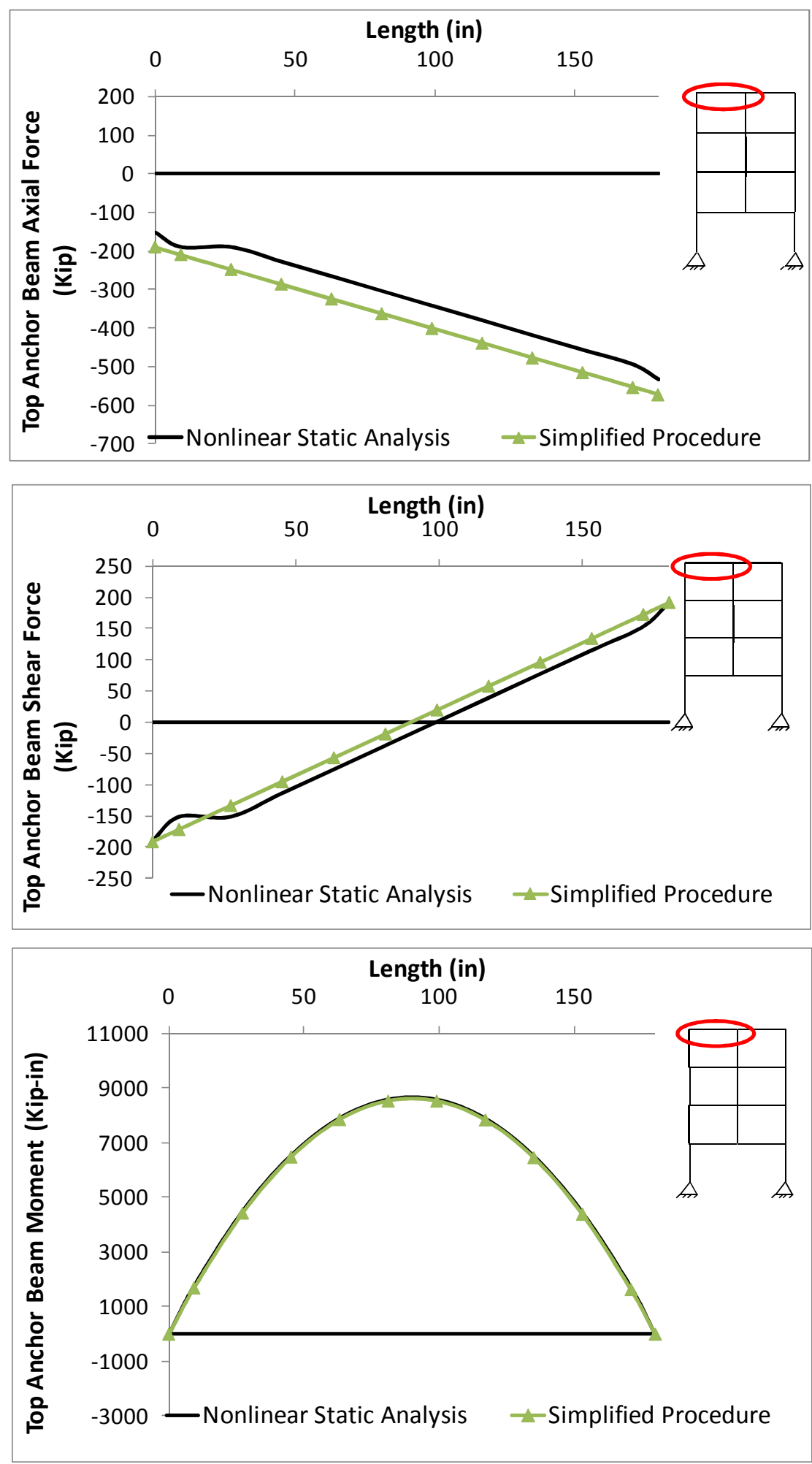

Figure 7-4: Axial, shear, and moment diagrams for the top anchor beam under Boundary Condition \#1 

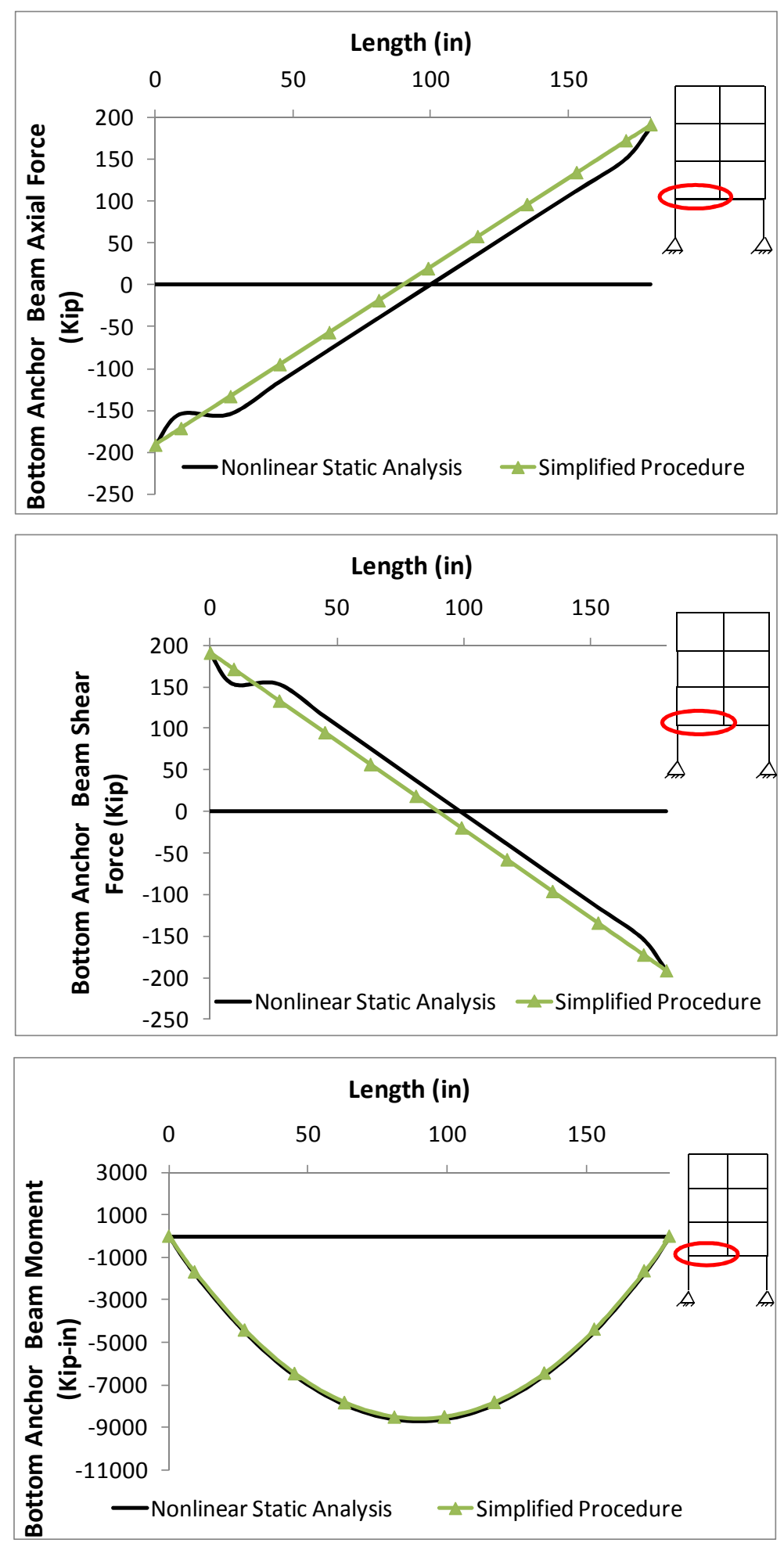

Figure 7-5: Axial, shear, and moment diagrams for the bottom anchor beam under Boundary Condition \#1 


\subsection{Intermediate Beams}

The axial, shear and bending moment diagrams for the intermediate beam are presented Figure 7-6. As shown, the axial demands on the intermediate beam can be accurately captured by the simplified procedure. Note that according to the simplified procedure the shear and bending moment diagrams should be zero because the infill plates above and below the intermediate beam have the same strength and thickness, resulting in identical infill plate tension field actions and thus zero resultant forces on the intermediate beam. The observed difference in shear and bending moment demands were caused by the numerical errors from the nonlinear static analysis. Compared with the order of the internal axial forces $\left(10^{2} \mathrm{kips}\right)$, the observed numerical errors are negligible. It is also recognized that the axial force at the left end of the intermediate beam is twice as much as those at the same ends of the anchor beams because the column length tributary to the intermediate beam is twice that of the anchor beams. 

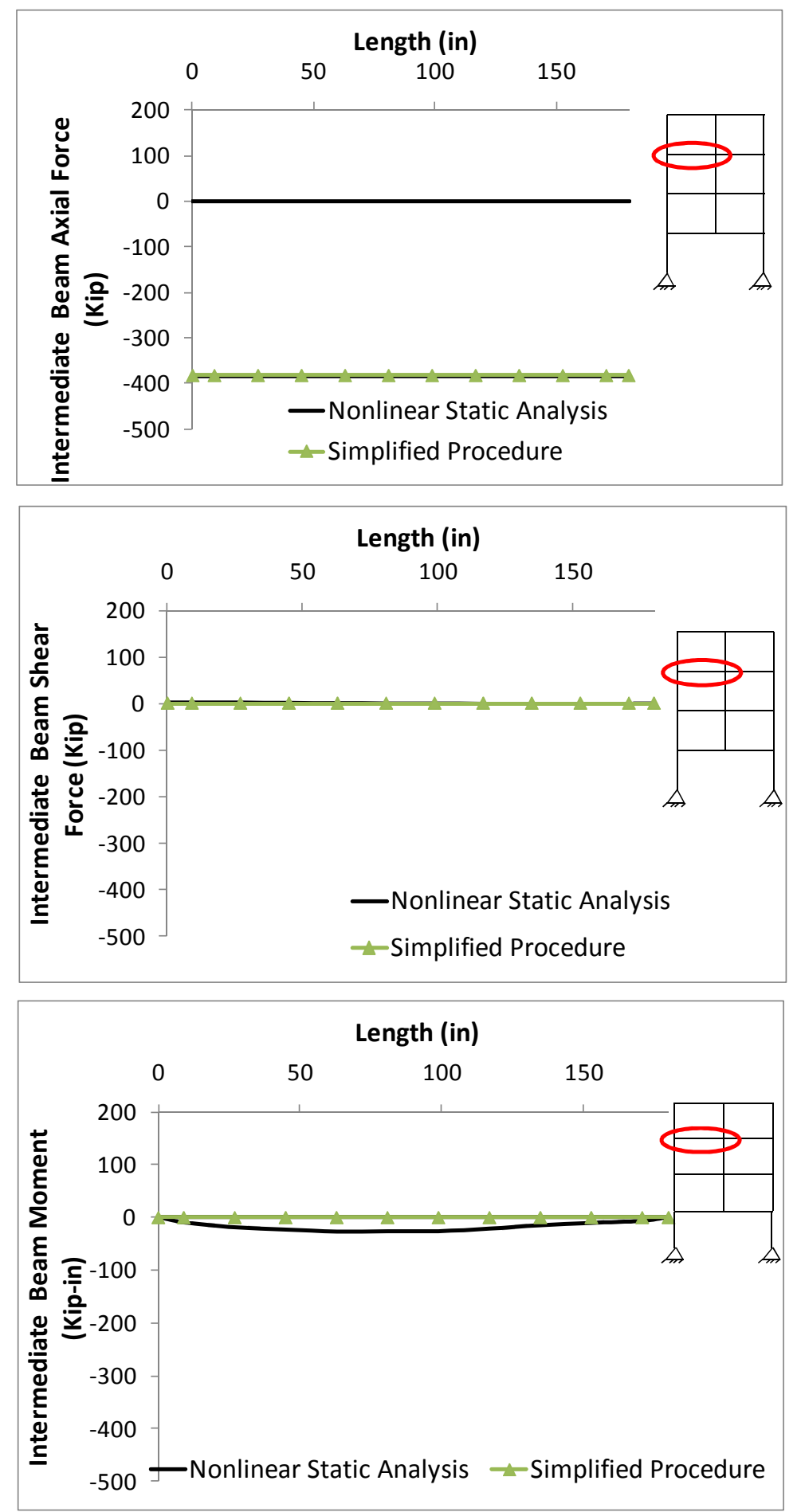

Figure 7-6: Axial, shear, and moment diagrams for the intermediate beam under Boundary Condition \#1 


\subsubsection{Boundary Condition \#2}

Under Boundary Condition \#2, the interior column is removed and sidesway is only inhibited on the left side of the frame. As a result, the catenary action will not develop in the beams due to the absence of the anchorage on the right side of the frame. Therefore, the FBD presented in Figure 7-3(a) is used in the simplified procedure. It is expected that the beam demands under Boundary Condition 2 will be identical to the corresponding results under Boundary Condition \#1. This point is further confirmed by the results presented in Sections 7.3.2.2.1 and 7.3.2.2.2.

\subsection{Anchor Beams}

Figure 7-7 and Figure 7-8, illustrate the axial, shear and bending moment diagrams for the top and bottom anchor beams. As shown, the results predicted from the proposed FBDs agree well with those obtained from the nonlinear static analysis. In addition, the demand distributions along the anchor beams under Boundary Condition \#2 is the same as those under Boundary condition \#1 (see Figure 7-4 ,Figure 7-5, Figure 7-7 and Figure 7-8). 

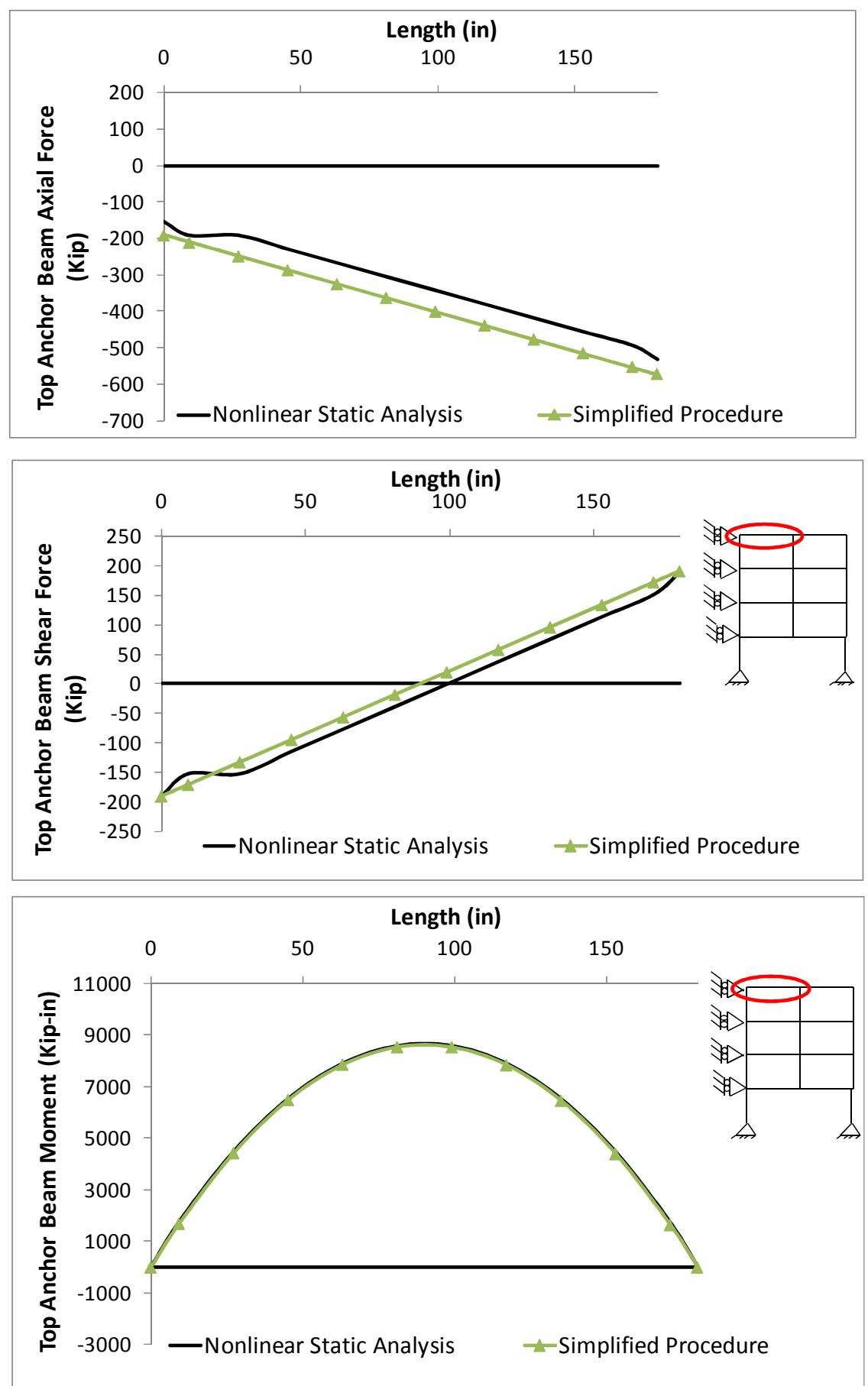

Figure 7-7: Axial, shear, and moment diagrams for the top anchor beam under Boundary Condition \#2 

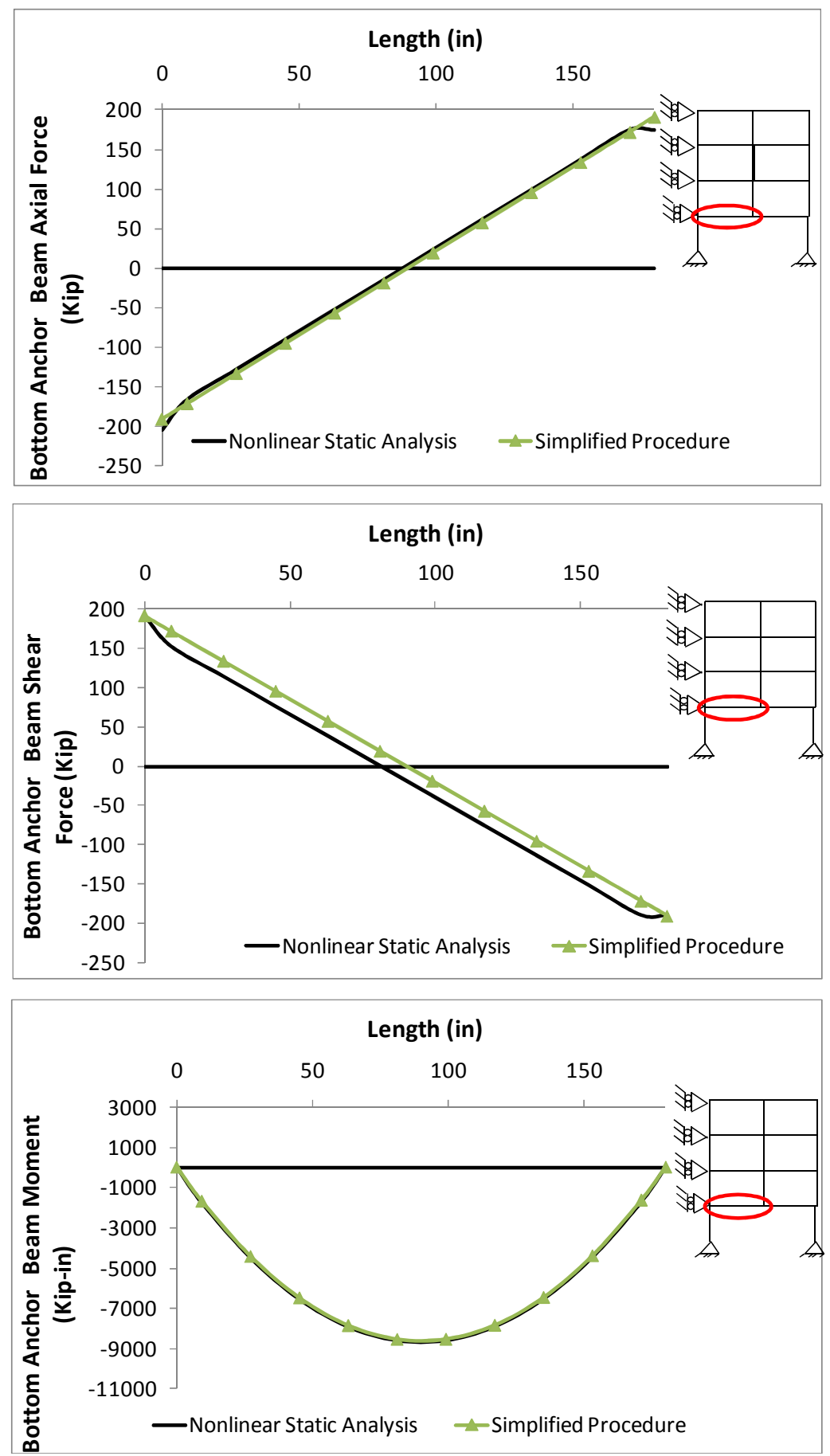

Figure 7-8: Axial, shear, and moment diagrams for the bottom anchor beam under Boundary Condition \#2 


\subsection{Intermediate Beams}

The axial, shear, and bending moment diagrams for the intermediate beams are presented in Figure 7-9. As shown, similar to the anchor beams, the demand distributions in the intermediate beams under Boundary Condition \#2 is the same as those under Boundary Condition \#1 (see Figure 7-6). 

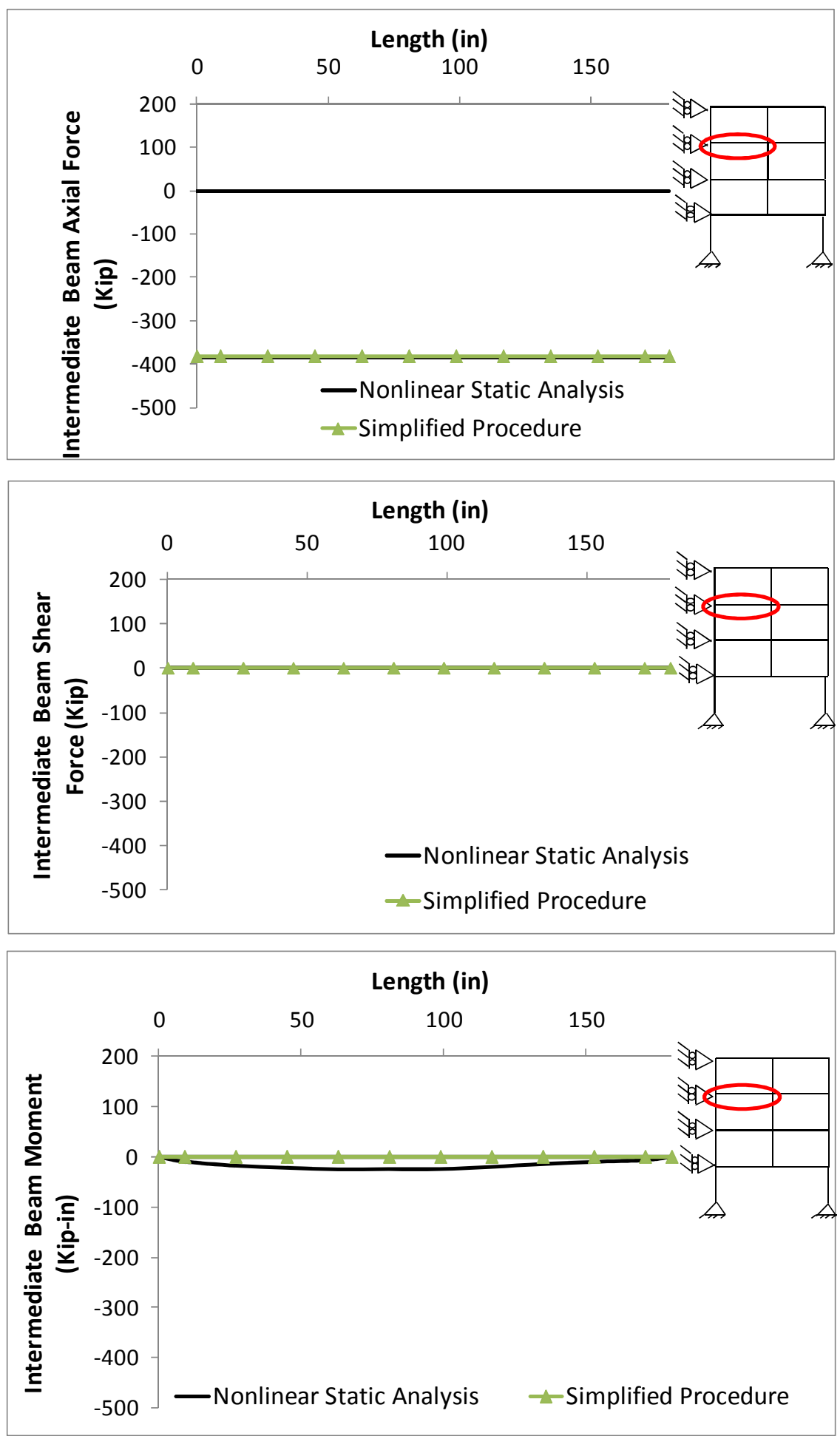

Figure 7-9: Axial, shear, and moment diagrams for the intermediate anchor beams under Boundary Condition \#2 


\subsubsection{Boundary Condition \#3}

Boundary Condition \# 3 considers the removal of interior column and assigns the lateral displacement restraints (i.e. sideway inhibited) on both sides of the frame. Due to the presence of restraints, all beams are expected to develop catenary action. Therefore, the FBD presented in Figure 7-3(b) is used to calculate the beam demands.

\subsection{Anchor Beams}

The axial, shear, and bending moment diagrams for the top and bottom anchor beams under Boundary Condition\#3 are shown in Figure 7-10 and Figure 7-11, respectively. Compared to the anchor beams under Boundary Conditions \#1 and \#2, the axial tension forces in the anchor beams under Boundary Condition \#3 are significantly larger due to the development of catenary action. 

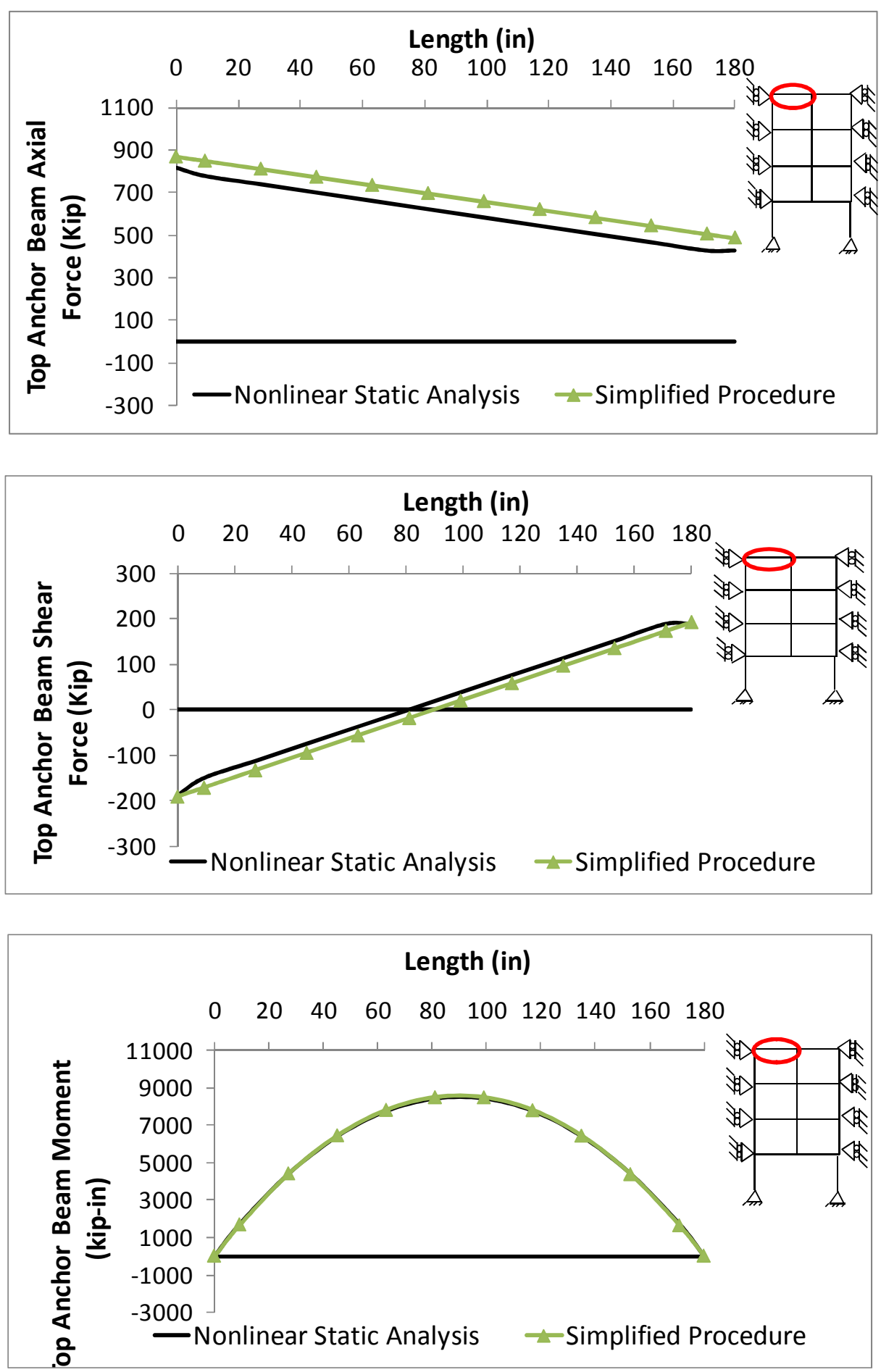

Figure 7-10: Axial, shear, and moment diagrams for the top anchor beam under Boundary Condition \#3 

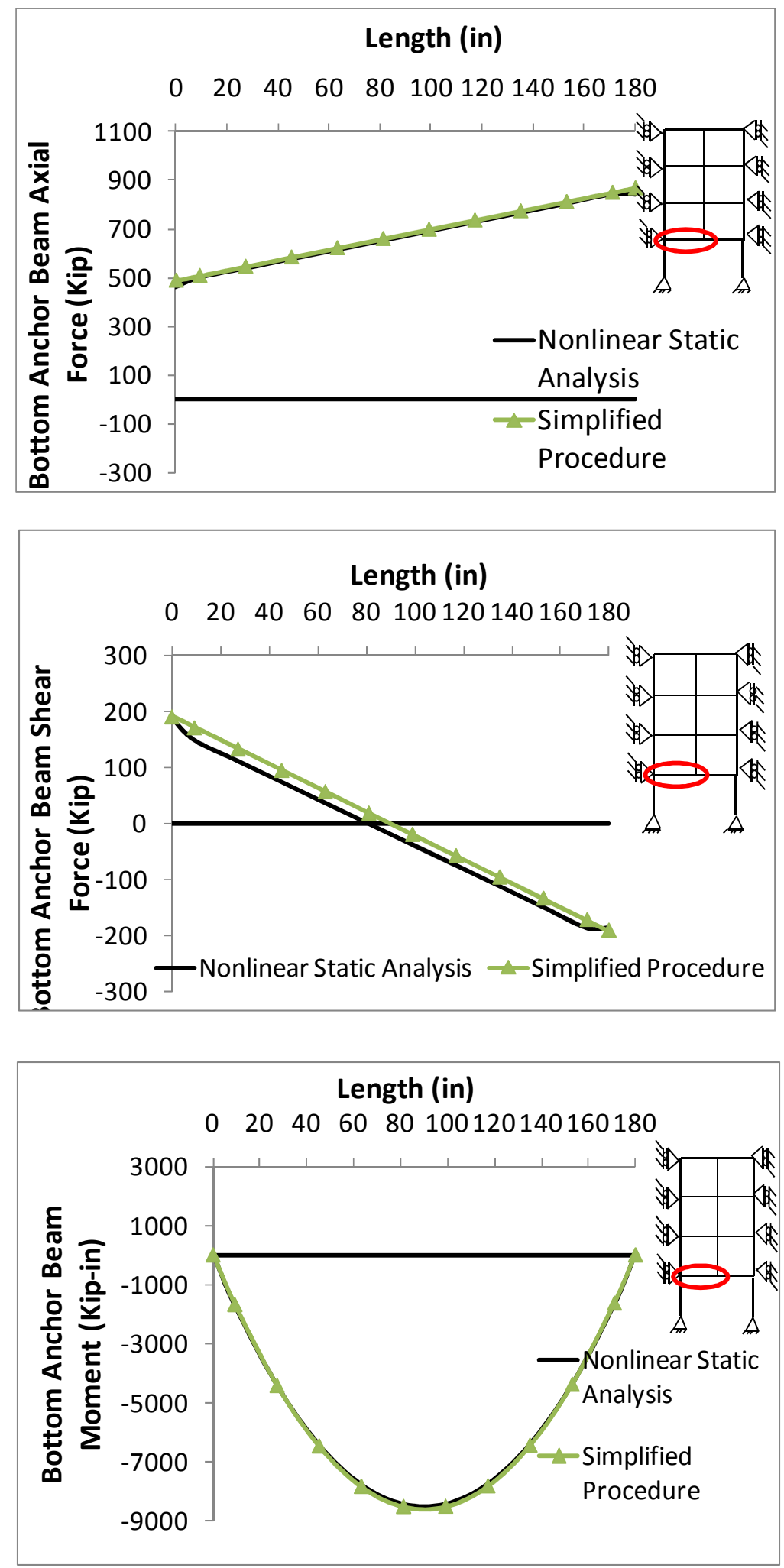

Figure 7-11: Axial, shear, and moment diagrams for the bottom anchor beam under Boundary Condition \#3 


\subsection{Intermediate Beams}

Figure 7-12 shows the demand on the intermediate beam under Boundary Condition \#3. Good agreement is observed in the axial force comparison. However, the shear and bending moment demands obtained from the simplified procedure is vaguely different from those obtained from nonlinear static analysis. This is due to the fact that the simplified procedure assumes ideally uniform and identical tension field actions above and below the intermediate beam, resulting in no shear and bending moment in the beam, while the nonlinear static analysis allows development of the non-uniform tension field actions. 

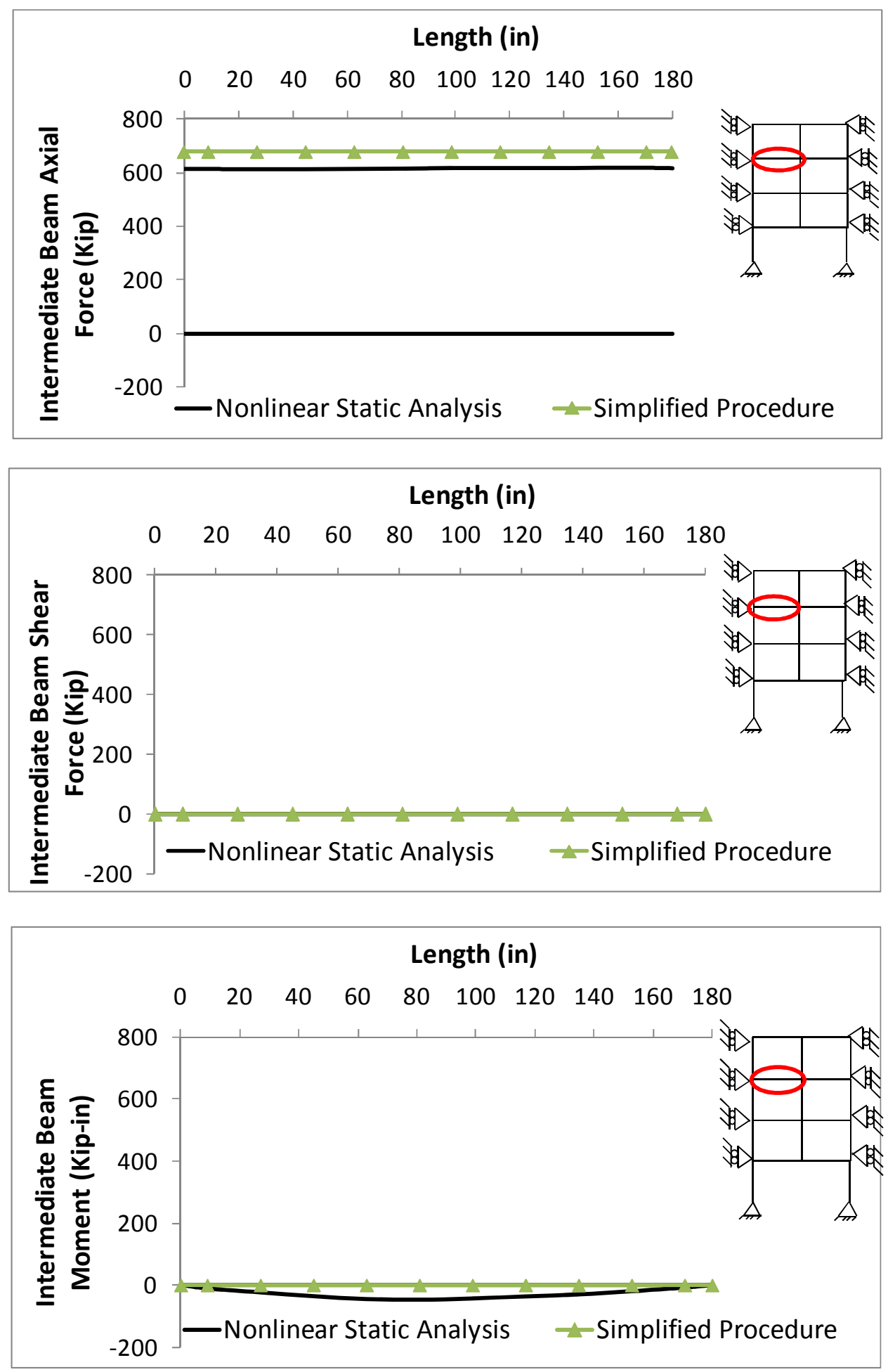

Figure 7-12: Axial, shear, and moment diagrams for the intermediate beams under Boundary Condition \#3 


\subsubsection{Boundary Condition \#4}

Boundary Condition \#4 accounts for removal of the exterior column at the bottom story and allows lateral deformation at the left side of the frame. For this boundary condition beam catenary action does not develop. As such, the FBD presented in Figure 7-3(a) is used to determine the demand on the beams.

\subsection{Anchor Beams}

For Boundary Condition \#4, geometric symmetry no longer applies and the two top anchors and the two bottom anchors beams (on each side of the interior column) were consider respectively.

The axial, shear, and bending moments for the top right and bottom right anchor beams are respectively shown in Figure 7-13 and Figure 7-14 and good agreements are observed between the results from the simplified procedure and the nonlinear static analysis.

The demands for the top left and bottom left anchor beams are shown in Figure 7-15 and Figure 7-16, respectively. Good agreements are observed in all comparisons except that the axial force in the top left anchor beam predicted by the simplified procedure is slightly different from that from nonlinear static analysis. This observation can be attributed to the fact that the FBD considered in the simplified procedure assumes uniform yielding of the infill plate that is unlikely to develop under this boundary condition. However, the observed difference is acceptable from the design perspective. 

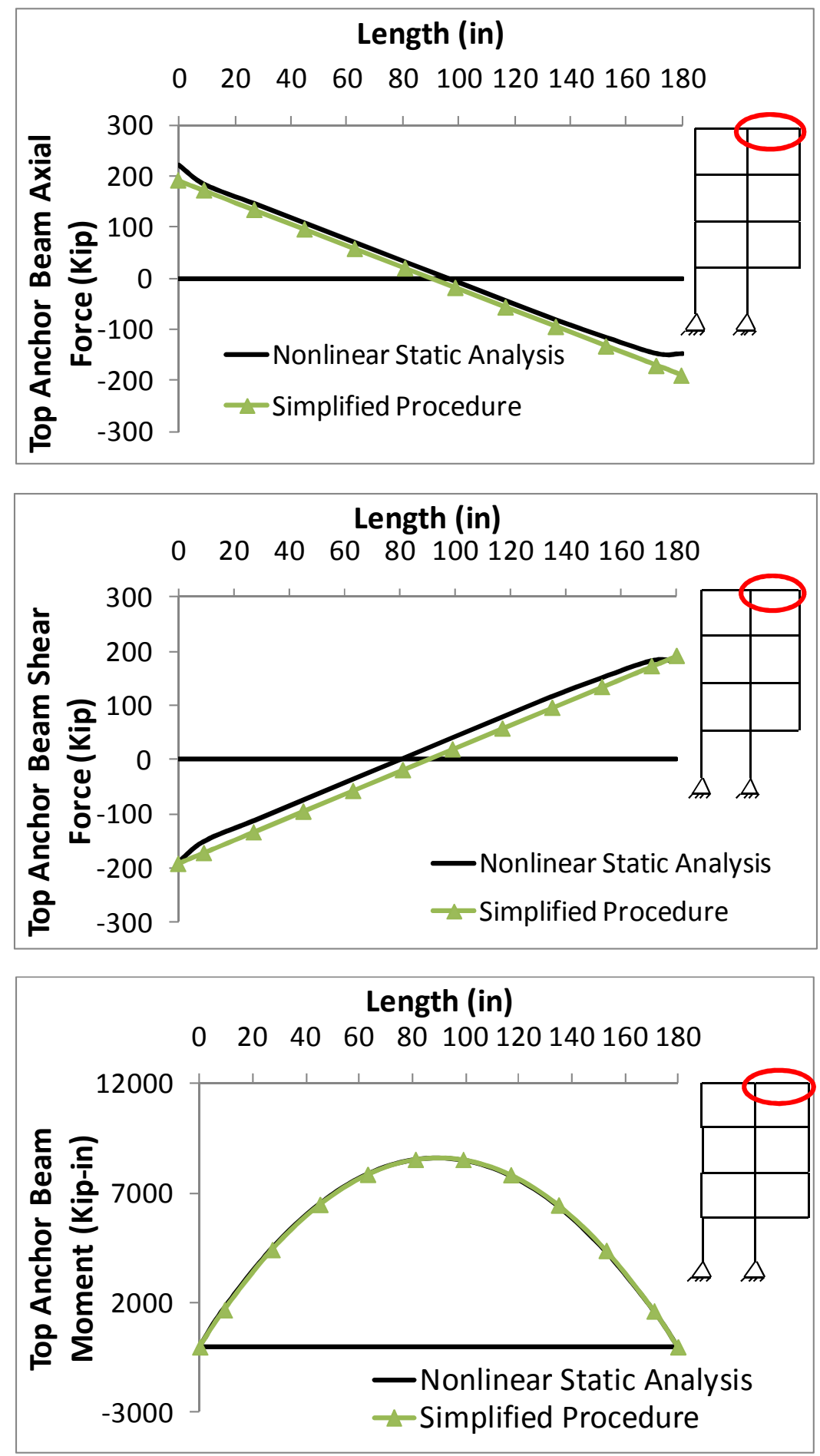

Figure 7-13: Axial, shear, and moment diagrams for the top right anchor beam under Boundary Condition \#4 

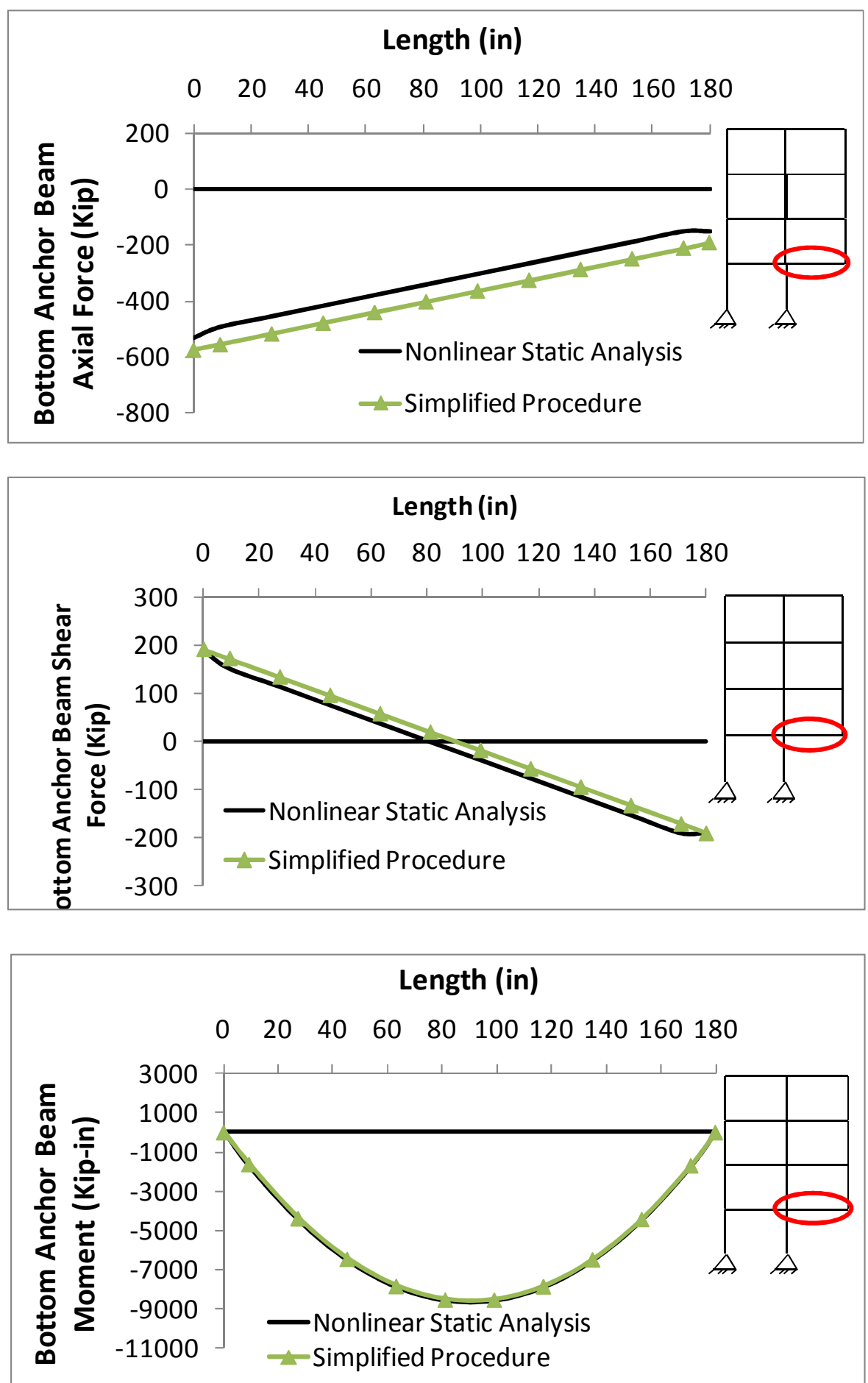

Figure 7-14: Axial, shear, and moment diagrams for the bottom right anchor beam under Boundary Condition \#4 

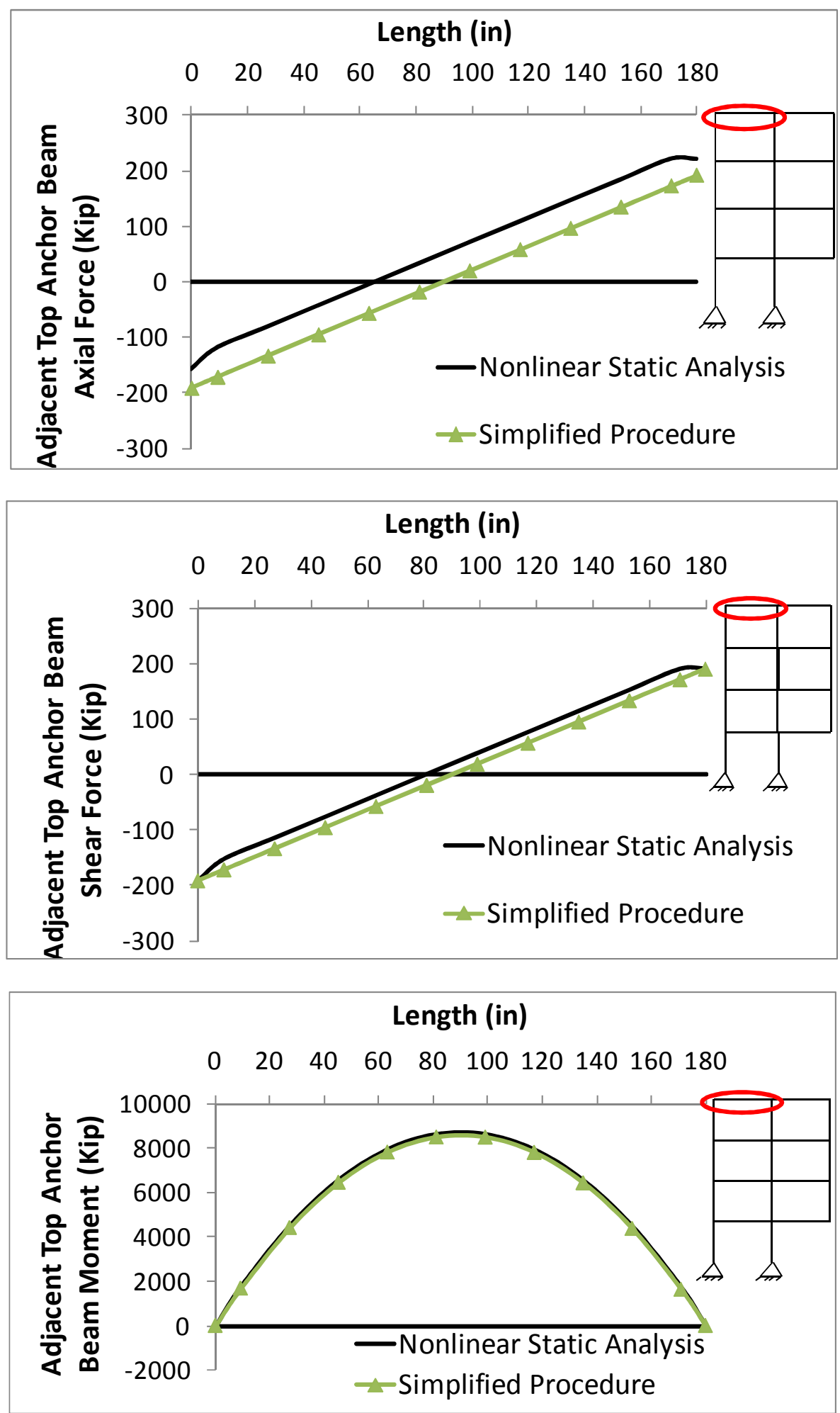

Figure 7-15: Axial, shear, and moment diagrams for the top left anchor beam under Boundary Condition \#4 

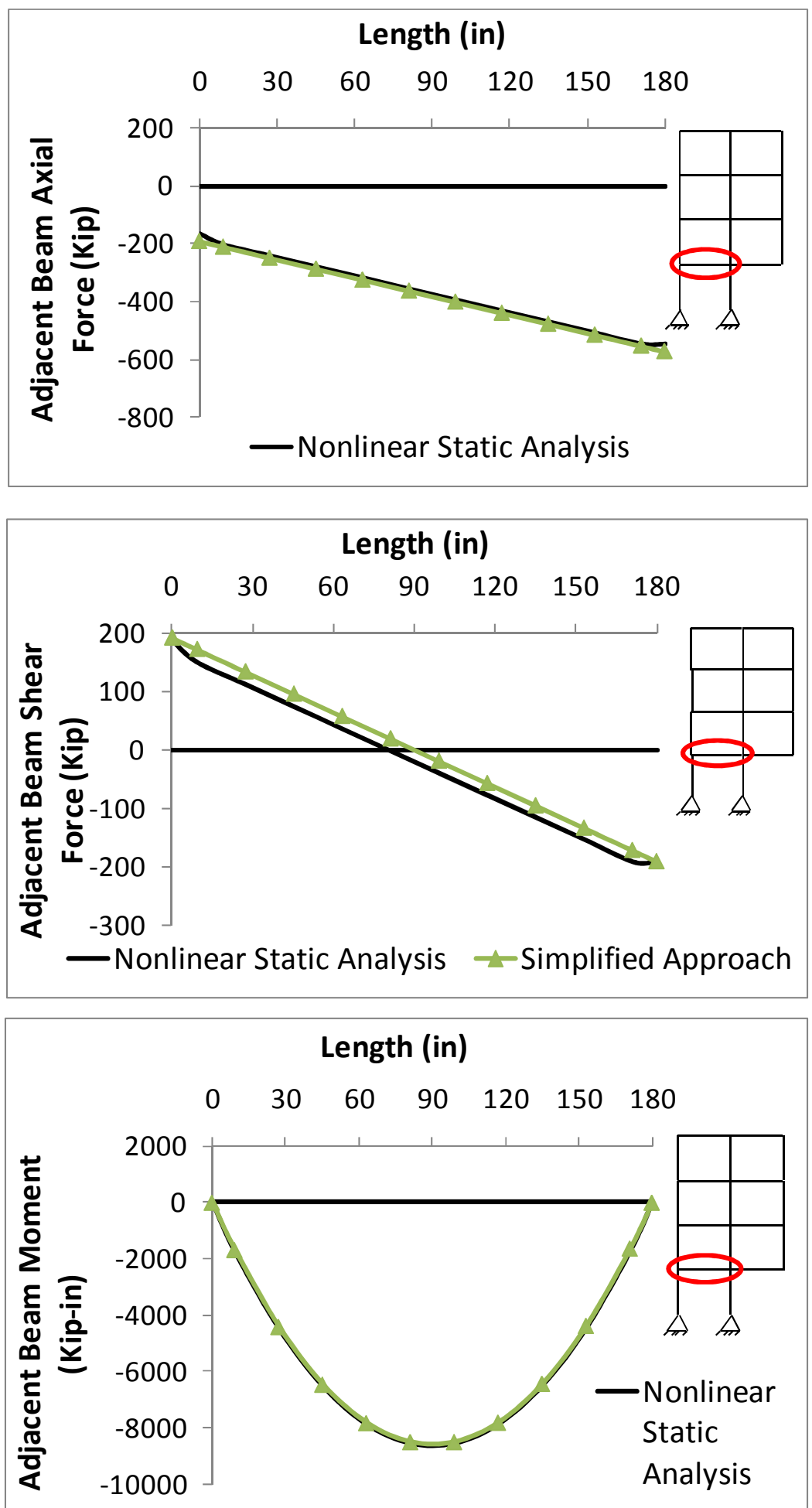

Figure 7-16: Axial, shear, and moment diagrams for the bottom left anchor beam under Boundary Condition \#4 


\subsection{Intermediate Beams}

Under Boundary Condition \#4, the four intermediate beams are expected to have identical or symmetric demand distribution. As such, only one intermediate beam was selected for analysis. The axial demand in the intermediate beam can be satisfactorily approximated by the simplified procedure as shown in Figure 7-17. However, slight differences are observed in the shear and moment comparisons due to numerical errors in the nonlinear static analysis model. 

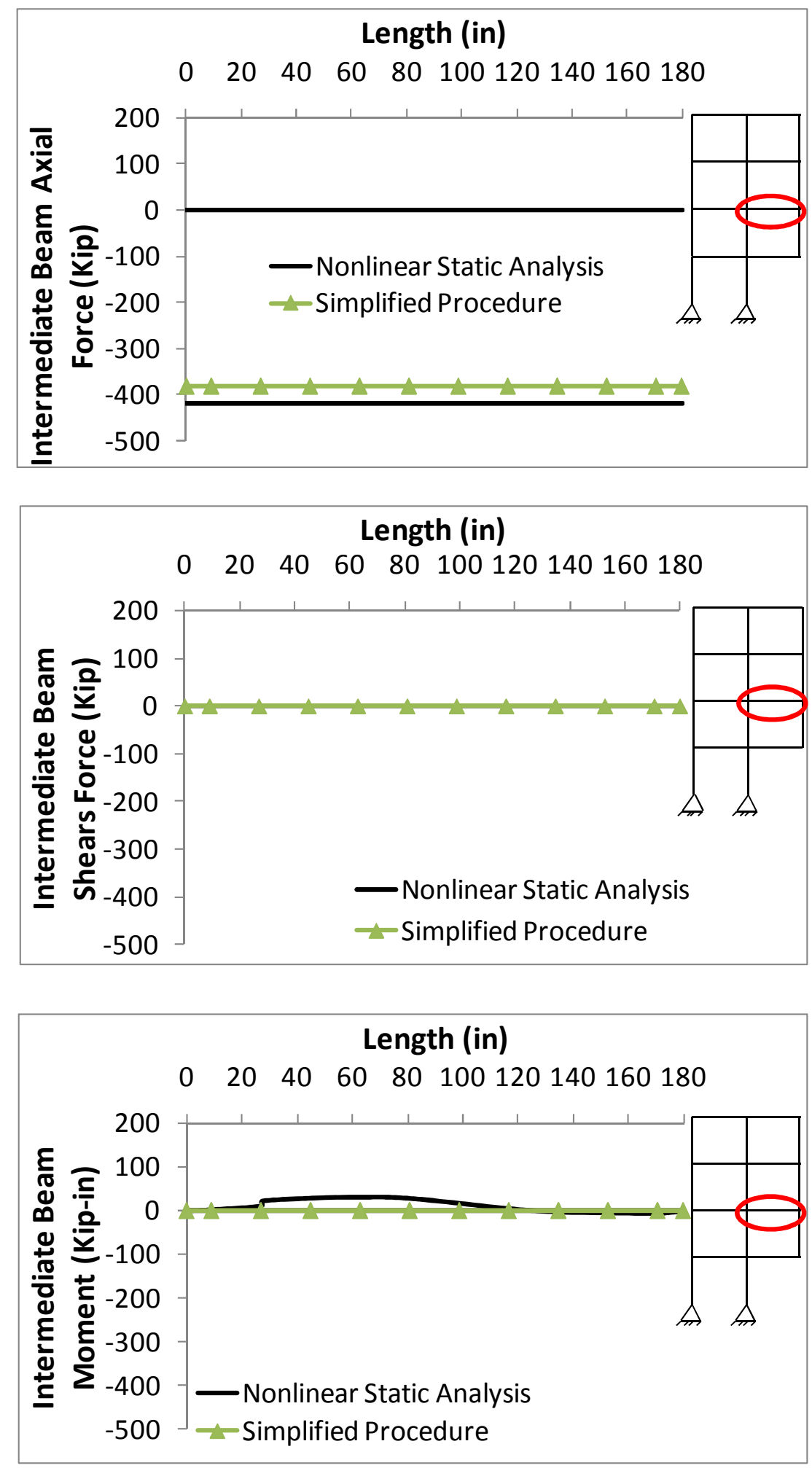

Figure 7-17: Axial, shear, and moment diagrams for the intermediate beams under Boundary Condition \#4 


\subsubsection{Boundary Condition \#5}

Boundary Condition \#5 takes into account the loss of the exterior column at the bottom story and inhibits the sideway deformation on the left side of the frame. Under such a boundary condition, the catenary action does not develop in the beams due to the absence of anchorage effects on the right side of the frame. Thus, the FBD presented in Figure 7-3(a) is used to quantify the demands in the beams.

\subsection{Anchor Beam}

The axial, shear, and bending moment diagrams for the right top and bottom anchor beams under Boundary Condition\#5, are presented in Figure 7-18 and Figure 7-19, respectively. Note that the demands on these anchor beams are identical to those under Boundary Condition \#4 (see Figure 7-13 and Figure 7-14 for details). 

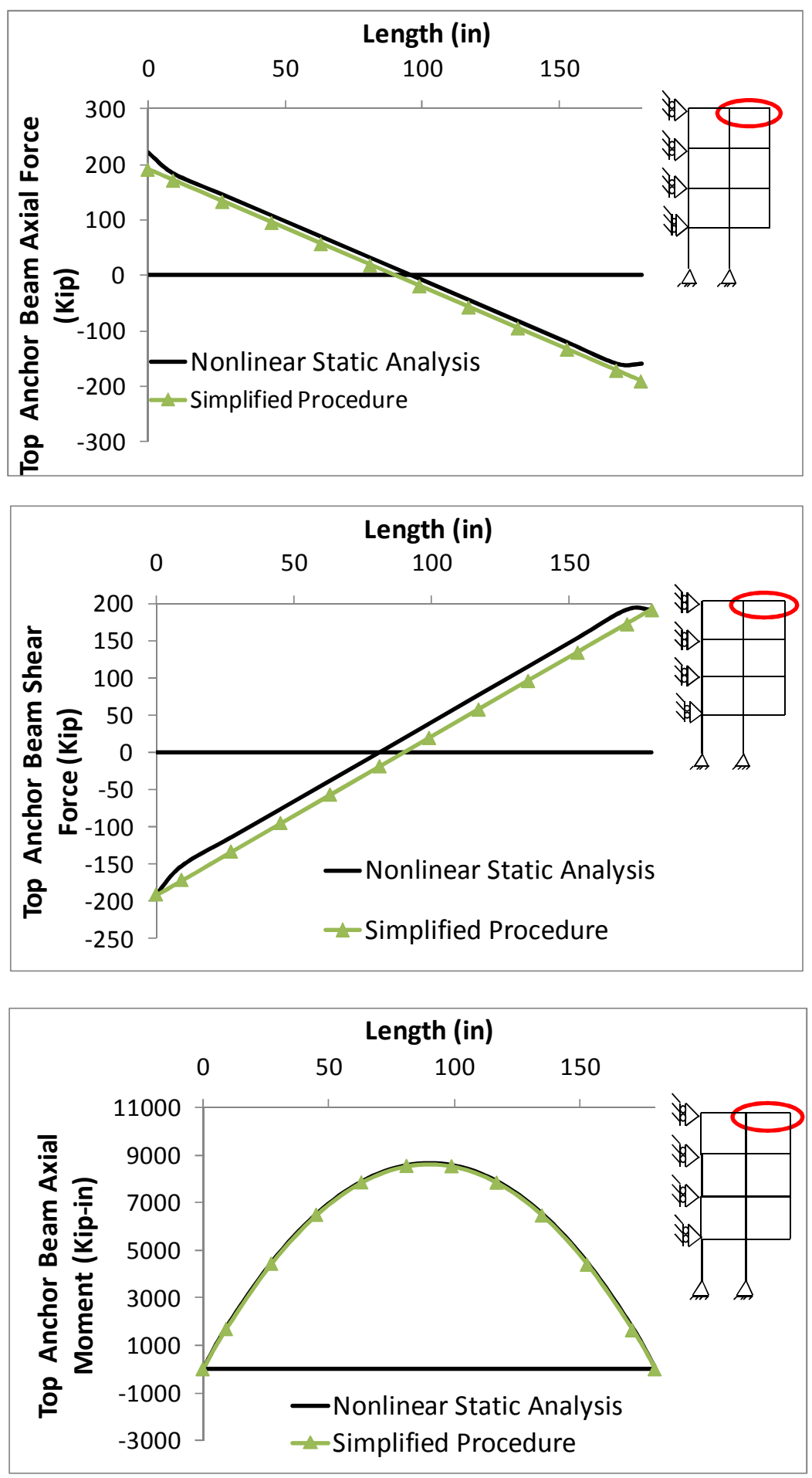

Figure 7-18: Axial, shear, and moment diagrams for the top right anchor beam under Boundary Condition \#5 

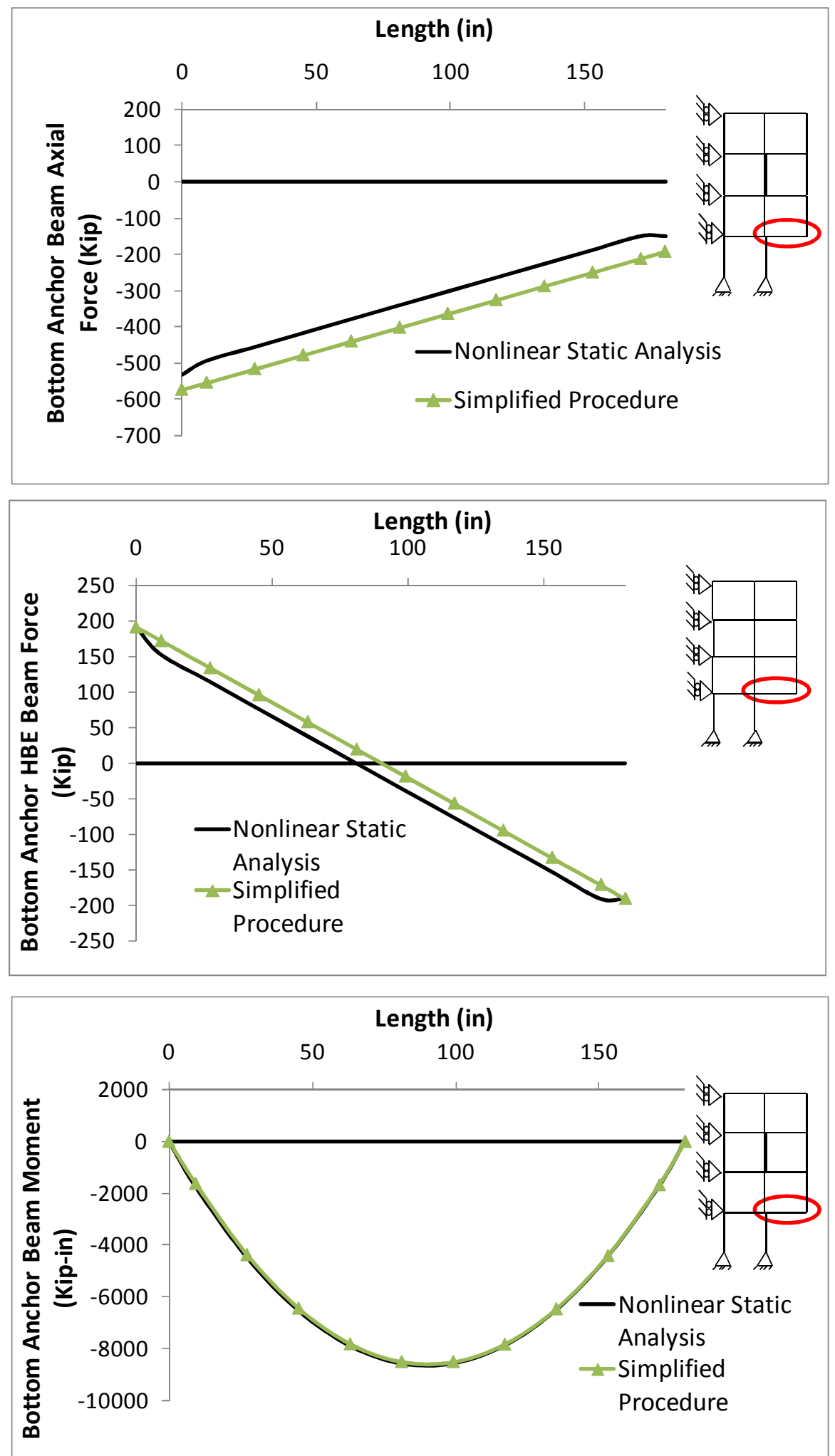

Figure 7-19: Axial, shear, and moment diagrams for the bottom right anchor beam under Boundary Condition \#5 
The demands on the left anchor beams under Boundary Condition\#5 cannot be estimated using the FBDs because the infill panels installed in the left bay of the frame do not form the diagonal tension field actions that are assumed in the FBDs. As such, only the results from the nonlinear static analysis are provided in Figure 7-20 and Figure 7-21.

Compared to the corresponding results from the other boundary conditions, the top and bottom anchor beams on the left side of the frame have relatively low demands due to the incomplete development of the tension field actions. 

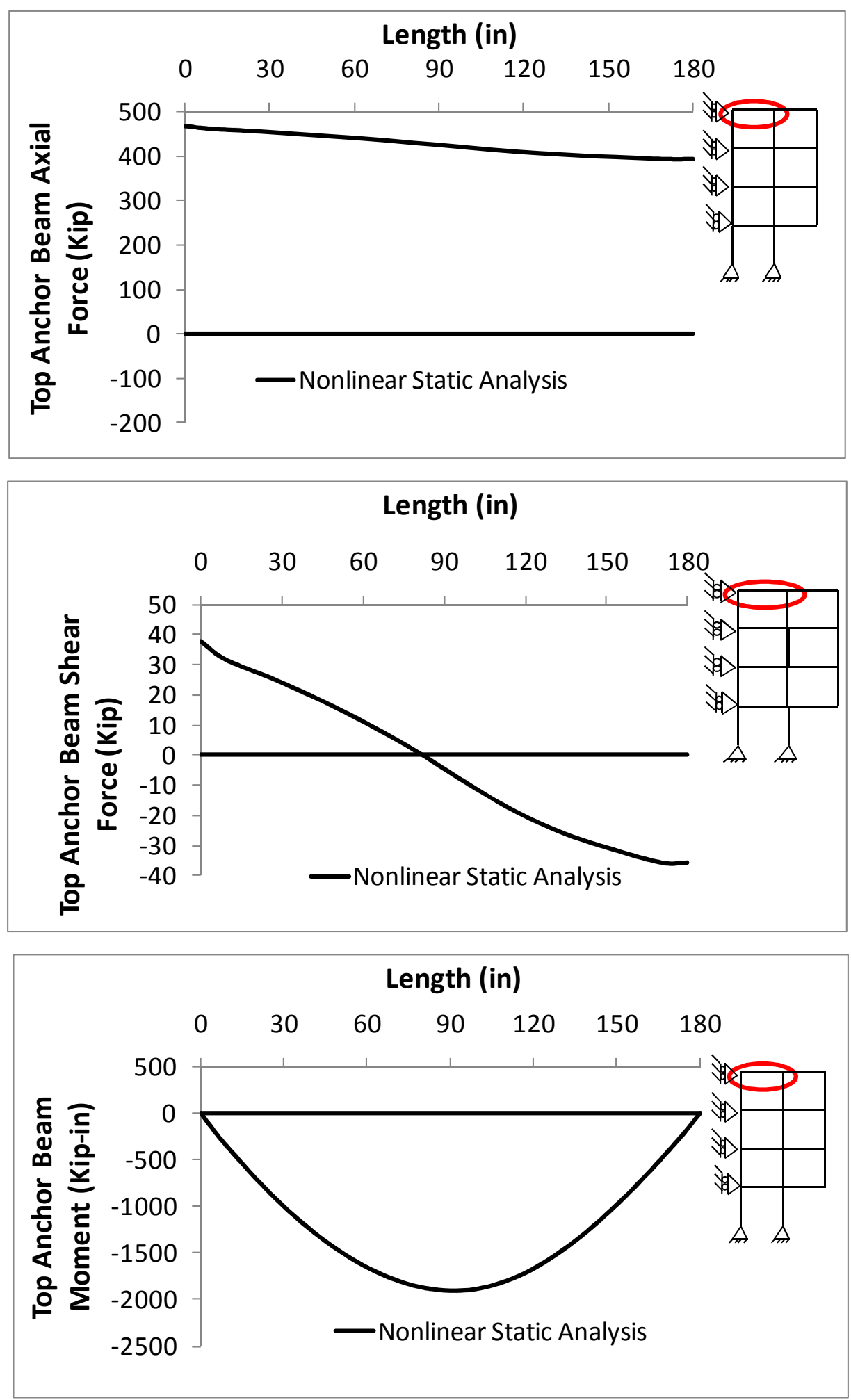

Figure 7-20: Axial, shear, and moment diagrams for the top left anchor beam under Boundary Condition \#5 

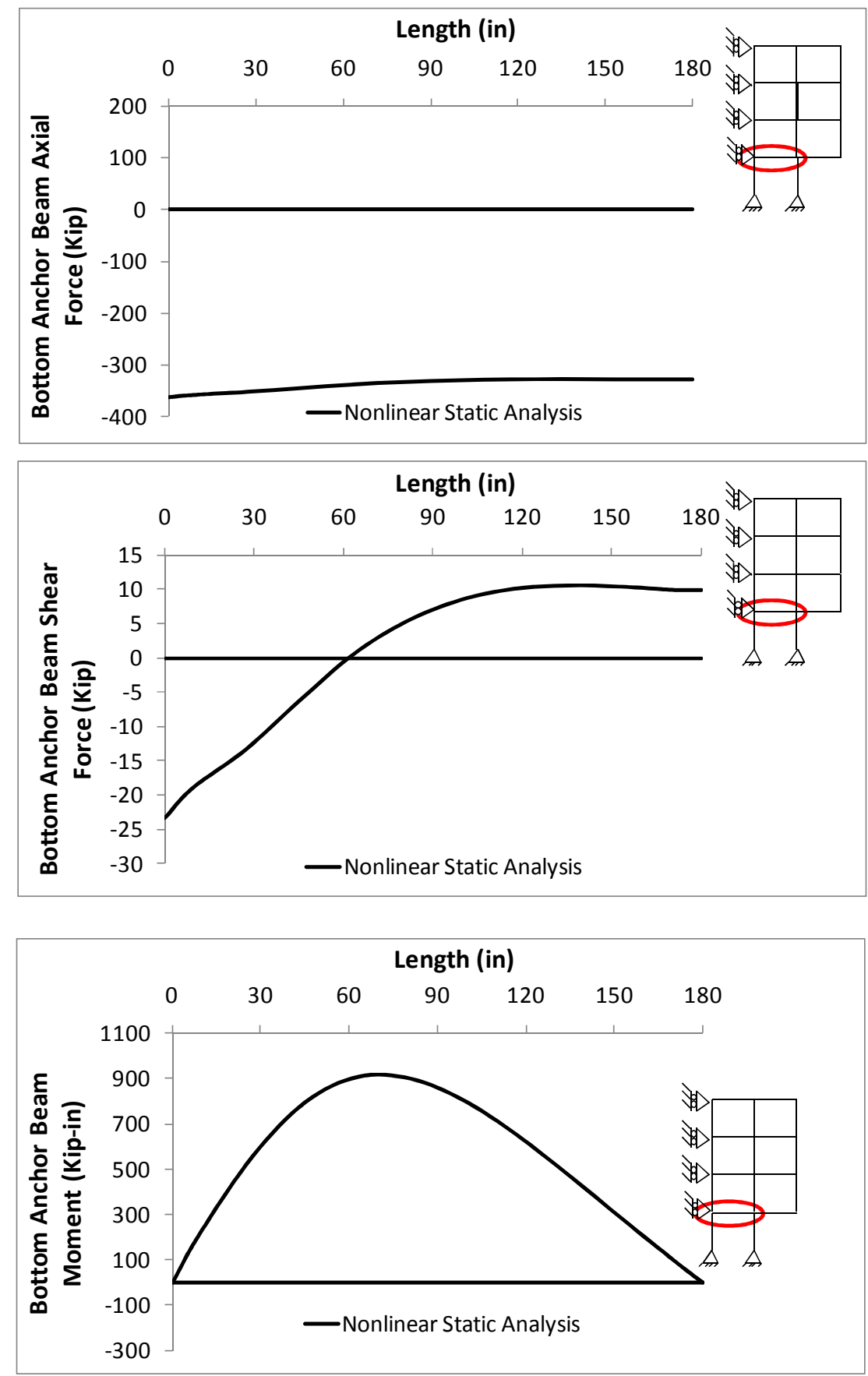

Figure 7-21: Axial, shear, and moment diagrams for the bottom left anchor beam under Boundary Condition \#5 


\subsection{Intermediate Beams}

Comparing the results presented in Figure 7-17 and Figure 7-22, it is observed that the demands on the right bay intermediate beam under Boundary Condition\#4 are identical to those from Boundary Condition \#5. Note that agreement is observed in the axial force comparison, but slight differences exist in the shear and bending moment comparisons as shown in Figure 7-22. Similar to the other cases, such observed differences are caused by the numerical error in the nonlinear static analysis.

Figure 7-23 show the results for the left bay intermediate beam. It is recognized that the tension field actions assumed in the FBDs do not develop on the left structural frames as explained previously. As such, the simplified procedure is unlikely to provide useful data for this case and only results from the nonlinear static analysis are presented here for comparison purpose. 

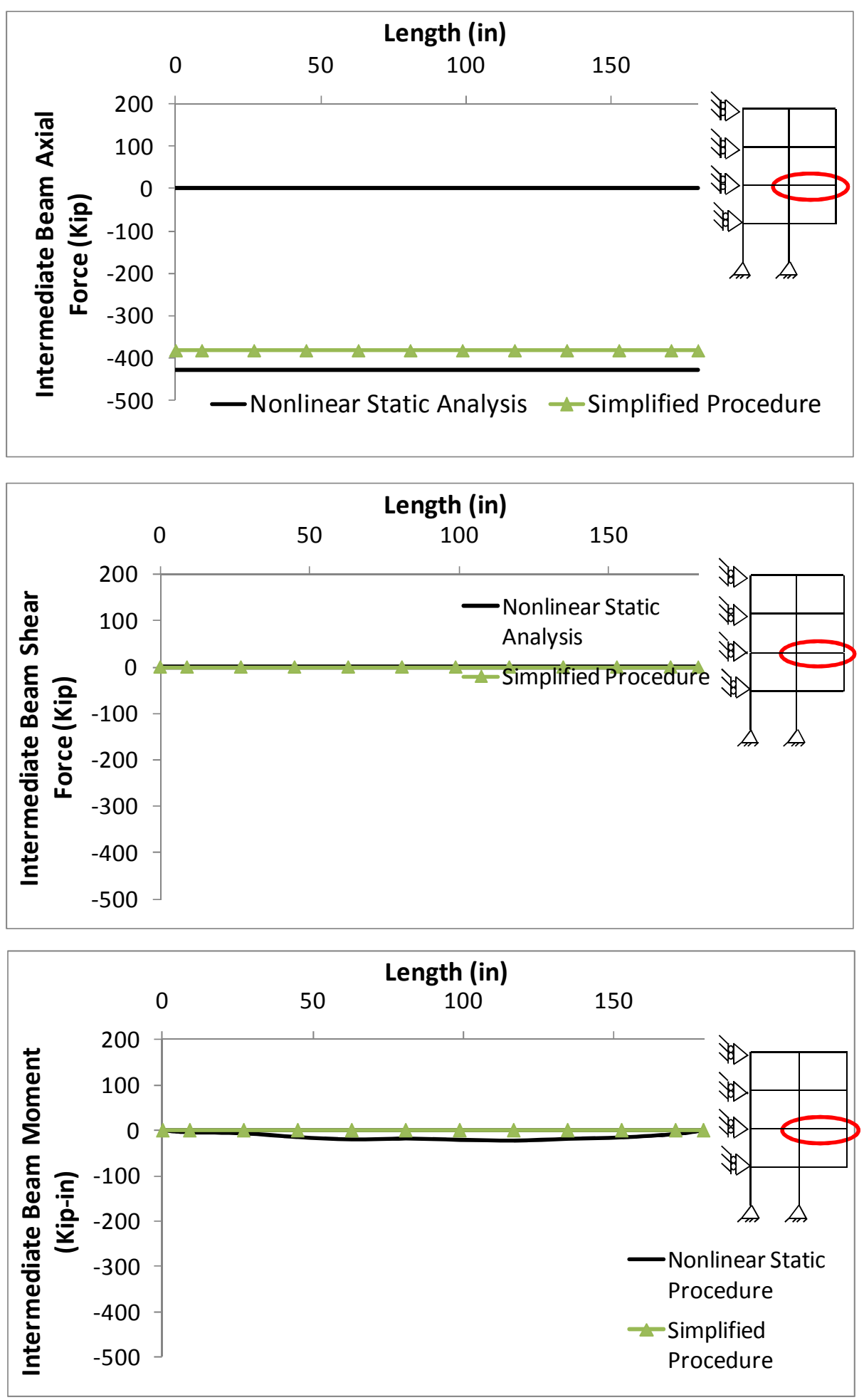

Figure 7-22: Axial, shear, and moment diagrams for the right intermediate beams under Boundary Condition \#5 

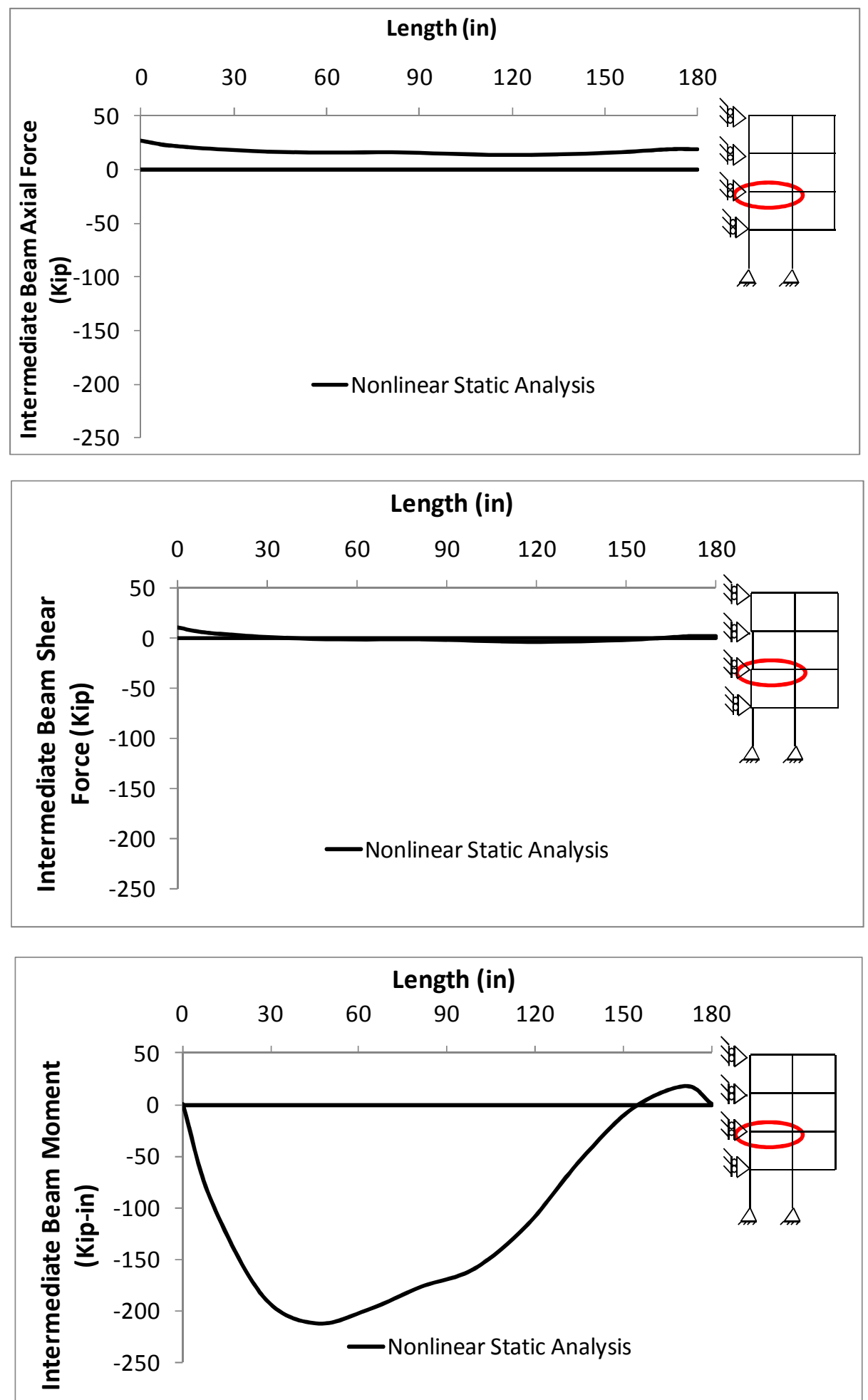

Figure 7-23: Axial, shear, and moment diagrams for the top left intermediate beam under Boundary Condition \#5 


\subsection{Demands on Columns}

FBDs can also be used to find the demands on columns. The column demands depend on the boundary conditions of the frame. The following sections describe development of the FBDs for columns and analytical work conducted to validate such FBDs.

\subsubsection{General FBDs of the Columns}

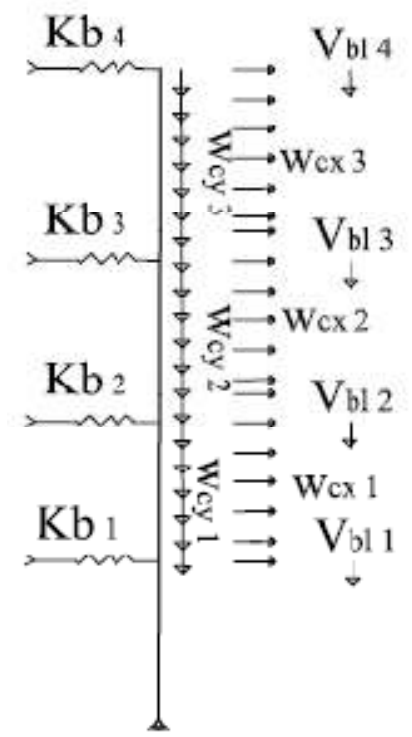

(a)

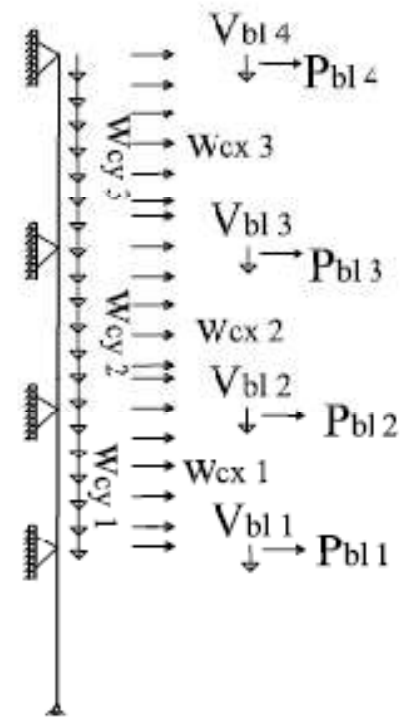

(b)

\section{Figure 7-24: General FBDs of columns: (a) Sidesway uninhibited (b) Sidesway inhibited}

The column demand distributions depend on the boundary condition of the frame. The general FBDs for columns are presented Figure 7-24 (a) and (b), respectively. These FBDs will be utilized to calculate the column demands.

As shown in Figure 7-24 (a), when sideway is uninhibited at the floor levels, the column can be considered as a continuous beam element pinned to ground and supported by 
elastic springs which represent the beams. The loads on the column include the horizontal and vertical components of the tension field actions and the shear force at the end of the beams. According to Berman and Bruneau (2008), stiffness of the spring at the $i^{\text {th }}$ floor level, $k_{b i}$ which represents the axial restraint of beams can be calculated as:

$$
k_{b i}=\frac{A_{b i} E}{L_{b}}
$$

where, $A_{b i}=$ cross-sectional area of the $i^{\text {th }}$ beam

$$
\begin{aligned}
& L_{b}=\text { the beams length } \\
& E=\text { modulus of elasticity }
\end{aligned}
$$

The shear force at the end of the $\mathrm{i}^{\text {th }}$ beams, denoted as $V_{b i}$ in the FBDs shown in Figure 7-24 can be estimated using the following equation:

$$
V_{b i}=\left(\omega_{b y i+1}-\omega_{b y i}\right) \cdot \frac{L_{b}}{2}
$$

where, $L_{b}=$ the beams length; and all the other variable have been previously defined

When sideway is inhibited at the floor levels, the column can be also modeled as a continuous beam element pinned to ground and laterally supported by rollers which represent the sidesway displacement restraints. The loads on the column consist of horizontal and vertical components of the infill panel forces and the shear forces from the beam ends. Also included in the FBD is the tension force at the beam ends caused by the catenary action. However, it is recognized that these tension forces should be only included in the FBD when sideway boundary conditions are applied on both sides of the 
frame (i.e. Boundary Condition \#3). For the case sidesway is only inhibited on one side of the frame, the tension forces at the beam ends should not be included in the FBD.

It should be noted that the FBDs shown in Figure 7-24 (a) and (b) cannot be used for the columns subjected to damage since the columns are assumed to be pinned to ground in the FBDs. As such, only the results from the nonlinear static analysis are presented for the damaged columns in the following sections.

\subsubsection{Results from Different Boundary Conditions}

Demands on the columns under the boundary conditions presented in Figure 5-1 were investigated using both the FBDs and the nonlinear static FE analysis. The following sections describe detailed result comparison.

\subsubsection{Boundary Condition \#1}

Boundary Condition \#1 assumes the loss of interior column at the bottom story and allows sidesway deformations on both sides of the frame. As such, the FBD shown in Figure 7-24 (a) is utilized to determine the column demands in the simplified procedure. Due to symmetry, the demands on the left and right columns are expected to be symmetric. As such, only the right column was selected for analysis purpose. Figure 7-25 shows the axial force, shear and bending moment distribution along the column. As shown, the column demands can be accurately estimated using the FBD shown in Figure $7-24$ (a). 

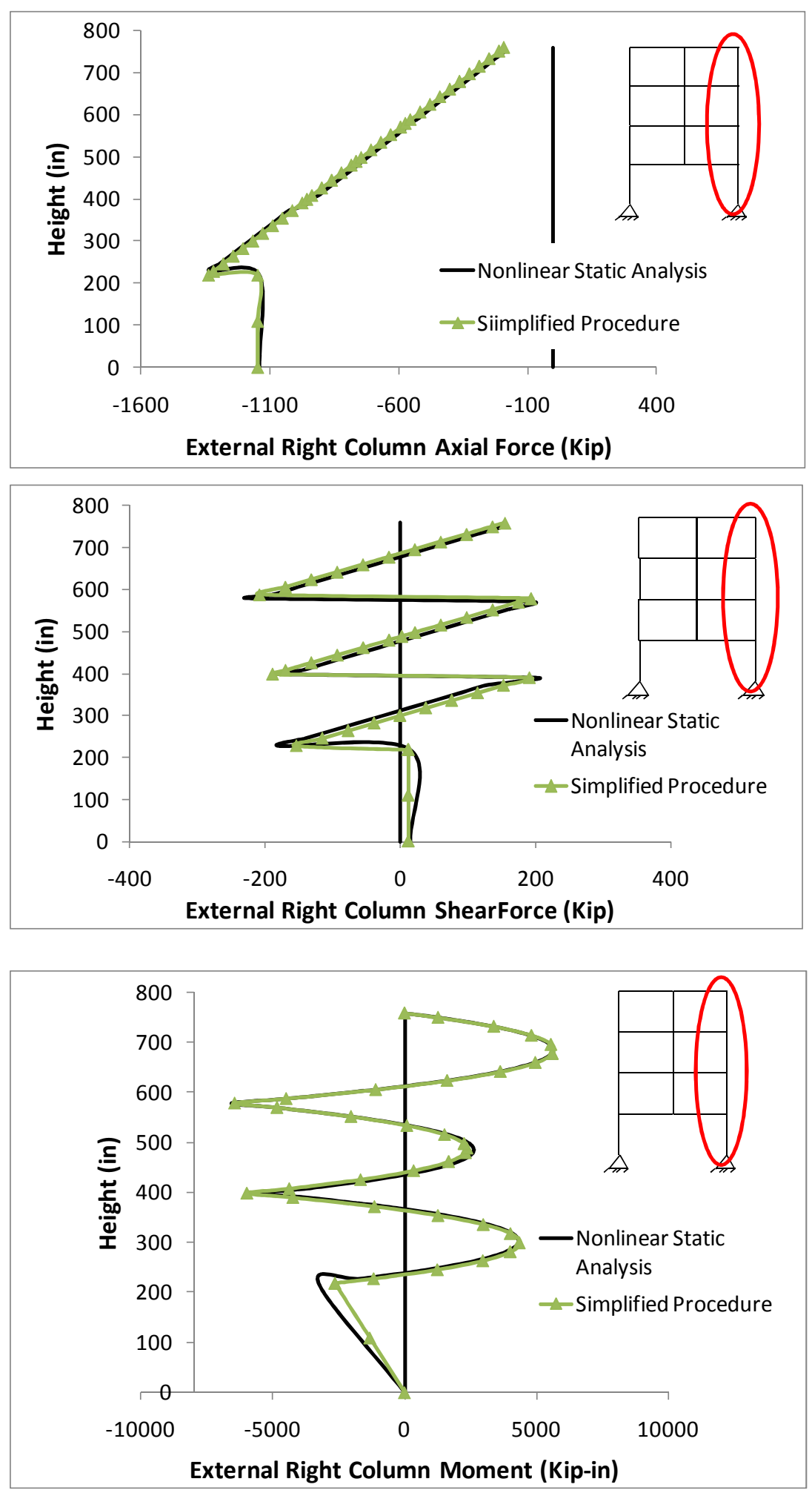

Figure 7-25: Axial, shear, and moment diagrams for the right column under Boundary Condition \#1 
In addition to the exterior columns, the interior column which suffered from damages at the bottom story was also investigated. Given that the FBDs shown in Figure 7-24 assumes that the columns are pinned to the ground, the simplified procedure is not able to predict the column demands. As such, only results from the nonlinear static analysis are presented in Figure 7-26. It is noteworthy that the shear and bending moment in the interior column are zero since the loads (including tension field actions and forces at the beam ends) on both sides of the column are mirror images. 

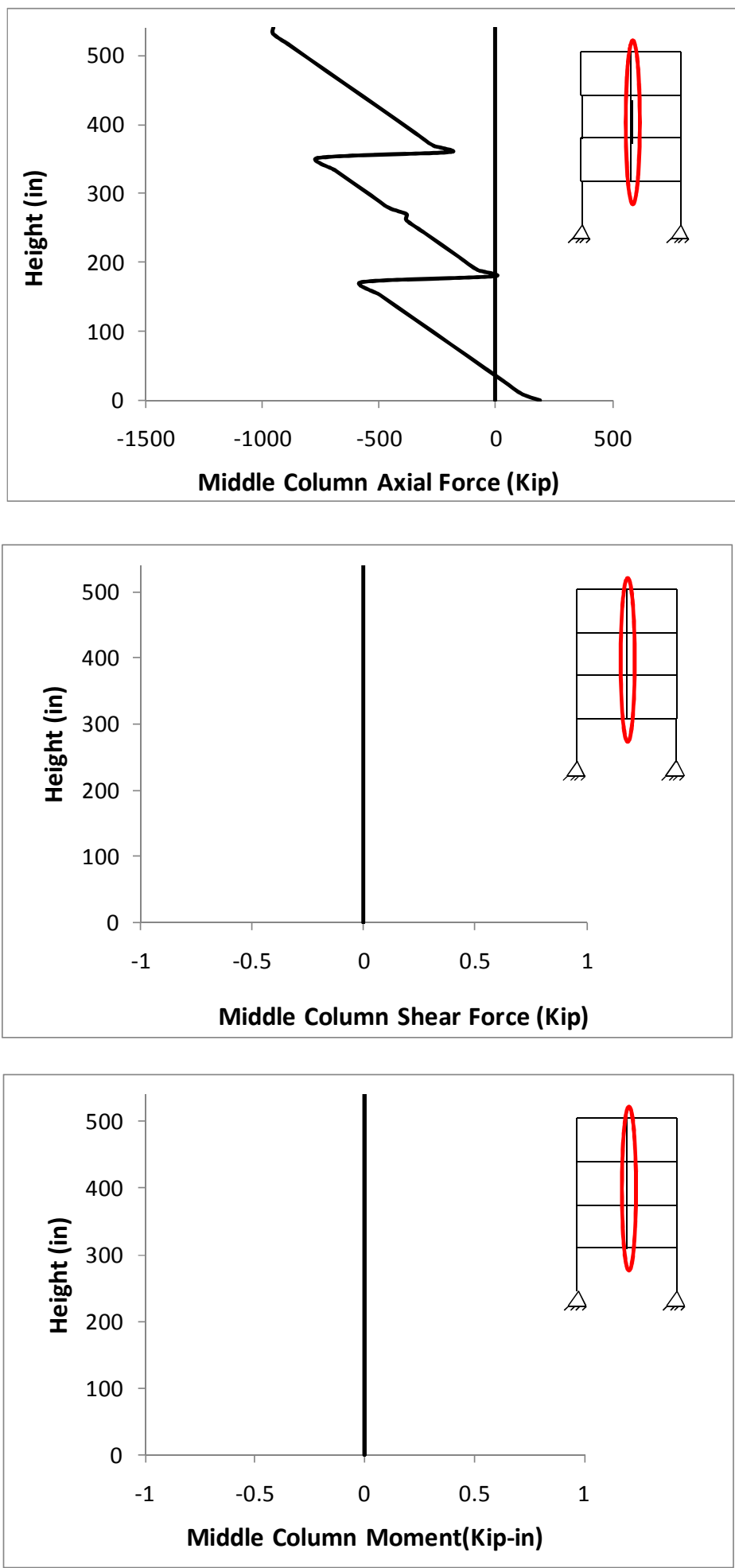

Figure 7-26: Axial, shear, and moment diagrams for the middle column under Boundary Condition \#1 


\subsubsection{Boundary Condition \#2}

Boundary Condition \#2 accounts for the loss of interior column at the bottom story and assigns sideway inhibited restraints only on the left side of the frame (note: lateral deformation is allowed at the right side of the frame). Due to the absence of the anchorage on the right side of the frame, catenary action does not develop in the beams. Therefore, the FBDs shown in Figure 7-24(a) and (b) were utilized to calculate the demands on the exterior columns on the right and left sides of the frame, respectively. Figure 7-27 and Figure 7-28 illustrate the axial, shear and bending moment diagram for the right and left exterior columns, respectively. As show, the demand distributions are either identical or symmetric in both columns. Figure 7-29 shows the demands on the interior column which is damaged at the first story. For the reason presented previously, only results from the nonlinear static analysis are presented. 

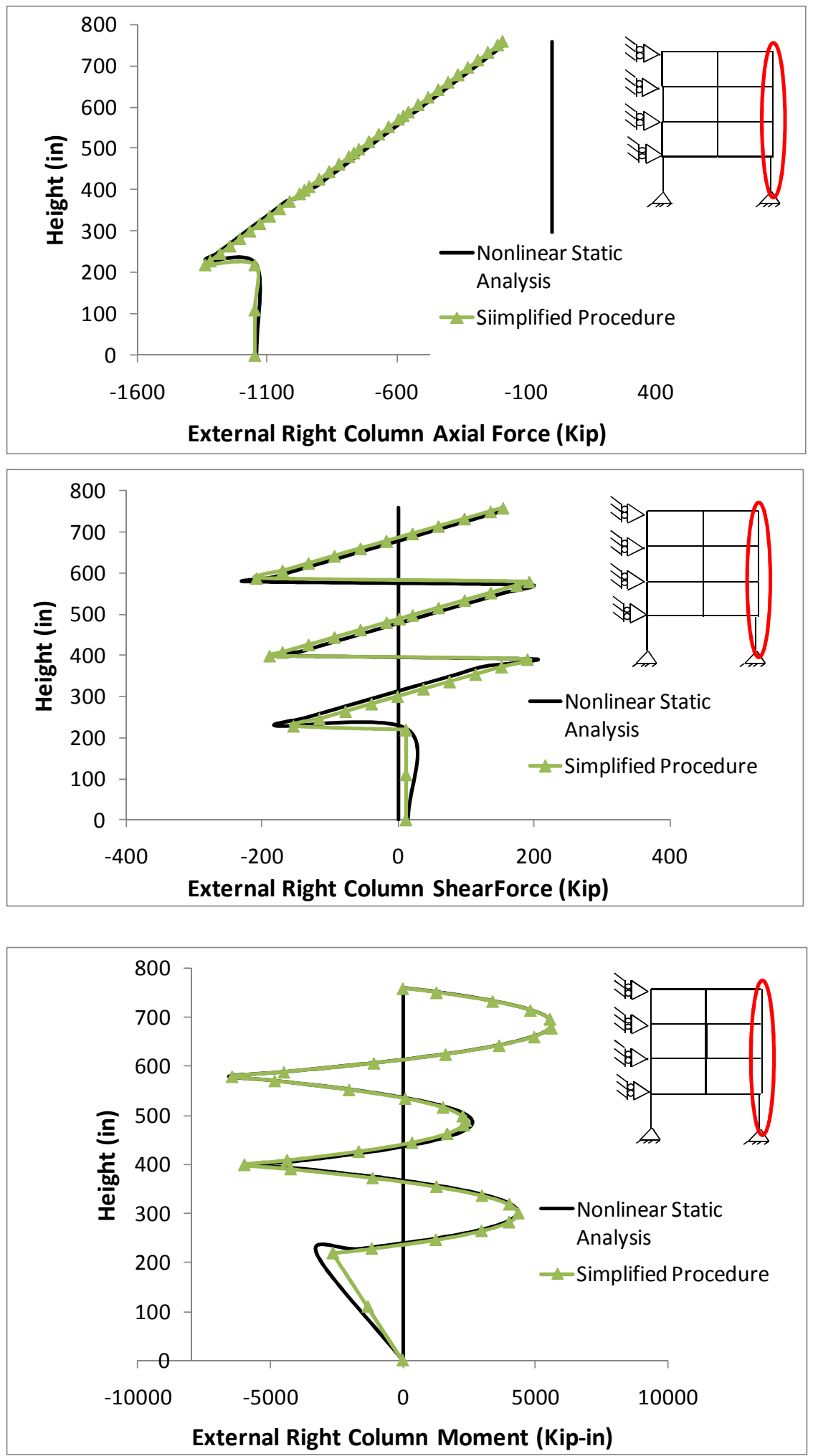

Figure 7-27: Axial, shear, and moment diagrams for the right column due under Boundary Condition \#2 

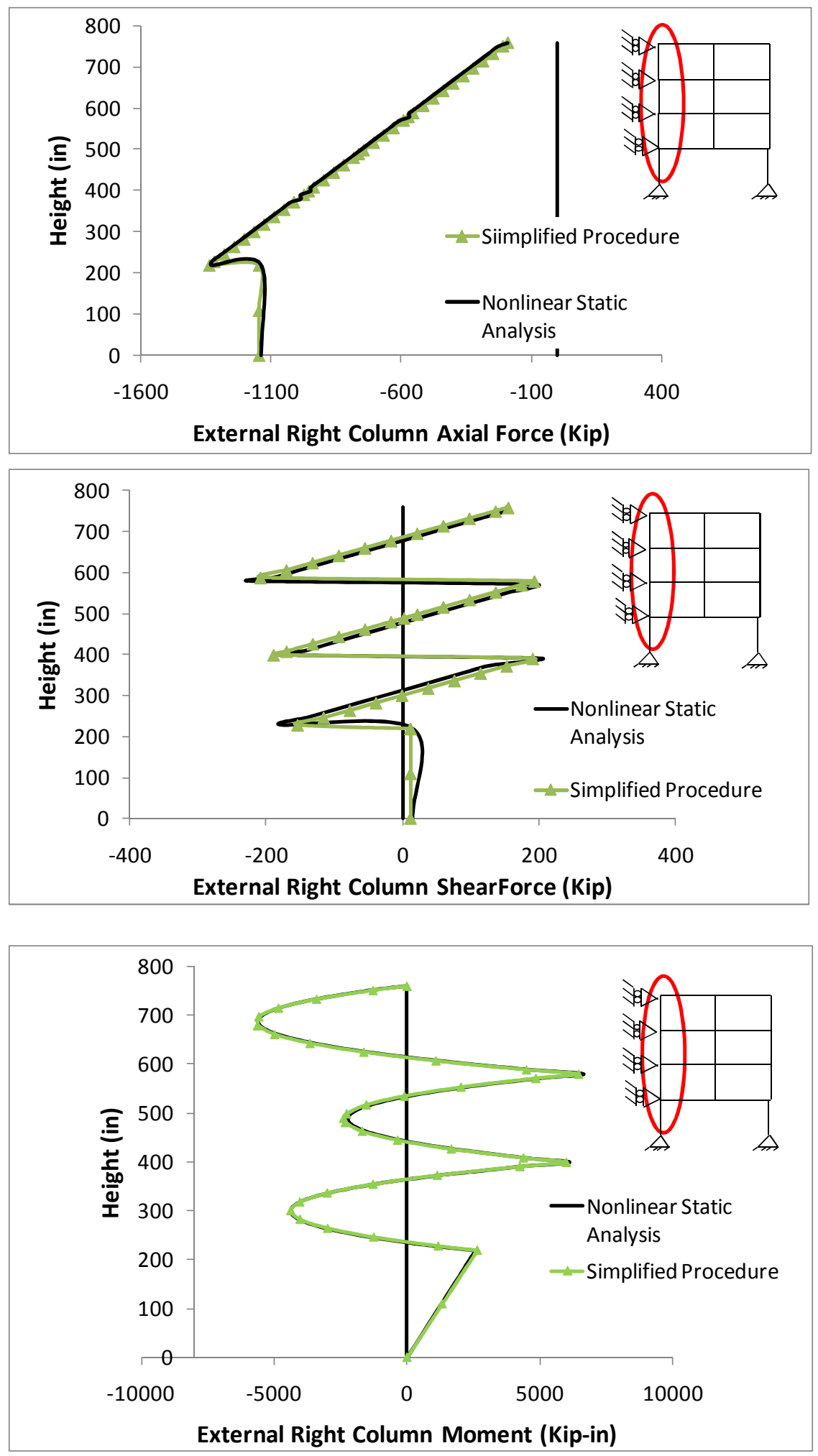

Figure 7-28: Axial, shear, and moment diagrams for the left column under Boundary Condition \#2 

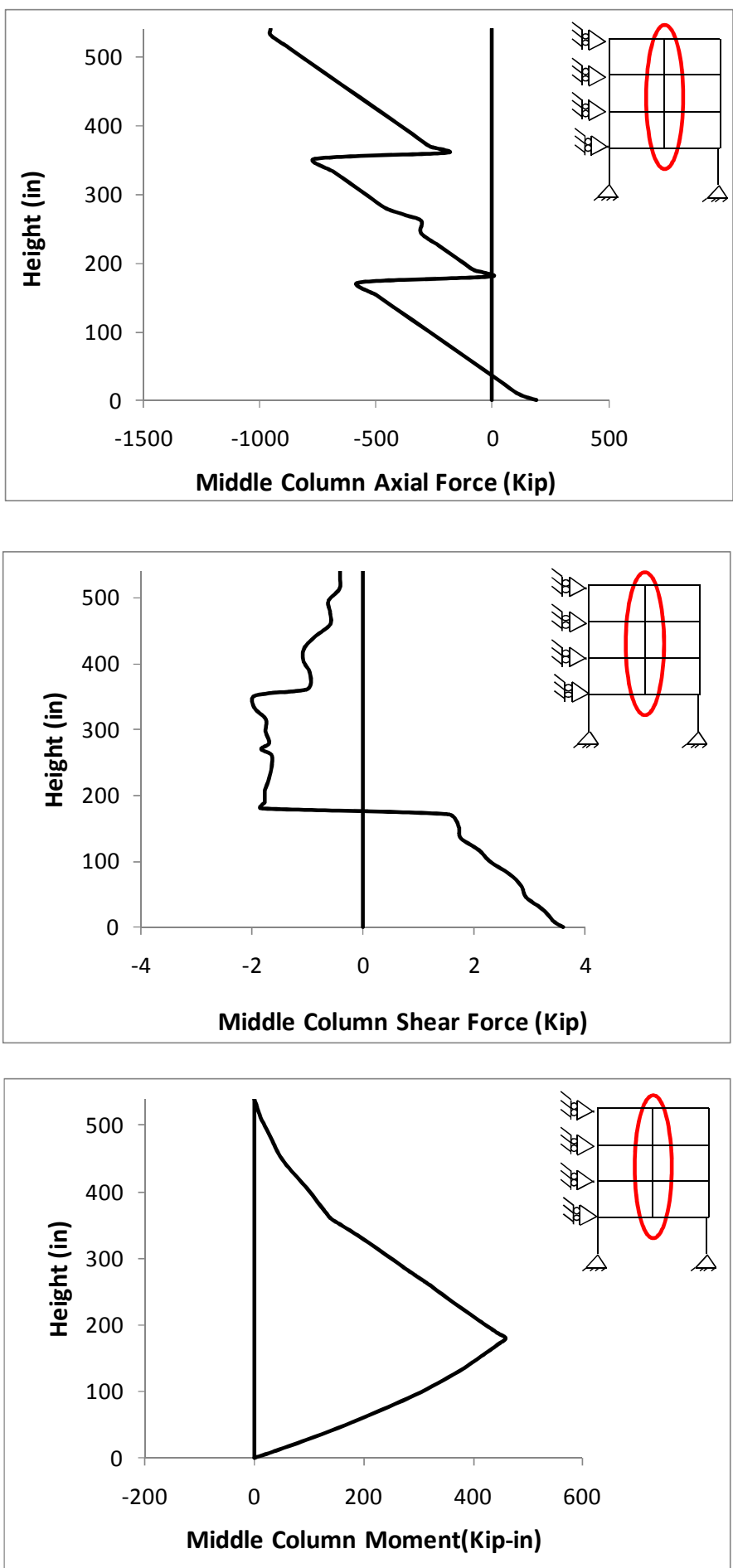

Figure 7-29: Axial, shear, and moment diagrams for the middle column under Boundary Condition \#2 


\subsubsection{Boundary Condition \#3}

Similar to Boundary Conditions \#1 and 2, Boundary Condition \#3 takes into account the loss of the interior column. In addition, sidesway is inhibited on both sides of the frame. This boundary condition results in the development of catenary actions in all beams. Therefore, the FBD in Figure 7-24(b) is utilized to quantify the demands on exterior columns. Due to symmetry; only the exterior column on the right side of the frame was investigated. Figure 7-30 shows the demand distributions in this column. As shown, the simplified procedure and the nonlinear static analysis produce similar results. For the interior column which is damaged at the bottom story, results from the nonlinear static analysis are presented in Figure 7-31. 

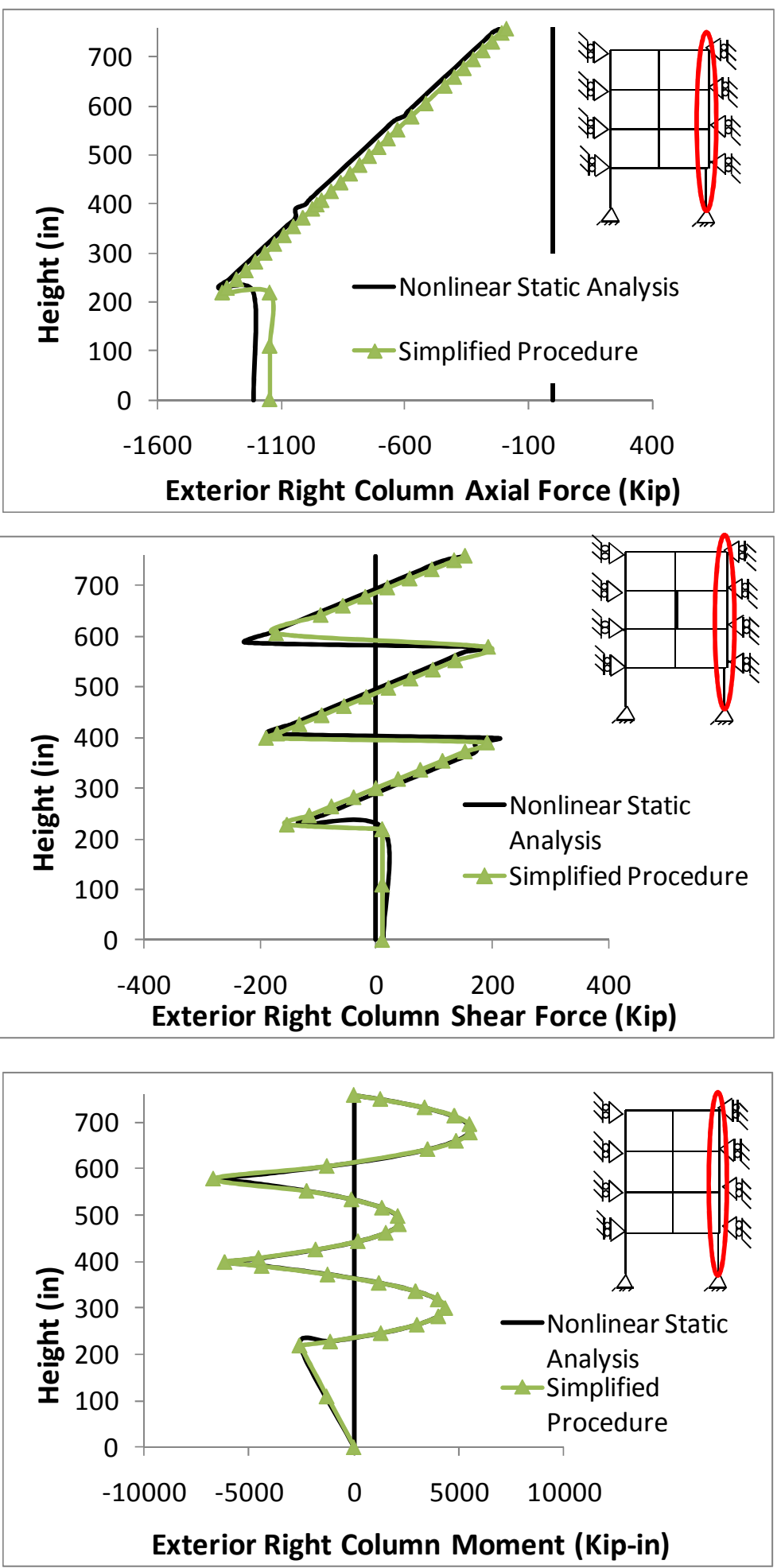

Figure 7-30: Axial, shear, and moment diagrams for the right column under Boundary Condition \#3 

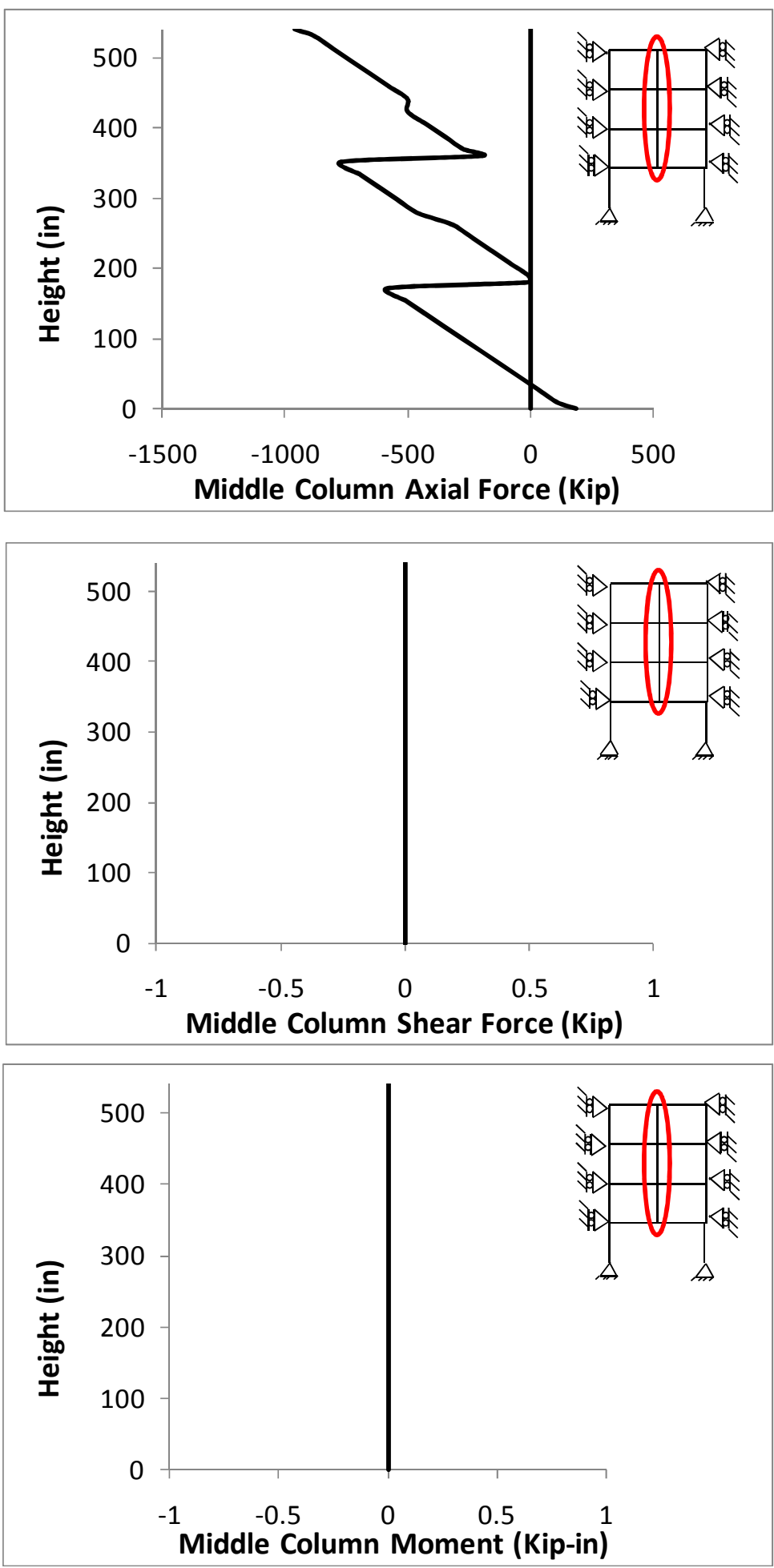

Figure 7-31: Axial, shear, and moment diagrams for the middle column under Boundary Condition \#3 


\subsubsection{Boundary Condition \#4}

Boundary Condition \#4 considers the loss of an exterior column at the bottom story and allows sidesway displacement of the frame. The FBD shown in Figure 7-24(a) was used to calculate the demands in the left exterior column and the corresponding results are compared with those from the nonlinear static analysis in Figure 7-32. As shown, results from the simplified procedure agree well with those from the nonlinear static analysis.

In addition to the left exterior column, the right exterior column and the interior column were analyzed. It should be noted that the tension field actions develop completely in the right bay of the frame; however, incompletely in the left bay of the frame. Therefore, the FBDs cannot be used for these two columns and only the nonlinear static analysis was conducted. Detailed results are presented in Figure 7-33 and Figure 7-34, respectively. 

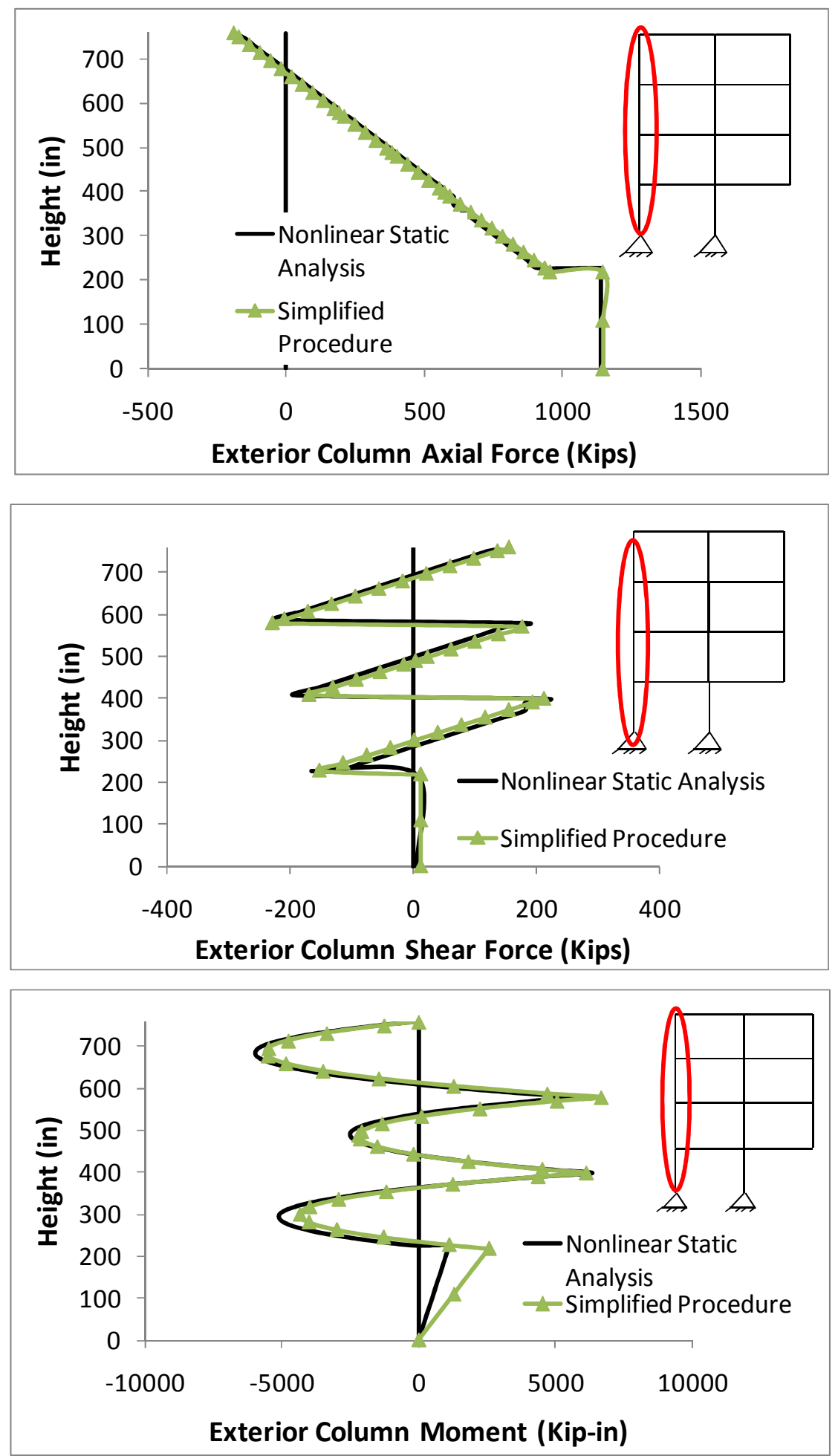

Figure 7-32: Axial, shear, and moment diagrams for the left column under Boundary Condition \#4 

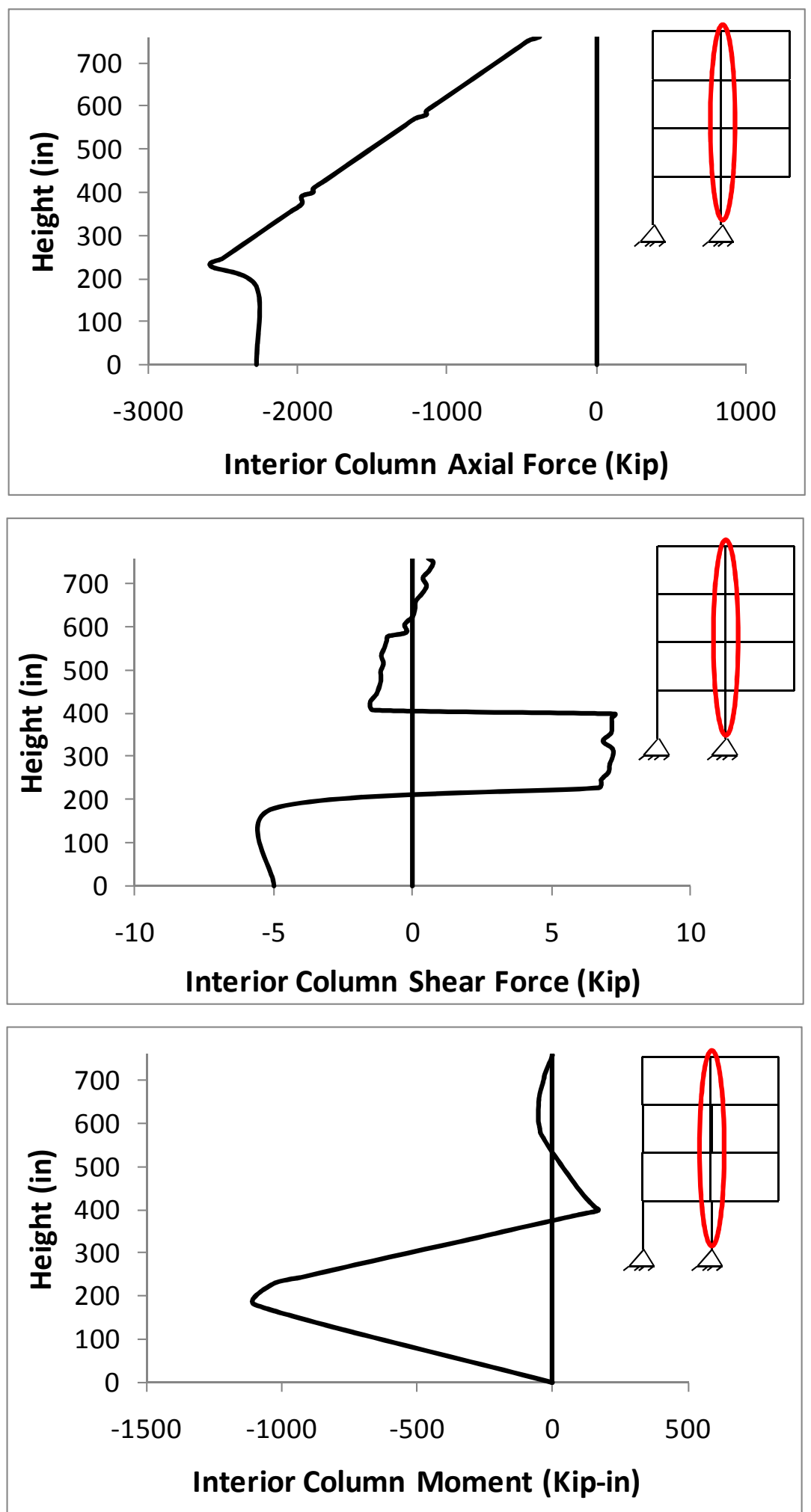

Figure 7-33: Axial, shear, and moment diagrams for the middle beam under Boundary Condition \#4 

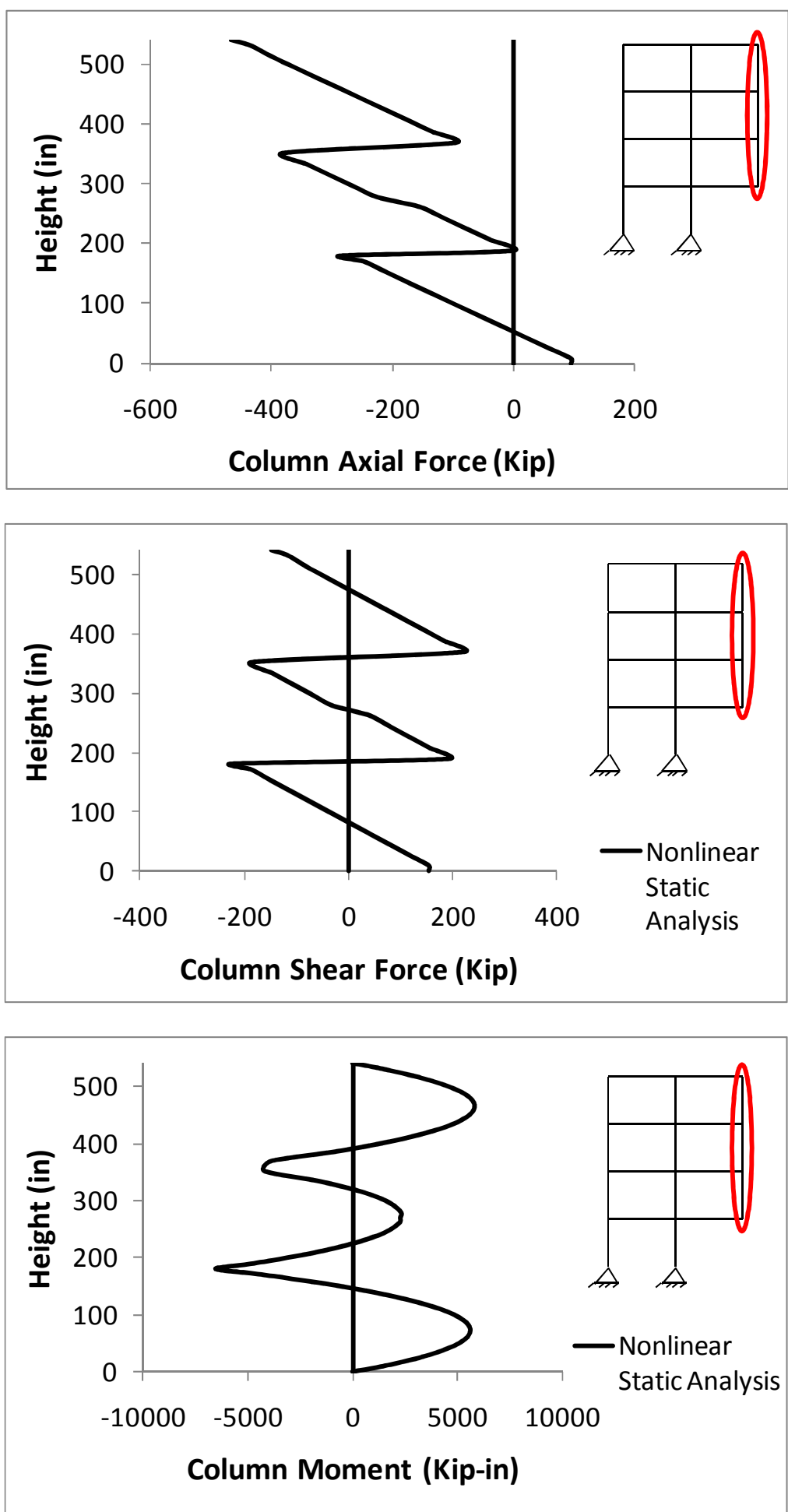

Figure 7-34: Axial, shear, and moment diagrams for the right column under Boundary Condition \#4 


\subsubsection{Boundary Condition \#5}

Similar to Boundary Condition \#4, Boundary Condition \#5 considers the loss of an exterior column. In addition, Boundary Condition \#5 assumes that the sideway displacement of the frame is inhibited. Under the downward displacement along the right exterior column, the infill panels installed in the right bay of the frame fully yield; however, the infill panels of the left bay do not fully yield, resulting in complete and partial infill panel tension field actions on the right and left bays, respectively. As such, the FBDs presented in Figure 7-24, which assume complete tension field actions along the columns, may not be able to exactly capture the column demand distributions under this boundary condition. As such, while complete results from the nonlinear static analysis were provided here, the FBD presented in Figure 7-24(a) were only used for calculating the axial force, shear, and moment for the interior column. Detailed results for the left exterior, interior and right exterior columns are presented in Figure 7-35, Figure 7-36, and Figure 7-37, respectively. As shown, the FBD provides reasonable results for the interior column in this case. 

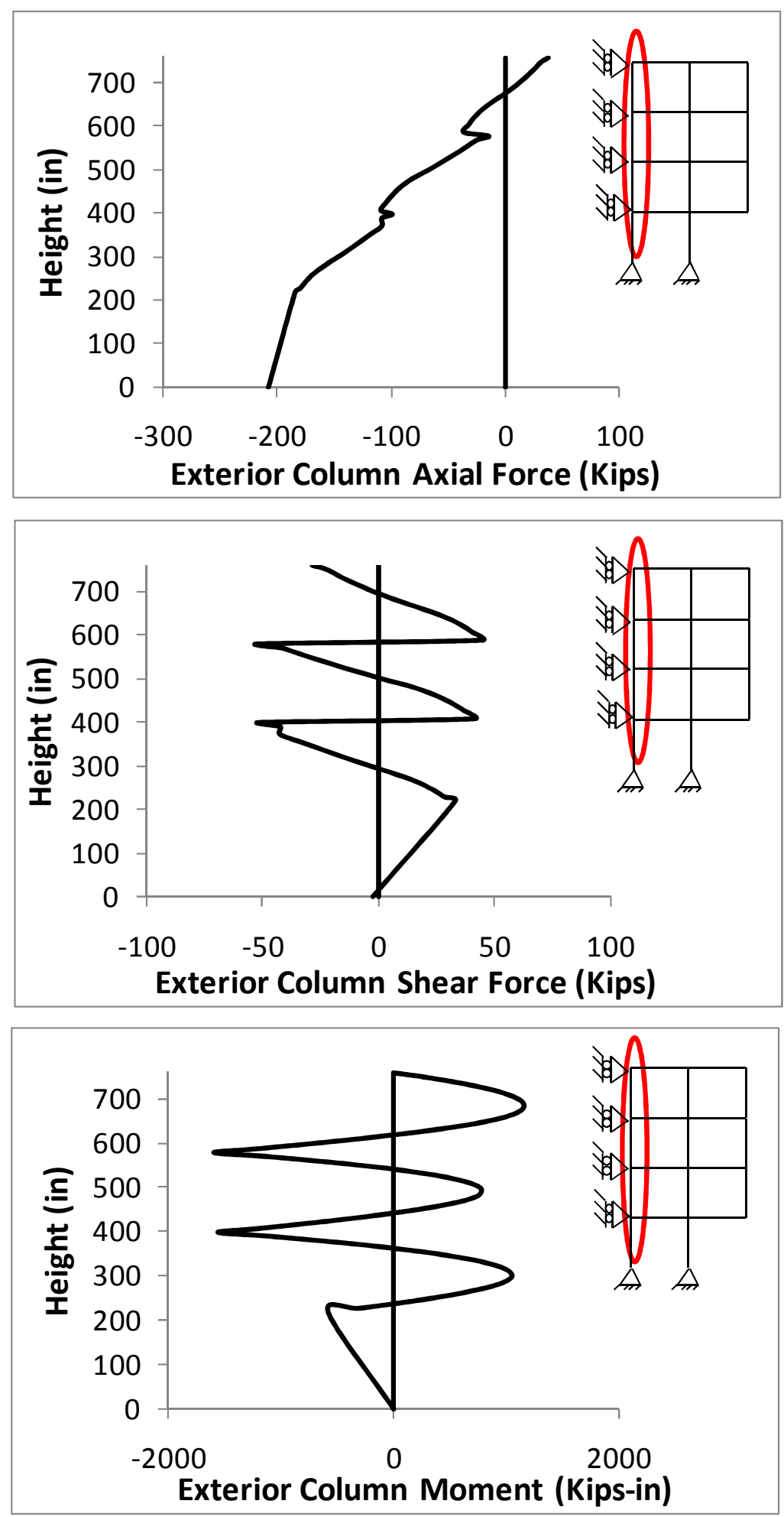

Figure 7-35: Axial, shear, and moment diagrams for the left column under Boundary Condition \#5 

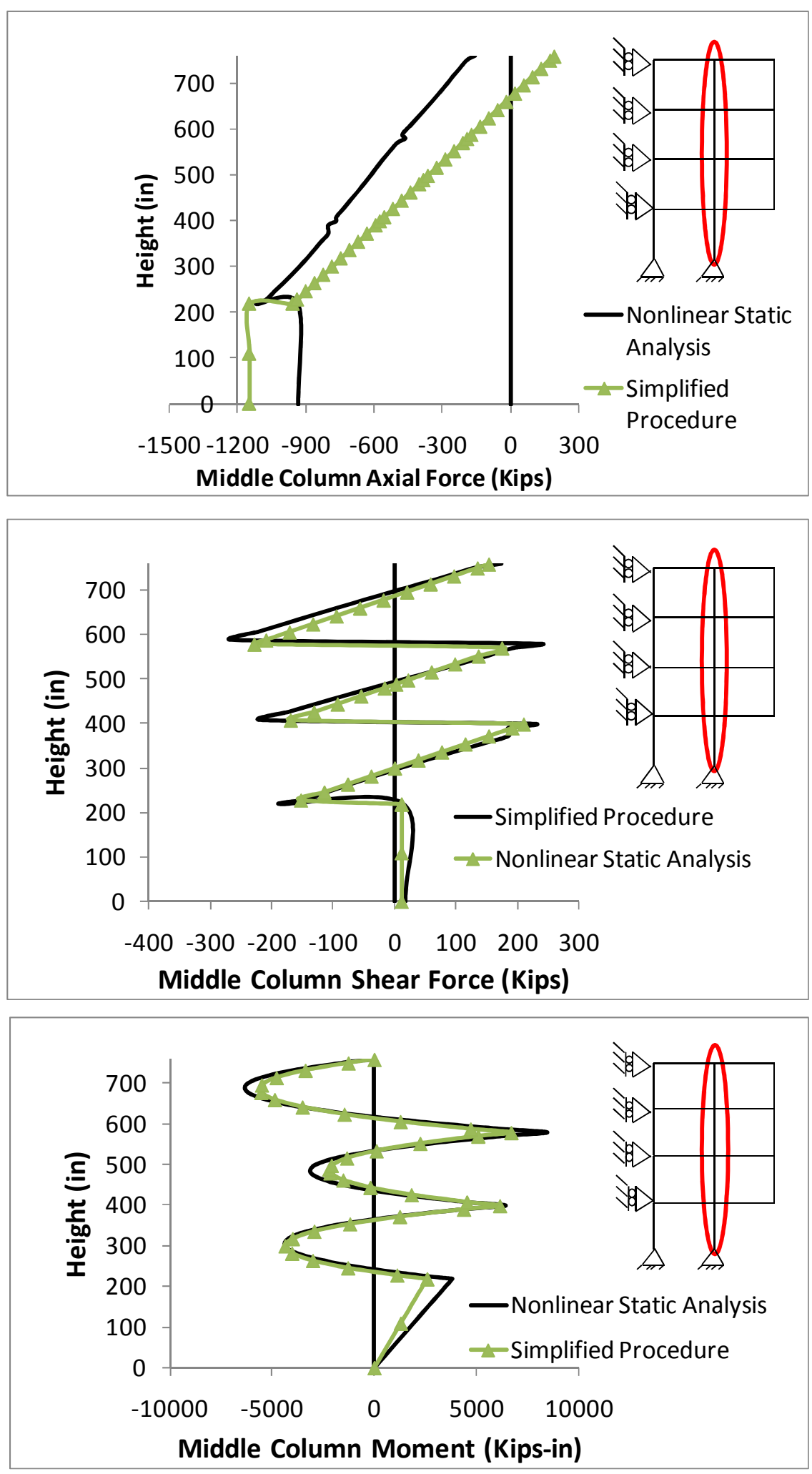

Figure 7-36: Axial, shear, and moment diagrams for the middle column under Boundary Condition \#5 

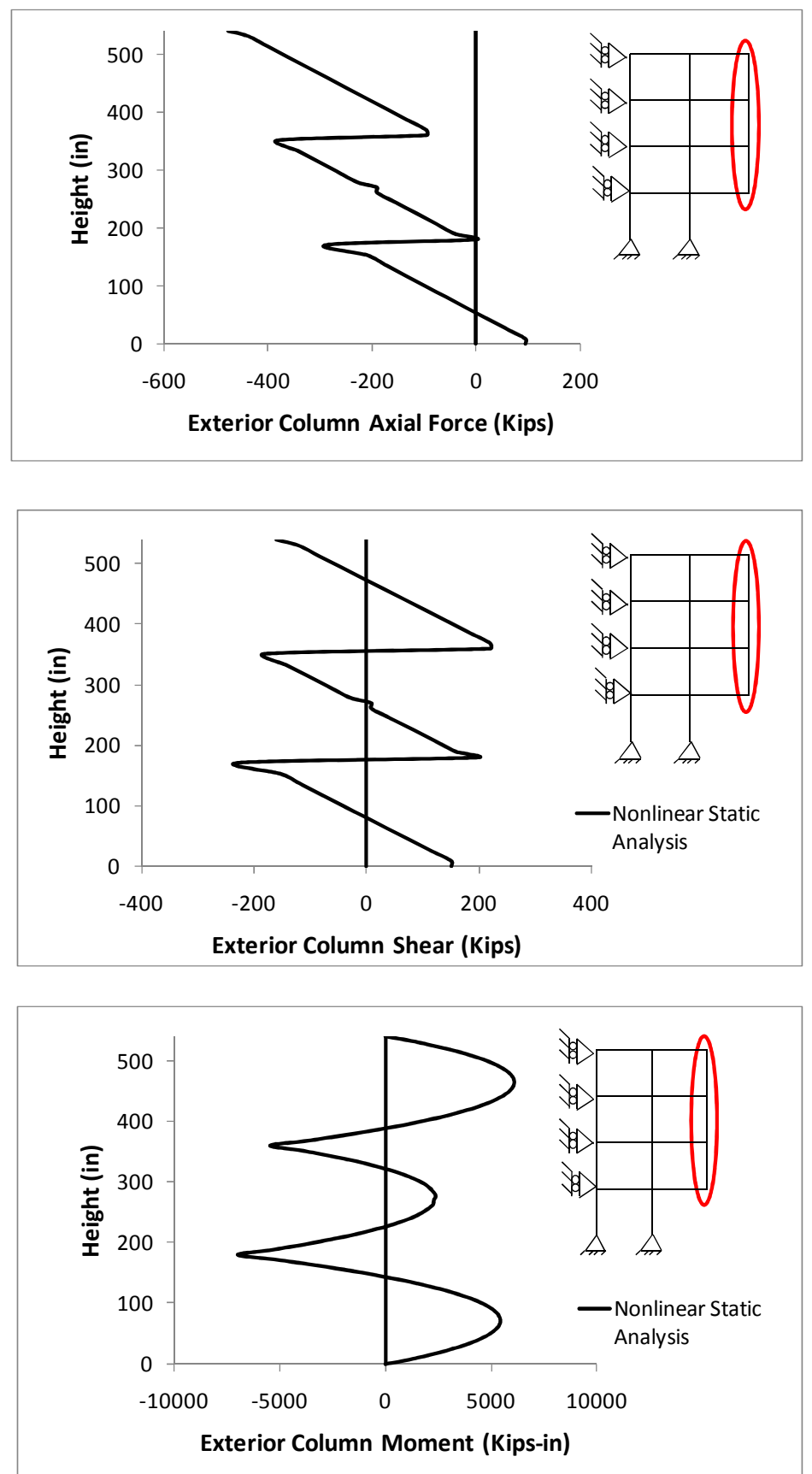

Figure 7-37: Axial, shear, and moment diagrams for the right column under Boundary Condition \#5

\subsection{Summary}

The demands on the boundary frame members (i.e. beams and columns) were investigated in this chapter. All five boundary conditions presented in Figure 5-1 were considered. The demands obtained respectively from the nonlinear static analysis using 
the 2D FE models and the simplified procedure using the developed FBDs were compared. It was observed that the simple FBDs adequately capture the demand distributions along the frame members. 


\section{IMPACT OF BEAM-TO-COLUMN CONNECTION FAILURE ON SYSTEM BEHAVIOR}

\subsection{Introduction}

As discussed in the previous sections, beam-to-column connections play an important role to transfer the axial forces in the beam to the adjacent columns when sudden column failure occurs. To date, significant research efforts have been made to improve the performance of beam-to-column connections to enhance the system progressive collapse resistance (Li 2009).

In the proposed system, the beam-to-column connections may suffer from premature failure for the following two reasons: 1) the deformation capacity (i.e., ductility) of the connections may not be sufficient for fully developing the system strength; and 2) significant tensile force may exist in the beam-to-column connections when the frame boundary conditions allow the development of catenary actions. This chapter investigates how the progressive collapse resistance of the proposed system will be affected when premature failure occurs in the beam-to-column connections.

The 3D FE model developed in ABAQUS and considered in Chapter 4 was used here for modeling the behavior of the proposed system under connection failures. First, the beams with connection failures were partitioned into three segments: two exterior segments and one interior segment, which represent the connection elements and the beam element, respectively. The length of each connection element is $5 \%$ of the original beam length. The failures of the beam-to-column connections were then taken into 
account by assigning reduced yield strength (3\% of the beam yield strength) and a reduced cross-section area $(50-70 \%$ of the original beam cross-section area) to the connection elements. The progressive collapse resistances of the retrofitted system with and without beam-to-column failure are then compared to quantify the impact of connection failures.

Additionally, the system strength with connection failures is estimated using the following equation:

$$
P=\frac{1}{2} \cdot f_{y} \cdot h \cdot \sin 2 \alpha\left(\sum_{i=1}^{n} t_{p t_{i}}\right)+(b-c) \cdot \frac{1}{2} \cdot \theta^{3} \cdot A \cdot E
$$

where, $c=$ number of beams affected by connection failures; and all other variables have been previously defined.

Note that the above equation is based on equation (3-59), which was derived based on plastic analysis. Additionally, it takes into account the loss of beam catenary actions due to the beam-to-column connection failures.

Given that the beam-to-column connections may be more vulnerable to failure when large tensile forces caused by the catenary action develop in the beams, the system under Boundary Condition \#3 (which assumes sideway inhibited boundary conditions on both sides of the frame and allow the development of the beam catenary actions) was selected for investigation. 


\subsection{Case Studies}

This section investigates the impact of connection failure on the behavior of the proposed system under Boundary Condition \#3. For comparison purpose, a total of four cases (i.e. Cases A through D, see Table 8-1 for detailed information) were considered here to investigate the impacts of 1) connection failures occurring at different locations and 2) number of connection failures. Detailed results from Cases A through D are presented below. 
Table 8-1: Cases considered for system with beam-to-column failures

\begin{tabular}{|c|c|c|}
\hline Case & Description & Illustration \\
\hline A & $\begin{array}{l}\text { Top floor exterior beam-to- } \\
\text { column connections failures }\end{array}$ & \\
\hline B & $\begin{array}{l}\text { Bottom floor interior beam- } \\
\text { to-column connections } \\
\text { failures }\end{array}$ & \\
\hline C & $\begin{array}{l}\text { Top floor exterior and bottom } \\
\text { floor interior beam-to-column } \\
\text { connections failures }\end{array}$ & \\
\hline D & $\begin{array}{l}\text { All floors beam-to-column } \\
\text { connections failures }\end{array}$ & \\
\hline
\end{tabular}


Case A considers the beam-to-column connections failures in the top anchor beams. According to the results presented in Chapter 7 the top anchor beams will have larger tensile forces than the other beams when Boundary Condition \#3 applies. From the FE results shown in Figure 8-2, strength of the system with Case A connection failures is $6.5 \%$ lower than the system without any connections failures at the end of the analysis (i.e. when the interior column downward displacement reaches $2.6 \%$ of the beam length). The strength reduction is caused due to the following two facts: 1) the loss of catenary actions in the top anchor beams due to connection failures; and 2) the incomplete formation of the tension field actions in the top story as shown in Figure 8-1. Note that the connection failure in the top floor prevents a portion of the infill panels from yielding. Given that Equation (8-1) only considers the loss of catenary actions and assumes complete formation of the tension field actions in all stories, it is expected to overestimate the system strength. The result comparison presented in Figure 8-2 further confirms this point. As shown, for the system with Case A connection failures, the result from Equation (8-1) is $4.1 \%$ higher than the FE result at the end of the analysis. 


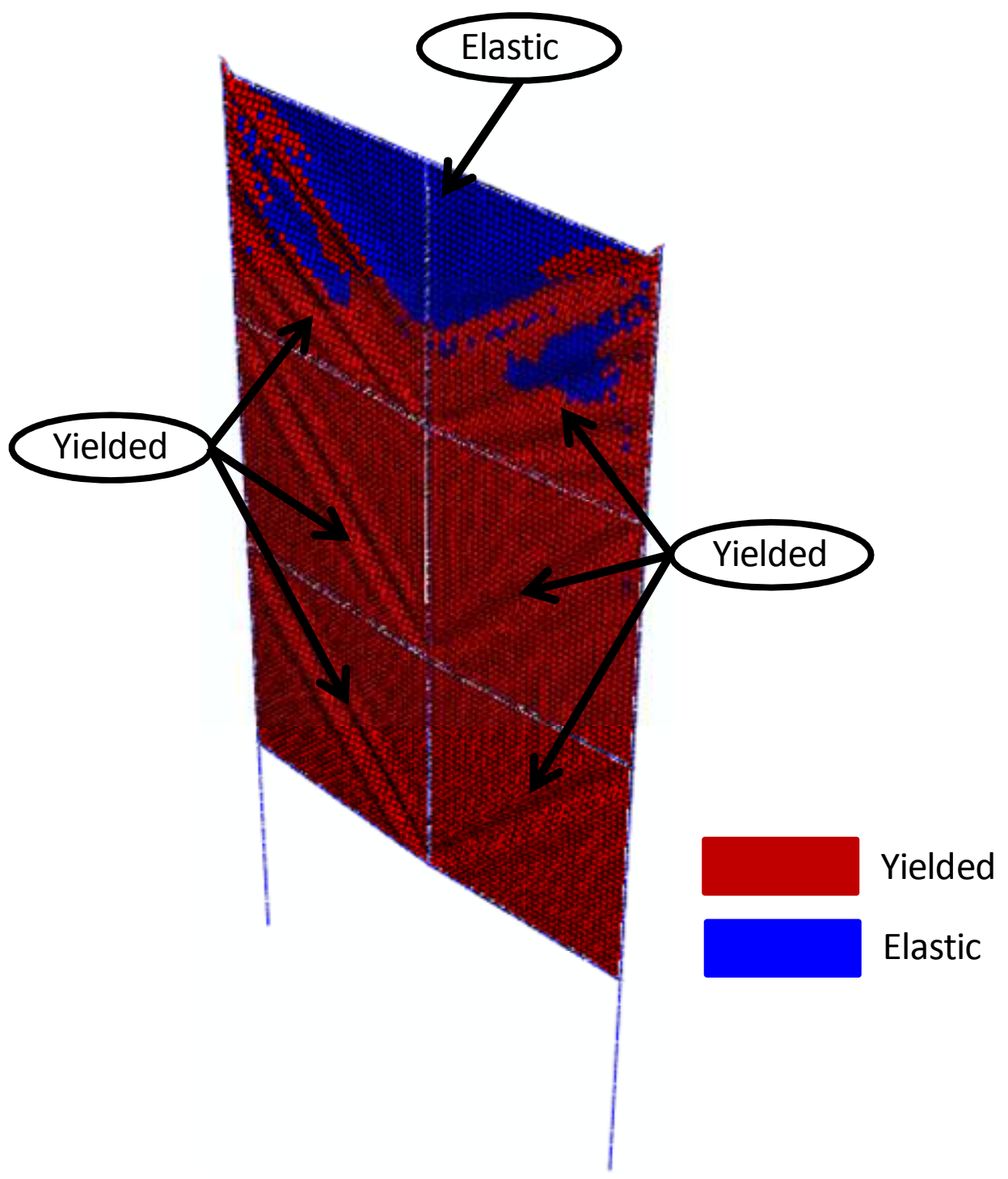

Figure 8-1: Tension field action distribution in the frame under Boundary Condition \#3 and Case A connection failures 


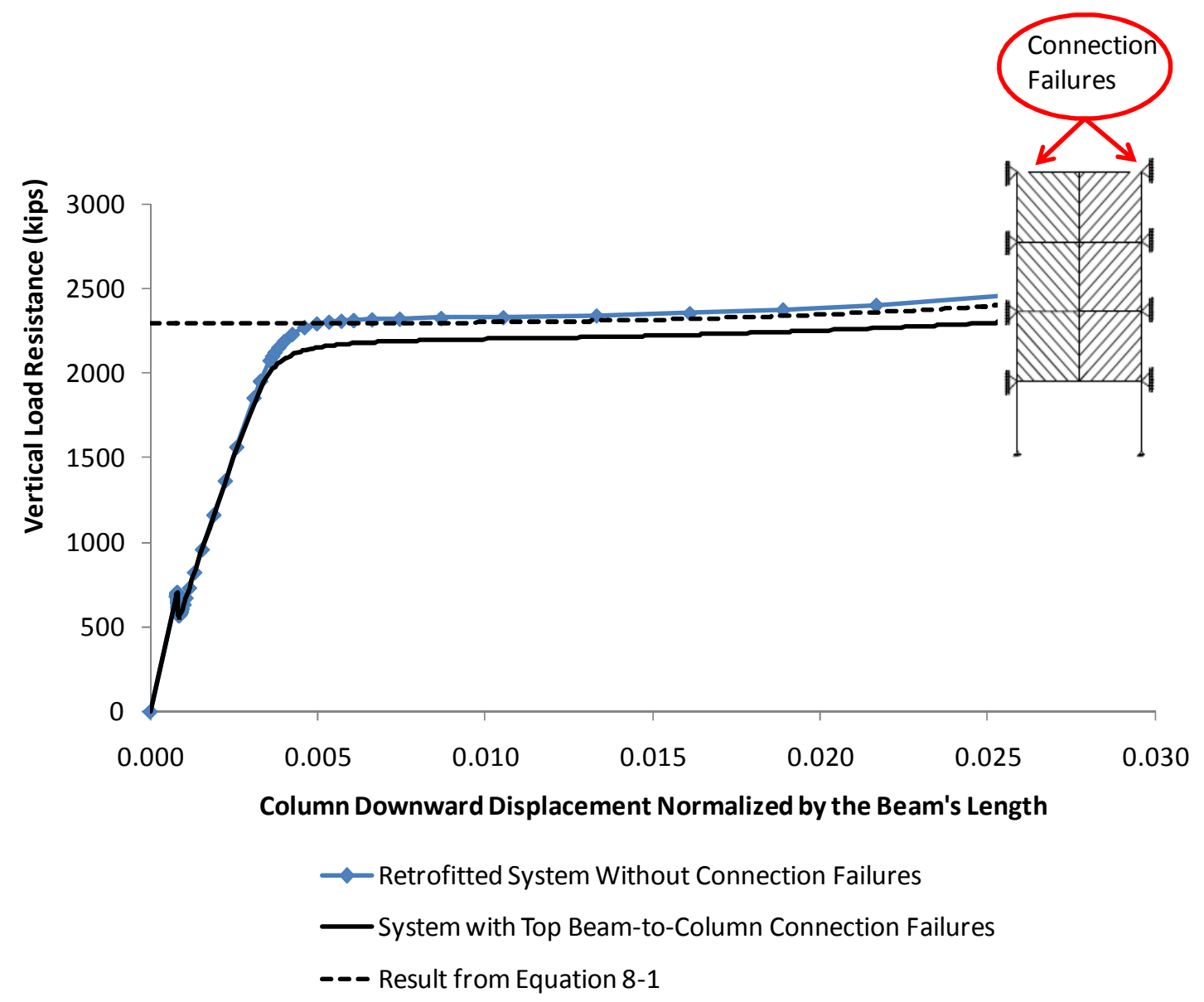

Figure 8-2: Vertical resistance of the system under Boundary Condition \#3 and Case A connection failures

A similar study was conducted for Case B which assumes beam-to-column connection failures at the bottom anchor beams. Case B was selected due to the following two facts: 1) the axial tensile forces in the bottom anchor beams, while lower than those in the top anchor beams, are greater than the intermediate beams; and 2) the connections at the end of the bottom anchor beams are more vulnerable to damages when the loss of the bottom story interior column is caused by blast loading or vehicle collision. The tension field distribution is shown in Figure 8-3. Consistent with Case A, due to the connection failures in the bottom anchor beams, incomplete tension field actions were observed in 
the second story. Moreover, as shown in Figure 8-4, a reduced strength was observed in the system and the plastic analysis equation slightly overestimates the strength of the system.

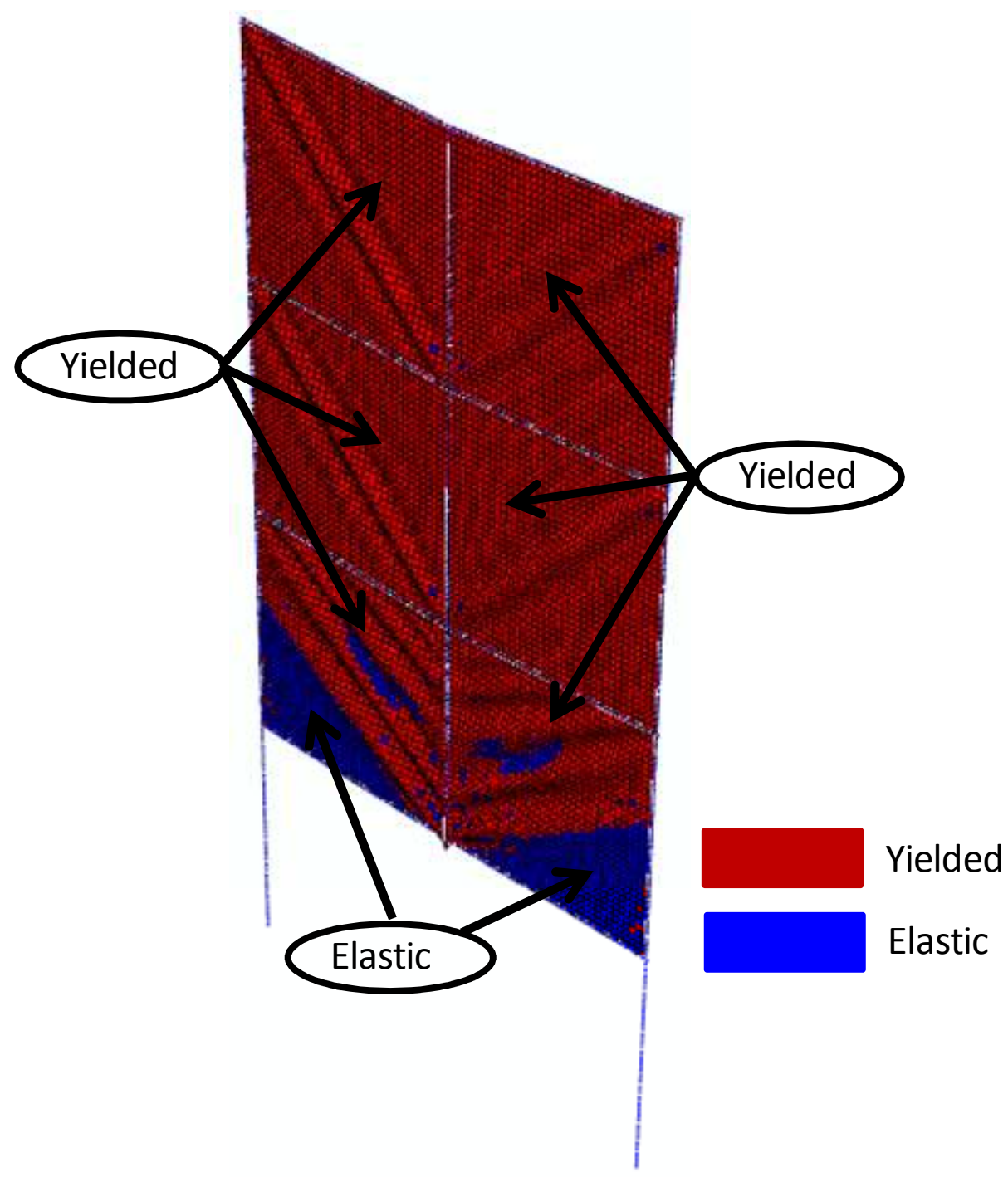

Figure 8-3: Tension field action distribution in the frame under Boundary Condition \#3 and Case B connection failures 


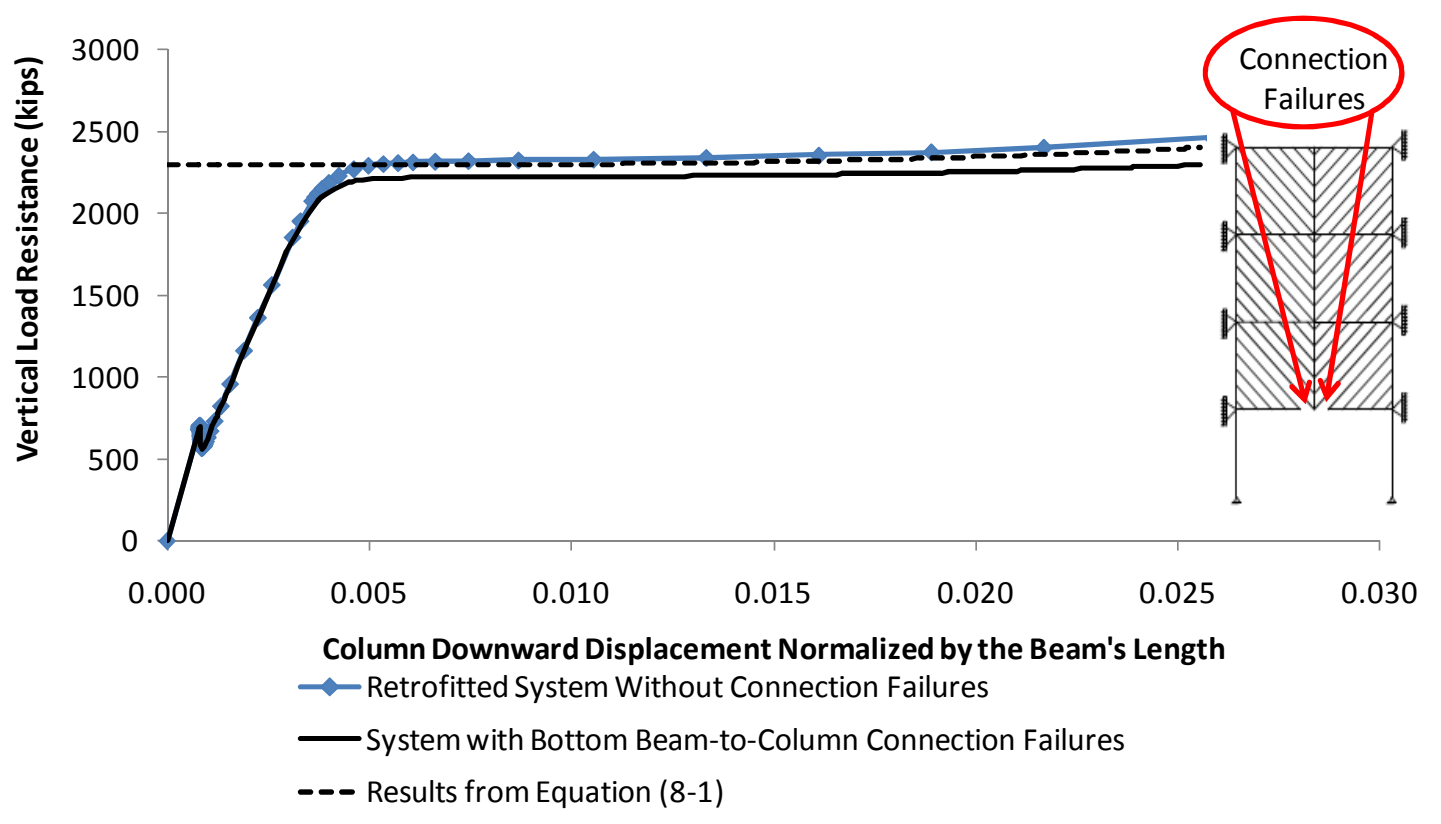

Figure 8-4: Vertical resistance of the system under Boundary Condition \#3 and Case B connection failures

Case $\mathrm{C}$ combines the connection failures considered in Cases A and B, i.e. assuming connection failures in all anchor beams. As shown in Figure 8-5, the tension fields are not fully developed in the structural frames with connection failures, which is similar to the observations from Cases A and B. The system strength curves are presented in Figure 8-6. Compared with the results presented in Figure 8-2 and Figure 8-4, the damaged system of Case $\mathrm{C}$ exhibits a lower ultimate strength than Cases A and B. Moreover, the plastic analysis overestimate the reduced system strength for the same reason explained earlier. 


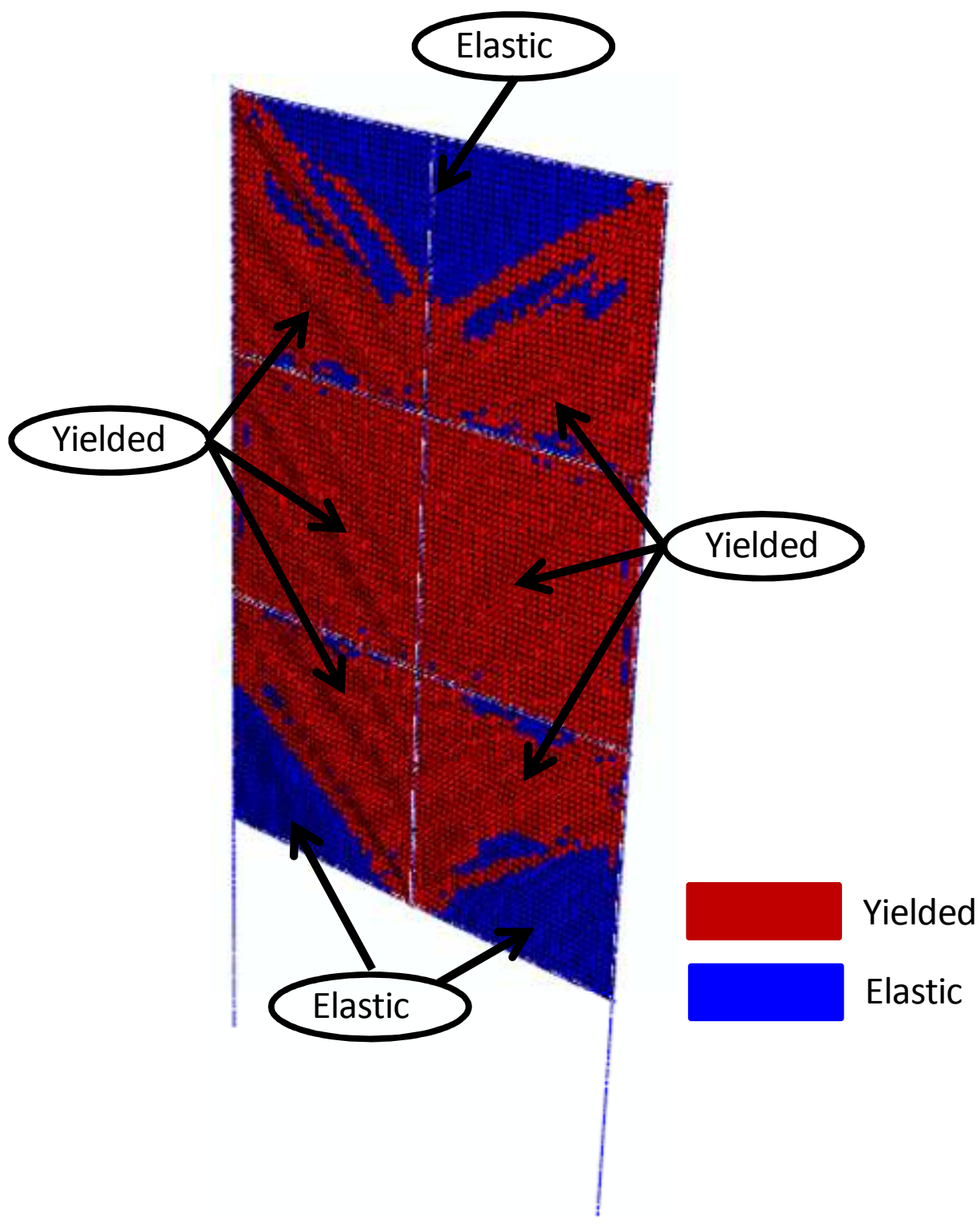

Figure 8-5: Tension field action distribution in the frame under Boundary Condition \#3 and Case $C$ connection failures 


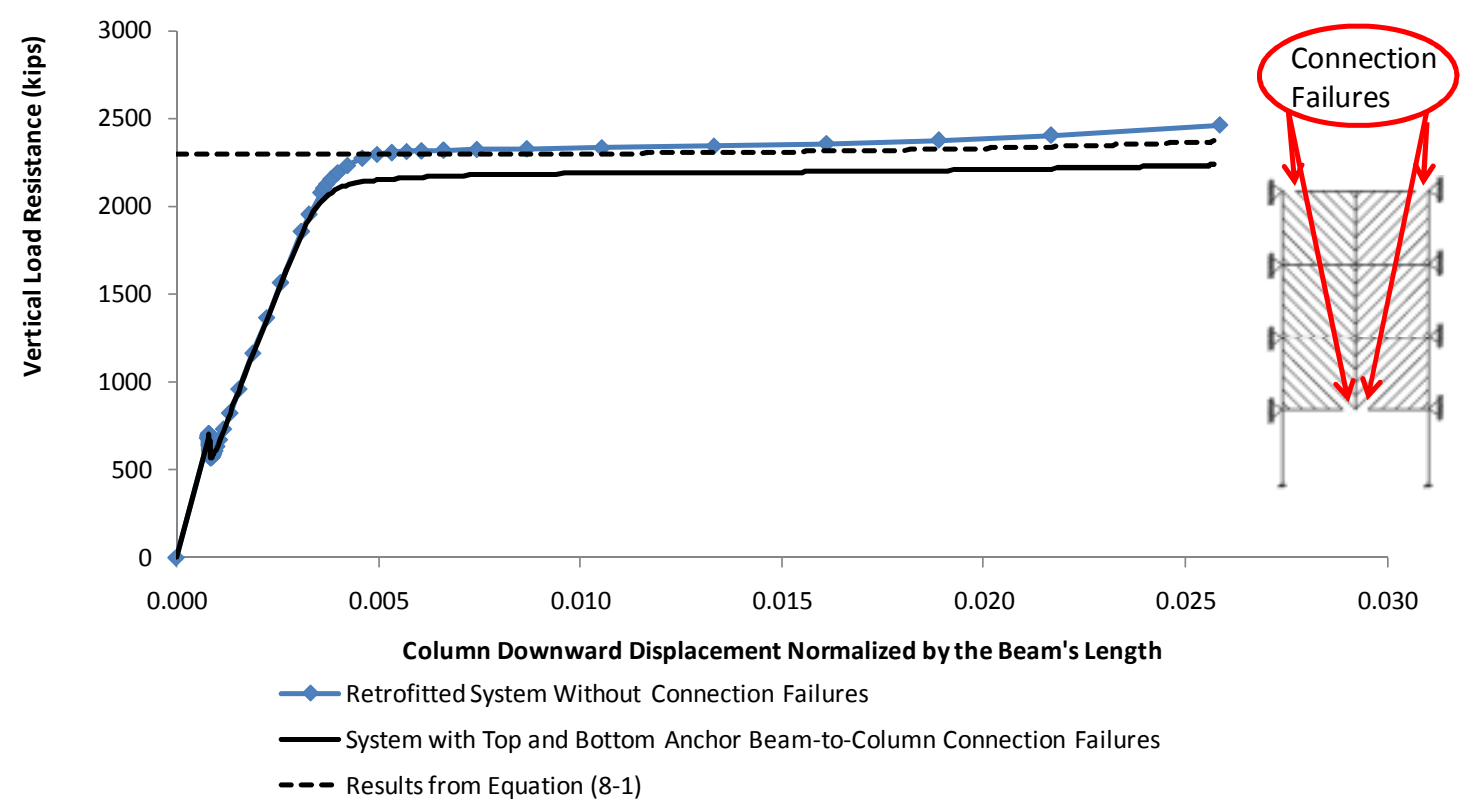

Figure 8-6: Vertical resistance of the system under Boundary Condition \#3 and Case $C$ connection failures

Case D considers the worst scenario in which connection failures occurs in all beam members. The locations where connection failures occur are given in Figure 8-8 together with the system responses. Compared with Cases A to C, the system considered in Case D has a lower vertical load resistance due to the loss of catenary action in all beams and the absence of complete tension field actions. The plate yielding distribution is shown in Figure 8-7. It is observed that the tension field distribution of Case D is similar to that of Case $\mathrm{C}$, indicating that connections failures in intermediate beams have a negligible impact on development of tension field actions when plates with identical thickness and strength are used in all stories. Similar to the prior cases, the plastic analysis procedure produces an overestimate of the system strength. 
Table 8-2 present the strengths of the systems considered in Cases A through D at different downward displacement levels.

Table 8-2: Capacities of the systems with connection failures*

\begin{tabular}{|l|l|l|l|l|l|l|l|l|}
\hline \multirow{2}{*}{$\begin{array}{l}\text { Downward } \\
\text { displacement }\end{array}$} & \multicolumn{2}{|l|}{ Case A } & \multicolumn{2}{l|}{ Case B } & \multicolumn{2}{l|}{ Case C } & \multicolumn{2}{l|}{ Case D } \\
\cline { 2 - 9 } & $\mathrm{FE}$ & $\begin{array}{c}\mathrm{Eq} \\
(8-1)\end{array}$ & $\mathrm{FE}$ & $\begin{array}{c}\mathrm{Eq} \\
(8-1)\end{array}$ & $\mathrm{FE}$ & $\begin{array}{c}\mathrm{Eq} \\
(8-1)\end{array}$ & FE & $\begin{array}{c}\text { Eq } \\
(8-1)\end{array}$ \\
\hline $0.5 \%$ & .925 & .996 & .952 & .996 & .930 & .995 & .934 & .995 \\
\hline $1.0 \%$ & .945 & .988 & .957 & .988 & .939 & .988 & .950 & .986 \\
\hline $1.5 \%$ & .941 & .982 & .948 & .982 & .931 & .979 & .937 & .974 \\
\hline $2.0 \%$ & .943 & .982 & .944 & .982 & .925 & .975 & .923 & .961 \\
\hline $2.6 \%$ & .935 & .976 & .933 & .976 & .907 & .961 & .890 & .932 \\
\hline
\end{tabular}

normalized by the strength of the system without any connection failures ** normalized by the beam length 


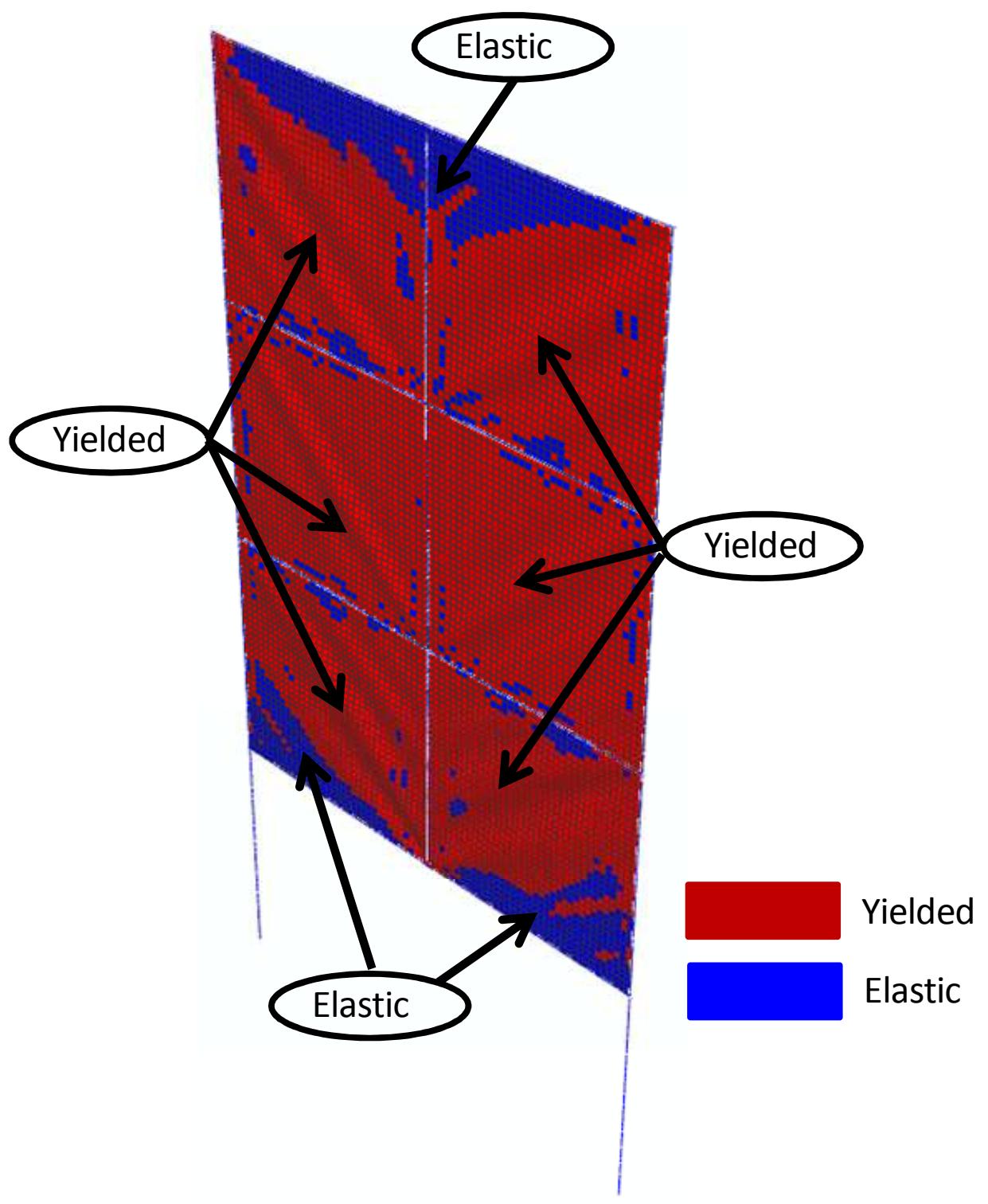

Figure 8-7: Tension field action distribution in the frame under Boundary Condition \#3 and Case D connection failures 


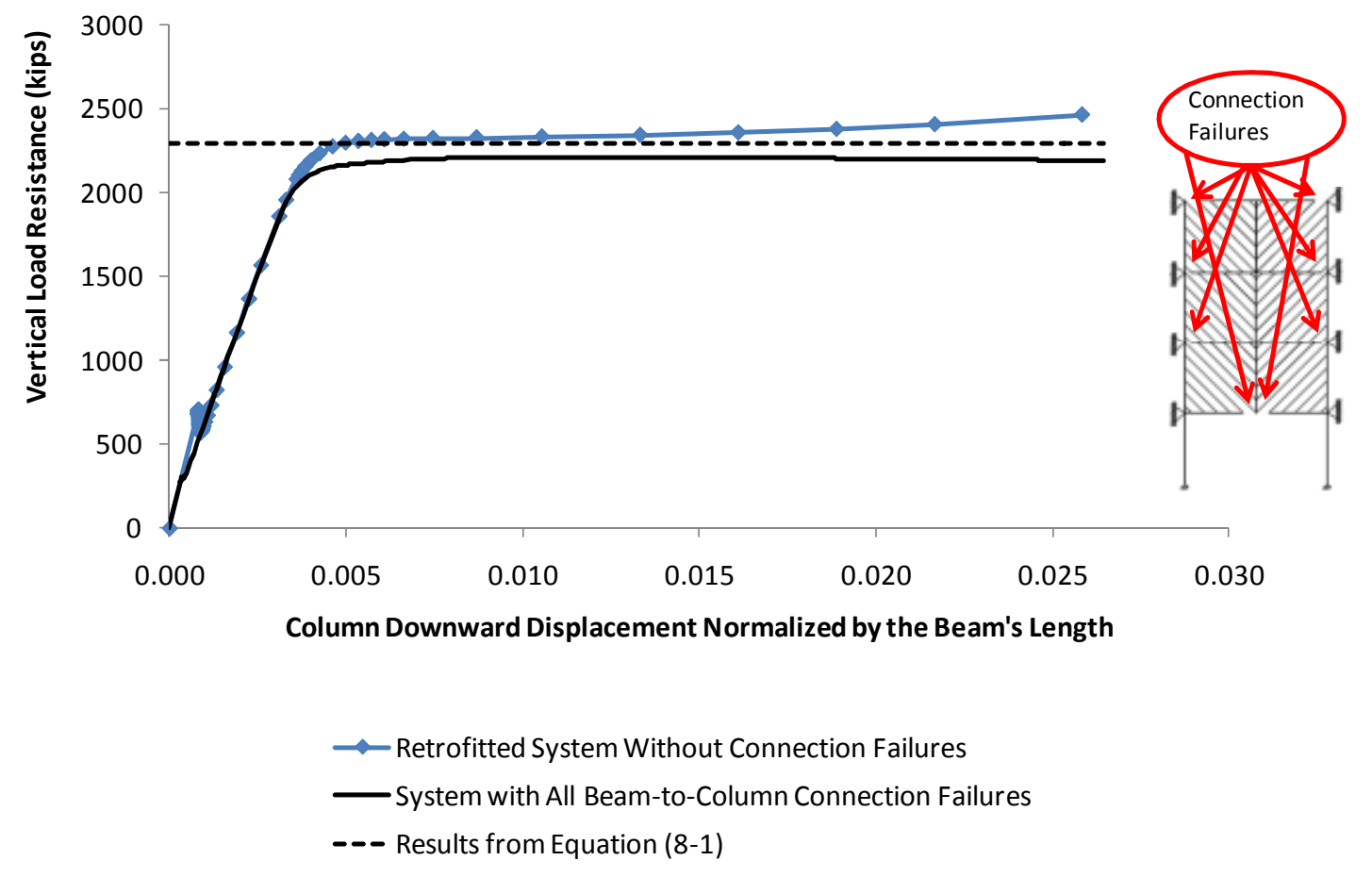

Figure 8-8: Vertical resistance of the system under Boundary Condition \#3 and Case D connection failures

\subsection{Summary}

The impact of beam-to-column connection failures on the strength of the retrofitted system was investigated in this chapter. A total of four cases which consider different locations and numbers of connection failures were investigated. It was observed that the connection failures, while result in the loss of beam catenary action and prevent complete formation of the infill panel tension field actions, have a minor impact on the system strength, demonstrating the robustness of the proposed system. In addition, the estimate from the plastic analysis model, while slightly larger, can be used as a reasonable estimate of the strength of the system subjected to beam-to-column connection failures. 


\section{SUMMARY, CONCLUSIONS, AND RECOMMENDATIONS FOR FUTURE RESEARCH}

\subsection{Summary and Conclusions}

This thesis investigated the potential use of thin infill panels in steel frames for enhancement of the system's progressive collapse resistance. Five boundary conditions were examined to consider the impacts of the different locations of initial column failures and the different lateral displacement restraints on both sides of the frame. Three analytical models were developed. The first model was based on plastic analysis theory. The second and third models are FE models requiring different levels of modeling efforts. Performance of the proposed system was evaluated using all the three developed models. In addition, the system performance obtained from nonlinear static FE analysis was modified to take into account the dynamic effects of progressive collapse. Furthermore, simple FBDs for quantifying the demands including axial force, shear force and bending

moment on the boundary frame members were developed. Last, the impact of premature beam-to-column connection failures on the system progressive collapse resistance was addressed.

Through the analytical work conducted in this research, the following conclusions may be drawn:

1. the proposed system is effective to enhance the system progressive collapse resistance under all the considered boundary conditions.

2. all the developed analytical models are effective for calculating the system ultimate strength. The plastic model is very simple and can be used in hand 
calculations for preliminary design of the plate thickness. The 3D FE model can be used for capturing the plate buckling and other local component behaviors. The 2D FE model can be used for a better determination of demand distributions in the boundary frame members.

3. the dynamic effects can be considered by modifying the system response obtained from the nonlinear static FE analysis.

4. the demands on boundary frame members can be calculated using the developed simple FBDs.

5. the proposed system is very robust and exhibits stable progressive collapse resistance even when premature beam-to-column connection failures occur in the system.

\subsection{Recommendations for Future Research}

While the dynamic effects were indirectly considered in Chapter 7, it would be interesting to explore the actual dynamic behavior of the proposed system through nonlinear dynamic analysis.

In addition, this thesis only considered simple beam-to-column connections. It would be beneficial to investigate the behavior of the proposed system when the beam-to-column connections are fully rigid.

Furthermore, this thesis assumed either ideally rigid or ideally flexible lateral boundary conditions (i.e., either sidesway inhibited or sidesway uninhibited); it would be 
interesting to investigate the performance of the proposed system when the stiffness of the lateral restraints varies over a practical range. 


\section{REFERENCES}

ACI. Building code Requirements for Structural Concrete (ACI Standard 318-08). Farmington Hills, MI: American Concrete Institute, 2008.

AISC. (2005). “American Institute of Steel Construction.” Chicago, Illinois.

ASCE Standard 7-05, Minimum Design Loads for Buildings and Other Structures (ASCE/SEI 7-2005) (2005), American Society of Civil Engineers, Reston, VA.

Astaneh-Asl, A. "Progressive Collapse Prevention of Steel Frames with Shear Connections." Department of Civil and Environmental Engineering and Center for Catastrophic Risk Management University of California, Berkeley, 2007.

Astaneh-Asl, A, D. McCallen, E. Madsen, and C. Noble (2001) "Experimental and Analytical Studies of Floor Catenary Action to Prevent Progressive Collapse," Report Number UCB/CESteel-01/03, Department of Civil and Environmental Engineering, University of California, Berkeley, December (www.ce.berkeley.edu/ astaneh).

Behbahanifard, M. R., Grondin, G. Y., and Elwi, A. E. (2003). "Experimental and Numerical Investigation of Steel Plate Shear Wall." Structural Engineering Report 254, Department of Civil Engineering, University of Alberta, Edmonton, Alberta, Canada.

Berman, J. W. and Bruneau, M. (2003), "Experimental Investigation of Light-Gauge Steel Plate Shear Walls for the Seismic Retrofit Of Buildings." Technical Report MCEER-03-0001, Multidisciplinary Center for Earthquake Engineering Research, Buffalo, N.Y., May 2, 2003.

Berman, J. W., and Bruneau, M. (2008), "Capacity Design of Vertical Boundary Elements in Steel Plate Shear Walls.” AISC Engineering Journal Vol.45, No.1., pp.57-71.

Cleland, N.M. "Containing Progressive Collapse in Precast Concrete Systems." ASCENT, Summer 2007.

DoD. Design of Buildings to Resist Progressive Collapse (UFC 4-023-03). Washington, DC: United States Department of Defense, 2009.

Driver, R. G., Kulak, G. L., Kennedy, D. J. L., and Elwi, A. E. (1997). "Seismic Behavior of Steel Plate Shear Walls." Structural Engineering Report 215, Department of Civil Engineering, University of Alberta, Edmonton, Alberta, Canada.

Federal Emergency Management Agency (FEMA 403). (2002). "World Trade Center building performance study: Data collection, preliminary observations, and recommendations." < http://www.fema.gov/rebuild/mat/mat_fema403.shtm $>$ (January, 2011) 
Federal Emergency Management Agency (FEMA 450). (2004), "NEHRP Recommended Provisions For Seismic Regulations For New Buildings And Other Structures." Building Seismic Safety Council for the Federal Emergency Management Agency, Washington, D.C.

Hibbitt, Karlsson, and Sorenson, Inc. (HKS) (2009), "ABAQUS/Standard Users Manual." Version 6.9, Hibbitt, Karlsson, and Sorenson, Inc., Pawtucket, Rhode Island.

Hoffman S. T. (2010) "Behavior and performance of steel moment-framed buildings subject to dynamic column loss scenarios" Master Thesis, University of Illinois at Urbana Champaign. 2010.

Izzuddin B.A. "Ductility assessment for an idealized elasto-Plastic structural system subject to an instantaneous applied load." Internal discussion document. Imperial College London (UK). 2004.

Izzuddin B.A., Vlassis A.G., Elghazouli A.Y., Nethercot D.A., "Progressive collapse of multi-storey buildings due to sudden column loss-Part I: Simplified assessment framework." Imperial College London (UK). 2007.

Level3.com (Sep 20, 2001) <http://mirror-uk-rb1.gallery.hd.org> "moment of collision of flight UA175 Boeing 767 jet with south tower causing huge explosion seen from side of entry 2 ANON.jpg" (January, 2011)

Li J.L. "Preventing progressive collapse through strengthening beam-to-column connection, Part 1: Theoretical analysis" Journal of Constructional Steel Research 66 (2010) 229_237. September 13, 2009.

Marchand A. K., Alfawakhiri F. American Institute of Steel Construction, Inc. "Facts for Steel Buildings-Blast and Progressive Collapse”vol. 2. USA: AISC; 2004.

Marchand A. K., Moore W. P., Alfawakhiri F. American Institute of Steel Construction, Inc. "Facts for Steel Buildings-Blast and Progressive Collapse" 2004.

Qu, B., and Bruneau (2008), "Seismic Behavior and Design of Boundary Frame Members in Steel Plate Shear Walls" Technical Rep. No. MCEER-08-0012, Multidisciplinary Center for Earthquake Engineering Research, Buffalo, N.Y., June 20, 2008.

Qu, B., and Bruneau (2010), "Capacity Design of Intermediate Horizontal Boundary Elements of Steel Plate Shear Walls" ASCE Journal of Structural Engineering, Vol. 136, No. 6, June 1, 2010.

Simulia. Abaqus. Providence, RI: Dassault Systemes Corp., 2008. 
Thorburn, L. Jane, Kulak, G. L., and Montgomery, C. J. (1983). "Analysis of Steel Plate Shear Walls." Structural Engineering Report No. 107, Department of Civil Engineering, University of Alberta, Edmonton, Alberta, Canada.

Timler, P. A. and Kulak, G. L. (1983). "Experimental Study of Steel Plate Shear Walls." Structural Engineering Report No. 114, Department of Civil Engineering, University of Alberta, Edmonton, Alberta, Canada.

Timoshenko, S.(1955). Strength of Materials New York: D. Van Nostrand Company.

Wagner, H., Flat Sheet Metal Girders with Very Thin Metal Webs. Part I-General Theories and Assumptions, National Advisory Committee for Aeronautics, Technical Memo No. 604, 1931

Wearne, P. (2000). Collapse: When buildings fall down, TV Books, New York 


\section{APPENDIX A - ALGORITHM USED TO DETERMINE THE PSEUDO-STATIC RESPONSE}

Assuming a nonlinear static response defined in terms of a $\left(P, u_{s}\right)$ curve, the following algorithm can be used to construct the pseudo-static response $\left(P, u_{d}\right)$ curve and to establish the dynamic displacement corresponding to the suddenly applied gravity

loading $\left(P=P_{o}\right)$. In this algorithm, $\mathrm{P}_{\mathrm{m} \backslash \mathrm{n}}$ refers to the suddenly applied load $\left(\lambda_{\mathrm{m} n} \mathrm{P}_{\mathrm{o}}\right)$, while $\mathrm{P}_{\mathrm{d}, \mathrm{m} n}$ refers to the amplified static load $\left(\lambda_{\mathrm{d}, \mathrm{m} \text { n }} \mathrm{P}_{\mathrm{o}}\right)$, with $m$ and $n$ indicating the start and end of the current increment, respectively.

1. Initialize: $\mathrm{P}_{\mathrm{d}, \mathrm{m}}=\mathrm{P}_{\mathrm{m}}=0, \mathrm{u}_{\mathrm{d}, \mathrm{m}}=0, \mathrm{~A}_{\mathrm{m}}=0$; choose a small displacement increment $\Delta \mathrm{u}_{\mathrm{d}}$. 2. Set: $\mathrm{u}_{\mathrm{d}, \mathrm{n}}=\mathrm{u}_{\mathrm{d}, \mathrm{m}}+\Delta \mathrm{u}_{\mathrm{d}}$.

3. Determine $\mathrm{P}_{\mathrm{d}, \mathrm{n}}$ corresponding to $\mathrm{u}_{\mathrm{d}, \mathrm{n}}$ from the nonlinear static response $\left(\mathrm{P}, \mathrm{u}_{\mathrm{s}}\right)$ curve; obtain the current area under the $\left(\mathrm{P}, \mathrm{u}_{\mathrm{s}}\right)$ curve: $\mathrm{A}_{\mathrm{n}}=\mathrm{A}_{\mathrm{m}}+\left(\mathrm{P}_{\mathrm{d}, \mathrm{m}}+\mathrm{P}_{\mathrm{d}, \mathrm{n}}\right) \Delta \mathrm{u}_{\mathrm{d}} / 2$.

4. Determine the current pseudo-static load: $\mathrm{P}_{\mathrm{n}}=\mathrm{A}_{\mathrm{n}} / \mathrm{u}_{\mathrm{d}, \mathrm{n}}$; establish a new point $\left(\mathrm{P}_{\mathrm{n}}, \mathrm{u}_{\mathrm{d}, \mathrm{n}}\right)$ on pseudo-static response $\left(\mathrm{P}, \mathrm{u}_{\mathrm{d}}\right)$ curve.

5. If $\left(\mathrm{P}_{\mathrm{m}}<\mathrm{P}_{\mathrm{o}} \leq \mathrm{P}_{\mathrm{n}}\right)$, obtain and output dynamic displacement corresponding to Po: $\mathrm{u}_{\mathrm{d}}=$ $\mathrm{u}_{\mathrm{d}, \mathrm{m}}+\left(\mathrm{u}_{\mathrm{d}, \mathrm{n}}-\mathrm{u}_{\mathrm{d}, \mathrm{m}}\right)\left(\mathrm{P}_{\mathrm{o}}-\mathrm{P}_{\mathrm{m}}\right) /\left(\mathrm{P}_{\mathrm{n}}-\mathrm{P}_{\mathrm{m}}\right)$.

6. If more points are required for pseudo-static response curve: update: $\mathrm{P}_{\mathrm{d}, \mathrm{m}}=\mathrm{P}_{\mathrm{d}, \mathrm{n}}, \mathrm{P}_{\mathrm{m}}=$ $\mathrm{P}_{\mathrm{n}}, \mathrm{u}_{\mathrm{d}, \mathrm{m}}=\mathrm{u}_{\mathrm{d}, \mathrm{n}}, \mathrm{A}_{\mathrm{m}}=\mathrm{A}_{\mathrm{n}}$; repeat from step 2 